\title{
The therapeutic relevance of microRNA-199b in preclinical models of heart failure
}

Citation for published version (APA):

Duygu, B. (2017). The therapeutic relevance of microRNA-199b in preclinical models of heart failure.

[Doctoral Thesis, Maastricht University]. Maastricht University. https://doi.org/10.26481/dis.20171027bd

Document status and date:

Published: 01/01/2017

DOI:

10.26481/dis.20171027bd

Document Version:

Publisher's PDF, also known as Version of record

\section{Please check the document version of this publication:}

- A submitted manuscript is the version of the article upon submission and before peer-review. There can be important differences between the submitted version and the official published version of record.

People interested in the research are advised to contact the author for the final version of the publication, or visit the DOI to the publisher's website.

- The final author version and the galley proof are versions of the publication after peer review.

- The final published version features the final layout of the paper including the volume, issue and page numbers.

Link to publication

\footnotetext{
General rights rights.

- You may freely distribute the URL identifying the publication in the public portal. please follow below link for the End User Agreement:

www.umlib.nl/taverne-license

Take down policy

If you believe that this document breaches copyright please contact us at:

repository@maastrichtuniversity.nl

providing details and we will investigate your claim.
}

Copyright and moral rights for the publications made accessible in the public portal are retained by the authors and/or other copyright owners and it is a condition of accessing publications that users recognise and abide by the legal requirements associated with these

- Users may download and print one copy of any publication from the public portal for the purpose of private study or research.

- You may not further distribute the material or use it for any profit-making activity or commercial gain

If the publication is distributed under the terms of Article $25 \mathrm{fa}$ of the Dutch Copyright Act, indicated by the "Taverne" license above, 
The therapeutic relevance of microRNA-199b in preclinical models of heart failure 
Copyright $@$ C Burcu Duygu, Maastricht 2017

No part of this book may be reproduced or transmitted in any form or by any means, without prior permission in writing by the author, or when appropriate, by the publishers of the publications.

Cover Design: Jean Scheijen

Layout: Tiny Wouters

Published by:

ISBN: 


\title{
The therapeutic relevance of microRNA-199b
}

\section{in preclinical models of heart failure}

\author{
PROEFSCHRIFT \\ Ter verkrijging van de graad van doctor aan de Universiteit Maastricht \\ op gezag van de Rector Magnificus, Prof. Dr. Rianne M. Letschert \\ het besluit van het college van Decanen, \\ In het openbaar te verdedigen \\ op vrijdag 27 oktober 2017 om 14:00 uur
} door

\section{Burcu Duygu}

Geboren te Istanbul, Turkije, op 19 December, 1984 


\section{Promotor}

Prof. dr. Leon J. de Windt

\section{Co-promotor}

Dr. Paula A. Da Costa Martins

\section{Assessment Committee}

Prof. dr. Chris Reutelingsperger (chairman)

Prof. dr. Monika Stoll

Prof. dr. Erik Biessen

Prof. dr. Marie-Jose Goumans

Prof. dr. Rudolph de Boer

\section{Funded by}

\section{Hartstichting}

Financial support by the Dutch Heart Foundation for the publication of this thesis is gratefully acknowledged. The research described in this thesis was supported by a grant of the Dutch Heart Foundation (2010B261). 


\section{Contents}

$\begin{array}{lll}\text { Chapter } 1 & \text { General introduction } & 7\end{array}$

Chapter 2 Genetics and epigenetics of arrhythmia and heart failure

Chapter 3 Targeting microRNAs in heart failure

Chapter 4 Contribution of miR-199b to right ventricular remodeling and failure

Chapter 5 MiR-199b is a regulator of left ventricular remodeling following myocardial infarction

Chapter 6 Comparison of different chemically modified inhibitors of miR-199b in vivo

Chapter 7 Summary and General Discussion

Chapter 8 Valorization

Appendices Acknowledgement

Biography

List of publications 

1

General introduction

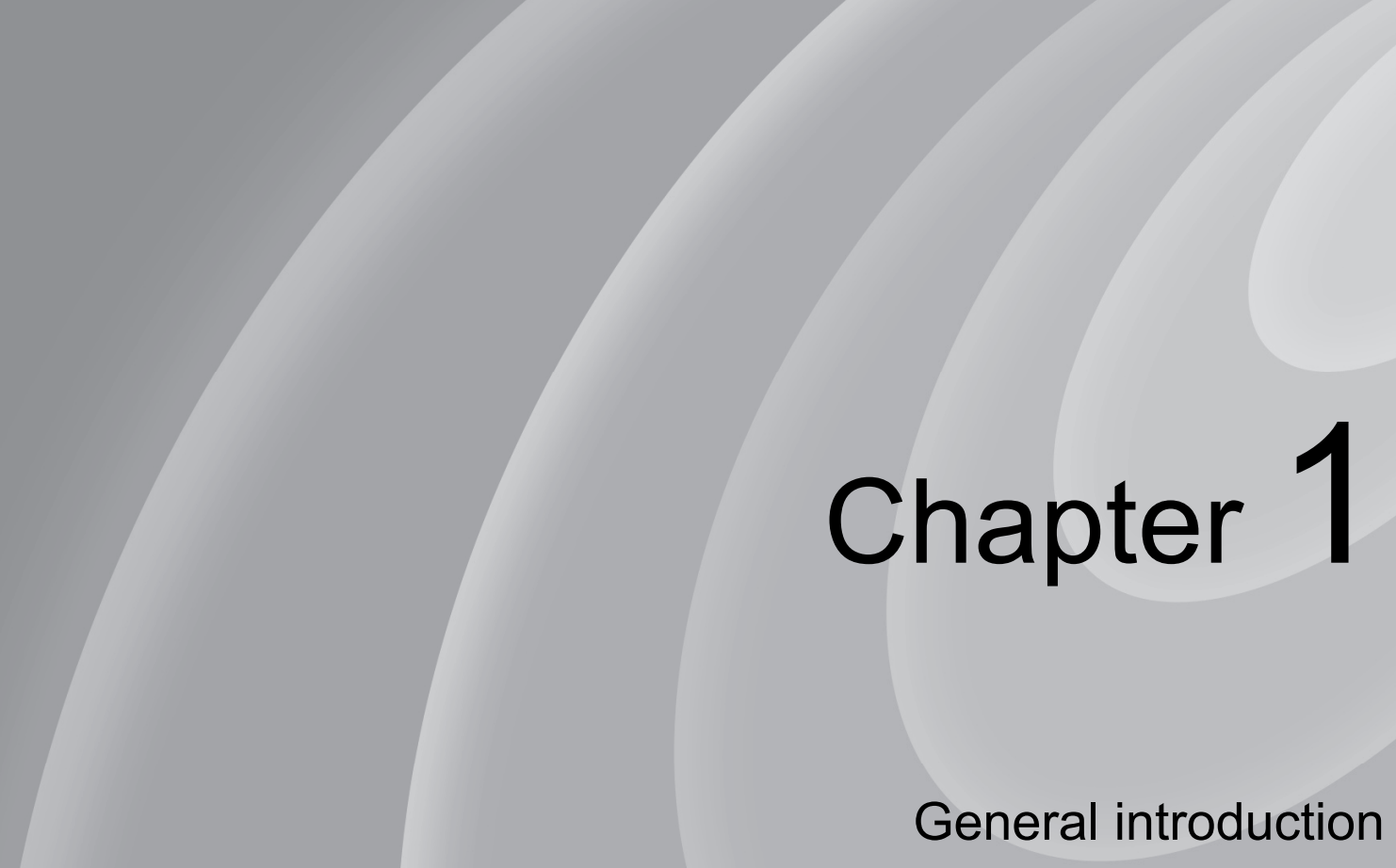





\section{Heart failure}

\section{Epidemiology \& etiology}

Heart failure (HF) occurs when the heart fails to pump adequate amount of blood to fulfil the requirements of the body due to pathophysiological remodeling of the cardiac muscle. ${ }^{1}$ In general, HF prevalence is $1-2 \%$ in developed countries, however, this increases with age; approximately $10 \%$ among people at the age of $>70$ years. ${ }^{2-4}$ For instance, around 5.7 million in the United States and above 37.7 million people worldwide clinically manifest $\mathrm{HF}$ and the prevalence continues to increase. ${ }^{4}$ The total cost of HF care is expected approximately 53.1 billion by 2030.,4 Despite the advancements in the development of new diagnostic, prognostic and treatment tools, HF remains the leading worldwide cause of death with approximately $50 \%$-year mortality after diagnosis. ${ }^{4}$ On the other hand, the most recent mortality statistics of cardiovascular disease (CVD), including HF, reveals high social and economic burden of this disease across Europe, with over 4 million people dying each year from CVD. ${ }^{5}$ Therefore, in Europe, CVD remains to be the most common cause of death resulting in $49 \%$ of deaths among woman and $41 \%$ among men. ${ }^{5}$ These statistical data and facts point out a dire need for the development of new and more effective therapeutic strategies in the treatment of HF, for which it is imperative to better understand the molecular mechanisms behind $\mathrm{HF}$.

The etiology of HF can be roughly divided into two categories, ischemic and non-ischemic forms of HF. In ischemic HF, ventricular dysfunction is a consequence of myocardial ischemia related to coronary artery disease, while causes of non-ischemic HF are more pleiotropic, including chronic hypertension, monogenetic cardiomyopathies, toxic injury, or metabolic disorders. ${ }^{6}$ In epidemiological surveys and in large-scale therapeutic trials, the prognosis of patients with ischemic HF is worse than in patients with a non-ischemic etiology. ${ }^{7}$ The therapeutic effect of essential drugs such as angiotensinconverting enzyme inhibitors, beta-blockers and diuretics does not significantly differ between ischemic and non-ischemic forms of $\mathrm{HF}^{8}{ }^{8}$ Hypertension, a medical condition determined by elevated blood pressure in the arteries, enhances left ventricular afterload and thereby, as an adaptive response, induces a number of structural changes within the myocardium. An increase in left ventricular wall thickness due to hypertrophied cardiac muscle cells is accompanied by increased interstitial fibrosis and reduced capillary density leading to impaired contractility and increased stiffness. ${ }^{9}$ Since HF is a progressive disease, all these changes, which can also be referred as "pathological cardiac remodeling', occur over time. Initially, hypertension is accompanied by diastolic dysfunction with preserved ejection fraction, then progresses to systolic dysfunction with 
reduced cardiac output. ${ }^{10}$ Coronary artery disease is the result of atherosclerotic plaque formation in the coronary arteries, which are responsible for the proper supply of oxygen-rich blood to the heart muscles. ${ }^{11}$ While accumulation of plaques can gradually cause narrowing of arteries and limit blood supply to the myocardium leading to ischemia, such plaques may also rupture and cause sudden occlusion of the artery and lead to acute myocardial infarction. ${ }^{12}$ Both conditions result in loss of myocardium, which eventually leads to abrupt loading conditions and a unique pattern of cardiac remodeling including fibrotic scar formation, cardiac hypertrophy and dilatation. ${ }^{13}$ Distinct patterns of cardiac remodeling can occur as response to different loading conditions generated by cardiac stress (Figure 1.1). Pressure overload as a result of chronic hypertension is mainly associated with 'concentric hypertrophy', characterized by increased wall thickness and decreased chamber volume, whereas volume overload due to coronary heart diseases or ischemic cardiomyopathy generally relates to 'eccentric hypertrophy' characterized by thinner ventricular walls and increased chamber volumes (Figure 1.1). ${ }^{14-16}$

Next to the aforementioned causes, there are other pathologies involved in HF including congenital heart defects (CHD), cardiomyopathies and arrhythmia. CHDs are structural cardiac malformations present at birth in many forms and children can be treated with surgery or catheter placement. ${ }^{17}$ Cardiomyopathies are a heterogeneous group of myocardial diseases with the majority having genetic causes (inherited forms). These genetic forms, classified as familial dilated cardiomyopathy (FDCM), hypertrophic (FHCM) and arrhythmogenic right ventricular cardiomyopathy (ARCV), besides leading to development of HF, are also the most common cause of sudden cardiac death under the age of $35 .^{18,19}$ Cardiac arrhythmia is caused by impaired cardiac conduction properties, which may arise in response to ischemia, inflammation, fibrosis, and aging or from several genetic factors. ${ }^{20}$ Ventricular arrhythmias are common in patients with HF and cardiomyopathy. ${ }^{21}$ Importantly, arrhythmia can cause cardiac arrest and thereby, sudden cardiac death. These pathologies of HF have been extensively discussed in relation to epigenetics and genetic factors in Chapter 2.

So far, we have mainly discussed left-sided HF; however, HF can also occur due to alterations in the right side of the heart. Right HF is primarily caused by elevation of blood pressure in the pulmonary arteries and a subsequent increased afterload in the right ventricle. ${ }^{22}$ Pulmonary arterial hypertension $(\mathrm{PAH})$ is one of the major causes for the development of right $\mathrm{HF}^{23}$ with the hallmarks of right ventricle (RV) remodeling in response to $\mathrm{PAH}$ being cardiac muscle cell hypertrophy, fibrosis and cardiac dilatation. ${ }^{24,25}$ 

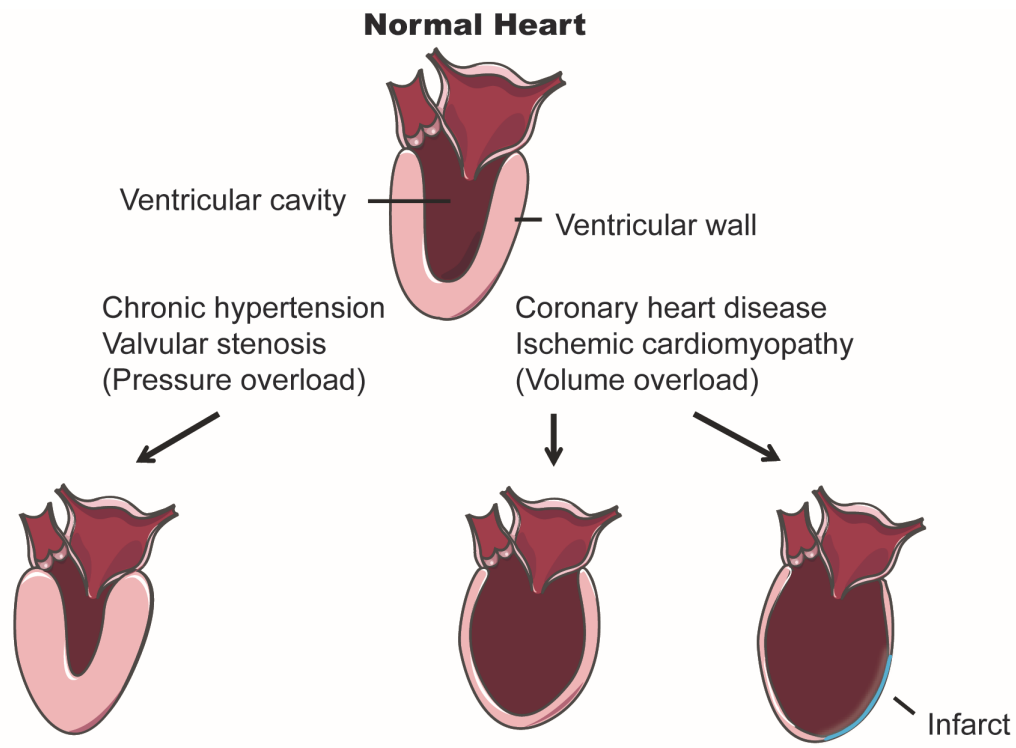

\section{Concentric Hypertrophy Eccentric Hypertrophy Myocardial Infarction \\ - Wall thickness $\uparrow$ \\ - Chamber volume $\downarrow$ \\ - Wall thickness $\downarrow$ \\ - Chamber volume $\uparrow$ \\ - Wall thickness $\downarrow$ \\ - Chamber volume $\uparrow$ \\ - Fibrotic scar}

Figure 1.1 Schematic representation of cardiac remodeling in response to altered hemodynamic load. Pressure overload by chronic hypertension or valvular stenosis is mainly associated with concentric hypertrophy, characterized by increased wall thickness and decreased chamber volume, whereas volume overload due to coronary heart diseases or ischemic cardiomyopathy generally relates to eccentric hypertrophy characterized by thinner ventricular walls and increased chamber volumes. Myocardial infarction presents a unique pattern of remodeling including fibrotic scar (Infarct; depicted in blue), and the non-infarcted area, which eventually develops eccentric hypertrophy due to increased volume overload.

Molecular mechanisms of heart failure

There are different proposed models to explain the complex molecular mechanisms underlying the clinical syndrome of HF. At first, HF was thought to be a problem of renal blood flow due to increased water and sodium retention, however, further hemodynamic assessments revealed HF to be related to decreased cardiac output and enhanced arterial vasoconstriction. ${ }^{26}$ This model, also known as the 'hemodynamics model', centers on declined cardiac contractility as well as peripheral vascular resistance ${ }^{26}$ Relatedly, first attempts to treat HF were to enhance contractility and to increase cardiac output. For these purposes, inotropic agents such as beta-adrenergic agonist ( $\beta$-agonist) or cardiac glycosides were employed. ${ }^{27-30}$ Despite short-term hemodynamic 
improvement, survival of HF patients was not prolonged which may correlate to the high-energy costs related to these agents. ${ }^{31,32}$ In contrast, the use of betablockers to inhibit adrenergic receptor activity, regardless of negative inotropic effects, prolonged survival, reduced patient hospitalization and improved life quality. ${ }^{33,34}$ Moreover, vasodilators were also introduced for their potential to reduce afterload and thus improve cardiac output. ${ }^{35,36}$ Yet, despite to a trend in improving survival, no long-term benefits were obtained after administration of a combination of isosorbide, hydralazine and the $\alpha$-adrenergic blocker, prazosin. ${ }^{35}$ Promising results were achieved during the Cooperative North Scandinavian Enalapril Survival study (CONSENSUSI) I, where the application of angiotensin II-converting enzyme (ACE) inhibitor as a vasodilator resulted in a substantial treatment benefit. ${ }^{37}$ This study puts forward the involvement of the reninangiotensin-aldosterone system (RAAS) in the development of HF, also known as the 'neurohumoral model'. ${ }^{26}$ RAAS is known to regulate blood pressure via the function of angiotensin II on nitric oxide (NO) production in vascular endothelium of various tissues and also on the secretion of vasopressin, water retaining hormone, from pituitary gland and adrenaline, noradrenalin and aldosterone secretion from adrenal gland. ${ }^{38}$ In this way angiotensin II is a key molecule in the regulation of both HF-associated water retention and vasoconstriction $^{39}$ but also with a direct impact on cardiac remodeling by decelerating cavity enlargement after myocardial infarction. ${ }^{40,41}$

As already mentioned, the heart is capable of undergoing adaptive cellular and molecular changes under stress condition. While initially these changes may improve cardiac output, if stress persists they become however, overruled and will eventually lead to cardiac dysfunction. These changes include myocyte growth without apparent proliferation, re-activation of a cardiac fetal gene program, collagen deposition, decreased capillary density and increased apoptosis and necrosis. ${ }^{42-44}$ Alterations in various myocardial signaling pathways were described to be involved during pathological cardiac remodeling ${ }^{45,46}$ and modulation of such signaling cascades may provide new therapeutic avenues for the treatment of HF.

Studies in animal models facilitated the identification of various signaling cascades involved in different cardiac pathologies. ${ }^{47}$ Among these signal transduction cascades, the calcineurin-nuclear factor of activated T cells (NFAT) signaling is well characterized as an important mediator of cardiac growth response since it is activated during HF and responsible for an excessive increase in heart size due to induced hypertrophic growth of the heart muscle cells. $^{48,49}$ Elevated intercellular levels of calcium $\left(\mathrm{Ca}^{2+}\right)$ activates the protein phosphatase calcineurin via its interaction with calmodulin. ${ }^{50}$ Once activated, calcineurin dephosphorylates NFAT, a transcription factor that resides in the 
cytoplasm in an inactive hyperphosphorylated state. ${ }^{50}$ Upon dephosphorylation, NFAT translocates to the nucleus in order to regulate various target genes involved in development of the cardiac hypertrophic phenotype and eventually HF. ${ }^{51}$ In agreement, expression of a constitutively active form of the calcineurin catalytic subunit in murine heart results in enlarged hearts with disorganized and hypertrophied cardiomyocytes compared to the hearts of wild type animals. ${ }^{52}$ In contrast, blocking the calcineurin-NFAT pathway by ablation of either calcineurin-A $\beta$, nfatc 3 or nfatc 2 gene in mice resulted in reduced hypertrophy in response to pressure overload or angiotensin II infusion. ${ }^{53-55}$

\section{microRNAs (miRNAs) in heart failure}

In the past two decades, a novel class of non-coding regulatory RNA molecules called microRNAs (miRNAs), referring to their short size ( 22 nucleotides), has emerged. miRNAs have developed as essential modulators of gene expression within large and complex signaling networks ${ }^{56}$ and there is growing body of evidence of their crucial roles in the pathophysiology of heart failure (HF) (Figure 1.2).

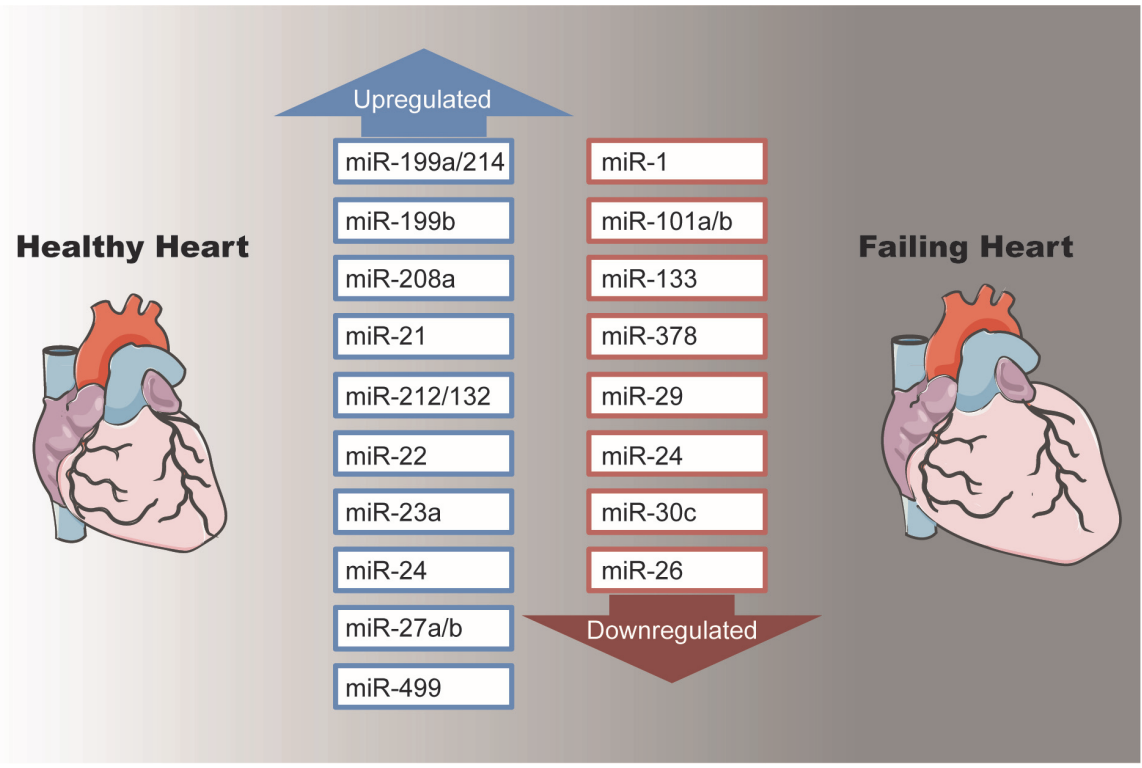

Figure 1.2 The most commonly studied miRNAs that are differentially expressed during the development of heart failure. List of miRNAs are either upregulated or downregulated during the transition from healthy heart to failing heart. These miRNAs have been shown to involve in various processes of heart failure pathology in preclinical models. Upregulated miRNAs are depicted in blue and downregulated ones in red. 
miRNAs display a critical function as post-transcriptional regulators of protein coding genes via binding to their target messenger RNA (mRNA) resulting in reduced protein levels through diverse mechanisms including mRNA degradation and/or translational repression. ${ }^{57,58}$ In animals, the vast majority of miRNAs forms partial duplexes with their target mRNA by pairing between nucleotides 2 and 7 at the 5' end of the miRNA, known as 'seed' region, and the complementary sequence on the cognate mRNA. ${ }^{59}$ Discovery of miRNA target genes is critical for functional characterization of miRNAs; however, partial complementarity makes the prediction of miRNA-mRNA interaction, a challenge. To overcome this, several target prediction algorithms (e.g. Target Scan, miRanda, miRwalk and DIANA_microT) have been generated based on different criteria such as seed region complementary, binding free energy and site conversion. ${ }^{60-63}$ More recently, many of these algorithms were upgraded with the programs including the hidden Markov model (HMM), support vector machine (SVM) classifier and the Bayesian phylogenetic model, ${ }^{64-66}$ in order to increase their predictive power.

Hence, these in silico tools provide hundreds of predicted targets, which must be experimentally validated in order to evaluate their biological function. ${ }^{67} \mathrm{~A}$ commonly used method to validate the direct interaction between a miRNA and a potential target mRNA is the dual-luciferase activity assay, which is performed by co-transfection of cells with a luciferase reporter plasmid carrying the 3'UTR of a predicted target together with synthetic microRNA mimic or a miRNA expression vector. ${ }^{68}$ While this method is not applicable for transcriptome-wide studies, argonaute 2-immunoprecipitation (AGO2-IP) followed by RNA sequencing or microarray enables comprehensive target identification. ${ }^{69}$ AGO proteins are the catalytic components of the RNA-induced silencing complex (RISC) with AGO2 being the most abundant in the majority of tissues. ${ }^{70}$ AGO2IP followed by RNA sequencing allows for identification of all targets mRNA that are enriched in the RISC upon overexpression of a specific miRNA. ${ }^{71}$ Target validation should be additionally demonstrated by changes in transcript and/or the protein levels for the target gene following modulation of expression levels of the corresponding miRNA, either in vitro or in vivo in order to establish miRNA specificity in silencing its biological target. Whilst transcript levels can be determined by quantitative (real time) polymerase chain reaction (QPCR) and/or northern blotting ${ }^{72,73}$ on total RNA from any cell or tissue of interest and using primers or probes for the specific mRNA target. Gene microarrays ${ }^{74,75}$ or RNA sequencing $^{76}$ can also be performed to demonstrate the alterations in mRNA target levels in a genome-wide manner. To determine the effect on the target protein, western blotting using specific antibodies is commonly used but complementation by ELISA or immune-cyto(histo)chemistry can be utilized to determine protein quantity. ${ }^{77}$ Moreover, proteomic approaches could also be 
applied in order to identify a comprehensive set of differentially expressed proteins as a response to changes in a specific miRNA expression level. ${ }^{78,79}$ Once a miRNA has been predicted to regulate a certain gene, the next step is to validate whether regulation leads to changes in a biological function. Despite all the above suggested experimental procedures, target prediction and subsequent validation remains challenging in the miRNA field. The molecular function and (pre)clinical relevance of numerous microRNAs involved in various stages of HF is discussed in detail under Chapter 3 of this thesis.

As the attempts to improve target prediction and validation methods continue to develop, antisense technology to modulate miRNA expression in vivo for therapeutic purposes is rapidly progressing. ${ }^{80,81}$ In fact, successful phase I/II clinical trials were recently conducted by using Locked Nucleic Acid (LNA) to specifically target miR-122 in the liver. ${ }^{82}$ Although targeting miR-92a with an LNA in a pig model of ischemia/reperfusion has generated promising results for the treatment of myocardial infarction. ${ }^{83}$ To date, no clinical trial involving the application of antimiRs or mimics to treat cardiovascular disease has been initiated. While issues such as organ/cell type specific delivery and optimal design of antimiR oligonucleotides and mimics for an effective and specific effect remain to be improved, as discussed in Chapter 3 , the use of miRNA therapeutics in numerous preclinical models encompassing diverse etiologies of HF have been carried out yielding encouraging outcomes and implying that clinical studies are also on the way for the HF.

\section{microRNA-199b (miR-199b)}

Human miR-199b is an intragenic miRNA located on the opposite strand of dynamin 1 (DNM1) gene, in a $2.2 \mathrm{~kb}$ intronic region between exons 14 and 15 on chromosome 9 of the human genome. The mature miR-199b strand (5p arm) is highly conserved among different species ${ }^{84}$ and its expression has been found to be independent of the host gene in the failing heart. ${ }^{84}$ Furthermore, miR-199b has been reported to be deregulated in various types of cancer including chronic $^{85,86}$ and acute ${ }^{87}$ myeloid leukemia (CML and AML), ovarian, ${ }^{88}$ breast $^{89}$ and prostate cancers, ${ }^{90}$ osteosarcoma, ${ }^{91}$ endometrioid endometrial carcinoma, ${ }^{92}$ choriocarcinomas, $^{93}$ medulloblastoma, ${ }^{94,95}$ hepatocellular carcinoma (HCC). ${ }^{96}$ Furthermore, deregulation of miR-199b in cancer is frequently associated with drug resistance and adverse prognosis as downregulation is associated with imatinab resistance and adverse prognosis in $\mathrm{CML}^{86}$ chemo-resistance in ovarian cancer $^{88}$ and directly correlated with malignancy in $\mathrm{HCC}^{96}$ as well as rapid growth of choriocarcinomas. ${ }^{93}$ In contrast, miR-199b by directly targeting genes involved in the Notch signaling pathway ${ }^{94,95,97}$ as well as $\mathrm{HIF}-1 \mathrm{a},{ }^{96} \mathrm{C}^{\mathrm{ckit}}{ }^{98}$ 
podocalyxin (PODXL), discoidin domain receptor 1 (DDR1) ${ }^{87}$ and protein phosphatase $2 \mathrm{~A}$ inhibitor (SET), ${ }^{93}$ may also be a promising therapeutic target for several types of cancer by targeting proliferation and maturation of erythroid cell, ${ }^{88}$ angiogenesis, ${ }^{97}$ cell growth and death. ${ }^{90}$

In the human and murine heart, elevated miR-199b levels are correlated to a pro-hypertrophic function related to the development of $\mathrm{HF}$ as established previously by our group. ${ }^{84}$ miR-199b exerts its action through activation of the calcineurin/NFAT signaling pathway and inhibition of miR-199b using cholesterol-conjugated antimiRs, named antagomirs, in a model of pressure overload -induced heart failure resulted in normalization of its direct target gene, dual specificity tyrosine-phosphorylation-regulated kinase 1A (Dyrk1a), and consequently reduced calcineurin/NFAT activity. More importantly, inhibition of miR-199b preserved cardiac function and opened a potential new avenue for the treatment of $\mathrm{HF}^{84}$

The clear implication of miR-199b-mediated gene regulation in different pathologies puts forward the great therapeutic potential of targeting this miRNA in different human diseases and thus reflecting the need to better understand the biology of miR-199b before further developing any clinical applications. 


\section{Aim and outline of this thesis}

Heart failure is a complex disease, driven by alterations in various molecular mechanisms and factors in response to a chronic or acute cardiac insult. Because differential expression of miRNAs and subsequent functional changes are correlated with diverse etiologies of heart failure, here we highlight specific differentially expressed miRNAs that have been described and established as important regulators at the onset, development and progression to heart failure in animal models and, more importantly, in humans (Chapter 2). In this chapter I will also discuss the genetic factors and the epigenetic mechanisms involved in heart failure and development of arrhythmias such as DNA methylation and histone modification.

Since a single miRNA has the ability to simultaneously regulate multiple target genes with related functions, modulating the expression of one miRNA may affect an entire gene network and thereby influence complex disease phenotypes. This aspect underlines miRNAs as potent therapeutic targets in many complex diseases including heart failure. To date several preclinical studies using miRNA-based therapies have revealed promising outcomes for the treatment of HF as outlined in Chapter 3. Among those studies, miR-199b was identified as a pro-hypertrophic miRNA and its inhibition provides an attractive therapeutic strategy for the treatment of diastolic heart failure. Because calcineurin/NFAT signaling has been implicated in the development of right ventricular failure, in Chapter 4 we also address the role of miR-199b in this type of HF by exploring its contribution during right ventricular remodeling following pulmonary artery banding (PAB). In Chapter 5 we investigate the therapeutic potential of targeting miR-199b in ischemic heart disease in order to gain further insights on the function of this miRNA in different etiologies of heart failure.

In Chapter 6, we aim at addressing delivery optimization of antimiR oligonucleotides regarding issues such as optimal chemical design, optimal dose range and organ/cell type specific delivery. To this end we compare dosedependent inhibitory efficacy of six different chemistry-based antimiR oligonucleotides against microRNA-199b (miR-199b) in the murine heart.

This thesis culminates in a general discussion followed by a general conclusion and future perspectives (Chapter 7). 


\section{References}

1. Houser SR, Margulies KB, Murphy AM, Spinale FG, Francis GS, Prabhu SD, Rockman HA, Kass DA, Molkentin JD, Sussman MA, Koch WJ. Animal models of heart failure: a scientific statement from the American Heart Association J Circ Res 2012;111(1):131-50.

2. Ponikowski P, Voors AA, Anker SD, Bueno H, Cleland JG, Coats AJ, et al. 2016 ESC Guidelines for the diagnosis and treatment of acute and chronic heart failure: The Task Force for the diagnosis and treatment of acute and chronic heart failure of the European Society of Cardiology (ESC). Developed with the special contribution of the Heart Failure Association (HFA) of the ESC. Eur J Heart Fail. 2016;18(8):891-975.

3. Ziaeian B, Fonarow GC. Epidemiology and aetiology of heart failure. Nat Rev Cardiol. 2016; 13(6):368-78.

4. Mozzafarian D, Benjamin EJ, Go AS, Arnett DK, Blaha MJ, Cushman M, et al. on behalf of the American Heart Association Statistics Committee and Stroke Statistics Subcommittee. Heart disease and stroke statistics-2016 update: a report from the American Heart Association. Circulation. 2016;133:e38-e360.

5. Townsend N, Nichols M, Scarborough P, Rayner M. Cardiovascular disease in Europe epidemiological update 2015. Eur Heart J 2015;36(40):2696-705.

6. Follath F. Nonischemic heart failure: epidemiology, pathophysiology, and progression of disease. J Cardiovasc Pharmacol 1999;33 Suppl 3:S31-5.

7. Follath F, Cleland JG, Klein W, MurphyR. Etiology and response to drug treatment in heart failure. J Am Coll Cardiol 1998;32(5):1167-72.

8. Pepine CJ, Deedwania PC. How do we best treat patients with ischemic heart disease? Circulation 1998;98(19):1985-6.

9. Drazner MH. The progression of hypertensive heart disease. Circulation 2011;123(3):327-34.

10. Lamb HJ, Beyerbacht HP, van der Laarse A, Stoel BC, Doornbos J, van der Wall EE, et al. Diastolic dysfunction in hypertensive heart disease is associated with altered myocardial metabolism. Circulation 1999;99(17):2261-7.

11. Libby P, Theroux P. Pathophysiology of coronary artery disease. Circulation 2005;111(25): 3481-8.

12. White HD, Chew DP. Acute myocardial infarction. Lancet 2008;372(9638):570-84.

13. French BA, Kramer CM. Mechanisms of Post-Infarct Left Ventricular Remodeling. Drug Discov Today Dis Mech 2007;4(3):185-196.

14. Mihl C, Dassen WR, Kuipers H. Cardiac remodeling: concentric versus eccentric hypertrophy in strength and endurance athletes. Neth Heart J 2008;16(4):129-33.

15. Lorell BH, Carabello BA. Left ventricular hypertrophy: pathogenesis, detection, and prognosis. Circulation 2000;102(4):470-9.

16. Maillet $\mathrm{M}$, van Berlo JH, Molkentin JD. Molecular basis of physiological heart growth: fundamental concepts and new players. Nat Rev Mol Cell Biol 2013;14(1):38-48.

17. Fahed AC, Gelb BD, Seidman JG, Seidman CE. Genetics of congenital heart disease: the glass half empty. Circ Res 2013;112(4):707-20.

18. Watkins H, Ashrafian H, Redwood C. Inherited cardiomyopathies. N Engl J Med 2011;364(17): 1643-56.

19. Millar L, Sharma S. Diagnosis and management of inherited cardiomyopathies. Practitioner 2014;258(1775):21-5, 2-3.

20. Duygu B, Poels EM, da Costa Martins PA. Genetics and epigenetics of arrhythmia and heart failure. Front Genet 2013;4:219.

21. Lo R, Hsia HH. Ventricular arrhythmias in heart failure patients. Cardiol Clin 2008;26(3): 381-403, vi.

22. Montani D, Gunther S, Dorfmuller P, Perros F, Girerd B, Garcia G, et al. Pulmonary arterial hypertension. Orphanet J Rare Dis 2013;8:97.

23. Schermuly RT, Ghofrani HA, Wilkins MR, Grimminger F. Mechanisms of disease: pulmonary arterial hypertension. Nat Rev Cardiol 2011;8(8):443-55. 
24. Naeije $\mathrm{R}$, Manes $\mathrm{A}$. The right ventricle in pulmonary arterial hypertension. Eur Respir Rev 2014;23(134):476-87.

25. Franco V. Right ventricular remodeling in pulmonary hypertension. Heart Fail Clin 2012;8(3): 403-12.

26. Packer M. The neurohormonal hypothesis: a theory to explain the mechanism of disease progression in heart failure. J Am Coll Cardiol 1992;20(1):248-54.

27. Talan MI, Ahmet I, Xiao RP, Lakatta EG. Beta(2) AR agonists in treatment of chronic heart failure: long path to translation. J Mol Cell Cardiol 2011;51(4):529-33.

28. Uretsky BF, Young JB, Shahidi FE, Yellen LG, Harrison MC, Jolly MK. Randomized study assessing the effect of digoxin withdrawal in patients with mild to moderate chronic congestive heart failure: results of the PROVED trial. PROVED Investigative Group. J Am Coll Cardiol 1993;22(4):955-62.

29. Packer M, Gheorghiade M, Young JB, Costantini PJ, Adams KF, Cody RJ, et al. Withdrawal of digoxin from patients with chronic heart failure treated with angiotensin-converting-enzyme inhibitors. RADIANCE Study. N Engl J Med 1993;329(1):1-7.

30. Digitalis Investigation Group. The effect of digoxin on mortality and morbidity in patients with heart failure. N Engl J Med 1997;336(8):525-33.

31. Abramson MJ, Walters J, Walters $\mathrm{EH}$. Adverse effects of beta-agonists: are they clinically relevant? Am J Respir Med 2003;2(4):287-97.

32. Ho HT, Stevens SC, Terentyeva R, Carnes CA, Terentyev D, Gyorke S. Arrhythmogenic adverse effects of cardiac glycosides are mediated by redox modification of ryanodine receptors. J Physiol 2011;589(Pt 19):4697-708.

33. de Milliano PA, Tijssen JG, van Zwieten PA, Lie KI. Beta blockers in heart failure haemodynamics, clinical effects and modes of action. Neth Heart J 2001;9(8):334-42.

34. Gheorghiade M, Colucci WS, Swedberg K. Beta-blockers in chronic heart failure. Circulation 2003;107(12):1570-5.

35. Cohn JN, Archibald DG, Ziesche S, Franciosa JA, Harston WE, Tristani FE, et al. Effect of vasodilator therapy on mortality in chronic congestive heart failure. Results of a Veterans Administration Cooperative Study. N Engl J Med 1986;314(24):1547-52.

36. Cohn JN. Efficacy of vasodilators in the treatment of heart failure. J Am Coll Cardiol 1993;22(4 Suppl A):135A-138A.

37. The CONSENSUS Trial Study Group. Effects of enalapril on mortality in severe congestive heart failure. Results of the Cooperative North Scandinavian Enalapril Survival Study (CONSENSUS). N Engl J Med 1987;316(23):1429-35.

38. Hall JE. Control of blood pressure by the renin-angiotensin-aldosterone system. Clin Cardiol 1991;14(8 Suppl 4):IV6-21; discussion IV51-5.

39. Unger $\mathrm{T}, \mathrm{Li} \mathrm{j}$. The role of the renin-angiotensin-aldosterone system in heart failure. J Renin Angiotensin Aldosterone Syst 2004;5 Suppl 1:S7-10.

40. Greenberg B, Quinones MA, Koilpillai C, Limacher M, Shindler D, Benedict C, et al. Effects of long-term enalapril therapy on cardiac structure and function in patients with left ventricular dysfunction. Results of the SOLVD echocardiography substudy. Circulation 1995;91(10): 2573-81.

41. Pfeffer MA, Lamas GA, Vaughan DE, Parisi AF, Braunwald E. Effect of captopril on progressive ventricular dilatation after anterior myocardial infarction. N Engl J Med 1988; 319(2):80-6.

42. Dirkx E, da Costa Martins PA, De Windt LJ. Regulation of fetal gene expression in heart failure. Biochim Biophys Acta 2013;1832(12):2414-24.

43. Sabbah HN, Sharov VG, Lesch M, Goldstein S. Progression of heart failure: a role for interstitial fibrosis. Mol Cell Biochem 1995;147(1-2):29-34.

44. Hilfiker-Kleiner D, Landmesser U, Drexler H. Molecular Mechanisms in Heart FailureFocus on Cardiac Hypertrophy, Inflammation, Angiogenesis, and Apoptosis. Journal of the American College of Cardiology 2006;48(9s1):A56-A66.

45. Kehat I, Molkentin JD. Molecular pathways underlying cardiac remodeling during pathophysiological stimulation. Circulation 2010;122(25):2727-35. 
46. Hunter JJ, Chien KR. Signaling pathways for cardiac hypertrophy and failure. N Engl J Med 1999;341(17):1276-83.

47. Heineke J, Molkentin JD. Regulation of cardiac hypertrophy by intracellular signalling pathways. Nat Rev Mol Cell Biol 2006;7(8):589-600.

48. Wilkins BJ, Dai YS, Bueno OF, Parsons SA, Xu J, Plank DM, et al. Calcineurin/NFAT coupling participates in pathological, but not physiological, cardiac hypertrophy. Circ Res 2004;94(1): 110-8.

49. Diedrichs $\mathrm{H}$, Chi M, Boelck B, Mehlhorn U, Schwinger RH. Increased regulatory activity of the calcineurin/NFAT pathway in human heart failure. Eur J Heart Fail 2004;6(1):3-9.

50. Hogan PG, Chen L, Nardone J, Rao A. Transcriptional regulation by calcium, calcineurin, and NFAT. Genes Dev 2003;17(18):2205-32.

51. Crabtree GR, Olson EN. NFAT signaling: choreographing the social lives of cells. Cell 2002; 109 Suppl:S67-79.

52. Molkentin JD, Lu JR, Antos CL, Markham B, Richardson J, Robbins J, et al. A calcineurindependent transcriptional pathway for cardiac hypertrophy. Cell 1998;93(2):215-28.

53. Bueno OF, Wilkins BJ, Tymitz KM, Glascock BJ, Kimball TF, Lorenz JN, et al. Impaired cardiac hypertrophic response in Calcineurin Abeta -deficient mice. Proc Natl Acad Sci USA 2002; 99(7):4586-91.

54. Wilkins BJ, De Windt LJ, Bueno OF, Braz JC, Glascock BJ, Kimball TF, et al. Targeted disruption of NFATc3, but not NFATc4, reveals an intrinsic defect in calcineurin-mediated cardiac hypertrophic growth. Mol Cell Biol 2002;22(21):7603-13.

55. Bourajjaj M, Armand AS, da Costa Martins PA, Weijts B, van der Nagel R, Heeneman S, et al. NFATc2 is a necessary mediator of calcineurin-dependent cardiac hypertrophy and heart failure. J Biol Chem 2008;283(32):22295-303.

56. Lee RC, Feinbaum RL, Ambros V. The C. elegans heterochronic gene lin-4 encodes small RNAs with antisense complementarity to lin-14. Cell 1993;75(5):843-54.

57. Lee I, Ajay SS, Yook JI, Kim HS, Hong SH, Kim NH, et al. New class of microRNA targets containing simultaneous 5'-UTR and 3'-UTR interaction sites. Genome Res 2009;19(7): 1175-83.

58. Hafner M, Landthaler M, Burger L, Khorshid M, Hausser J, Berninger P, et al. Transcriptomewide identification of RNA-binding protein and microRNA target sites by PAR-CLIP. Cell 2010; 141(1):129-41.

59. Bartel DP. MicroRNAs: target recognition and regulatory functions. Cell 2009;136(2):215-33.

60. Agarwal V, Bell GW, Nam JW, Bartel DP. Predicting effective microRNA target sites in mammalian mRNAs. Elife, 2015;4.

61. Reczko M, Maragkakis M, Alexiou P, Papadopoulos GL, Hatzigeorgiou AG. Accurate microRNA Target Prediction Using Detailed Binding Site Accessibility and Machine Learning on Proteomics Data. Front Genet 2011;2:103.

62. John B, Enright AJ, Aravin A, Tuschl T, Sander C, Marks DS. Human MicroRNA targets. PLoS Biol 2004;2(11):e363.

63. Dweep H, Sticht C, Pandey P, Gretz N. miRWalk--database: prediction of possible miRNA binding sites by "walking" the genes of three genomes. J Biomed Inform 2011;44(5):839-47.

64. Shen W, Chen M, Wei G, Li Y. MicroRNA prediction using a fixed-order Markov model based on the secondary structure pattern. PLoS One 2012;7(10):e48236.

65. Li L, Gao Q, Mao X, Cao Y. New support vector machine-based method for microRNA target prediction. Genet Mol Res 2014;13(2):4165-76.

66. Gaidatzis D, van Nimwegen E, Hausser J, Zavolan M. Inference of miRNA targets using evolutionary conservation and pathway analysis. BMC Bioinformatics 2007;8:69.

67. Kuhn DE, Martin MM, Feldman DS, Terry AV Jr, Nuovo GJ, Elton TS. Experimental validation of miRNA targets. Methods 2008;44(1):47-54.

68. Guo R, Abdelmohsen K, Morin PJ, Gorospe M. Novel MicroRNA Reporter Uncovers Repression of Let-7 by GSK-3beta. PLoS One 2013;8(6):e66330.

69. Easow $\mathrm{G}$, Teleman $\mathrm{A}$, Cohen SM. Isolation of microRNA targets by miRNP immunopurification. RNA 2007;13(8):1198-204. 
70. Valdmanis PN, Gu S, Schuermann N, Sethupathy P, Grimm D, Kay MA. Expression determinants of mammalian argonaute proteins in mediating gene silencing. Nucleic Acids Res 2012;40(8):3704-13.

71. Fan M, Krutilina R, Sun J, Sethuraman A, Yang $\mathrm{CH}, \mathrm{Wu} \mathrm{ZH}$, et al. Comprehensive analysis of microRNA (miRNA) targets in breast cancer cells. J Biol Chem 2013;288(38):27480-93.

72. Valoczi A, Hornyik C, Varga N, Burgyan J, Kauppinen S, Havelda Z. Sensitive and specific detection of microRNAs by northern blot analysis using LNA-modified oligonucleotide probes. Nucleic Acids Res 2004;32(22):e175.

73. Huang JC, Babak T, Corson TW, Chua G, Khan S, Gallie BL, et al., Using expression profiling data to identify human microRNA targets. Nat Methods 2007;4(12):1045-9.

74. Liu CG, Calin GA, Volinia S, Croce CM. MicroRNA expression profiling using microarrays. Nat Protoc 2008;3(4):563-78.

75. Wang $X$, Wang $X$. Systematic identification of microRNA functions by combining target prediction and expression profiling. Nucleic Acids Res 2006;34(5):1646-52.

76. Majoros $\mathrm{WH}$, Lekprasert $\mathrm{P}$, Mukherjee $\mathrm{N}$, Skalsky RL, Corcoran DL, Cullen BR, et al. MicroRNA target site identification by integrating sequence and binding information. Nat Methods 2013;10(7):630-3.

77. Zhao Y, Ransom JF, Li A, Vedantham V, von Drehle M, Muth AN, et al. Dysregulation of cardiogenesis, cardiac conduction, and cell cycle in mice lacking miRNA-1-2. Cell 2007; 129(2):303-17.

78. Jovanovic M, Reiter L, Picotti P, Lange V, Bogan E, Hurschler BA, et al. A quantitative targeted proteomics approach to validate predicted microRNA targets in C. elegans. Nat Methods 2010; 7(10):837-42.

79. Li C, Xiong Q, Zhang J, Ge F, Bi LJ. Quantitative proteomic strategies for the identification of microRNA targets. Expert Rev Proteomics 2012;9(5):549-59.

80. van Rooij E, Purcell AL, Levin AA. Developing microRNA therapeutics. Circ Res 2012;110(3): 496-507.

81. Broderick JA, Zamore PD. MicroRNA therapeutics. Gene Ther 2011;18(12):1104-10.

82. Luna JM, Scheel TK, Danino T, Shaw KS, Mele A, Fak JJ, et al. Hepatitis C virus RNA functionally sequesters miR-122. Cell 2015;160(6):1099-110.

83. Hinkel R, Penzkofer D, Zuhlke S, Fischer A, Husada W, Xu QF, et al. Inhibition of microRNA92a protects against ischemia/reperfusion injury in a large-animal model. Circulation 2013; 128(10):1066-75.

84. da Costa Martins PA, Salic K, Gladka MM, Armand AS, Leptidis S, el Azzouzi H, et al. MicroRNA-199b targets the nuclear kinase Dyrk1a in an auto-amplification loop promoting calcineurin/NFAT signalling. Nat Cell Biol 2010;12(12):1220-7.

85. Joshi D, Chandrakala S, Korgaonkar S, Ghosh K, Vundinti BR. Down-regulation of miR-199b associated with imatinib drug resistance in 9q34.1 deleted BCR/ABL positive CML patients. Gene 2014;542(2):109-12.

86. Chaubey A, Karanti S, Rai D, Oh T, Adhvaryu SG, Aguiar RC. MicroRNAs and deletion of the derivative chromosome 9 in chronic myeloid leukemia. Leukemia 2009;23(1):186-8.

87. Favreau AJ, Cross EL, Sathyanarayana P. miR-199b-5p directly targets PODXL and DDR1 and decreased levels of miR-199b-5p correlate with elevated expressions of PODXL and DDR1 in acute myeloid leukemia. Am J Hematol 2012;87(4):442-6.

88. Liu MX, Siu MK, Liu SS, Yam JM, Ngan HY, Chan DW. Epigenetic silencing of microRNA$199 b-5 p$ is associated with acquired chemoresistance via activation of JAG1-Notch1 signaling in ovarian cancer. Oncotarget 2014;5(4):944-58.

89. Fang C, Zhao Y, Guo B. MiR-199b-5p targets HER2 in breast cancer cells. J Cell Biochem 2013;114(7):1457-63.

90. Shang W, Chen X, Nie L, Xu M, Chen N, Zeng H, et al. MiR199b suppresses expression of hypoxia-inducible factor 1alpha (HIF-1alpha) in prostate cancer cells. Int J Mol Sci 2013;14(4): 8422-36.

91. Won KY, Kim YW, Kim HS, Lee SK, Jung WW, Park YK. MicroRNA-199b-5p is involved in the Notch signaling pathway in osteosarcoma. Hum Pathol 2013;44(8):1648-55. 
92. Torres A, Torres K, Pesci A, Ceccaroni M, Paszkowski T, Cassandrini P, et al. Deregulation of miR-100, miR-99a and miR-199b in tissues and plasma coexists with increased expression of mTOR kinase in endometrioid endometrial carcinoma. BMC Cancer 2012;12:369.

93. Chao A, Tsai CL, Wei PC, Hsueh S, Chao AS, Wang CJ, et al. Decreased expression of microRNA-199b increases protein levels of SET (protein phosphatase 2A inhibitor) in human choriocarcinoma. Cancer Lett 2010;291(1):99-107.

94. Andolfo I, Liguori L, De Antonellis $\mathrm{P}$, Cusanelli E, Marinaro F, Pistollato F, et al. The micro-RNA 199b-5p regulatory circuit involves Hes1, CD15, and epigenetic modifications in medulloblastoma. Neuro Oncol 2012;14(5):596-612.

95. Garzia L, Andolfo I, Cusanelli E, Marino N, Petrosino G, De Martino D, et al. MicroRNA-199b$5 p$ impairs cancer stem cells through negative regulation of HES1 in medulloblastoma. PLoS One 2009;4(3):e4998.

96. Wang C, Song B, Song W, Liu J, Sun A, Wu D, et al. Underexpressed microRNA-199b-5p targets hypoxia-inducible factor-1alpha in hepatocellular carcinoma and predicts prognosis of hepatocellular carcinoma patients. J Gastroenterol Hepatol 2011;26(11):1630-7.

97. Chen T, Margariti A, Kelaini S, Cochrane A, Guha ST, Hu Y, et al. MicroRNA-199b Modulates Vascular Cell Fate During iPS Cell Differentiation by Targeting the Notch Ligand Jagged1 and Enhancing VEGF Signaling. Stem Cells 2015;33(5):1405-18.

98. Li Y, Bai H, Zhang Z, Li W, Dong L, Wei X, et al. The up-regulation of miR-199b-5p in erythroid differentiation is associated with GATA-1 and NF-E2. Mol Cells 2014;37(3):213-9. 


\section{Chapter 2}

Genetics and epigenetics of arrhythmia and heart failure

Burcu Duygu, Ella M. Poels, Paula A. da Costa Martins

Adapted from

Front Genet. 2013 Oct; 4:219 


\section{Abstract}

Heart failure (HF) is the end stage of several pathological cardiac conditions including myocardial infarction, cardiac hypertrophy and hypertension. Various molecular and cellular mechanisms are involved in the development of HF. At the molecular level, the onset of HF is associated with reprogramming of gene expression, including downregulation of the alpha-myosin heavy chain ( $\alpha-\mathrm{MHC})$ gene and sarcoplasmic reticulum $\mathrm{Ca}^{2+}$ ATPase genes and reactivation of specific fetal cardiac genes such as atrial natriuretic factor (ANF) and brain natriuretic peptide (BNP). These deviations in gene expression result in structural and electrophysiological changes, which eventually progress to HF. Cardiac arrhythmia is caused by altered conduction properties of the heart, which may arise in response to ischemia, inflammation, fibrosis, aging or from genetic factors. Because changes in the gene transcription program may have crucial consequences as deteriorated cardiac function, understanding the molecular mechanisms involved in the process has become a priority in the field. In this context, various studies besides having identified different DNA methylation patterns in HF patients have also focused on specific disease processes and their underlying mechanisms, also introducing new concepts such as epigenomics. This review highlights specific genetic mutations associated to the onset and progression of HF, also providing an introduction to epigenetic mechanisms such as histone modifications, DNA methylation and RNA-based modification, and highlights the relation between epigenetics, arrhythmogenesis and HF. 


\section{Introduction}

Genetic mutations can contribute to the diverse pathologies of heart failure (HF) by altering structure and therefore, the function of proteins responsible for various cellular activities. ${ }^{1}$ While several studies have been devoted to the evaluation of genetic factors related to heart disease and genetic complications, much less is known about the relevance of epigenetics. The term "epigenetics" is defined as changes in gene expression that cannot be explained by changes in DNA sequence ${ }^{2}$ but rather result from alterations related to packaging and/or translation of genetic information. ${ }^{3}$ Epigenetic mechanisms can be acquired or heritable and constitute a mean by which interactions between genes and environment can occur. Epigenetic regulation occurs by three key mechanisms: (i) methylation of $\mathrm{CpG}$ islands, mediated by DNA methyltransferases, (ii) modification of histone proteins and (iii) microRNAs (miRNAs). Such modifications will lead to differential expression of similar information depending on the surrounding conditions, resulting in gene activation or silencing. Although epigenetic variability of genetic information is part of normal development and differentiation, it also depends on exogenous stimuli (e.g. smoking, drug abuse) and can, therefore, reflect the influence of those factors on the development of disease. ${ }^{4}$ The role of epigenetics has been mainly evaluated in cancer but recent studies have begun to address the involvement of epigenetics in the development and progression of cardiovascular diseases (CVD).

Heart failure (HF) is the end stage of several pathological cardiac conditions including myocardial infarction, cardiac hypertrophy and hypertension. Various molecular and cellular mechanisms are involved in the development of HF. At the molecular level, the onset of $\mathrm{HF}$ is associated with reprogramming of gene expression, including downregulation of the alpha-myosin heavy chain ( $\alpha-\mathrm{MHC})$ gene and sarcoplasmic reticulum $\mathrm{Ca}^{2+}$ ATPase genes and reactivation of specific fetal cardiac genes such as atrial natriuretic factor (ANF) and brain natriuretic peptide (BNP). ${ }^{5,6}$ These deviations in gene expression result in structural and electrophysiological changes, which eventually progress to HF. Cardiac arrhythmia is caused by altered conduction properties of the heart, which may arise in response to ischemia, inflammation, fibrosis, aging or from genetic factors. Because changes in the gene transcription program may have crucial consequences as deteriorated cardiac function, understanding the molecular mechanisms involved in the process has become a priority in the field. In this context, various studies besides having identified different DNA methylation patterns in HF patients, ${ }^{7,8}$ have also focused on specific disease processes $^{9,10}$ and their underlying mechanisms, ${ }^{11-13}$ also introducing new concepts such as epigenomics. This review highlights specific genetic mutations associated to the onset and progression of $\mathrm{HF}$, also providing an introduction to 
epigenetic mechanisms such as histone modifications, DNA methylation and RNA-based modification, and highlights the relation between epigenetics, arrhythmogenesis and HF.

\section{Genetics of heart failure}

Genetic forms of HF are mainly known as familial dilated cardiomyopathy (FDCM). There are, however, two other familial forms of cardiomyopathy: hypertrophic cardiomyopathy (FHCM) and arrhythmogenic right ventricular cardiomyopathy (ARVC). In fact, FHCM is the most common form of inherited $\mathrm{HF}$ with a prevalence of 1 in every 500 individuals. ${ }^{14} \mathrm{FHCM}$ is mainly defined as unexplained left ventricular hypertrophy with increased heart mass. ${ }^{15}$ The majority of patients with FHCM (approximately 60\%) exhibit autosomal dominant mutations in genes encoding for sarcomere proteins such as $\alpha$-myosin heavy chain (MYH7), cardiac myosin binding protein C (MYBPC3), cardiac troponin T (TNNT2), troponin I (TNNI3), alpha-tropomyosin (TPM1), myosin light chains (MYL2 and MYL3) and cardiac actin (ACTCI). ${ }^{16-18}$

Familial dilated cardiomyopathy (FDCM) is characterized as idiopathic DCM with a prevalence of $20-50 \%$ determined by epidemiological studies using family history and clinical, electrocardiographic and echocardiographic screening of first-degree relatives. ${ }^{19,20}$ FDCM is mainly inherited in a autosomal dominant manner (approximately 90\%) however, X-linked (5-10\%) and much less commonly autosomal recessive (AR) or mitochondrial inheritance have also been reported. ${ }^{21} \mathrm{~A}$ genetic cause of FDCM was identified in 30-35 \% cases and mainly mutant variants of Laminin A/C (LMNA) have been reported as the most common cause of FDCM (in $7.3 \%$ of patients with DCM). ${ }^{21,22}$ In a recent study, Titin (TTN) truncating mutations were attributed as the cause of FDCM in $27 \%$ of a total of 312 DCM patients. ${ }^{23}$ Furthermore, GATA zinc finger domain containing protein 1 (GATAD1) has been identified as a disease-causing gene for autosomal recessive DCM by genome-wide mapping and exome sequencing in a unique family. ${ }^{24}$

\section{Epigenetic mechanisms}

There are several epigenetic mechanisms in eukaryotes and many have already been linked to cardiac development, cardiovascular diseases and/or HF. The main alterations encompassing epigenetic in cardiovascular diseases are 
described below and include ATP-dependent chromatin remodeling, DNA methylation, histone modification and RNA-based mechanisms.

\section{Chromatin remodeling through ATP-dependent enzymes}

The ATP-dependent chromatin-remodeling complexes do not perform covalent modifications of the DNA or histones but rather use energy derived from ATP hydrolysis to move, destabilize, eject or restructure nucleosomes. There are 4 different families of ATP-dependent chromatin remodeling complexes: switching defective/sucrose non-fermenting complexes (SWI/SNF); imitation switch complexes (ISWI); chromodomain, helicase, DNA binding complexes (CHD) and inositol requiring 80 complexes (INO80). ${ }^{25-28}$ Although all members of each family have distinct flanking domains, they all share an evolutionarily conserved SWI-like ATPase catalytic domain that serves as vehicle to adjust histone-DNA contacts for DNA movement and chromatin restructuring. On their turn, the other domains act in the recognition of covalently modified histones, modulation of ATPase activity and/or interaction with other chromatin and transcription factors. Consequently, these unique domains and their associated proteins determine the genomic targeting specificity and biological functions of each family of chromatin remodelers. In fact, chromatin modification through ATP-dependent enzymes is associated to regulation of expression of distinct gene programs in organ development and adaptation. ${ }^{25}$

\section{DNA methylation}

DNA methylation is the most common epigenetic modification in the mammalian genome. This long-term stable epigenetic modulation involves the addition of a methyl group to the 5' carbon of a cytosine by DNA methyltransferase (DNMT) enzymes (Figure 2.1) and mostly occurs at the CpG (Cytosine preceding Guanosine) dinucleotide sequences, also known as $\mathrm{CpG}$ islands, in the mammalian genome. ${ }^{29} \mathrm{CpG}$ islands, in contrast to the remainder genome, are Cytosine-Guanosine-rich (CpG-rich), generally not methylated, ${ }^{30}$ and mostly acting as sites of transcription initiation once they are associated with promoter regions of genes ( $70 \%$ of gene promoters). ${ }^{31,32}$ DNA methylation is known to be catalyzed by three different DNMTs: DNMT1, DNMT3a and DNMT3b, ${ }^{33}$ where DNMT1 is the core enzyme in mammals. Methylation of DNA is considered a maintenance function of DNMTs as it results in post-replicative restoration of hemi-methylated sites to full methylation. ${ }^{34}$ Reduction of DNMT1 activity may result in demethylation and recent studies even showed that this is an active process. ${ }^{35}$ However, this has not been shown yet for the cardiovascular system.

DNA methylation is, generally, attributed to gene silencing by hampering the accessibility of cis-DNA binding elements present in the promoter regions of 
genes to the transcriptional machinery ${ }^{36}$ and plays a crucial role in the regulation of chromatin structure including $X$ chromosome inactivation, genomic imprinting, silencing of repetitive DNA elements and transposon transcription. ${ }^{31,37,38}$ Moreover, DNA methylation has been linked to biological processes underlying various diseases from cancer $^{39}$ to cardiovascular diseases such as hypertension, ${ }^{40}$ diabetes, ${ }^{41,42}$ atherosclerosis and inflammation. ${ }^{43}$

\section{Histone modifications}

The eukaryotic DNA is tightly compact and organized in chromatin. The nucleosome is the central unit of chromatin and is composed of an octamer center of two copies of each histone protein $(\mathrm{H} 2 \mathrm{~A}, \mathrm{H} 2 \mathrm{~B}, \mathrm{H} 3 \text {, and } \mathrm{H} 4)^{44}$ around which a DNA segment of $14-150$ base pairs is looped. Each histone has an amino-terminal tail that protrudes from the surface of the nucleosome and which can be subjected to various posttranscriptional modifications such as phosphorylation, sumoylation, ubiquitination, methylation, ADP-ribosylation, proline isomerization, deamination and acetylation. ${ }^{12}$ These modifications lead to conformational changes in the chromatin resulting in altered gene expression ${ }^{45}$ depending on whether DNA becomes accessible (euchromatin) or inaccessible (heterochromatin) for transcription (Figure 2.1).

\section{Histone acetylation}

Histone acetylation occurs at the lysine residues of the histone tails resulting in de-condensation of the chromatin structure and serving as a binding site for bromodomain proteins and transcriptional activators, and leading eventually to transcriptional activation. ${ }^{14,15}$ Conversely, histone deacetylation induces chromatin condensation and therefore transcriptional repression ${ }^{46,47}$ (Figure 2.1). Acetylation of histones is a dynamic process mediated by two counteracting enzyme families, the histone acetyltransferases (HATs) and histone deacetylases (HDACs). The harmony between the activities of these two sets of enzymes is a crucial element during regulation of gene expression and its deregulation is linked to several pathological conditions varying from cancer to cardiovascular diseases. ${ }^{48,49}$

\section{Histone methylation}

Other key modulator of posttranslational regulation is histone methylation which can occur on all basic amino acid residues of the histone tail; arginine, lysine and histidine. ${ }^{50}$ In addition, different amino acids can be methylated to a different extent and while lysine can be subjected to mono-, di- and trimethylation, arginine residues can only become mono- or dimethylated. ${ }^{50}$ Methylation of histones is a dynamic process mediated by histone methyltransferases (HTMs) and histone demethylases (HDMs) ${ }^{51}$ and, unlike acetylation, histone methylation 
can induce either activation or repression of gene expression depending on the target sites and degree of methylation ${ }^{52}$ (Figure 2.1). In contrast to histone acetylation, histone methylation governed mainly by histone methyltransferases SUV39H1 and G9a, ${ }^{53,54}$ has long been considered to be a permanent epigenetic mark. ${ }^{44}$ However, the discovery of new players such as histone demethylases has shifted the paradigm and, in fact, several studies showed that histone methylation is tightly regulated in inflammatory and metabolic disorders. ${ }^{55-57}$

\section{RNA-based mechanisms}

It is now proven and accepted that the majority of the genomic DNA is transcribed as non-coding RNAs and that such RNA species play pivotal regulatory roles during development, ${ }^{58}$ in response to environmental adversity, ${ }^{59}$ and at the onset and progression of disease. ${ }^{58}$ In this context, myriad studies were directed at revealing the role of non-coding RNAs in physiological and pathological processes.

There are two main classes of non-coding RNAs: infrastructural (small nuclear and nucleolar RNAs, ribosomal RNAs) and regulatory RNAs (microRNAs, long non-coding RNAs, small interfering RNAs and Piwi-interacting RNAs). To date, only miRNAs have been associated with epigenetic regulatory mechanisms in HF. Epigenetic regulation through long non-coding RNAs have been extensively studied in cancer but have also been associated to cardiovascular disease, mainly in maintenance of vascular homeostasis. ${ }^{60,61}$

\section{MicroRNAs}

MiRNAs were first described in the nematode Caenorhabditis elegans, in the early 1990s. ${ }^{62}$ From then on, a multitude of miRNAs have been identified and investigated, and presently there are $\sim 1600$ human miRNA sequences annotated at miRBase 19. ${ }^{63}$

MiRNAs are transcribed as primary transcripts (pri-miRNA) from intergenic, intronic or exonic regions in the genome, by RNA polymerase II. These primiRNAs fold into an hairpin shape with five prime (5') capped (mGpppG) and a polyadenylated tail which is subsequently cleaved by an enzyme complex composed of the RNase III endonuclease Drosha and the dsRNA binding protein Pasha (also known as DiGeorge critical region 8 (DGCR8)). ${ }^{64,65}$ The resulting shorter (70-100 nucleotide in length) hairpin-shaped precursor miRNA (pre-miRNA) is transported from the nucleus into the cytoplasm by Ran-GTP and exportin-5. ${ }^{66}$ In the cytoplasm, pre-miRNAs are further processed by an RNase III enzyme, Dicer, into a short (20-25 nucleotides in length) transient double stranded RNA molecule. At this stage, the formed mature RNA molecule is included in a protein complex - the so-called RNA-inducing silencing complex 
(RISC), while the passenger strand is degraded. ${ }^{67}$ The RISC-miRNA complex specifically targets mRNA sequences leading to negative regulation of protein synthesis or mRNA degradation. ${ }^{67}$ One miRNA can regulate a vast number of mRNAs simultaneously ${ }^{68}$ by predominantly acting through destabilization of target mRNAs and subsequently leading to reduced protein output. ${ }^{69}$ Therefore, decreased protein production can result from a combination of mRNA destabilization and translational inhibition. MiRNAs have been shown to be involved in different pathological processes such as cancer and cardiovascular diseases. $^{70,71}$ While in cancer epigenetic mechanisms have been widely associated to silencing of miRNA-encoding genes and thus recognized to greatly influence the expression of genetic information, only recently the importance of such mechanisms has started to be addressed in cardiovascular disease, and more specifically in HF.

\section{Epigenetics and arrhythmia}

Recent technological advances in DNA sequencing have enabled epigenome mapping and provided unprecedented insight into the distribution, interplay, and potential novel functions of chromatin modification and associated proteins. Remarkably, when using such technologies in evaluating the heart rhythm prominence of selected gene networks epigenetic modulators, not previously associated with arrhythmia, were identified as relevant under particular circumstances. A first evidence for epigenetic regulation of cardiac rhythm was raised from a study conducting microarrays on heart rhythm determinants (HRD) on tissue from mice exposed to either intermittent or chronic hypoxia and untreated wild type mice. A different environment (hypoxia) profoundly restructured the HRD web by changing the hierarchy of the composing genes and by identifying new role players. This was the case for the epigenetic modulators HDAC5, Mef2b and Mef2c. ${ }^{72}$

\section{Chromatin remodeling and arrhythmia}

Postural tachycardia syndrome (POTS) has multiple symptoms including tachycardia. Dysfunction of the norepinephrine transporter (NET) gene has previously been implicated with POTS, with a reported coding mutation in the norepinephrine transporter gene (SLC6A2). ${ }^{73}$ Head-up tilt experiments in POTS patients and found that the expression of norepinephrine transported was lower in POTS patients compared to healthy subjects. In the absence of altered SLC6A2 gene sequence or promoter methylation, the observed reduced expression of norepinephrine was directly correlated with chromatin modifications. Changes in expression were attributable to increased binding of 
the repressive methyl CpG-binding protein 2 (MeCP2) regulatory complex, in association with an altered histone modification composition at the promoter region of the SLC6A2 gene. ${ }^{73}$

\section{DNA methylation and arrhythmia}

The KCNQ1 gene is located on chromosome 11 in a region that contains a cluster of 6 genes that are expressed from either only the maternal or the paternal allele. In mice, the KCNQ1 overlapping transcript (KCNQ1ot1) is transcribed from a promoter located in intron 10 of the KCNQ1 gene. This promoter region is a $\mathrm{CpG}$ island and undergoes methylation on the maternal chromosome, preventing transcription, and therefore allowing expression of the gene cluster. However, this promoter region is not methylated on the paternal chromosome allowing expression of the regulatory transcript and suppressing the expression of the gene cluster. ${ }^{74}$ The maternal allele is transcribed in early embryogenesis with the paternal allele being progressively methylated and therefore only activated during late embryogenesis.

Variable imprinting of the KCNQ1 gene provides a possible explanation for the existence of long QT syndrome (LQTS) in the absence of a coding sequence mutation in KCNQ1. Paternal imprinting is probably relieved in cardiac tissue, meaning that during differentiation methylation of the paternal chromosome must occur to block production of the suppressive KCNQot1 transcript. Mutations that disrupt the $\mathrm{CpG}$ island could prevent methylation and silence the paternal allele in the heart. ${ }^{74,75} \mathrm{~A}$ more recent study by Fatima and colleagues ${ }^{76}$ associates $^{2}$ epigenetic modifications with regulation of the ATP sensitive potassium (KATP). In cardiac myocytes, different isoform combinations of the SURx (SUR1, SUR2) and Kir6.2 (KCNJ11) will be responsible for distinct physiological and pharmacological properties, depending on the isoforms expressed. Promotor CpG methylation appears to be one of the regulators of SURx isoform expression and therefore, regulated or aberrant $\mathrm{CpG}$ methylation might play a role in controlling channel structure and function under different conditions. ${ }^{76}$

\section{Histone modifications in arrhythmia}

HDAC-1 and HDAC-2 have important functions in regulating cardiac gene expression and cardiomyocyte differentiation. While myocardium-specific deletion of either HDAC-1 or HDAC-2 shows no apparent cardiac phenotype, when both are specifically deleted in murine myocardium, these mice die within 2 weeks after birth, due to cardiac arrhythmias and dilated cardiomyopathy. ${ }^{77}$ This is likely caused by upregulation of genes that encode for fetal calcium channels and skeletal muscle-specific contractile proteins, including hyperpolarization-activated nonselection cation current (If) and T-type $\mathrm{Ca}^{2+}$ 
current $(\mathrm{ICa}, \mathrm{T})$, both involved in calcium handling. Such genes are normally transcriptionally repressed by the RE1-silencing transcription factor (REST) through class I and Ila HDACs. Knockout of both HDAC-1 and -2 seems to result in incapacity of REST to repress these fetal genes, resulting in, among other things, arrhythmia. ${ }^{77,78}$

Ablation of PAX-interacting protein 1 (PTIP), a key component of the histone H3 lysine 4 (H3K4me) methyltransferase complex, leads to reduced H3K4me expression levels and is sufficient to alter subsequent gene expression profiles. One of those $\mathrm{H} 3 \mathrm{~K} 4$ me-regulated genes is the $\mathrm{Kv}$ channel-interacting protein 2 (Kcnip2), a regulator of cardiac repolarization current that is known to have functions in arrhythmogenesis. Regulation of Kcnip2 by H3K4me leads to decreased sodium current and action potential upstroke velocity and significantly prolonged action potential duration (APD), thereby increasing the risk of lethal ventricular arrhythmias. These results suggest that maintaining H3K4me marks is necessary for the stability of a specific transcriptional program and cellular homeostasis. $^{78,79}$

In Duchenne, muscular dystrophy (DMD) more than $30 \%$ of deaths result from a progressive deterioration in cardiac function. Ventricular arrhythmia is a common complication in DMD patients and a risk factor for sudden cardiac death. Colussi and colleagues ${ }^{80}$ used X-chromosome-linked muscular dystrophy ( $\mathrm{mdx}$ ) mice, a model for DMD, and treated them with the histone deactylase inhibitor suberoylanilide hydroxamic acid (SAHA). In resting state, there was no difference between treated and untreated groups, however, upon restraint, an increase was seen in ventricular arrhythmias in untreated mdx animals compared to mdx SAHA- treated animals or wild type control animals. Epicardial recordings revealed prolongation of the QRS complex in mdx- untreated mice in comparison to mdx-SAHA treated mice and WT mice, together with a significant reduction in impulse propagation velocity. Further analysis revealed that SAHA induces connexin 40 (Cx40), Cx37 and Cx32 remodeling but expression of Cx43 and Cx45 remains unaltered. Treatment with SAHA not only reversed Cx43 lateralization, which was observed in $\mathrm{mdx}$ - untreated animals, but also reinduced $\mathrm{Na}_{v} 1.5$ expression. This indicates that in mdx mice SAHA attenuates arrhythmias by mechanisms in which connexin-remodeling and sodium channel re-expression may play a role. ${ }^{80}$

Atrial fibrillation (AF), induced by atrial fibrosis, seems to also be epigenetically regulated and this was suggested in a study sought to determine whether the HDAC inhibitor trichostatin A (TSA) reduces the amount of atrial fibrosis and concomitant AF. ${ }^{81}$ Transgenic mice overexpressing the homeo-domain-only protein (HopX-Tg), which recruits HDAC activity to induce cardiac hypertrophy, 
were either treated or untreated with TSA and compared to control groups. Invasive electrical stimulation induced more atrial arrhythmias in HopX-Tg untreated mice than in HopX-Tg TSA-treated mice. TSA reduced atrial arrhythmia duration and atrial fibrosis in HopX-Tg animals. In the HopX-Tg untreated mice, atrial Cx40 was found to be lower than in WT mice, a phenomenon that was abrogated by introducing TSA in these mice. Myocardial angiotensin II levels were similar between groups, suggesting that HDACinhibition reverses atrial fibrosis, Cx40 remodeling and atrial arrhythmia vulnerability, rendering the atrium almost refractory to arrhythmia inducibility, independent of angiotensin II in cardiac hypertrophy. ${ }^{81}$

\section{Non-coding RNA in arrhythmias}

Several studies have been conducted to look at the association between microRNAs and arrhythmias. MiRNA expression profiles were shown to differ in right atrial disease, with 47 microRNAs being differentially expressed between diseased and control states, whereas similar changes in expression could not be found in left atrial disease. ${ }^{82,83}$ In a different study, miRNAs that were differentially expressed between atrial fibrillation and sinus rhythm in patients with mitral stenosis were showed by microarrays. ${ }^{83,84}$ These data indicate that microRNAs play a role in regulating cardiac conduction and in the induction of arrhythmias.

Multiple studies have shown that miR-208a plays an important role in action potential conduction. Overexpression of miR-208a leads to arrhythmia, cardiac fibrosis and hypertrophy, and is a strong predictor of cardiac death. ${ }^{85}$ Genetic deletion of miR-208a, on the other hand, also leads to an increased risk of atrial fibrillation (AF) and other arrhythmias, due to aberrant conduction mainly caused by dysregulation of $\mathrm{C} \times 40 .^{85,86}$ Similarly, also miR-328 is upregulated not only in animal models of atrial fibrillation but also in human tissue samples from AF patients. Overexpression of miR-328 in mice increased vulnerability to AF as confirmed by diminished L-type $\mathrm{Ca}^{2+}$ current and shortened atrial action potential duration. AF vulnerability could be reversed by concomitant inhibition of the miRNA by an antagomir. ${ }^{83,87}$

The most well established cardiac conduction-related miRNA is by far, miR-1. This miRNA plays a role in myotonic dystrophy, a disease where degeneration of the conduction system occurs and increased CACNA1C (CAV 1.2) expression, a cardiac L-type $\mathrm{Ca}^{2+}$ channel gene, is observed. ${ }^{83}$ The involvement of miR-1 in electrocardiophysiology was further confirmed by a targeted deletion of miR-1-2 by Zhou et al., ${ }^{88}$ which lead to a high rate of sudden death, caused by conduction blockade due to direct targeting of Irx5, a transcription factor that regulates cardiac repolarization. ${ }^{88}$ In rats, induction of myocardial infarction by 
occlusion of the left anterior descending artery results in miR-1 upregulation and arrhythmia exacerbation but treating the animals with an antisense inhibitor could abrogate these effects. Furthermore, miR-1 also directly targets KCNJ2, which encodes for the calcium channel subunit Kir 2.1, providing a possible mechanism for increase of arrhythmias in myocardial infarction. ${ }^{89}$ The role of miR-1 in arrhythmogenesis was further confirmed in humans where atrial cells from AF patients display a $86 \%$ decrease in miR-1 expression, a subsequent increased Kir 2.1 protein expression and an increase in $I_{k 1}$ density. ${ }^{83,90}$ MiR-1 is also involved in cardiac electrical remodeling in viral myocarditis where it is upregulated, resulting in decreased $\mathrm{Cx} 43$, which is required for transfer of electric activation, and indicating that miR-1 plays a role in intercellular communication.

Another prominent miRNA in the regulation of cardiac conduction is miR-133. Matkovich and colleagues ${ }^{91}$ showed that an increase in miR-133a leads to prolonged QT intervals. This miRNA is highly and preferentially expressed in cardiac and skeletal muscle and is known to be regulate cardiac ion channels such as Kv4- encoded $\mathrm{I}_{\mathrm{to}, \mathrm{f}}(\mathrm{Kcnip} 2) .{ }^{83,91}$ Furthermore, the catalytic and regulatory subunits of protein phosphatase 2A (PP2A) are decreased in cardiomyocytes in chronic heart failure and were shown to be targets of both miR-1 and miR-133. Because pharmacologic inhibition of PP2A leads to altered diastolic $\mathrm{Ca}^{2+}$ waves this indicates a role for these two microRNAs in calcium handling. ${ }^{83,92}$

Interestingly, a relation between nicotine abuse and cardiac arrhythmias has been suggested by several studies. Nicotine treatment of canine atrial fibroblasts, resulted in upregulation of transforming growth factor beta-1 (TGF$\beta 1$ ) and TGF- beta receptor type II levels (TGF- $\beta$ RII), with concomitant decreased levels of miR-133 and miR-590, both directly targeting TGF- $\beta 1$ and TGF- $\beta$ RII. This effect was abolished by synthetic downregulation of both miRNAs. ${ }^{83,93}$

Apart from miR-1 and miR-133, there are several other miRNAs that have been associated with regulation of cardiac conduction to some extent. This is the case for miR-212 that seems to regulate inward rectifier $\mathrm{K}^{+}$current density by targeting Kir 2.1, ${ }^{83}$ and for miR-21 that is increased in the left atria of patients with $\mathrm{AF}$ and which abrogation leads to repression of atrial fibrosis and $A F{ }^{83,94,95}$ Furthermore, conditional overexpression of miR-17-92 in cardiac and smooth muscle tissue results in both dilated, hypertrophic cardiomyopathy as well as in arrhythmias. An increase in atrial and ventricular ectopy was observed in homozygous and heterozygous animals compared to wildtype, as well as increased susceptibility to arrhythmia. After programmed electrical stimulation all transgenic animals developed sustained and lethal ventricular tachycardia (VT) 
or ventricular fibrillation (VF) and these effects were mainly caused by dysregulation of two downstream targets of miR-17-92, the lipid phosphatase and tensin homolog PTEN and Cx43. ${ }^{96}$ Likewise, also miR-155 and miR-181 have been associated to cardiac conduction defects. Circulating levels of miR155 are upregulated in patients with specific angiotensin receptor type 1 (AT1R) polymorphisms that have been shown to be associated with an increased risk of ventricular tachyarrhythmia and sudden death. ${ }^{97}$ On its turn, miR-181a seems to play $a$ in ventricular tachycardia after myocardial infarction. ${ }^{98}$ Altogether, the data available regarding the relation between microRNAs and arrhythmias establish microRNAs as crucial players in regulating cardiac electrophysiology and electric potential conduction through an array of different mechanisms.

\section{Epigenetic control of heart failure}

Recent genetic and biochemical studies indicate that epigenetic changes play a crucial role in the development of cardiac hypertrophy and heart failure, with dysregulation in histone acetylation status being directly linked to impaired contraction of cardiac myocytes. In fact, it has been shown that there is a cardiac chamber -specific histone acetylation pattern suggesting that cardiac ventricular chambers are epigenetically distinct. ${ }^{99}$

\section{ATP-dependent enzymes and chromatin remodeling in HF}

ATP-dependent chromatin remodeling complexes play crucial roles in vertebrates, mainly in organ development and adaptation. Most of them have been associated to heart development and only a few were implicated in heart disease. The BAF (brahma-associated factor) complex is the vertebrate homolog of the yeast SWI/SNF family of chromatin remodelers. In mammals, this complex contains 12 protein components from which an ATPase subunit encoded by either Brm (brahma) or Brg1 (brahma-related gene 1). These two subunits, although highly homologous, exhibit distinctive functions in vivo. While several studies have demonstrated that individual subunits of the BAF complex are essential during heart development ${ }^{100-102}$ and may be implicated in human congenital diseases, ${ }^{103,104}$ BRG1 was recently involved in cardiac disease. ${ }^{105}$ In embryos, Brg1 promotes myocyte proliferation and it preserves fetal cardiac differentiation by interacting with HDACs and poly (ADP ribose) polymerase (PARP) to repress $\alpha-\mathrm{MHC}$ to $\beta-\mathrm{MHC}$ shift. Brg1 (also known as Smarca4) is not expressed in the adult heart but it is reactivated by stress conditions such as pressure overload. Once reactivated, Brg1 forms a complex with its embryonic partners (HDAC and PARP), to induce the pathologic $\alpha-\mathrm{MHC}$ to $\beta-\mathrm{MHC}$ shift. Adult myocardial gene deletion of Brg1 inhibited cardiac hypertrophic growth and 
reversed the MHC switch. Accordingly, Brg1 is activated in patients with hypertrophic cardiomyopathy, correlating with disease severity and MHC changes. ${ }^{105}$ PPAR is a nuclear enzyme known to respond to DNA damage and facilitate repair. Besides DNA repair, PPAR-1 also modulates chromatin to control the transcriptional machinery in response to diverse stimuli. Such stimuli induce PPAR activation and PAR-dependent striping of histones from chromatin, thereby favoring the opening of chromatin to allow transcriptional regulation. ${ }^{106,107}$ PARP is activated in cardiac hypertrophy and its activity is increased in murine and human failing hearts. ${ }^{108,109}$ Deletion of PARP-1 in mice or pharmacological inhibition of PARP activity decreases cardiac hypertrophy induced by angiotensin ${ }^{1110}$ or pressure overload, ${ }^{108,111}$ delays the progression from hypertensive cardiomyopathy to $\mathrm{HF},{ }^{112}$ decreases cell death and HF after $\mathrm{MI}^{113}$ and diminishes myocardial ischemia/reperfusion injury. ${ }^{114}$

Although very preliminary, there seems to be a link, at the chromatin level, between fetal hearts and adult diseased hearts, and in the future, targeting the regulation of chromatin remodeling processes may become a promising approach to prevent or maybe even reverse pathological cardiac hypertrophic growth and HF.

\section{DNA methylation in heart failure}

Unlike in other diseases such as cancer, the role of DNA methylation in HF remains elusive. Movassagh et al. compared genome-wide methylation profiles of left ventricle tissue from HF patients and healthy controls by methylated DNA immunoprecipitation-chip (MeDIP-chip), in which immunoprecipitation of methylated DNA is followed by microarray hybridization and further validation by bisulfite sequencing. ${ }^{115}$ As a result, three differentially methylated angiogenesisrelated loci have been identified and correlated to differential expression levels of the corresponding gene. ${ }^{115}$ Hyper-methylation of the 5' regulatory region of platelet endothelial cell adhesion molecule 1 (PECAM-1) and hypo-methylation of the angiomotin-like protein 2 (AMOTL2) in failing hearts correlated with reduced expression of those genes, while hyper-methylation within the Rho GTPase activating protein 24 gene (ARHGAP24) is correlated with increased expression of ARHGAP24 in failing hearts. ${ }^{115}$ Moreover, a follow up study ${ }^{8}$ generated a genome-wide DNA methylation map of human hearts and revealed a significant decrease in global promoter methylation of genes with increased expression in failing hearts. ${ }^{8}$ The genome-wide methylation profile of patients with idiopathic dilated cardiomyopathy was recently generated. ${ }^{116}$ In an attempt to validate the methylation profiling of the twenty most differentially methylated genes, MassARRAY and Bisulfite sequencing were used in a large independent cohort (thirty patients). ${ }^{11}$ Interestingly, twelve (out of twenty) genes showed 
similar methylation patterns between the two independent studies. Such approach allowed the identification of two novel genes with differential methylation profiles between patient and control subjects, lymphocyte antigen 75 (ly75) and adenosine A2a receptor (adora2a). Curiously, downregulation of those genes in zebrafish by using specific morpholino technology resulted in reduced ventricular contractility and HF. ${ }^{117}$ More recently, DNA methylation was found to be responsible for the hypermutability of distinct cardiac genes. This is the case for the cardiac isoform of the myosin binding protein $\mathrm{C}$ gene (Mybpc3) that has a significantly higher level of exonic methylation of $\mathrm{CpG}$ sites than the skeletal isoform (Mybpc2). ${ }^{118}$ This suggests that there are unique aspects of the Mybpc3 gene or its epigenetic environment that are prone to generate genetic mutations.

Very recently, a report in the Journal of the American Heart Association ${ }^{119}$ provided evidence for the effects of ambient particulate-matter (PM) on blood pressure (BP). In humans, exposure to fine and coarse concentrated ambient particles (CAPs) induce blood hypomethylation of Alu, a transposable repeated element, and Toll-like receptor 4 (TLR4). Hypomethylation of both factors was found to be associated with increased systolic BP after exposure. This is of great interest since many epidemiological studies ${ }^{120,121}$ have reported a correlation between PM exposure, cardiovascular disease and death, and may, therefore, represent a novel mechanism that mediates environmental effects on BP and indirectly cardiovascular disease and HF.

\section{Histone modification in heart failure}

\section{Histone acetylation}

Cardiac hypertrophy is the initial response to cardiac stress leading to adverse cardiac remodeling and eventually to HF. In order to elucidate the underlying mechanisms behind the development of cardiac hypertrophy, the role of histone acetylation/deacetylation has been extensively studied. Gusterson et al. ${ }^{18}$ demonstrated that overexpression of the transcriptional co-activators CREB binding protein (CRB) or p300, individually, could induce hypertrophic growth of cardiomyocytes depending on their histone HAT activity. Consequently, inhibition of these co-activators repressed phenylephrine (PE)-induced cell hypertrophic growth. ${ }^{122}$ High expression and induced activity of HAT were observed in animals subjected to pressure overload, compared to sham operated animals, while heterozygous p300 transgenic animals revealed limited cardiac hypertrophy with preserved cardiac function when subjected to pressure overload. $^{18}$ Intriguingly, another study showed that p300 transgenic animals develop HF at baseline, as indicated by high mortality, adverse remodeling and 
impaired cardiac function. ${ }^{123}$ Although these studies indicate that p300 is a crucial modulator of cardiac remodeling they do not specifically address the importance of its HAT activity in vivo. To assess this question, studies with transgenic animals carrying a mutant form of p300, with no HAT activity, were performed revealing a rescue of myocardial infarction (MI)-induced pathological remodeling as well as preserved cardiac function compared to intact p300carrying transgenic animals. ${ }^{124}$ These responses to p300 modulation in vivo are, most likely, related to the fact that p300 can directly acetylate non-histone proteins such as hypertrophy-responsive transcriptional factors like MEF $2^{125}$ and GATA-4. ${ }^{123,124}$

The regulation of gene expression by HDACs seems to be more complex. HDACs are divided into four different classes (class-I, -Ila, -IIb and -IV) based on differences in their structure, enzymatic function, expression patterns and subcellular localization. Class I HDACs (HDAC1, 2, 3 and 8) are expressed ubiquitously and predominantly localized in the nucleus. Class Ila HDACs (HDAC4, 5, 7, and 9) shuttle between the nucleus and the cytoplasm and are strictly expressed in muscle, heart and brain tissues. ${ }^{126}$ A first demonstration of the relevant role of HDAC activity in cardiomyocytes derived from a study where myocardial differentiation of monkey ES cells was facilitated by TSA, an HDAC inhibitor. ${ }^{127}$ Furthermore, differential chromatin scanning (DCS) is a technique used to genome-widely profile HDAC targets enabling the isolation of genomic fragments associated with histones and, therefore, carrying different acetylation marks. ${ }^{128}$ Such studies provide a basis for all following studies into the role of epigenetic modifications in cardiac disorders (Table 2.1). Interestingly, the two classes of HDACs show opposite roles in cardiac hypertrophy with class I HDACs being pro-hypertrophic and class lla HDACs being antihypertrophic. $^{129-131}$ Induced expression of HDAC2 in cardiomyocytes mimics hypertrophic growth in an Akt-dependent manner. In vivo, class I HDAC2 overexpressing transgenic animals develop cardiac hypertrophy whereas HDAC2-null animals are protected from cardiac hypertrophic response after stimulation either by pressure overload or isoproteranol (ISO) administration. ${ }^{132}$ Similar to HATs, HDACs also interact with DNA binding proteins regulating their activity. For instance, class Ila HDACs (HDAC4, -5, -7 and -9) can directly interact with MEF2 leading to inhibition of MEF2 activity and subsequent reduced cardiac hypertrophy. ${ }^{133}$ On the other hand, when MEF2 is discharged of HDACs, it may become an available target for HATs binding which in turn leads to enhanced activity of MEF2. ${ }^{133}$ 
Table 2.1 Role of HDACs in heart disease.

\begin{tabular}{|c|c|c|c|c|}
\hline Class & $\begin{array}{l}\text { Chromatin } \\
\text { Modifying Factor }\end{array}$ & Modulation & Phenotype & Mechanism \\
\hline \multirow[t]{6}{*}{ Class I } & HDAC2 & Germline deletion & $\begin{array}{l}\text { Lethal at birth, } \\
\text { Surviving adults are } \\
\text { resistant to } \\
\text { hypertrophy. }\end{array}$ & $\begin{array}{l}\text { Suppression of SRF and } \\
\text { GATA4-dependent gene } \\
\text { expression; Inhibition of } \\
\text { hypertrophic Akt/GSK3 } \\
\text { pathway }\end{array}$ \\
\hline & & $\begin{array}{l}\text { Overexpression in } \\
\text { myocardium }\end{array}$ & Cardiac hypertrophy & $\begin{array}{l}\text { Activation of hypertrophic } \\
\text { Akt/GSK3 } 3 \text { pathway }\end{array}$ \\
\hline & & $\begin{array}{l}\text { Deletion in } \\
\text { myocardium }\end{array}$ & No cardiac phenotype & Redundancy with HDAC1 \\
\hline & & $\begin{array}{l}\text { Deletion of HDAC1 } \\
\text { and HDAC2 }\end{array}$ & $\begin{array}{l}\text { Lethal at } 2 \text { weeks after } \\
\text { birth: arrhythmias, } \\
\text { dilated cardiomyopathy }\end{array}$ & $\begin{array}{l}\text { Interaction with REST: } \\
\text { repression of fetal genes } \\
\text { involved in calcium } \\
\text { handling and contractility }\end{array}$ \\
\hline & HDAC3 & Overexpression & $\begin{array}{l}\text { Cardiac hyperplasia } \\
\text { without hypertrophy }\end{array}$ & $\begin{array}{l}\text { Suppression of Cdk } \\
\text { inhibitors: promotion of } \\
\text { cardiomyocyte } \\
\text { proliferation }\end{array}$ \\
\hline & & $\begin{array}{l}\text { Deletion in } \\
\text { myocardium }\end{array}$ & $\begin{array}{l}\text { Lethality at 3-4 months } \\
\text { of age: cardiac } \\
\text { hypertrophy, fibrosis, } \\
\text { defects in fatty acid } \\
\text { metabolism and lipid } \\
\text { accumulation in the } \\
\text { heart }\end{array}$ & $\begin{array}{l}\text { Suppression of PPARa } \\
\text { activity on gene } \\
\text { promoters involved in } \\
\text { metabolic regulation }\end{array}$ \\
\hline Class II & HDAC5/HDAC9 & Germline deletion & $\begin{array}{l}\text { Enhanced hypertrophic } \\
\text { response to cardiac } \\
\text { stress; female hearts } \\
\text { are protected from } \\
\text { ischemia injury }\end{array}$ & $\begin{array}{l}\text { Suppression of Mef2 and } \\
\text { CAMTA2; suppression of } \\
\text { Mef2-ERa-VEGFa } \\
\text { pathway }\end{array}$ \\
\hline \multirow[t]{4}{*}{ Class III } & SIRT1 & $\begin{array}{l}\text { Overexpression in } \\
\text { myocardium }\end{array}$ & $\begin{array}{l}\text { Low-moderate } \\
\text { expression of SIRT1 } \\
\text { reduces cardiac } \\
\text { hypertrophy; High } \\
\text { levels induces cardiac } \\
\text { hypertrophy and } \\
\text { apoptosis } \\
\end{array}$ & $\begin{array}{l}\text { SIRT1 expression is } \\
\text { activated by cardiac } \\
\text { stress and regulates the } \\
\text { response to stress in a } \\
\text { dose-dependent manner }\end{array}$ \\
\hline & SIRT3 & Germline deletion & $\begin{array}{l}\text { Cardiac hypertrophy } \\
\text { and fibrosis at } 2 \\
\text { months of age }\end{array}$ & $\begin{array}{l}\text { Inhibition the proapoptotic } \\
\text { activity of } \mathrm{Bax}\end{array}$ \\
\hline & & $\begin{array}{l}\text { Overexpression in } \\
\text { myocardium }\end{array}$ & $\begin{array}{l}\text { Resistant to stress- } \\
\text { induced cardiac } \\
\text { hypertrophy }\end{array}$ & $\begin{array}{l}\text { Activation of FOXO3a- } \\
\text { dependent pathways; } \\
\text { attenuation of the } \\
\text { prohypertrophic } \\
\text { MAPK/ERK and PI3K/Akt } \\
\text { pathways. }\end{array}$ \\
\hline & SIRT7 & Germline deletion & $\begin{array}{l}\text { Cardiac fibrosis, } \\
\text { hypertrophy and } \\
\text { shortened lifespan }\end{array}$ & $\begin{array}{l}\text { Deacetlylation of p53; } \\
\text { protection from stress- } \\
\text { induced apoptosis }\end{array}$ \\
\hline
\end{tabular}


Besides transcriptional factors, HATs and HDACs can also interact with sarcomeric proteins. PCAF, a HAT, class II HDAC4 co-localize with cardiomyocyte sarcomere in the Z-disc whereas class I HDAC3 localizes mainly in A-band. ${ }^{134,135}$ In addition, inhibition of HDAC4 results in altered calcium sensitivity and therefore altered contractility. HDAC4 has a unique docking site for the binding of calcium/calmodulin-dependent kinase II (CaMKII), which is absent in other class Ila HDACs. Phosphorylation of HDAC4 by CaMKII promotes nuclear export and de-repression of HDAC target genes, which, in cardiomyocytes, will lead to hypertrophic growth, ${ }^{136}$ indicating a central role for CaMKII-HDAC4 signaling pathways in the development of cardiac hypertrophy. From the HDAC class IIb, HDAC6 catalytic activity seems to be consistently increased in stressed myocardium and is activated by different extracellular stimuli in cultured cardiac myocytes. ${ }^{137}$ Recently, Cao et al. showed that inhibition of HDAC by TSA (HDAC inhibitor) treatment limits cardiac hypertrophy by suppressing autophagy. Further in vitro experiments, by selectively downregulation of HDAC isoforms in cardiomyocytes, indicated HDAC1/2 as responsible for PE- induced autophagy. ${ }^{138}$ Autophagy is a self-degradative process during development and in response to nutrient stress and can be altered under pathological conditions. ${ }^{139}$ Increasing evidence suggests more distinctive roles for HDACs then only acting as histone deacetyltransferases.

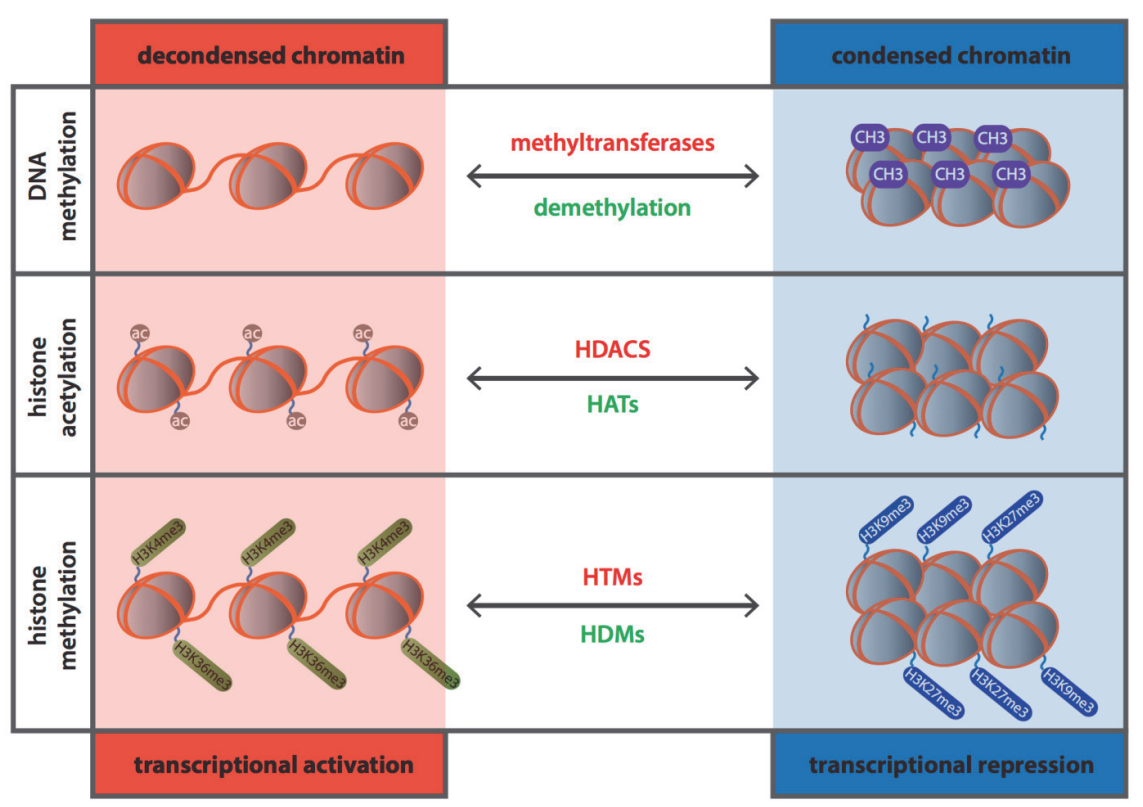

Figure 2.1 Schematic representation of the role of DNA methylation and histone modifications in transcriptional gene regulation. 


\section{Histone methylation}

The most widely studied histone methylations are lysine methylations: histone $\mathrm{H} 3$ lysine 4 (H3K4), H3K9, H3K27, H3K36, H3K79 and H4K20. ${ }^{140}$ There is limited information about the function of histone methylation in heart failure. It is known that differential methylation patterns for H3K4 and H3K9 occur in the vicinity of various gene clusters of failing human hearts. ${ }^{141}$ Because such sets of genes encode proteins that function in the same signal transduction pathways and H3K9 mark-profile seems to be less sensitive to disease status, this indicates differential H3K4 marking during the development of HF. ${ }^{141}$ Furthermore, in a Dahl salt-sensitive rat model of congestive heart failure (CHF), genome-wide histone methylation analysis revealed $\mathrm{H} 3 \mathrm{~K} 4 \mathrm{me} 3$ and $\mathrm{H} 3 \mathrm{~K} 9 \mathrm{me} 3$ as the most abundant histone methylation marks. ${ }^{142}$ Interestingly, mapping of $\mathrm{H} 3 \mathrm{~K} 4 \mathrm{me} 3$ and H3K9me3 enriched regions in the genome of human CHF samples compared to controls revealed many HF-associated genes located in these regions. ${ }^{142}$ Moreover, histone methylation has been shown to mark not only protein coding genes but also non-coding RNA regions. ${ }^{8}$ The genome wide mapping of H3K36me3 in end-stage falling human hearts allowed to identify novel 4-non-coding RNA regions, which have active transcription and might involve in heart failure. ${ }^{8}$ This differential profile of histone methylation marks found in both human and animal samples suggests a potential role for HTMs and HDMs in HF. Accordingly, JMJD2A, a histone trimethyl demetyhlase,${ }^{143}$ is found to be upregulated in human hypertrophic cardiomyopathy (HCM) patients compare to control. ${ }^{144}$ Moreover, transgenic mice with cardiac-specific overexpression of JMJD2A develop exaggerated cardiac hypertrophy compare to control following transverse aortic constriction (TAC) whereas jmjd2a-null animals seem to be protected against TAC induced cardiac stress. ${ }^{144}$ All in all, these experiments indicate a potential modulator function for histone modification in heart failure; however, there are still a lot of missing pieces.

\section{Non-coding RNA in heart failure}

Post-transcriptional regulation of gene expression is mainly achieved by noncoding RNA molecules including microRNAs (miRNAs) and, based on rather recent findings, long-noncoding RNAs (IncRNAs).

Comparison of miRNA expression profiles in healthy and failing heart samples from human or animal models revealed differential miRNA expression patterns indicating their potential involvement in the development and progression of heart failure. In this regard, miRNA microarray analysis of cardiac tissue from mouse models of cardiac hypertrophy and congestive heart failure detected five upregulated miRNAs (namely miR-24, miR-125b, miR-195, miR-199a and miR214), which were further confirmed in idiopathic end stage failing human 
hearts. ${ }^{145}$ Furthermore, mice overexpressing miR-195 developed pathological remodeling, impaired cardiac function and subsequently heart failure. ${ }^{145}$ Besides distinct expression signatures of miRNAs in healthy and failing hearts, the differential miRNA expression profile among failing hearts is dependent on the underlying heart failure etiology. ${ }^{146,147}$ Ikeda and colleagues, ${ }^{146}$ found thirteen aortic stenosis-specific miRNAs while a set of other eight miRNAs were mainly expressed in a cardiomyopathic form of heart failure. In a similar study, different sets of miRNAs were found for idiopathic dilated and ischemic cardiomyopathy. ${ }^{147}$ Furthermore, the expression levels of miRNAs can vary as the disease progresses. ${ }^{148}$ This was shown in a double transgenic mouse model, harboring mutations in both the myosin heavy chain gene and the cardiac troponin I gene, resulting in severe hypertrophic cardiomyopathy and premature mortality by age 21 day. Global miRNA profiles in those mice, at age of 10 and 16 days, revealed stable downregulation of specific miRNAs such as miR-1 and miR-133 and therefore, suggesting a functional role for these miRNAs throughout the progression to heart failure. Counterwise, miR-31 was upregulated at the end-stage of HF which points to a specific function for this miRNA during final phase of the disease. ${ }^{148}$

Another miRNA microarray profiling study has been carried out in human endstage congestive heart failure (CHF) with or without left ventricular assist device (LVAD) compared to healthy subjects. ${ }^{149}$ Twenty-eight miRNAs were differentially expressed in diseased hearts regardless of LVAD support and, interestingly, the expression levels of twenty out of those miRNAs were either normalized or reversed in CHF group after LVAD support suggesting an eventual value of such miRNAs as prognostic tools for end-stage CHF patients. ${ }^{149}$ Recent data also emphasizes the variations between adult and child idiopathic dilated cardiomyopathy patients, regarding their miRNA expression profile. $^{150}$ Naga Prasad et al. ${ }^{151}$ performed miRNA microarrays in end stage dilated cardiomyopathic hearts (with $>15$ ejection fraction) followed by in silico network analysis in order to obtain a global picture of the molecular networks and key proteins regulated by the dysregulated miRNAs. As a result, eight miRNAs displayed different expression levels in DCM subjects compared to controls and two out of this eight miRNAs, namely miR-7 and miR-378, were novel miRNAs, shown for the first time to be downregulated in end stage failing hearts. $^{151}$ Confirmation of network analysis revealed upregulation of erythroblastic leukemia viral oncogene homolog 2 (ERBB2) and collagen, type I, alpha 1 (Col1A1) which are predicted targets of miR-7 and thus, confirming that the regulatory function of miRNAs results in alterations of global signaling networks during development and progression towards cardiac hypertrophy and heart failure. $^{151}$ 
A more recent study, besides showing that miRNA expression profiles differ between healthy and failing hearts, in consensus with previous findings, also demonstrated that failing adult hearts and fetal hearts display similar miRNA profiles supporting the paradigm of reactivation of a fetal gene program ${ }^{152,153}$ at onset and/or during the development of heart failure.

On top of these profiling studies, a myriad of selected miRNAs was associated to cardiac disease-specific roles. MicroRNAs have also become a research focus on defining novel biomarkers of HF by characterizing miRNA patterns in easy accessible sources such as serum, plasma and even whole blood, and specific miRNA signatures have been identified as biomarkers of myocardial infarction. $^{154}$

Interestingly, but not yet studied in the context of cardiovascular diseases, miRNA genes can be subject of DNA methylation with direct impact on the miRNA expression levels. Epigenetic-regulation of miRNA genes was mainly showed, so far, for different types of cancer. MicroRNAs such as miR-127 and miR-137 are sensitive to DNA methyltransferase inhibitors and chromatinmodifying drugs. Interestingly, the miR-127 gene is embedded in a CpG island and is subject of epigenetic silencing. ${ }^{155}$ Because miR-127 is physiologically expressed as a member of a miRNA cluster together with miR-136, -431, -432 and -433 not only in normal tissues but also in cultured fibroblasts this could hint for a role of epigenetic regulation of this $\mathrm{miR}$ in cardiovascular disease, e.g. fibrosis, but this remains to be clarified. ${ }^{155}$ Similarly, the promoter region of miR137 is heavily methylated in cancer cell lines and this is reversible after treatment with DNA methyltransferase inhibitors. ${ }^{156}$

To date, the epigenetic regulation of microRNA expression through methylation of $\mathrm{CpG}$ islands or other modifications in the promoter regions that encode for specific miRNAs has not been assessed in the context of cardiovascular diseases. Nevertheless, the above-mentioned studies strongly suggest a crucial role for such mechanisms at the onset of cardiovascular pathologies.

\section{Pharmacoepigenetics in heart failure}

The existent therapies for heart failure seem to be insufficient since heart failure remains the leading cause of death in the developed countries. Therefore, there is an increasing necessity for finding novel therapeutic targets. Because the wide variability in an individual's disease

predisposition and response to treatment is only partially ascribed to heritable factors, epigenetically modifications diverging from DNA methylation to noncoding RNAs have gained much attention in several diseases, including HF.,157 
Therefore, epigenetic changes are currently being considered as therapeutic approaches in synergy with nucleotide variations at the drug response level. ${ }^{158}$ This rapidly emerging new discipline, so-called pharmacoepigenomics, assesses the influence of epigenetic factors in the interindividual variation to drugs with the ultimate goal of discovering novel therapeutic targets. ${ }^{159}$ To date, the most advances have been made in the oncology field. ${ }^{159}$ However, the knowledge obtained from such studies combined with the knowledge on the role of epigenetic modifications is being applied to other complex forms of disease including $\mathrm{HF}$.

In this context, several studies performed in animal models of disease endorse modifiers of epigenetic marks as therapeutic target points. Curcumin, a natural compound found in the spice trumeric, has an HAT inhibitory activity with specificity to p300/CREB-binding protein. It has been shown to rescue pathological cardiac remodeling and preserve cardiac function in two different rat models of heart failure, namely the salt-sensitive Dahl rats and in rats that were subjected to myocardial infarction (MI). ${ }^{160}$ An analogous study suggests that administration of curcumin in combination with a conventional therapy such as angiotensin conversion enzyme inhibitors (ACEi), in Ml-induced rats results in a beneficial additive effect on cardiac function. ${ }^{161}$ Additionally, trichostatin A (TSA), an HDAC inhibitor, was showed to blunt the hypertrophic response of cardiomyocytes to PE-treatment in a dose dependent manner and excluding the eventual cytotoxic effect of TSA. ${ }^{129}$ Moreover, treatment with TSA and valproic acid (VPA), another HDAC inhibitor, was able to attenuate cardiac hypertrophic growth in transgenic mice with cardiac overexpression of the atypical homeodomain protein Hop, known to be able to inhibit certain cardiac-gene expression by blocking serum response factor (SRP) transcription activity on a HDAC dependent way. ${ }^{162}$ TSA is also able to attenuate pathological cardiac remodeling in other mouse models such as isoprotenol-, angiotensin II- and pressure overload-induced hypertrophy. ${ }^{162,163}$

Considering that epigenetics regulates phenotypic variation in health and disease, it is conceivable to expect that understanding and controlling the epigenome will prime great developments in the prevention and treatment of common diseases, including heart failure.

\section{Conclusions}

The dynamic aspects of epigenetics may not only provide more accurate evidences to the role of changing environmental factors in the drug response, associating the environment with the genome, but also offer a way to reactivate 
silenced genes. While pharmacogenetics has been very valuable in the identification of interindividual variation in drug uptake and metabolism, epigenomics offers yet another layer of information that may help developing more personalized therapy. In the oncology field, epigenetic drugs have already entered the clinical arena and methylation patterns are used as biomarkers to subtype and stage various cancers as a critical and more personalized care. $^{164,165}$

It is clear that epigenetic modifications such as DNA methylation, histone modifications and RNA-based mechanisms are the molecular targets for disadvantageous environment stimuli and may lead to the onset of other complex and heterogeneous diseases such as arrhythmia heart failure. However, additional research is obviously necessary to further clarify how epigenetic mechanisms impact in the onset and development of heart disease, to eventually identify new drugable targets in HF and allowing disease classification or risk stratification. 


\section{References}

1. Creemers EE, Wilde AA, Pinto YM. Heart failure: advances through genomics. Nat Rev Genet 2011;12(5):357-62.

2. Egger G, Liang G, Aparicio A, Jones PA. Epigenetics in human disease and prospects for epigenetic therapy. Nature 2004;429(6990):457-63.

3. Bird A. Perceptions of epigenetics. Nature 2007:447(7143):396-8.

4. Feinberg AP. Phenotypic plasticity and the epigenetics of human disease. Nature 2007; 447(7143):433-40.

5. Herron TJ, McDonald KS. Small amounts of alpha-myosin heavy chain isoform expression significantly increase power output of rat cardiac myocyte fragments. Circ Res 2002; 90(11): 1150-2.

6. Olson EN, Backs J, McKinsey TA. Control of cardiac hypertrophy and heart failure by histone acetylation/deacetylation. Novartis Foundation symposium. 2006;274:3-12; discussion 13-9, 152-5, 272-6.

7. Movassagh M, Vujic A, Foo R. Genome-wide DNA methylation in human heart failure. Epigenomics 2011;3(1):103-9.

8. Movassagh M, Choy MK, Knowles DA, Cordeddu L, Haider S, Down T, et al., Distinct epigenomic features in end-stage failing human hearts. Circulation 2011:124(22):2411-22.

9. Kim GH, Ryan JJ, Marsboom G, Archer SL. Epigenetic mechanisms of pulmonary hypertension. Pulm Circ 2011;1(3):347-56.

10. Yan MS, Matouk CC, Marsden PA. Epigenetics of the vascular endothelium. J Appl Physiol 2010;109(3):916-26.

11. Baccarelli A, Bollati V. Epigenetics and environmental chemicals. Curr Opin Pediatr 2009;21(2):243-51.

12. Handy DE, Castro R, Loscalzo J. Epigenetic modifications: basic mechanisms and role in cardiovascular disease. Circulation 2011;123(19):2145-56.

13. Shirodkar AV, Marsden PA. Epigenetics in cardiovascular disease. Curr Opin Cardiol 2011; 26(3):209-15.

14. Rodriguez JE, McCudden CR, Willis MS. Familial hypertrophic cardiomyopathy: basic concepts and future molecular diagnostics. Clin Biochem 2009;42(9):755-65.

15. Elliott P, McKenna WJ. Hypertrophic cardiomyopathy. Lancet 2004;363(9424):1881-91.

16. Morita H, Rehm HL, Menesses A, McDonough B, Roberts AE, Kucherlapati R, et al., Shared genetic causes of cardiac hypertrophy in children and adults. N Engl J Med 2008;358(18): 1899-908.

17. Lopes LR, Elliott PM. Genetics of heart failure. Biochim Biophys Acta 2013;1832(12):2451-61.

18. Morita H, Nagai R, Seidman JG, Seidman CE. Sarcomere gene mutations in hypertrophy and heart failure. J Cardiovasc TransI Res 2010;3(4):297-303.

19. Michels VV, Moll PP, Miller FA, Tajik AJ, Chu JS, Driscoll DJ, et al., The frequency of familial dilated cardiomyopathy in a series of patients with idiopathic dilated cardiomyopathy. $\mathrm{N}$ Engl J Med 1992;326(2):77-82.

20. Grunig E, Tasman JA, Kucherer H, Franz W, Kubler W, Katus HA. Frequency and phenotypes of familial dilated cardiomyopathy. J Am Coll Cardiol 1998;31(1):186-94.

21. Hershberger RE, Lindenfeld J, Mestroni L, Seidman CE, Taylor MR, Towbin JA. Genetic evaluation of cardiomyopathy--a Heart Failure Society of America practice guideline. J Card Fail 2009;15(2):83-97.

22. Hershberger RE, Siegfried JD. Update 2011: clinical and genetic issues in familial dilated cardiomyopathy. J Am Coll Cardiol 2011;57(16):641-9.

23. Herman DS, Lam L, Taylor MR, Wang L, Teekakirikul P, Christodoulou D, et al., Truncations of titin causing dilated cardiomyopathy. N Engl J Med 2012;366(7):619-28.

24. Theis JL, Sharpe KM, Matsumoto ME, Chai HS, Nair AA, Theis JD, et al., Homozygosity mapping and exome sequencing reveal GATAD1 mutation in autosomal recessive dilated cardiomyopathy. Circ Cardiovasc Genet 2011;4(6):585-94. 
25. Ho L, Crabtree GR. Chromatin remodeling during development. Nature 2010;463(7280): 474-84.

26. Clapier CR, Cairns BR. The biology of chromatin remodeling complexes. Annu Rev Biochem 2009;78:273-304.

27. Li E. Chromatin modification and epigenetic reprogramming in mammalian development. Nat Rev Genet 2002;3(9):662-73.

28. Yang $\mathrm{XJ}$, Seto $\mathrm{E}$. The Rpd3/Hda1 family of lysine deacetylases: from bacteria and yeast to mice and men. Nat Rev Mol Cell Biol 2008;9(3):206-18.

29. Feinberg AP. Epigenetics at the epicenter of modern medicine. JAMA 2008;299(11):1345-50.

30. Deaton AM, Bird A. CpG islands and the regulation of transcription. Genes Dev 2011;25(10): 1010-22.

31. Li E, Beard C, Jaenisch R. Role for DNA methylation in genomic imprinting. Nature 1993; 366(6453):362-5.

32. Saxonov S, Berg P, Brutlag DL. A genome-wide analysis of CpG dinucleotides in the human genome distinguishes two distinct classes of promoters. Proc Natl Acad Sci USA 2006;103(5): 1412-7.

33. Broadbent HM, Peden JF, Lorkowski S, Goel A, Ongen H, Green F, et al., Susceptibility to coronary artery disease and diabetes is encoded by distinct, tightly linked SNPs in the ANRIL locus on chromosome 9p. Hum Mol Genet 2008;17(6):806-14.

34. Laird PW. The power and the promise of DNA methylation markers. Nat Rev Cancer 2003; 3(4):253-66.

35. Bhutani N, Burns DM, Blau HM. DNA demethylation dynamics. Cell 2011;146(6):866-72.

36. Suzuki MM, Bird A. DNA methylation landscapes: provocative insights from epigenomics. Nat Rev Genet 2008;9(6):465-76.

37. Li E. Chromatin modification and epigenetic reprogramming in mammalian development. Nat Rev Genet 2002;3(9):662-73.

38. Panning B, Jaenisch R. DNA hypomethylation can activate Xist expression and silence Xlinked genes. Genes Dev 1996;10(16):1991-2002.

39. Feinberg AP, Tycko B. The history of cancer epigenetics. Nat Rev Cancer 2004;4(2):143-53.

40. Millis RM. Epigenetics and hypertension. Curr Hypertens Rep 2011;13(1):21-8.

41. Ling C, Groop L. Epigenetics: a molecular link between environmental factors and type 2 diabetes. Diabetes 2009;58(12):2718-25.

42. MacFarlane AJ, Strom A, Scott FW, Epigenetics: deciphering how environmental factors may modify autoimmune type 1 diabetes. Mamm Genome 2009;20(9-10):624-32.

43. Wierda RJ, Geutskens SB, Jukema JW, Quax PH, van den Elsen PJ. Epigenetics in atherosclerosis and inflammation. J Cell Mol Med 2010;14(6A):1225-40.

44. Jenuwein T, Allis CD. Translating the histone code. Science 2001;293(5532):1074-80.

45. Margueron R, Reinberg D. Chromatin structure and the inheritance of epigenetic information. Nat Rev Genet 2010;11(4):285-96.

46. Clayton AL, Hazzalin CA, Mahadevan LC. Enhanced histone acetylation and transcription: a dynamic perspective. Mol Cell 2006;23(3):289-96.

47. Shahbazian MD, Grunstein M. Functions of site-specific histone acetylation and deacetylation. Annu Rev Biochem 2007;76:75-100.

48. Burgess DJ. Cancer genomics: Histone modification at the gene level. Nat Rev Genet 2012; 13(3):148-9.

49. Ordovas JM, Smith CE. Epigenetics and cardiovascular disease. Nat Rev Cardiol 2010;7(9): 510-9.

50. Cheung $P$, Lau $P$. Epigenetic regulation by histone methylation and histone variants. Mol Endocrinol 2005;19(3):563-73.

51. Teperino R, Schoonjans K, Auwerx J. Histone methyl transferases and demethylases; can they link metabolism and transcription? Cell Metab 2010;12(4):321-7.

52. Lachner $\mathrm{M}$, Jenuwein $\mathrm{T}$. The many faces of histone lysine methylation. Curr Opin Cell Biol 2002;14(3):286-98.

53. Shi Y, Whetstine JR. Dynamic regulation of histone lysine methylation by demethylases. Mol Cell 2007;25(1):1-14. 
54. Martin $\mathrm{C}$, Zhang $\mathrm{Y}$. The diverse functions of histone lysine methylation. Nature reviews. Mol Cell Biol 2005;6(11):838-49.

55. Saccani S, Natoli G. Dynamic changes in histone H3 Lys 9 methylation occurring at tightly regulated inducible inflammatory genes. Genes Dev 2002;16(17):2219-24.

56. Brasacchio D, Okabe J, Tikellis C, Balcerczyk A, George P, Baker EK, et al., Hyperglycemia induces a dynamic cooperativity of histone methylase and demethylase enzymes associated with gene-activating epigenetic marks that coexist on the lysine tail. Diabetes 2009;58(5): 1229-36.

57. Villeneuve LM, Reddy MA, Lanting LL, Wang M, Meng L, Natarajan R. Epigenetic histone H3 lysine 9 methylation in metabolic memory and inflammatory phenotype of vascular smooth muscle cells in diabetes. Proc Natl Acad Sci USA 2008;105(26):9047-52.

58. Sayed D, Abdellatif M. MicroRNAs in development and disease. Physiol Rev 2011;91(3): 827-87.

59. Ferguson LR. RNA silencing: Mechanism, biology and responses to environmental stress. Mut Res 2011;714(1-2):93-4.

60. Li K, Blum Y, Verma A, Liu Z, Pramanik K, Leigh NR, et al., A noncoding antisense RNA in tie1 locus regulates tie-1 function in vivo. Blood 2010;115(1):133-9.

61. Robb GB, Carson AR, Tai SC, Fish JE, Singh S, Yamada T, et al., Post-transcriptional regulation of endothelial nitric-oxide synthase by an overlapping antisense mRNA transcript. J Biol Chem 2004;279(36):37982-96.

62. Lee RC, Feinbaum RL, Ambros V. The C. elegans heterochronic gene lin-4 encodes small RNAs with antisense complementarity to lin-14. Cell 1993;75(5):843-54.

63. Kozomara A, Griffiths-Jones S. miRBase: integrating microRNA annotation and deepsequencing data. Nucleic Acids Res 2011;39(Database issue): D152-7.

64. Lee Y, Kim M, Han J, Yeom KH, Lee S, Baek SH, et al., MicroRNA genes are transcribed by RNA polymerase II. EMBO J 2004;23(20):4051-60.

65. Lee Y, Ahn C, Han J, Choi H, Kim J, Yim J, et al., The nuclear RNase III Drosha initiates microRNA processing. Nature 2003;425(6956):415-9.

66. Kim VN. MicroRNA precursors in motion: exportin-5 mediates their nuclear export. Trends Cell Biol 2004;14(4):156-9.

67. Winter J, Jung S, Keller S, Gregory RI, Diederichs S. Many roads to maturity: microRNA biogenesis pathways and their regulation. Nat Cell Biol 2009;11(3):228-34.

68. Lewis BP, Burge CB, Bartel DP. Conserved seed pairing, often flanked by adenosines, indicates that thousands of human genes are microRNA targets. Cell 2005;120(1):15-20.

69. Guo H, Ingolia NT, Weissman JS, Bartel DP. Mammalian microRNAs predominantly act to decrease target mRNA levels. Nature 2010;466(7308):835-40.

70. Lujambio A, Lowe SW. The microcosmos of cancer. Nature 2012;482(7385):347-55.

71. Quiat $D$, Olson EN. MicroRNAs in cardiovascular disease: from pathogenesis to prevention and treatment. J Clin Invest 2013;123(1):11-8.

72. lacobas DA, lacobas S, Haddad GG. Heart rhythm genomic fabric in hypoxia. Biochem Biophys Res Commun 2010;391(4):1769-74.

73. Bayles R, Harikrishnan KN, Lambert E, Baker EK, Agrotis A, Guo L, et al., Epigenetic modification of the norepinephrine transporter gene in postural tachycardia syndrome. Arterioscler Thromb Vasc Biol 2012;32(8):1910-6.

74. Mancini-DiNardo D, Steele SJ, Ingram RS, Tilghman SM. A differentially methylated region within the gene Kcnq1 functions as an imprinted promoter and silencer. Hum Mol Genet 2003; 12(3):283-94.

75. Bokil NJ, Baisden JM, Radford DJ, Summers KM. Molecular genetics of long QT syndrome. Mol Genet Metab 2010;101(1):1-8.

76. Fatima N, Schooley JF Jr, Claycomb WC, Flagg TP. Promoter DNA methylation regulates murine SUR1 (Abcc8) and SUR2 (Abcc9) expression in HL-1 cardiomyocytes. PloS One 2012; 7(7):e41533.

77. Montgomery RL, Davis CA, Potthoff MJ, Haberland M, Fielitz J, Qi X, et al., Histone deacetylases 1 and 2 redundantly regulate cardiac morphogenesis, growth, and contractility. Genes Dev 2007;21(14):1790-802. 
78. Chang CP, Bruneau BG. Epigenetics and cardiovascular development. Annu Rev Physiol 2012;74:41-68.

79. Stein AB, Jones TA, Herron TJ, Patel SR, Day SM, Noujaim SF, et al. Loss of H3K4 methylation destabilizes gene expression patterns and physiological functions in adult murine cardiomyocytes. J Clin Invest 2011;121(7):2641-50.

80. Colussi C, Berni R, Rosati J, Straino S, Vitale S, Spallotta F, et al. The histone deacetylase inhibitor suberoylanilide hydroxamic acid reduces cardiac arrhythmias in dystrophic mice. Cardiovasc Res 2010;87(1):73-82.

81. Liu F, Levin MD, Petrenko NB, Lu MM, Wang T, Yuan LJ, et al. Histone-deacetylase inhibition reverses atrial arrhythmia inducibility and fibrosis in cardiac hypertrophy independent of angiotensin. J Mol Cell Cardiol 2008;45(6):715-23.

82. Cooley N, Cowley MJ, Lin RC, Marasco S, Wong C, Kaye DM, et al. Influence of atrial fibrillation on microRNA expression profiles in left and right atria from patients with valvular heart disease. Physiol Genomics, 2012;44(3):211-9.

83. Kim GH. MicroRNA regulation of cardiac conduction and arrhythmias. Transl Res 2013; 161(5):381-92.

84. Xiao J, Liang D, Zhang Y, Liu Y, Zhang H, Li L, et al. MicroRNA expression signature in atrial fibrillation with mitral stenosis. Physiol Genomics 2011;43(11):655-64.

85. Oliveira-Carvalho V, Carvalho VO, Bocchi EA. The Emerging Role of miR-208a in the Heart. DNA Cell Biol 2013;32(1):8-12.

86. Callis TE, Pandya K, Seok HY, Tang RH, Tatsuguchi M, Huang ZP, et al. MicroRNA-208a is a regulator of cardiac hypertrophy and conduction in mice. J Clin Invest 2009;119(9):2772-86.

87. Lu Y, Zhang Y, Wang N, Pan Z, Gao X, Zhang F, et al. MicroRNA-328 contributes to adverse electrical remodeling in atrial fibrillation. Circulation 2010;122(23):2378-87.

88. Zhao Y, Ransom JF, Li A, Vedantham V, von Drehle M, Muth AN, et al. Dysregulation of cardiogenesis, cardiac conduction, and cell cycle in mice lacking miRNA-1-2. Cell 2007; 129(2):303-17.

89. Yang B, Lin H, Xiao J, Lu Y, Luo X, Li B, et al. The muscle-specific microRNA miR-1 regulates cardiac arrhythmogenic potential by targeting GJA1 and KCNJ2. Nat Med 2007;13(4):486-91.

90. Girmatsion Z, Biliczki P, Bonauer A, Wimmer-Greinecker G, Scherer M, Moritz A, et al. Changes in microRNA-1 expression and IK1 up-regulation in human atrial fibrillation. Heart Rhythm 2009;6(12):1802-9.

91. Matkovich SJ, Wang W, Tu Y, Eschenbacher WH, Dorn LE, Condorelli G, et al. MicroRNA133a protects against myocardial fibrosis and modulates electrical repolarization without affecting hypertrophy in pressure-overloaded adult hearts. Circ Res 2010;106(1):66-75.

92. Belevych AE, Sansom SE, Terentyeva R, Ho HT, Nishijima Y, Martin MM, et al. MicroRNA-1 and -133 increase arrhythmogenesis in heart failure by dissociating phosphatase activity from RyR2 complex. PloS One 2011;6(12):e28324.

93. Shan H, Zhang Y, Lu Y, Pan Z, Cai B, Wang N, et al. Downregulation of miR-133 and miR-590 contributes to nicotine-induced atrial remodeling in canines. Cardiovasc Res 2009;83(3): 465-72.

94. Adam O, Lohfelm B, Thum T, Gupta SK, Puhl SL, Schafers HJ, et al. Role of miR-21 in the pathogenesis of atrial fibrosis. Basic Res Cardiol 2012;107(5):278.

95. Cardin S, Guasch E, Luo X, Naud P, Le Quang K, Shi Y, et al. Role for MicroRNA-21 in atrial profibrillatory fibrotic remodeling associated with experimental postinfarction heart failure. Circ Arrhythm Electrophysiol 2012;5(5):1027-35.

96. Danielson LS, Park DS, Rotllan N, Chamorro-Jorganes A, Guijarro MV, Fernandez-Hernando $\mathrm{C}$, et al. Cardiovascular dysregulation of miR-17-92 causes a lethal hypertrophic cardiomyopathy and arrhythmogenesis. FASEB J 2013;27(4):1460-7.

97. Blanco RR, Austin H, Vest RN 3rd, Valadri R, Li W, Lassegue B, et al., Angiotensin receptor type 1 single nucleotide polymorphism $1166 \mathrm{~A} / \mathrm{C}$ is associated with malignant arrhythmias and altered circulating miR-155 levels in patients with chronic heart failure. J Card Fail 2012;18(9):717-23. 
98. Li YG, Zhang PP, Jiao KL, Zou YZ. Knockdown of microRNA-181 by lentivirus mediated siRNA expression vector decreases the arrhythmogenic effect of skeletal myoblast transplantation in rat with myocardial infarction. Microvasc Res 2009;78(3):393-404.

99. Mathiyalagan P, Chang L, Du XJ, El-Osta A. Cardiac ventricular chambers are epigenetically distinguishable. Cell Cycle 2010;9(3):612-7.

100. Lickert H, Takeuchi JK, Von Both I, Walls JR, McAuliffe F, Adamson SL, et al. Baf60c is essential for function of BAF chromatin remodeling complexes in heart development. Nature 2004;432(7013):107-12.

101. Takeuchi JK, Bruneau BG. Directed transdifferentiation of mouse mesoderm to heart tissue by defined factors. Nature 2009;459(7247):708-11.

102. Takeuchi JK, Lickert H, Bisgrove BW, Sun X, Yamamoto M, Chawengsaksophak K, et al. Baf60c is a nuclear Notch signaling component required for the establishment of left-right asymmetry. Proc Natl Acad Sci USA 2007;104(3):846-51.

103. Bajpai R, Chen DA, Rada-Iglesias A, Zhang J, Xiong Y, Helms J, et al. CHD7 cooperates with PBAF to control multipotent neural crest formation. Nature 2010;463(7283):958-62.

104. Kitagawa H, Fujiki R, Yoshimura K, Mezaki Y, Uematsu Y, Matsui D, et al. The chromatinremodeling complex WINAC targets a nuclear receptor to promoters and is impaired in Williams syndrome. Cell 2003;113(7):905-17.

105. Hang CT, Yang J, Han P, Cheng HL, Shang C, Ashley E, et al. Chromatin regulation by Brg1 underlies heart muscle development and disease. Nature 2010;466(7302):62-7.

106. Kim MY, Mauro S, Gevry N, Lis JT, Kraus WL. NAD+-dependent modulation of chromatin structure and transcription by nucleosome binding properties of PARP-1. Cell 2004;119(6): 803-14.

107. Tulin A, Spradling A. Chromatin loosening by poly(ADP)-ribose polymerase (PARP) at Drosophila puff loci. Science 2003;299(5606):560-2.

108. Xiao CY, Chen M, Zsengeller Z, Li H, Kiss L, Kollai M, et al. Poly(ADP-Ribose) polymerase promotes cardiac remodeling, contractile failure, and translocation of apoptosis-inducing factor in a murine experimental model of aortic banding and heart failure. J Pharmacol Exp Ther 2005;312(3):891-8.

109. Pillai JB, Russell HM, Raman J, Jeevanandam V, Gupta MP. Increased expression of poly(ADP-ribose) polymerase-1 contribues to caspase-independent myocyte cell death during heart failure. Am J Physiol Heart Circ Physiol 2005;288(2):H486-96.

110. Pillai JB, Gupta M, Rajamohan SB, Lang R, Raman J, Gupta MP. Poly(ADP-ribose) polymerase-1-deficient mice are protected from angiotensin II-induced cardiac hypertrophy. Am J Physiol Heart Circ Physiol 2006;291(4):H1545-53.

111. Pillai JB, Isbatan A, Imai S, Gupta MP. Poly(ADP-ribose) polymerase-1-dependent cardiac myocyte cell death during heart failure is mediated by NAD+ depletion and reduced Sir2alpha deacetylase activity. J Biol Chem 2005;280(52):43121-30.

112. Bartha E., Solti I, Kereskai L, Lantos J, Plozer E, Magyar K, et al. PARP inhibition delays transition of hypertensive cardiopathy to heart failure in spontaneously hypertensive rats. Cardiovasc Res 2009;83(3):501-10.

113. Palfi A, Toth A, Hanto K, Deres P, Szabados E, Szereday Z, et al. PARP inhibition prevents postinfarction myocardial remodeling and heart failure via the protein kinase C/glycogen synthase kinase-3beta pathway. J Mol Cell Cardiol 2006;41(1):149-59.

114. Szabo G, Bahrle S, Stumpf N, Sonnenberg K, Szabo EE, Pacher P, et al. Poly(ADP-Ribose) polymerase inhibition reduces reperfusion injury after heart transplantation. Circ Res 2002; 90(1):100-6.

115. Movassagh M, Choy MK, Goddard M, Bennett MR, Down TA, Foo RS. Differential DNA methylation correlates with differential expression of angiogenic factors in human heart failure. PLoS One 2010;5(1):e8564.

116. Haas J, Frese KS, Park YJ, Keller A, Vogel B, Lindroth AM, et al. Alterations in cardiac DNA methylation in human dilated cardiomyopathy. EMBO Mol Med 2013;5(3):413-29.

117. Haas J, Frese KS, Park YJ, Keller A, Vogel B, Lindroth AM, et al. Alterations in cardiac DNA methylation in human dilated cardiomyopathy. EMBO Mol Med 2013;5(3):413-29. 
118. Meurs KM, Kuan M. Differential methylation of $\mathrm{CpG}$ sites in two isoforms of myosin binding protein C, an important hypertrophic cardiomyopathy gene. Environ Molr Mutagen 2011;52(2):161-4.

119. Bellavia A, Urch B, Speck M, Brook RD, Scott JA, Albetti B, et al. DNA hypomethylation, ambient particulate matter, and increased blood pressure: findings from controlled human exposure experiments. J Am Heart Assoc 2013;2(3):e000212.

120. Brook RD, Rajagopalan S, Pope CA 3rd, Brook JR, Bhatnagar A, Diez-Roux AV, et al. Particulate matter air pollution and cardiovascular disease: An update to the scientific statement from the American Heart Association. Circulation 2010;121(21):2331-78.

121. O'Toole TE, Conklin DJ, Bhatnagar A. Environmental risk factors for heart disease. Rev Environ Health 2008;23(3):167-202.

122. Gusterson RJ, Jazrawi E, Adcock IM, Latchman DS. The transcriptional co-activators CREBbinding protein (CBP) and p300 play a critical role in cardiac hypertrophy that is dependent on their histone acetyltransferase activity. J Biol Chem 2003;278(9):6838-47.

123. Yanazume $T$, Hasegawa $K$, Morimoto $T$, Kawamura $T$, Wada H, Matsumori A, et al. Cardiac p300 is involved in myocyte growth with decompensated heart failure. Mol Cell Biol 2003; 23(10):3593-606.

124. Miyamoto S, Kawamura T, Morimoto $\mathrm{T}$, Ono $\mathrm{K}$, Wada H, Kawase $\mathrm{Y}$, et al. Histone acetyltransferase activity of p300 is required for the promotion of left ventricular remodeling after myocardial infarction in adult mice in vivo. Circulation 2006;113(5):679-90.

125. Wei JQ, Shehadeh LA, Mitrani JM, Pessanha M, Slepak TI, Webster KA, et al. Quantitative control of adaptive cardiac hypertrophy by acetyltransferase p300. Circulation 2008;118(9): 934-46.

126. Haberland M, Montgomery RL, Olson EN. The many roles of histone deacetylases in development and physiology: implications for disease and therapy. Nat Rev Genet 2009;10(1): 32-42.

127. Hosseinkhani M, Hasegawa K, Ono K, Kawamura T, Takaya T, Morimoto T, et al. Trichostatin A induces myocardial differentiation of monkey ES cells. Biochem Biophys Res Commun 2007;356(2):386-91.

128. Kaneda R, Ueno S, Yamashita Y, Choi YL, Koinuma K, Takada S, et al. Genome-wide screening for target regions of histone deacetylases in cardiomyocytes. Circulation Res 2005; 97(3):210-8.

129. Antos CL, McKinsey TA, Dreitz M, Hollingsworth LM, Zhang CL, Schreiber K, et al. Dosedependent blockade to cardiomyocyte hypertrophy by histone deacetylase inhibitors. J Biol Chem 2003;278(31):28930-7.

130. Zhang CL, McKinsey TA, Chang S, Antos CL, Hill JA, Olson EN. Class II histone deacetylases act as signal-responsive repressors of cardiac hypertrophy. Cell 2002;110(4):479-88.

131. Chang S, McKinsey TA, Zhang CL, Richardson JA, Hill JA, Olson EN. Histone deacetylases 5 and 9 govern responsiveness of the heart to a subset of stress signals and play redundant roles in heart development. Mol Cell Biol 2004;24(19):8467-76.

132. Trivedi CM, Luo $\mathrm{Y}$, Yin Z, Zhang M, Zhu W, Wang $T$, et al. Hdac2 regulates the cardiac hypertrophic response by modulating Gsk3 beta activity. Nat Med 2007;13(3):324-31.

133. Backs J, Olson EN. Control of cardiac growth by histone acetylation/deacetylation. Circ Res 2006;98(1):15-24.

134. Gupta MP, Samant SA, Smith SH, Shroff SG. HDAC4 and PCAF bind to cardiac sarcomeres and play a role in regulating myofilament contractile activity. J Biol Chem 2008; 283(15): 10135-46.

135. Samant SA, Courson DS, Sundaresan NR, Pillai VB, Tan M, Zhao Y, et al. HDAC3-dependent reversible lysine acetylation of cardiac myosin heavy chain isoforms modulates their enzymatic and motor activity. J Biol Chem 2011;286(7):5567-77.

136. Backs J, Song K, Bezprozvannaya S, Chang S, Olson EN/ CaM kinase II selectively signals to histone deacetylase 4 during cardiomyocyte hypertrophy. J Clin Invest 2006;116(7):1853-64.

137. Lemon DD, Horn TR, Cavasin MA, Jeong MY, Haubold KW, Long CS, et al. Cardiac HDAC6 catalytic activity is induced in response to chronic hypertension. $\mathrm{J}$ Mol Cell Cardiol 2011;51(1):41-50. 
138. Cao DJ, Wang ZV, Battiprolu PK, Jiang N, Morales CR, Kong Y, et al. Histone deacetylase (HDAC) inhibitors attenuate cardiac hypertrophy by suppressing autophagy. Proc Natl Acad Sci USA 2011;108(10):4123-8.

139. Wang ZV, Ferdous A, Hill JA, Cardiomyocyte autophagy: metabolic profit and loss. Heart Fail Rev 2013;18(5):585-94.

140. Martin C, Zhang Y. The diverse functions of histone lysine methylation. Nat Rev Mol Cell Biol 2005;6(11):838-49.

141. Kaneda R, Takada S, Yamashita Y, Choi YL, Nonaka-Sarukawa M, Soda M, et al. Genomewide histone methylation profile for heart failure. Genes Cells 2009;14(1):69-77.

142. Kaneda R, Takada S, Yamashita Y, Choi YL, Nonaka-Sarukawa M, Soda M, et al. Genomewide histone methylation profile for heart failure. Genes Cells 2009;14(1):69-77.

143. Kooistra SM, Helin L. Molecular mechanisms and potential functions of histone demethylases. Nat Rev Mol Cell Biol 2012;13(5):297-311.

144. Zhang QJ, Chen HZ, Wang L, Liu DP, Hill JA, Liu ZP. The histone trimethyllysine demethylase JMJD2A promotes cardiac hypertrophy in response to hypertrophic stimuli in mice. J Clin Invest 2011;121(6):2447-56.

145. van Rooij E, Sutherland LB, Liu N, Williams AH, McAnally J, Gerard RD, et al. A signature pattern of stress-responsive microRNAs that can evoke cardiac hypertrophy and heart failure. Proc Natl Acad SciUSA 2006;103(48):18255-60.

146. Ikeda S, Kong SW, Lu J, Bisping E, Zhang H, Allen PD, et al. Altered microRNA expression in human heart disease. Physiol Genomics 2007;31(3):367-73.

147. Sucharov C, Bristow MR, Port JD. miRNA expression in the failing human heart: functional correlates. J Mol Cell Cardiol 2008;45(2):185-92.

148. Bagnall RD, Tsoutsman T, Shephard RE, Ritchie W, Semsarian C. Global microRNA profiling of the mouse ventricles during development of severe hypertrophic cardiomyopathy and heart failure. PLoS One 2012;7(9):e44744.

149. Matkovich SJ, Van Booven DJ, Youker KA, Torre-Amione G, Diwan A, Eschenbacher WH, et al. Reciprocal regulation of myocardial microRNAs and messenger RNA in human cardiomyopathy and reversal of the microRNA signature by biomechanical support. Circulation 2009;119(9):1263-71.

150. Stauffer BL, Russell G, Nunley K, Miyamoto SD, Sucharov CC. miRNA expression in pediatric failing human heart. J Mol Cell Cardiol 2013;57:43-6.

151. Naga Prasad SV, Duan ZH, Gupta MK, Surampudi VS, Volinia S, Calin GA, et al. Unique microRNA profile in end-stage heart failure indicates alterations in specific cardiovascular signaling networks. J Biol Chem 2009;284(40):27487-99.

152. Thum T, Galuppo P, Wolf C, Fiedler J, Kneitz S, van Laake LW, et al. MicroRNAs in the human heart: a clue to fetal gene reprogramming in heart failure. Circulation 2007;116(3):258-67.

153. Barry SP, Davidson SM, Townsend A. Molecular regulation of cardiac hypertrophy. Int J Biochem Cell Biol 2008;40(10):2023-39.

154. Meder B, Keller A, Vogel B, Haas J, Sedaghat-Hamedani F, Kayvanpour E, et al. MicroRNA signatures in total peripheral blood as novel biomarkers for acute myocardial infarction. Basic Res cardiol 2011;106(1):13-23.

155. Saito Y, Liang G, Egger G, Friedman JM, Chuang JC, Coetzee GA, et al. Specific activation of microRNA-127 with downregulation of the proto-oncogene BCL6 by chromatin-modifying drugs in human cancer cells. Cancer Cell 2006;9(6):435-43.

156. Balaguer F, Link A, Lozano JJ, Cuatrecasas M, Nagasaka T, Boland CR, et al., Epigenetic silencing of miR-137 is an early event in colorectal carcinogenesis. Cancer Res 2010;70(16): 6609-18.

157. Mano H. Epigenetic abnormalities in cardiac hypertrophy and heart failure. Environ Health Prev Med 2008;13(1):25-9.

158. Szyf M. Toward a discipine of pharmacoepigenomics. Current Pharmacogenomics, 2004;2(4): 357-77.

159. Ingelman-Sundberg M, Sim SC, Gomez A, Rodriguez-Antona C. Influence of cytochrome P450 polymorphisms on drug therapies: pharmacogenetic, pharmacoepigenetic and clinical aspects. Pharmacol Ther 2007;116(3):496-526. 
160. Morimoto T, Sunagawa $\mathrm{Y}$, Kawamura T, Takaya T, Wada H, Nagasawa A, et al. The dietary compound curcumin inhibits p300 histone acetyltransferase activity and prevents heart failure in rats. J Clin Invest 2008;118(3):868-78.

161. Sunagawa $\mathrm{Y}$, Morimoto $\mathrm{T}$, Wada H, Takaya T, Katanasaka $\mathrm{Y}$, Kawamura $\mathrm{T}$, et al. A natural p300-specific histone acetyltransferase inhibitor, curcumin, in addition to angiotensinconverting enzyme inhibitor, exerts beneficial effects on left ventricular systolic function after myocardial infarction in rats. Circ J 2011;75(9):2151-9.

162. Kook H, Lepore JJ, Gitler AD, Lu MM, Wing-Man Yung W, Mackay J, et al. Cardiac hypertrophy and histone deacetylase-dependent transcriptional repression mediated by the atypical homeodomain protein Hop. J Clin Invest 2003;112(6):863-71.

163. Kee HJ, Sohn IS, Nam KI, Park JE, Qian YR, Yin Z, et al. Inhibition of histone deacetylation blocks cardiac hypertrophy induced by angiotensin II infusion and aortic banding. Circulation 2006;113(1):51-9.

164. Coppede F. Epigenetic biomarkers of colorectal cancer: Focus on DNA methylation. Cancer Lett 2014;342(2):238-47.

165. Litzow MR. Novel therapeutic approaches for acute lymphoblastic leukemia. Hematol Oncol Clin North Am 2011;25(6):1303-17. 



\section{Chapter 3}

\section{Targeting microRNAs in heart failure}

Burcu Duygu, Leon J. de Windt, Paula. A. da Costa Martins Adapted from

Trends Cardiovasc Med. 2016 Feb;26(2):99-110 


\section{Abstract}

MicroRNAs play pivotal roles in cardiac disease and their therapeutic modulation raises exciting and unique opportunities as well as challenges in the path toward clinical development and implementation. In this review, we provide a detailed overview of recent studies highlighting the important role of microRNAs in heart failure (HF) and the potential use of microRNA-based technology for diagnosis, prevention, and treatment of HF. We will focus on the strategies presently used for microRNA-based therapy by discussing their use and drawbacks as well as the challenges and future directions for their development in the context of human HF. 


\section{Introduction}

Heart failure (HF) is one of the major worldwide causes of death and disability. $\mathrm{HF}$ is a complex and progressive disease composed of several clinical syndromes, which result from the inability of the heart to provide adequate amount of blood to the organism and maintain its metabolic requirements. Moreover, HF can develop from several pathological conditions including myocardial infarction (MI), pressure overload (aortic stenosis, hypertension), inflammatory heart muscle disease (myocarditis) and volume overload (valvular regurgitation). ${ }^{1}$ Within these different etiologies, prolonged stress stimulates a ventricular remodeling process involving diverse molecular and cellular events such as genetic alterations, hypertrophic growth, fibrosis, apoptosis and endothelial dysfunction with subsequent weakened cardiac structure and impaired contractile function. ${ }^{2}$

MicroRNAs constitute a growing class of non-coding small RNAs that act as molecular switches of gene expression and are known to regulate complex cardiac signaling and transcriptional circuits during cardiac development and disease. The global significance of microRNAs during cardiac development was elucidated by the generation of cardiac specific Dicer knockout mice. Since Dicer is an RNAse III endonuclease responsible for cleavage of the precursor microRNA into an active mature microRNA, depletion of Dicer leads to disruption of the global regulation of microRNA expression and subsequent alterations in target gene expression levels. Not surprisingly, Dicer ablation resulted in embryonic lethality due to double outlet right ventricular and ventricular septum defects. $^{3}$ Whereas, in the adult heart, conditional Dicer depletion resulted in adverse cardiac remodeling manifested by cardiac hypertrophy and fibrosis, upregulation of fetal cardiac gene expression and cardiac dysfunction suggesting a global requirement of microRNAs to maintain homeostasis in the adult myocardium. ${ }^{4}$

Besides exhibiting developmental stage- and tissue-specific expression patterns, microRNAs also regulate distinct cellular processes such as proliferation, differentiation, cell metabolism, apoptosis and angiogenesis. Presently, advances in microRNA-based technology allow researchers to modulate the cellular levels of specific microRNAs in order to ameliorate cardiac remodeling and ultimately improve or design microRNA-based therapeutic tools. In the present review, we provide an overview of recent studies highlighting the important role of microRNAs in HF and the potential use of microRNA-based technology for diagnosis, prevention, and treatment of HF. 


\section{microRNAs in heart failure}

The myocardial tissue is composed of different cell types including heart muscle cells, endothelial cells, smooth muscle cells and fibroblasts, each of which contribute to the distinct structural, mechanical, biochemical and electrical properties of the heart (Figure 3.1). In response to cardiac injury or stress, cellular alterations such as interstitial fibrosis, angiogenesis, cellular hypertrophy and inflammation occur, which can lead to the onset of cardiac disease and/or progression to HF, and may also determine the severity of clinical outcomes. As crucial regulators of pathological cardiac remodeling, microRNAs constitute attractive therapeutic targets and several tools have been developed to specifically and efficiently modulate microRNA levels in vivo and to directly target the different cellular processes associated with cardiac disease (Figure 3.1).

\section{Fibrosis}

Cardiac fibroblasts contribute to adverse cardiac remodeling in response to stress or injury via secretion of matrix metalloproteinases and collagen leading to extracellular matrix modulation and interstitial fibrosis formation. Fibrosis is an important part of the healing process and when excessive it hampers contractility and increases the risk for arrhythmias. Therefore, blocking or reversing the formation of fibrosis may constitute an important therapeutic avenue for the treatment of HF and a number of microRNAs have previously been identified to critically affect fibrosis regulation.

microRNA-21: miR-21 is highly expressed in cardiac fibroblasts compared to other cardiac cell types and is upregulated in failing human myocardium as well as in myocardium from murine models of HF. ${ }^{5}$ There are, however, controversial findings concerning the importance of miR-21 in HF. miR-21 regulates fibroblast proliferation and survival by inhibiting Sprout homologue 1 (Spry1) and subsequently activating ERK-MAP kinase signaling. Inhibition of miR-21 by cholesterol-conjugated antagomirs in a pressure overload-induced cardiac disease model reduced ERK-MAP kinase activity, decreased interstitial fibrosis and improved cardiac function. Remarkably, inhibition of miR-21 three weeks after aortic banding, as a model of established cardiac hypertrophy, could still attenuate cardiac fibrosis and dysfunction. ${ }^{5}$ 


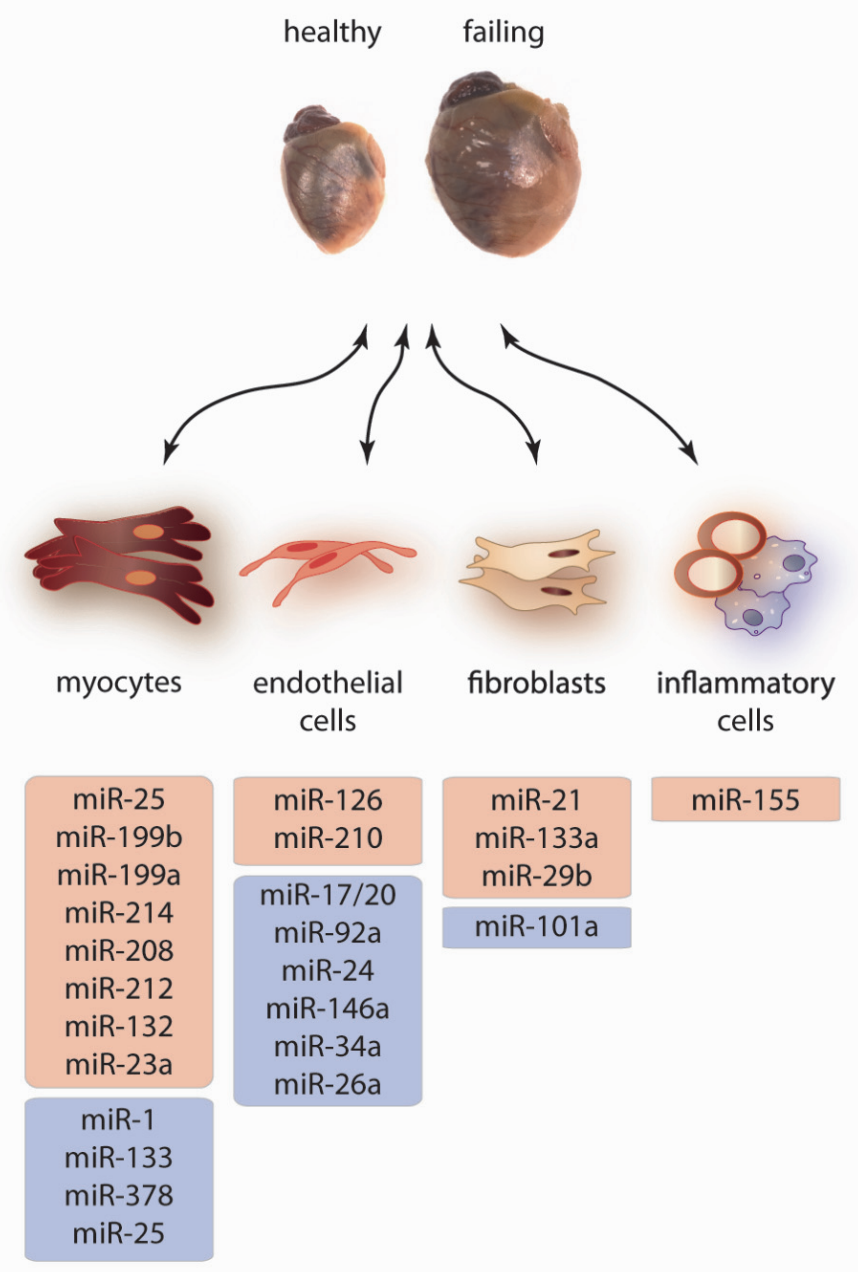

Figure 3.1 microRNAs regulate different molecular processes during heart failure. MicroRNA exert their regulatory roles in the different cardiac cell types (cardiomyocytes, endothelial cells, fibroblasts and inflammatory cells) being able to induce (red boxes) or repress (blue boxes) different pathophysiological processes that are associated with cardiac pathological remodeling in heart failure (cardiac hypertrophy, inflammation, angiogenesis and fibrosis).

In contrast, others demonstrated that miR-21 inhibition by genetic deletion or systemic administration of locked nucleic acid-modified (LNA) antimiR oligonucleotides does not reduce pathological myocardial remodeling nor prevents cardiac dysfunction in different mouse models of $\mathrm{HF} .{ }^{6}$ These findings suggest that caution is needed when interpreting studies using antisense 
approaches to elucidate the function of individual microRNAs in vivo. Moreover, following acute $\mathrm{Ml}$ the expression levels of miR-21 in the infarcted areas was reduced and overexpression of miR-21 in this setting even decreased myocardial infarct size. ${ }^{7}$ These contradictory results raise questions regarding not only the discrepancy between data obtained from antisense and genetic deletion techniques but, maybe more important, the therapeutic potential of miR-21 in HF. Although several, mainly technical, possibilities to justify the controversial findings were suggested by the different authors, it is clear that future studies are required to clarify the biology of miR-21 and its role in HF, preferably including cell type-specific genetic deletion strategies for miR-21.

microRNA-29: miR-29 family members are selectively expressed in cardiac fibroblasts and target mRNAs that promote extracellular matrix deposition. ${ }^{8}$ All different family members are downregulated in areas adjacent to the infarct, thereby de-repressing their targets and resulting in increased cardiac fibrosis. ${ }^{9}$ In a recent study ${ }^{10}$ where a set of microRNAs was measured in the plasma of patients with hypertrophic cardiomyopathy to identify which microRNAs can be regarded as biomarkers of the disease, only miR-29a levels were found to correlate with cardiac fibrosis, along with a set of microRNAs related to cardiac hypertrophy. This finding may help to correctly diagnose patients who are at risk of developing cardiac fibrotic remodeling.

microRNA-133: miR-133, is one of the most abundant microRNAs in the heart. The importance of miR-133 in cardiac fibrosis has been highlighted in several reports that miR-133-a1 and miR-133-a2 knockout mice develop a severe myocardial fibrosis response accompanied by increased cardiomyocyte apoptosis and $\mathrm{HF}^{11}$ which could be explained by the fact that miR-133 directly repressed connective tissue growth factor (CTGF), an important secreted protein during the process of fibrosis. ${ }^{12}$ In vivo and in vitro mechanistic studies showed that increased expression of miR-133 has cardiac protective effects not only by direct targeting the TGF- $\beta 1$ receptor, ${ }^{13}$ but it can also act together with miR-29b to upregulate collagen $1 \mathrm{~A} 1$ and exacerbate the levels of fibrosis in Angiotensin II-induced hypertension. ${ }^{14}$ Interestingly, a recent study using human foreskin fibroblasts revealed that miR-133a, in concert with several transcription factors, contributes to reprogramming of fibroblasts into cardiomyocytes. ${ }^{15}$

microRNA-101a: This fibroblast-enriched microRNA is involved in cardiac fibroblast proliferation and inhibits FBJ osteosarcoma oncogene (FOS), known to activate specific profibrotic pathways, such as those involving miR-21. While miR-101a is downregulated in hypertrophic and post-infarcted hearts, ${ }^{16}$ its overexpression in infarcted rat hearts revealed positive effects on cardiac function mostly caused by reduced fibrotic tissue formation. Interfering with miR- 
101a expression may present therapeutic value even though unresolved issues regarding its mechanism of action still remain.

\section{Angiogenesis}

Angiogenesis, the complex process of blood vessel formation, involves synergistic effects of distinct growth factors that can either be physiological or pathological. Pathological cardiac hypertrophy correlates with reduced capillary density, subsequent myocardial ischemia and eventually HF. Ameliorated blood flow, revascularization and myocardial function by means of therapeutically induced angiogenesis may promote new repairing mechanisms and myocardium survival and is therefore, a promising therapy for cardiovascular disease.

Studies aimed to better understand the angiogenic mechanisms in the heart have revealed a subset of microRNAs with the potential to regulate pro- or antiangiogenic factors and proper endothelial cell function. ${ }^{17}$ While a wealth of discoveries regarding the action of angiogenic microRNAs in cancer identified signaling pathways used to promote or inhibit angiogenesis, their participation and mode of action during vascular remodeling induced by cardiac pathological insults remains to be clarified. Understanding those mechanisms in various cardiac angiogenic settings could introduce new microRNA-based therapies, such as mimics and antagomirs, to manage and/or cure HF.

microRNA-17 92: Gain or loss of function studies targeting individual members of the miR-17 92 cluster, revealed miR-17, miR-18, miR-19 and miR-20 as the ones with anti-angiogenic function while both in vitro and in vivo assays revealed mir-17/20 inhibition to exert the most potent effect on neovascularization. ${ }^{18}$ Furthermore, miR-17 inhibition in rat and mouse models of pulmonary hypertension beneficially affects lung and heart remodeling ${ }^{19}$ by resulting in lower number of muscularized vessels, increased pulmonary artery acceleration time, decreased wall thickness of pulmonary vessels and subsequent improved cardiac outcome. miR-92a, mostly upregulated under cardiac ischemia, inhibits angiogenesis by targeting a pro-angiogenic factor, integrin a5 (ITGA5) and treatment of infarcted mice hearts with a specific antagomir improved cardiac function due to enhanced angiogenesis. ${ }^{20} \mathrm{~A}$ similar therapeutic approach but administrating a locked nucleic acid modified anti-sense (LNA)-miR-92a to a porcine model of ischemia reperfusion also resulted in reduced infarct area, increased capillary formation and consequently, cardiac function recovery. ${ }^{21}$

microRNA-126: this endothelial cell enriched microRNA is crucial for maintenance of vascular integrity, endothelial cell proliferation, migration and sprouting during embryonic development as well as in cardiac response to 
injury. ${ }^{22}$ As such, $40 \%$ of miR-126 null-mice display embryonic lethality while $50 \%$ of the surviving animals died one week after MI due to vascular deficiency. Furthermore, circulating miR-126 levels were decreased in time, in acute MI patients, suggesting its potential utility as novel biomarker for clinic diagnosis of acute $\mathrm{Ml}^{23}$

microRNA-24: this endothelial cell-enriched and pro-apoptotic microRNA is strictly elevated in the peri-infarct zone endothelium, following $\mathrm{MI}^{24,25}$ In vitro overexpression of miR-24 impairs endothelial cell angiogenic functions including proliferation, sprouting, and tube formation whereas its inhibition promotes angiogenesis. ${ }^{24,25}$ Although these effects are attributed to inhibition of the endothelium-enriched transcription factor GATA2, the p21-activated kinase PAK4 and their respective downstream targets, ${ }^{24}$ miR-24 is also known to target e-NOS, a pro-angiogenic factor. ${ }^{25}$ In vivo inhibition of miR-24 resulted in preserved cardiac function, decreased infarct size and enhanced vascularization after MI, as endothelial cell apoptosis was inhibited. ${ }^{24,25}$

microRNA-210: Unlike the previously mentioned microRNAs, miR-210 directly exert its pro-angiogenic function via the cardiomyocytes by inducing the release of angiogenic factors such as leptin, interleukin-1-a and tumor necrosis factoralpha $(\mathrm{TNF}-\alpha) \cdot{ }^{26}$ Overexpression of miR-210 in a mouse model of Ml enhanced capillary formation, reduced apoptosis and infarct size, and consequently improved cardiac function. ${ }^{26}$ As diagnostic tool, patients with improved plasma brain natriuretic peptide (BNP) profiles are classified in a subgroup of patients with low plasma miR-210 levels, suggesting that plasma miR-210 levels may reflect a mismatch between cardiac pump function and oxygen demand in the peripheral tissues, and therefore be a biomarker for chronic HF in addition to plasma BNP concentrations. ${ }^{27}$

microRNA-146a: this microRNA is abundantly expressed in the heart and is upregulated during development of $\mathrm{HF}$. In mice with cardiomyocyte-restricted genetic deficiency for the Dicer protein, miR-146a was found to be upregulated at juvenile and adult ages, suggesting a non-cardiomyocyte origin of miR-146a. ${ }^{4}$ A recent study identified $\mathrm{miR}-146 \mathrm{a}$ as key player in cardiomyocyte response during peripartum cardiomyopathy (PPCM), with increased levels being triggered by the activation of endothelial cells and their subsequent exosomemediated miR-146a release. ${ }^{28}$ Targeting of miR-146a by LNA and antagomir strategies in a mouse model of PPCM, prevented the development of the disease by reducing cardiac fibrosis, increasing capillary density and improving cardiac function. ${ }^{28}$ In contrast, overexpression of miR-146a in a mouse model of ischemia reperfusion conferred cardiac protection by indirect decrease of NF-kB activity. $^{29}$ 
microRNA-34: The miR-34 family consists of three members: miR-34a, miR-34b and miR-34c, all of them displaying increased expression levels in response to cardiac stress and in the ageing heart. ${ }^{30}$ In vivo ablation of miR-34a reduced age-associated cardiomyocyte death, reduced fibrosis and improved myocardial function in a mouse model of MI. The observed effects were attributed to angiogenesis induction in the border zone of the infarcted area and reduced DNA damage in cardiomyocytes. ${ }^{30}$ In a study where all miR-34 family members were inhibited and a common seed region was targeted, greater beneficial cardiac outcomes were observed in mouse models of $\mathrm{Ml}$ and pressure overload, compared to inhibition of miR-34a alone. ${ }^{31}$ The later study suggests a greater therapeutic potential by targeting whole microRNA families rather than single members.

microRNA-26a: miR-26a is an anti-angiogenic microRNA with a dynamic expression pattern in response to ischemia/reperfusion. Its expression is increased just one hour after forty-five minutes of ischemia-reperfusion induced myocardial injury whereas it was decreased twenty-four hours later. ${ }^{32}$ Furthermore, therapeutic inhibition of miR-26a by LNA technology in mice after acute injury induced by left arterial descending artery banding (LAD) resulted in protective cardiac effects with decreased infarct size and improved cardiac function. ${ }^{32}$ This outcome was attributed to improved angiogenesis observed within two days following LAD. ${ }^{32}$ Moreover, miR-26a seems to act as a previously unrecognized crucial regulator of pathological angiogenesis by inhibiting both the expression and phosphorylation of SMAD1 and subsequently downregulating its pro-angiogenic downstream target Id1. ${ }^{32}$

\section{Hypertrophy and metabolic balance}

Cardiac hypertrophy is the thickening of the ventricular walls in response to chronic cardiac stress. Intrinsic changes including re-expression of fetal genes, alterations in excitation-contraction coupling, and changes in energetic and metabolic balance induce cardiomyocyte size growth. Left ventricular hypertrophy $(\mathrm{LVH})$ is the most potent predictor of adverse cardiovascular outcomes in the cardiovascular disease (CVD) population, and is an independent risk factor for coronary heart disease, sudden death, HF and stroke. Hence, targeting hypertrophy may significantly reduce adverse clinical endpoints and aid in the treatment of HF. Studies from the past decade have demonstrated that microRNAs are atypically expressed in hypertrophic hearts and gain- and loss-of-function studies using appropriate disease models have revealed distinct roles for specific microRNAs in pathological cardiac hypertrophy. 
microRNA-25: The role and therapeutic potential of miR-25 in HF is supported by recent but somewhat controversial findings. Cardiac expression of miR-25 decreases during the development of cardiac hypertrophy and HF in rodents, while its inhibition with an antagomir approach exacerbates the pathological remodeling response and accelerates progression to HF. ${ }^{33}$ The observed effects were ascribed to increased levels of a basic helix-loop-helix (bHLH) transcription factor, HAND2, which besides being a central player during right ventricle development, is also activated in the stressed, adult heart as part of the embryonic gene program, a hallmark of HF. ${ }^{33}$ Paradoxically, others reported increased levels of miR-25 in rodent and human HF, which by directly targeting SERCA2a cause diminished $\mathrm{Ca}^{++}$uptake and impaired cell contractility. ${ }^{34}$ The divergences between these studies likely relate to different antisense chemistries, mode of delivery or degree of silencing achieved. Although other studies could confirm miR-25 downregulation in $\mathrm{HF}^{35,36}$ such conflicting reports probably reflect our poor understanding not only of the complexity of microRNA biology, regulation and function but also of the variations between different animal models of disease.

microRNA-199b: miR-199b is a very solid example that microRNAs can incite the cardiac hypertrophic program. Cardiac expression levels of miR-199b are increased in LVH and $\mathrm{HF}$ and its overexpression strongly promotes cardiac hypertrophic growth. miR-199b is directly regulated by the calcineurin/NFAT pathway $^{37}$ and is able to regulate its own signaling strength by promoting translocation of NFAT to the cytoplasm and indirectly inactivate its own regulator, Dyrk1a. Antagomir-mediated knockdown of miR-199b in a mouse model of cardiac pressure overload, prevented development of HF and, more interesting, reversed later stage cardiac failure phenotypes and dysfunction, bringing miR-199b forward as a very promising therapeutic target for the treatment of hypertrophic heart disease and HF.

microRNA-214: the miR-199a/214 cluster is encoded by a large non-coding RNA, DNM3os, which is located in the opposite strand of the DNM3 gene. Among this cluster, miR-214 plays a regulatory role in the metabolic switch from mitochondrial fatty acid oxidation towards glucose metabolism in the heart in response to hemodynamic stress. ${ }^{38}$ Silencing miR-214 in a mouse model of cardiac pressure overload normalized mitochondrial fatty acid oxidation, attenuated cardiac pathological remodeling and preserved cardiac function due to the de-repression of its target gene PPAR $\beta .^{38}$

microRNA-1: this anti-hypertrophic cardiomyocyte-enriched microRNA is suppressed in different murine models of HF and negatively controls the calcium signaling members calmodulin and myocyte enhancer factor 2A (MEF2A). ${ }^{39}$ 
MiR-1 can effect $\mathrm{Ca}^{++}$extrusion from cardiomyocytes via its direct targets $\mathrm{Na}^{+}$$\mathrm{Ca}^{++}$exchanger 1 (NCX1) and AnxA5. Because AnxA5 binds to NCX1 and controls its activity, once increased during HF AnxA5 impairs NCX1 function leading to reduced $\mathrm{Ca}^{2+}$ extrusion. ${ }^{40,41}$ This regulatory loop is controlled by the serum response factor (SRF) transcription factor and balances the translation of NCX1 and AnxA5 proteins. ${ }^{40}$ The AKT/FoxO3a pathway can also exert a regulatory role on miR-1 during HF. ${ }^{41,42}$ This happens either through insulin like growth factor 1 (IGF-1), a direct target of miR-1 that induces phosphorylation of AKT which, in turn, inactivates the FoxO3a transcription factor causing miR-1 downregulation in $\mathrm{HF}^{42}$ or through increased $\mathrm{Ca}^{++}$levels in $\mathrm{HF}$ causing calcium/calmodulin-dependent protein kinase (CaMKK)-dependent activation of AKT, inactivation of FoxO3a and subsequent decline in miR-1 levels. ${ }^{42}$ Conversely, induced expression of miR-1 by adenoviral gene therapy or cardiotropic adeno-associated 9 vector (AAV9) not only rescued the hypertrophic phenotype induced by isoproterenol administration in mice ${ }^{39}$ or by chronic pressure overload in rats, respectively, but also attenuated disease progress. The observed effects were long lasting suggesting long-term therapeutic effectiveness of miR-1 overexpression in pathological cardiac remodeling. ${ }^{43}$ Moreover, an inverse correlation between the expression of miR-1 and circulating levels of heart-type fatty acid binding protein 3 (FABP3), responsible for fatty acid uptake in cardiomyocytes, was described, suggesting that FABP3 levels can be useful in determining miR-1 expression levels in patients with heart or metabolic disease. ${ }^{44}$

microRNA-133: Despite some controversial findings about miR-133 and its correlation with cardiac hypertrophy, miR-133 is an established muscle-enriched microRNA that is highly expressed in the healthy heart. This microRNA is clustered with miR-1 and both are encoded from two genomic loci (mir-1-1/133a2 on mouse chromosome 2 and miR-1-2/miR-133a- 1 on mouse chromosome 18). Genetic deletion of both copies of this cluster leads to increased mortality of neonatal mice as a result of ventricular-septal defects (VSDs) associated with enhanced proliferation of neonatal cardiomyocytes and abrupt expression of smooth muscle genes in the heart, mainly the direct target genes cyclin $D$ and SRF. ${ }^{11}$ Although deletion of a single genomic loci results in vital mice with normal cardiac morphology and contractility, ${ }^{45}$ these single mutants develop long QT durations at low heart rates pointing to the importance of miR1/miR-133a cluster during cardiac repolarization. ${ }^{45}$ Such phenotype could be abrogated after inhibiting $\beta$-adrenergic signaling and L-type calcium channels by pharmaceutical interventions suggesting miR-1/miR-133a cluster to be a regulator of cardiac repolarization via adrenergic signaling. ${ }^{45}$ Moreover, inhibition of miR-133 expression by a specific antagomir spontaneously induces cardiac hypertrophy and impairs cardiac function by direct targeting of RhoA, Cdc42, both being part 
of the Rho subfamily of small GTP binding proteins, and NELF-A/Whsc2, a negative regulator of RNA polymerase II. ${ }^{46}$

Conversely, gain of function studies showed that inducing cardiac-specific-miR133 expression decreased cardiomyocyte apoptosis and collagen deposition and promoted cardiac function following chronic pressure overload. The underlying mechanism involves the direct inhibition of multiple components of the $\beta 1 A R$ signaling pathway including $\beta 1 A R$ itself and its downstream effectors adenyl cyclase type $\mathrm{VI}(\mathrm{ACVI})$ and cAMP-dependent protein kinase catalytic subunit beta (PKA Cbeta), a key modulator of the $\beta 1 \mathrm{AR}$-mediated accumulation of CAMP. ${ }^{47}$ In another study, a similar approach to induce miR133 expression in cardiac tissue also resulted in less fibrosis, less apoptosis and improved diastolic function after pressure overload but did not affect cardiac hypertrophic growth $^{48}$ despite the long QT intervals demonstrated in the ECG. Whether overexpression of miR-133 can diminish cardiac dysfunction in the failing heart remains disputable. Nevertheless, it is clear that this microRNA has a multidisciplinary role during pathological cardiac remodeling by acting on different cellular processes. In agreement, a recent report shows miR-133a to be attenuated and contribute to cardiac hypertrophy in diabetic hearts ${ }^{49}$ while overexpression of miR-133a attenuates cardiac fibrosis in diabetics. ${ }^{50}$ These effects are related to control of DNA methylation by miR-133 via direct regulation of DNA methyl transferases in diabetic cardiomyocytes. ${ }^{51}$ The role of miR-133 in regulating cardiac hypertrophy, fibrosis, epigenetic modification, and $\beta-A R$ signaling points miR-133 as a promising therapeutic target in managing HF.

microRNA-208: The microRNA-208 family is composed of miR-208a and miR$208 \mathrm{~b}$, encoded by intronic regions in the $\alpha-\mathrm{MHC}$ and $\beta-\mathrm{HMC}$ genes respectively. They show a similar expression pattern in rodents as their host genes with miR-208a being expressed in the adult heart while miR-208b is enriched in embryonic hearts. Gain- and loss-of-function studies in rodents showed that miR-208a is required for the expression of $\beta-\mathrm{MHC}$ in stressed hearts, and therefore directly implicated in the isoform switch from $\alpha-\mathrm{MHC}$ to $\beta-\mathrm{MHC}$ that characterizes pathologic hypertrophy and HF. In fact, inhibition of miR-208a levels in Dahl hypertensive rats, a hypertension-induced model of HF, not only prevents pathologic myosin switching and cardiac remodeling but also improves cardiac function and survival. ${ }^{52}$ miR-208 was recently identified circulating outside of cells, in body fluids such as blood, saliva and urine. Whether miR-208 is released from damaged cardiomyocytes into the bloodstream remains unknown but the fact that this microRNA is enriched in the heart and detected in peripheral blood makes it potentially useful for the diagnosis and treatment of HF. 
microRNA-23: the two isomers, miR-23a and miR-23b are part of the miR23a/27a/24-2 cluster ${ }^{53}$ and are both upregulated under conditions of cardiac stress. miR-23a is involved in cardiac hypertrophy as a downstream target of the calcineurin/NFAT pathway and targets the anti-hypertrophic protein, muscle ringfinger protein 1 (MURF1). ${ }^{53}$ Therapeutic studies in rodents using antagomir to silence miR-23a showed attenuation of cardiac hypertrophic growth in different models of $\mathrm{HF}^{53,54}$ with the underlying mechanism involving direct targeting of the forkhead box $\mathrm{O} 3$ gene (FOXO3A), a transcription factor involved in the regulation of cardiac hypertrophy. ${ }^{54}$ Moreover, miR-23a, similar to miR-199b, is regulated by the calcineurin/NFAT signaling pathway and it will be interesting to know how both microRNAs integrate to mediate calcineurin/NFAT signaling during cardiac hypertrophy and HF.

microRNA-378: this anti-hypertrophic microRNA was identified in a functional high-throughput screen for morphological changes in neonatal rat cardiomyocytes after transfection with a library of microRNA precursor molecules. ${ }^{55}$ MiR-378 exerts its anti-hypertrophic function by targeting four different components of the MAPK pathway: MAPK1 (also called extracellular regulated kinase 2), kinase suppressor of ras 1 (KSR1), growth factor receptorbound protein 2 (GRB2), and IGF1R. Thus, miR-378 sets a good example of the ability of microRNAs to target multiple hits in a single pathway, which also augments their therapeutic value. Furthermore, in vivo restoration of miR-378 expression levels in a mouse model of chronic pressure overload resulted in attenuation of pathological remodeling and cardiac dysfunction, ${ }^{55}$ which could be an effective therapeutic strategy in myocardial disease.

microRNA-212/132: The miR-212/132 microRNA family is upregulated in both murine and human failing hearts. ${ }^{56}$ Not only hypertrophic stimuli cause increased expression levels of miR-212 and miR-132 in cardiomyocytes, but also expression of both is necessary and sufficient to induce their hypertrophic growth. Genetic targeted deletion of miR-212 and miR-132 conferred protection from pressure-overload induced HF while their overexpression caused pathological hypertrophy, HF and death. Curiously, pharmacological approaches to inhibit miR-132 alone were sufficient to preserve cardiac function and attenuate hypertrophy and fibrosis in mice subjected to pressure overload. ${ }^{56}$ These therapeutic effects are attributed to increased expression levels of FOXO3A, a miR-132 target gene, and subsequent blunted calcineurin/NFAT signaling. Although decreased expression levels of miR-212/132 inhibit starvation-induced autophagy in cardiomyocytes, ${ }^{56}$ the study does not correlate this anti-autophagic function to the therapeutic effects of antagomir-mediated miR-132 knockdown. 


\section{Inflammation}

Inflammation is the process of immune cell influx to the side of injury or infection. Increasing evidence point to the importance and the therapeutic potential of inflammatory pathways in the treatment of HF. Although several microRNAs have been identified to regulate the immune system and inflammation in the context of other pathological conditions (as extensively reviewed $\mathrm{in}^{57}$ ), very few microRNAs have been suggested as main regulators of the chronic inflammatory processes that accompany HF and so far only miR-155 has been extensively studied in this context.

microRNA-155: Two different studies demonstrated the involvement of miR-155 in cardiac hypertrophy via diverse mechanisms. Recently, miR-155 was shown to be enriched in cardiomyocytes and whole-body loss of miR-155 to be protective against cardiac injury induced by pressure overload, ${ }^{58}$ partly due to repression of jumonji AT rich interactive domain 2 (Jarid2). ${ }^{58}$ On the other hand, the cardio-protective effect of miR-155 silencing has been associated to its decreased expression levels in macrophages rather than in cardiomyocytes. ${ }^{59}$ Silencing of miR-155 in leukocytes markedly reduced cardiac inflammation, hypertrophy and cardiac dysfunction following pressure overload in mice. Moreover, in vivo cardiomyocyte-specific modulation of miR-155 did not affect cardiac remodeling. In macrophages, miR-155 is responsible for the repression of suppressor cytokine signaling 1 gene (Socs1), which inhibits paracrine hypertrophic stimulation. ${ }^{59}$ The cardioprotective effect of miR-155 silencing supports the causative significance of inflammatory signals in hypertrophic cardiac disease, positioning miR-155 forward as a potential therapeutic target for cardiac hypertrophy.

\section{Advantages and disadvantages of microRNA therapeutics}

Intensive research in recent years aimed at targeting differential microRNA expression as a novel therapeutic approach. In vivo modulation of microRNAs with antisense oligonucleotides as microRNA inhibitors or with modified microRNA mimics such as plasmid or lentiviral vectors carrying microRNA sequences to increase the expression of microRNAs was proven successful in the aforementioned preclinical studies (Table 3.1 and Table 3.2) but to date no clinical trials were initiated yet for cardiovascular diseases. 


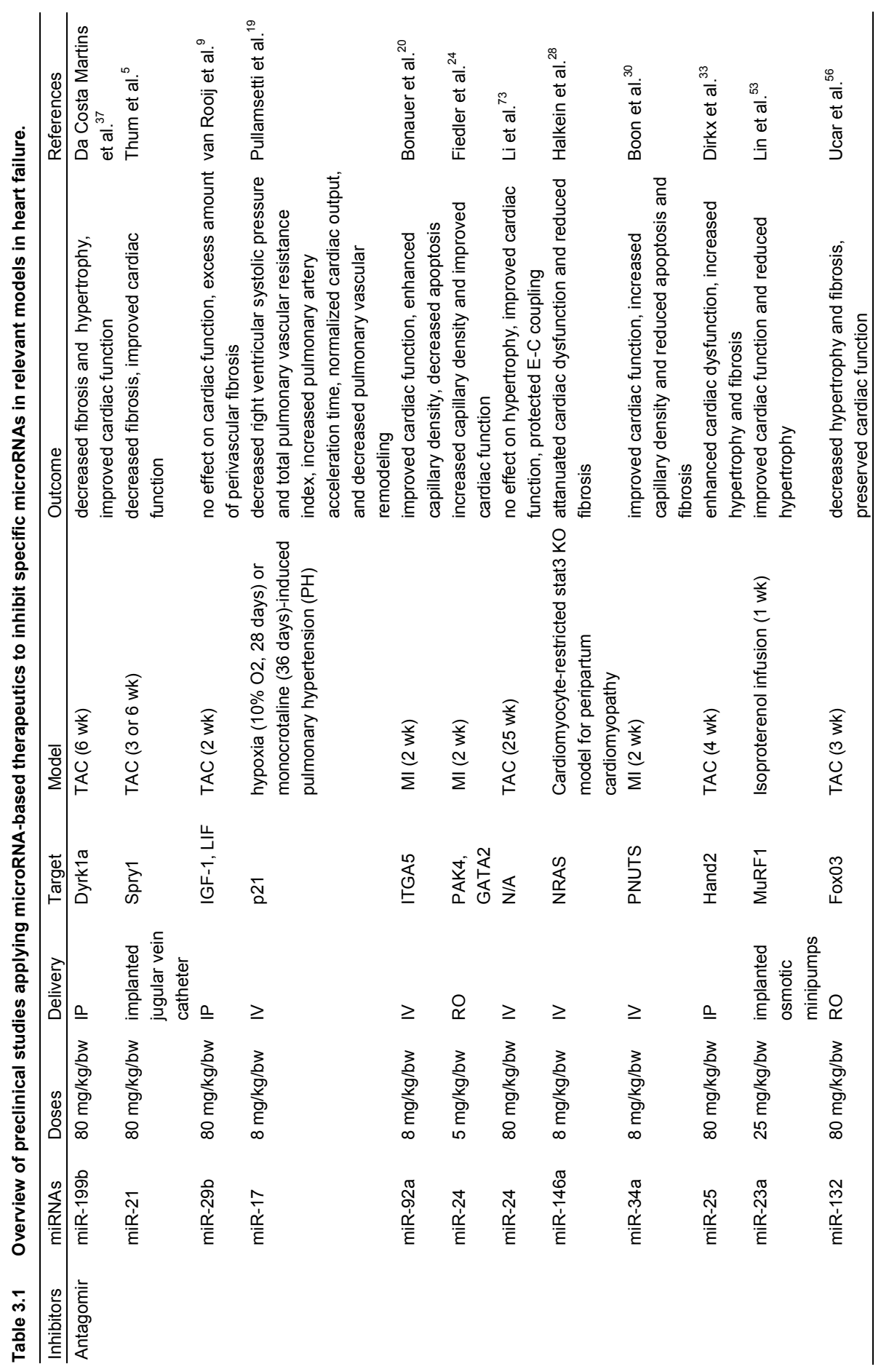




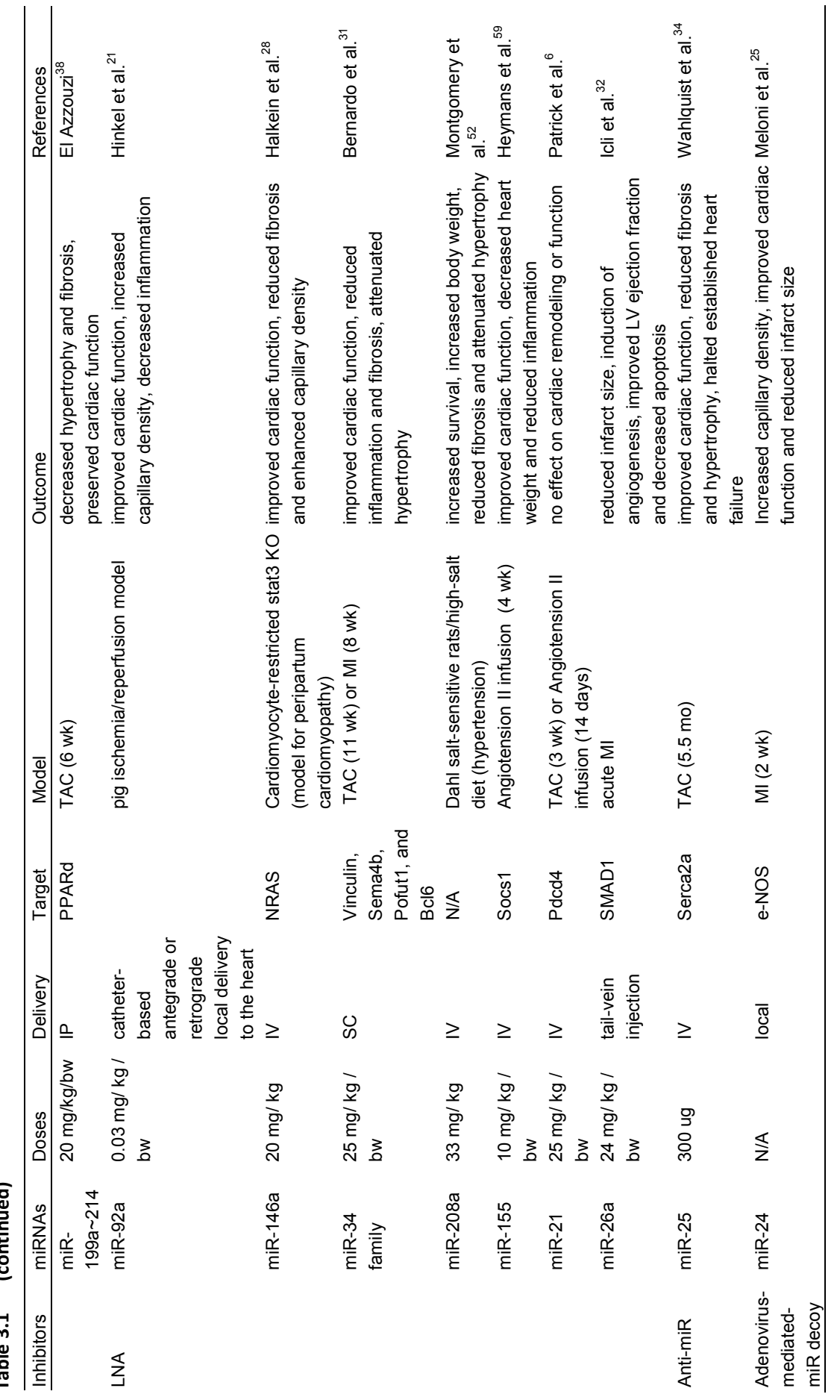




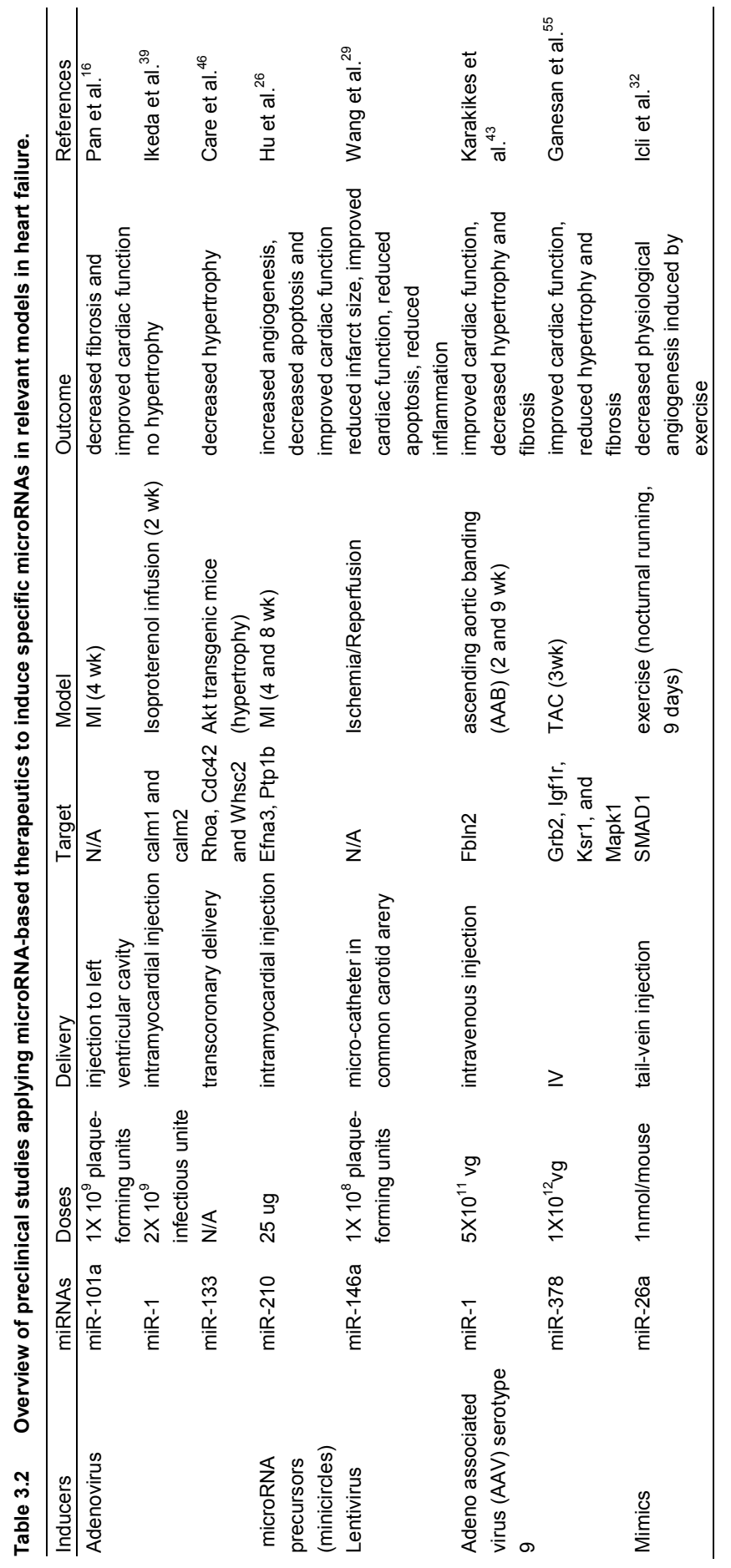


Two companies are currently developing inhibitors of miR-122 for the treatment of Hepatitis C virus (HCV). While Regulus Therapeutics developed a GalNACconjugated antimir-122 that recently entered a phase I study on healthy volunteers (http://www.regulusrx.com), Santaris Pharma developed another miR-122 targeting drug, miravirsen, for which phase I and phase II trials have been completed. ${ }^{60,61}$ Such achievements confirm that pharmacological inhibition of microRNA expression and activity can be achieved and is a feasible therapeutic strategy in patients. Nevertheless, several challenges still remain to implement the clinical use of microRNA-targeting drugs. Although microRNAbased therapeutics can provide stable and sustained effects in various HF models, issues related to delivery, dosage and specificity still remain to be addressed in the clinical use of these therapeutic tools. For instance, cell-type or tissue-specific delivery of microRNA-based therapeutics to prevent unintended off-target effects is an important issue in developing an efficient microRNAbased therapy. To overcome this issue, there are ongoing studies with ultrasound-mediated microbubble technique to provide organ-specific delivery of miR antimirs/mimics. ${ }^{62,63}$ Importantly, this technique has been shown to cause no functional or histological damage in the swine hearts. ${ }^{62}$ Additionally, to obtain efficient in vivo delivery and tissue distribution, several synthetic vehicles including cationic liposomes, polymers, inorganic (gold) nanoparticles, dendrimers and micelle have been generated and are being investigated (extensively reviewed in ${ }^{64,65}$ ).

Another important aspect is the dosage and administration frequency of microRNA-based drugs. AntimiRs have often been administered at high concentrations in order to obtain prolonged stable knockdown but further assessment is necessary regarding the effect of long-term inhibition of microRNAs in vivo in order to develop effective microRNA therapeutics.

Additionally, while decreased microRNA expression levels after antimiR treatment is often assessed as a measure of effectiveness, question remains whether this is the most reliable evaluation to determine microRNA inhibition. For example, binding of an antimiR to its target microRNA may interfere with detection but, depending on the chemistry, antimirs are able to inhibit microRNAs without inducing their degradation. ${ }^{66}$ The de-repression levels of microRNA targets as a secondary endpoint can also be a measure of antimiR efficacy. The strength of microRNA therapeutics may be explained by the fact that unlike conventional drugs (one drug, one target), microRNAs have multiple targets involved in various cellular processes. Targeting one microRNA may lead to alterations in several cellular pathways and while this may result in undesired side effects, so far these were not reported. To date, preclinical studies have demonstrated long lasting and reversible effects of microRNA- 
based therapeutics without adverse side effects or histophatological changes in the experimental animals. Their new mechanism of action, their ability to function as master regulators of the genome and the lack of adverse events in healthy cells or tissue make microRNAs promising therapeutic targets for current and future technology and product development. While generation of adjuvant carrier or delivery systems that increase stability, prevent renal clearance and enhance cellular uptake by target tissues is scientifically and technically challenging, it will ultimately be clinically rewarding.

Next to the therapeutic value, microRNAs are emerging as potential diagnostic and prognostic biomarkers in cardiovascular diseases including atherosclerosis, myocardial infarction, heart failure and hypertension. ${ }^{67}$ Secretion of microRNAs into apoptotic bodies, micro vesicles, exosomes and in association with RNA binding proteins not only protects them from degradation but also enables their detection in the circulation. ${ }^{68-71}$ However, whether these microRNAs are involved in the disease process or simply serve as biomarkers remain elusive and further studies including large patients cohorts are needed.

\section{Future directions and conclusion}

Along with understanding the importance of microRNAs in various cellular functions and pathophysiologic conditions, they are emerging potential therapeutic targets in cardiac diseases. Despite the need for better understanding of microRNA function, tissue- and cell type-specific delivery of microRNA-based therapeutics and safety to avoid off-target effects, the first clinical trials (phase I and II) using antimiR-122 against chronic hepatitis have been successful. ${ }^{72}$ Besides antimiR technology, also strategies to increase microRNA expression at specific sites are being developed. In fact, MIRNA therapeutics (http://www.mirnarx.com) recently initiated a new phase I clinical trial to induce expression of miR-34 in primary and metastatic liver cancer. miR34 is a naturally occurring microRNA tumor suppressor that is lost or downregulated in tumors of patients with a variety of cancers. Administration of the developed miR-34 mimic (MRX34), encapsulated using liposomal formulation induced tumor regression, enhanced the survival of mice carrying hepatocellular carcinomas, and inhibited the growth of other non-hepatic tumors.

Despite the fact that only one decade has passed since the identification of the first human microRNA, microRNAs have emerged as promising targets for therapeutic interventions in treating many types of pathologies including cardiovascular diseases. The next decade should focus on increasing knowledge and improving technology to solidify microRNA biology and establish 
microRNA-based therapies as the most effective therapeutic approaches for different human diseases, including HF.

\section{Acknowledgements}

L.D.W. acknowledges support from the Netherlands CardioVascular Research Initiative: the Dutch Heart Foundation, Dutch Federation of University Medical Centers, the Netherlands Organization for Health Research and Development (ZonMW) and the Royal Netherlands Academy of Sciences. L.D.W. was further supported by grant 311549 from the European Research Council (ERC). P.D.C.M. was supported by a Leducq Career Development Award, the Dutch Heart Foundation grant NHS2010B261 and a NWO MEERVOUD grant. 


\section{References}

1. Johnson FL. Pathophysiology and etiology of heart failure. Cardiol Clin, 2014;32(1):9-19, vii.

2. Kehat I, Molkentin JD. Molecular pathways underlying cardiac remodeling during pathophysiological stimulation. Circulation 2010;122(25):2727-35.

3. Saxena A, Tabin CJ. miRNA-processing enzyme Dicer is necessary for cardiac outflow tract alignment and chamber septation. Proc Natl Acad Sci USA 2010;107(1):87-91.

4. da Costa Martins PA, Bourajjaj M, Gladka M, Kortland M, van Oort RJ, Pinto YM, et al. Conditional dicer gene deletion in the postnatal myocardium provokes spontaneous cardiac remodeling. Circulation 2008;118(15):1567-76.

5. Thum T, Gross C, Fiedler J, Fischer T, Kissler S, Bussen M, et al. MicroRNA-21 contributes to myocardial disease by stimulating MAP kinase signalling in fibroblasts. Nature 2008;456(7224): 980-4.

6. Patrick DM, Montgomery RL, Qi X, Obad S, Kauppinen S, Hill JA, et al. Stress-dependent cardiac remodeling occurs in the absence of microRNA-21 in mice. J Clin Invest 2010;120(11): 3912-6.

7. Dong S, Cheng Y, Yang J, Li J, Liu X, Wang X, et al. MicroRNA expression signature and the role of microRNA-21 in the early phase of acute myocardial infarction. J Biol Chem 2009; 284(43):29514-25.

8. Abonnenc M, Nabeebaccus AA, Mayr U, Barallobre-Barreiro J, Dong X, Cuello F, et al. Extracellular matrix secretion by cardiac fibroblasts: role of microRNA-29b and microRNA-30c. Circ Res 2013;113(10):1138-47.

9. van Rooij, E., L.B. Sutherland, J.E. Thatcher, J.M. DiMaio, R.H. Naseem, W.S. Marshall, et al., Dysregulation of microRNAs after myocardial infarction reveals a role of miR-29 in cardiac fibrosis. Proceedings of the National Academy of Sciences of the United States of America, 2008. 105(35): 13027-32.

10. Roncarati R, Viviani Anselmi C, Losi MA, Papa L, Cavarretta E, Da Costa Martins P, et al. Circulating miR-29a, among other up-regulated microRNAs, is the only biomarker for both hypertrophy and fibrosis in patients with hypertrophic cardiomyopathy. J Am Coll Cardiol 2014; 63(9):920-7.

11. Liu N, Bezprozvannaya S, Williams AH, Qi X, Richardson JA, Bassel-Duby R, et al. microRNA133a regulates cardiomyocyte proliferation and suppresses smooth muscle gene expression in the heart. Genes Dev 2008;22(23):3242-54.

12. Duisters RF, Tijsen AJ, Schroen B, Leenders JJ, Lentink V, van der Made I, et al. miR-133 and miR-30 regulate connective tissue growth factor: implications for a role of microRNAs in myocardial matrix remodeling. Circ Res 2009;104(2):170-8, 6p following 178.

13. Shan H, Zhang Y, Lu Y, Zhang Y, Pan Z, Cai B, et al. Downregulation of miR-133 and miR-590 contributes to nicotine-induced atrial remodeling in canines. Cardiovasc Res 2009;83(3): 465-72.

14. Castoldi G, Di Gioia CR, Bombardi C, Catalucci D, Corradi B, Gualazzi MG, et al. MiR-133a regulates collagen 1A1: potential role of miR-133a in myocardial fibrosis in angiotensin IIdependent hypertension. J Cell Physiol 2012;227(2):850-6.

15. Nam YJ, Song K, Luo X, Daniel E, Lambeth K, West K, et al. Reprogramming of human fibroblasts toward a cardiac fate. Proc Natl Acad Sci USA 2013;110(14):5588-93.

16. Pan Z, Sun X, Shan H, Wang N, Wang J, Ren J, et al. MicroRNA-101 inhibited postinfarct cardiac fibrosis and improved left ventricular compliance via the FBJ osteosarcoma oncogene/transforming growth factor-beta1 pathway. Circulation 2012;126(7):840-50.

17. Wang S, Olson EN. AngiomiRs--key regulators of angiogenesis. Curr Opin Genet Dev 2009;19(3):205-11.

18. Doebele C, Bonauer A, Fischer A, Scholz A, Reiss Y, Urbich C, et al. Members of the microRNA-17-92 cluster exhibit a cell-intrinsic antiangiogenic function in endothelial cells. Blood 2010;115(23):4944-50. 
19. Pullamsetti SS, Doebele C, Fischer A, Savai R, Kojonazarov B, Dahal BK, et al. Inhibition of microRNA-17 improves lung and heart function in experimental pulmonary hypertension. Am J Respir Crit Care Med 2012;185(4):409-19.

20. Bonauer A, Carmona G, Iwasaki M, Mione M, Koyanagi M, Fischer A, et al. MicroRNA-92a controls angiogenesis and functional recovery of ischemic tissues in mice. Science 2009; 324(5935):1710-3.

21. Hinkel R, Penzkofer D, Zuhlke S, Fischer A, Husada W, Xu QF, et al. Inhibition of microRNA92a protects against ischemia/reperfusion injury in a large-animal model. Circulation 2013; 128(10):1066-75.

22. Wang S, Aurora AB, Johnson BA, Qi X, McAnally J, Hill JA, et al. The endothelial-specific microRNA miR-126 governs vascular integrity and angiogenesis. Dev Cell 2008;15(2):261-71.

23. Long G, Wang F, Duan Q, Chen F, Yang S, Gong W, et al. Human circulating microRNA-1 and microRNA-126 as potential novel indicators for acute myocardial infarction. Int J Biol Sci 2012; 8(6):811-8.

24. Fiedler J, Jazbutyte V, Kirchmaier BC, Gupta SK, Lorenzen J, Hartmann D, et al. MicroRNA-24 regulates vascularity after myocardial infarction. Circulation 2011;124(6):720-30.

25. Meloni M, Marchetti M, Garner K, Littlejohns B, Sala-Newby G, Xenophontos N, et al. Local inhibition of microRNA-24 improves reparative angiogenesis and left ventricle remodeling and function in mice with myocardial infarction. Mol Ther 2013;21(7):1390-402.

26. Hu S, Huang M, Li Z, Jia F, Ghosh Z, Lijkwan MA, et al. MicroRNA-210 as a novel therapy for treatment of ischemic heart disease. Circulation 2010;122(11 Suppl):S124-31.

27. Endo K, Naito Y, Ji X, Nakanishi M, Noguchi T, Goto Y, et al. MicroRNA 210 as a biomarker for congestive heart failure. Biol Ppharm Bull 2013;36(1):48-54.

28. Halkein J, Tabruyn SP, Ricke-Hoch M, Haghikia A, Nguyen NQ, Scherr M, et al. MicroRNA$146 a$ is a therapeutic target and biomarker for peripartum cardiomyopathy. J Clin Invest 2013; 123(5):2143-54.

29. Wang X, Ha T, Liu L, Zou J, Zhang X, Kalbfleisch J, et al. Increased expression of microRNA146a decreases myocardial ischaemia/reperfusion injury. Cardiovasc Res 2013;97(3):432-42.

30. Boon RA, lekushi K, Lechner S, Seeger T, Fischer A, Heydt S, et al. MicroRNA-34a regulates cardiac ageing and function. Nature 2013;495(7439):107-10.

31. Bernardo BC, Gao XM, Winbanks CE, Boey EJ, Tham YK, Kiriazis H, et al. Therapeutic inhibition of the miR-34 family attenuates pathological cardiac remodeling and improves heart function. Proc Natl Acad Sci USA 2012;109(43):17615-20.

32. Icli B, Wara AK, Moslehi J, Sun X, Plovie E, Cahill M, et al. MicroRNA-26a regulates pathological and physiological angiogenesis by targeting BMP/SMAD1 signaling. Circ Res 2013;113(11):1231-41.

33. Dirkx E, Gladka MM, Philippen LE, Armand AS, Kinet V, Leptidis S, et al. Nfat and miR-25 cooperate to reactivate the transcription factor Hand2 in heart failure. Nat Cell Biol 2013; 15(11):1282-93.

34. Wahlquist C, Jeong D, Rojas-Munoz A, Kho C, Lee A, Mitsuyama S, et al. Inhibition of miR-25 improves cardiac contractility in the failing heart. Nature 2014;508(7497):531-5.

35. Thum T, Galuppo P, Wolf $\mathrm{C}$, Fiedler J, Kneitz S, van Laake LW, et al. MicroRNAs in the human heart: a clue to fetal gene reprogramming in heart failure. Circulation 2007;116(3):258-67.

36. Varga ZV, Kupai K, Szucs G, Gaspar R, Paloczi J, Farago N, et al. MicroRNA-25-dependent up-regulation of NADPH oxidase 4 (NOX4) mediates hypercholesterolemia-induced oxidative/nitrative stress and subsequent dysfunction in the heart. J Mol Cell Cardiol 2013;62: $111-21$.

37. da Costa Martins PA, Salic K, Gladka MM, Armand AS, Leptidis S, el Azzouzi H, et al. MicroRNA-199b targets the nuclear kinase Dyrk1a in an auto-amplification loop promoting calcineurin/NFAT signalling. Nat Cell Biol 2010;12(12):1220-7.

38. el Azzouzi H, Leptidis S, Dirkx E, Hoeks J, van Bree B, Brand K, et al. The hypoxia-inducible microRNA cluster miR-199a approximately 214 targets myocardial PPARdelta and impairs mitochondrial fatty acid oxidation. Cell Metab 2013;18(3):341-54. 
39. Ikeda S, He A, Kong SW, Lu J, Bejar R, Bodyak N, et al. MicroRNA-1 negatively regulates expression of the hypertrophy-associated calmodulin and Mef2a genes. Mol Cell Biol 2009; 29(8):2193-204.

40. Tritsch E, Mallat $\mathrm{Y}$, Lefebvre F, Diguet N, Escoubet B, Blanc J, et al. An SRF/miR-1 axis regulates NCX1 and annexin A5 protein levels in the normal and failing heart. Cardiovasc Res 2013;98(3):372-80.

41. Kumarswamy R, Lyon AR, Volkmann I, Mills AM, Bretthauer J, Pahuja A, et al. SERCA2a gene therapy restores microRNA-1 expression in heart failure via an Akt/FoxO3A-dependent pathway. Eur Heart J 2012;33(9):1067-75.

42. Elia L, Contu R, Quintavalle M, Varrone F, Chimenti C, Russo MA, et al. Reciprocal regulation of microRNA-1 and insulin-like growth factor-1 signal transduction cascade in cardiac and skeletal muscle in physiological and pathological conditions. Circulation 2009;120(23):2377-85.

43. Karakikes I, Chaanine AH, Kang S, Mukete BN, Jeong D, Zhang S, et al. Therapeutic cardiactargeted delivery of miR-1 reverses pressure overload-induced cardiac hypertrophy and attenuates pathological remodeling. J Am Heart Assoc 2013;2(2):e000078.

44. Varrone F, Gargano B, Carullo P, Di Silvestre D, De Palma A, Grasso L, et al. The circulating level of FABP3 is an indirect biomarker of microRNA-1. J Am Coll Cardiol 2013;61(1):88-95.

45. Besser J, Malan D, Wystub K, Bachmann A, Wietelmann A, Sasse P, et al. MiRNA-1/133a clusters regulate adrenergic control of cardiac repolarization. PLoS One 2014;9(11):e113449.

46. Care A, Catalucci D, Felicetti F, Bonci D, Addario A, Gallo P, et al. MicroRNA-133 controls cardiac hypertrophy. Nat Med 2007;13(5):613-8.

47. Castaldi A, Zaglia T, Di Mauro V, Carullo P, Viggiani G, Borile G, et al. MicroRNA-133 Modulates the beta1-Adrenergic Receptor Transduction Cascade. Circ Res 2014;115(2): 273-83.

48. Matkovich SJ, Wang W, Tu Y, Eschenbacher WH, Dorn LE, Condorelli G, et al. MicroRNA-133a protects against myocardial fibrosis and modulates electrical repolarization without affecting hypertrophy in pressure-overloaded adult hearts. Circ Res 2010;106(1):166-75.

49. Feng B, Chen S, George B, Feng Q, Chakrabarti S. miR133a regulates cardiomyocyte hypertrophy in diabetes. Diabetes Metab Res Rev 2010;26(1):40-9.

50. Chen S, Puthanveetil P, Feng B, Matkovich SJ, Dorn GW 2nd, Chakrabarti S. Cardiac miR133a overexpression prevents early cardiac fibrosis in diabetes. J Cell Mol Med 2014;18(3): 415-21.

51. Chavali V, Tyagi SC, Mishra PK. MicroRNA-133a regulates DNA methylation in diabetic cardiomyocytes. Biochem Biophys Res Commun 2012;425(3):668-72.

52. Montgomery RL, Hullinger TG, Semus HM, Dickinson BA, Seto AG, Lynch JM, et al. Therapeutic inhibition of miR-208a improves cardiac function and survival during heart failure. Circulation 2011;124(14):1537-47.

53. Lin Z, Murtaza I, Wang K, Jiao J, Gao J, Li PF. miR-23a functions downstream of NFATc3 to regulate cardiac hypertrophy. Proc Natl Acad Sci USA 2009;106(29):12103-8.

54. Wang K, Lin ZQ, Long B, Li JH, Zhou J, Li PF. Cardiac hypertrophy is positively regulated by MicroRNA miR-23a. J Biol Chem 2012;287(1):589-99.

55. Ganesan J, Ramanujam D, Sassi Y, Ahles A, Jentzsch C, Werfel S, et al. MiR-378 controls cardiac hypertrophy by combined repression of mitogen-activated protein kinase pathway factors. Circulation 2013;127(21):2097-106.

56. Ucar A, Gupta SK, Fiedler J, Erikci E, Kardasinski M, Batkai S, et al. The miRNA-212/132 family regulates both cardiac hypertrophy and cardiomyocyte autophagy. Nat Commun 2012;3:1078.

57. Raisch J, Darfeuille-Michaud A, Nguyen HT. Role of microRNAs in the immune system, inflammation and cancer. World J Gastroenterol 2013;19(20):2985-96.

58. Seok HY, Chen J, Kataoka M, Huang ZP, Ding J, Yan J, et al. Loss of MicroRNA-155 protects the heart from pathological cardiac hypertrophy. Circ Res 2014;114(10):1585-95.

59. Heymans S, Corsten MF, Verhesen W, Carai P, van Leeuwen RE, Custers K, et al. Macrophage microRNA-155 promotes cardiac hypertrophy and failure. Circulation 2013; 128(13):1420-32.

60. Gebert LF, Rebhan MA, Crivelli SE, Denzler R, Stoffel M, Hall J. Miravirsen (SPC3649) can inhibit the biogenesis of miR-122. Nucleic Acids Res 2014;42(1):609-21. 
61. Sanchez-Nino MD, Ortiz A. HCV infection and miravirsen. N Engl J Med 2013;369(9):877-8.

62. Liu Y, Li L, Su Q, Liu T, Ma Z, Yang H/ Ultrasound-Targeted Microbubble Destruction Enhances Gene Expression of microRNA-21 in Swine Heart via Intracoronary Delivery. Echocardiography, 2015.

63. Gill SL, O'Neill H, McCoy RJ, Logeswaran S, O'Brien F, Stanton A, et al. Enhanced delivery of microRNA mimics to cardiomyocytes using ultrasound responsive microbubbles reverses hypertrophy in an in-vitro model. Technol Health Care 2014;22(1):37-51.

64. Wang $\mathrm{H}$, Jiang $\mathrm{Y}$, Peng $\mathrm{H}$, Chen $\mathrm{Y}$, Zhu $\mathrm{P}$, Huang $\mathrm{Y}$. Recent progress in microRNA delivery for cancer therapy by non-viral synthetic vectors. Adv Drug Deliv Rev 2015;81:142-60.

65. Zhang Y, Wang Z, Gemeinhart RA. Progress in microRNA delivery. J Control Release 2013; 172(3):962-74.

66. Davis S, Propp S, Freier SM, Jones LE, Serra MJ, Kinberger G, et al. Potent inhibition of microRNA in vivo without degradation. Nucleic Acids Res 2009;37(1):70-7.

67. Kinet V, Halkein J, Dirkx E, Windt LJ. Cardiovascular extracellular microRNAs: emerging diagnostic markers and mechanisms of cell-to-cell RNA communication. Front Genet 2013;4: 214.

68. Valadi H, Ekstrom K, Bossios A, Sjostrand M, Lee JJ, Lotvall JO. Exosome-mediated transfer of mRNAs and microRNAs is a novel mechanism of genetic exchange between cells. Nat Cell Biol 2007;9(6):654-9.

69. Hunter MP, Ismail N, Zhang X, Aguda BD, Lee EJ, Yu L, et al. Detection of microRNA expression in human peripheral blood microvesicles. PLoS One 2008;3(11):e3694.

70. Zernecke A, Bidzhekov K, Noels H, Shagdarsuren E, Gan L, Denecke B, et al. Delivery of microRNA-126 by apoptotic bodies induces CXCL12-dependent vascular protection. Sci Signal 2009;2(100):ra81.

71. Arroyo JD, Chevillet JR, Kroh EM, Ruf IK, Pritchard CC, Gibson DF, et al. Argonaute2 complexes carry a population of circulating microRNAs independent of vesicles in human plasma. Proc Natl Acad Sci USA 2011;108(12):5003-8.

72. Janssen HL, Reesink HW, Lawitz EJ, Zeuzem S, Rodriguez-Torres M, Patel K, et al. Treatment of HCV infection by targeting microRNA. N Engl J Med 2013;368(18):1685-94.

73. Li RC, Tao J, Guo YB, Wu HD, Liu RF, Bai Y, et al. In vivo suppression of microRNA-24 prevents the transition toward decompensated hypertrophy in aortic-constricted mice. Circ Res 2013;112:601-5. 


\section{Chapter 4}

Contribution of miR-199b to right ventricular remodeling and failure

Burcu Duygu, Sara Leite, Diana S. Nascimento, Ella M. Poels, Nicole Bitsch, André P. Lourenço, Adelino F. Leite-Moreira, Perpétua Pinto-do-Ó, Inês Falcão-Pires, Paula A. da Costa Martins

In preparation 


\section{Abstract}

Despite its association with high mortality and morbidity, research on the pathophysiology of right ventricle (RV) failure has remained behind in regard to the left ventricle (LV). Similar to what happens in the LV upon chronic pressure overload, calcineurin activation also contributes to RV remodeling under conditions of increased pressure overload. We have previously identified miR$199 \mathrm{~b}$ as a pro-hypertrophic microRNA during LV remodeling, which, in response to pressure overload, induces calcineurin/NFAT-signaling activity leading to exaggerated LV remodeling and cardiac dysfunction. Therefore, we aimed at understanding the contribution of $\mathrm{miR}-199 \mathrm{~b}$ to $\mathrm{RV}$ remodeling in response to pressure overload induced by pulmonary artery banding (PAB). In our study, however, the effect of increased miRNA-199b expression in the RV does not seem to overrule the effect of PAB under baseline expression levels of miRNA$199 \mathrm{~b}$, and thus suggesting a minor contribution of this microRNA to the process of $\mathrm{RV}$ remodeling induced by pressure overload. 


\section{Introduction}

Sustained pressure overload of the right ventricle (RV) is a major pathophysiological factor in several cardiovascular disorders, including pulmonary hypertension $(\mathrm{PH}){ }^{1-3}$ Noteworthy, RV failure due to pressure overload is the main determinant of the outcome of congenital heart diseases ${ }^{4}$ and the most common cause of death in patients with severe pulmonary artery hypertension (PAH), a form of $\mathrm{PH}$ where pathological changes in the pulmonary arteries result in elevated resistance and pressure in the pulmonary circulation. ${ }^{5-7}$ Long term increase in pressure will eventually culminate in RV hypertrophy. Hypertrophic cardiac growth is an initial beneficial response to reduce wall stress, improve contractility, preserve cardiac output ${ }^{8,9}$ and enhance capillary density in order to comply with the increased oxygen demand in the hypertrophied tissue. ${ }^{10}$ However, as the disease progresses, transition from RV adaptation to failure is inevitable. ${ }^{3} \mathrm{RV}$ failure is characterized by reduced RV capillary density, increased RV inflammation and profound fibrosis, leading to impaired contractility and decreased cardiac output. ${ }^{11,12}$

Despite its association with high mortality and morbidity, research on the pathophysiology of RV failure has remained behind in regard to the left ventricle $(\mathrm{LV}) .{ }^{13}$ Notwithstanding its worse prognosis, the impact of right ventricular function on the outcome of cardiovascular diseases has been neglected due to its less frequent and less obvious involvement in disease processes. As a consequence of being connected to low impedance pulmonary circulation, RV has thinner walls, lower oxygen demand and lower wall stress compared to LV. ${ }^{13}$ Thereby, even minor alterations in total pulmonary resistance may have a great impact on RV function in contrast to LV, which is less affected by larger changes in afterload. ${ }^{14}$ However, pathological RV remodeling seems to be reversible as lung transplantation results in decreased pulmonary pressure, smaller RV and normalized septal shape. ${ }^{15,16}$ These functional and structural differences between RV and LV highlight the fact that the current comprehensive knowledge on LV function and pathology cannot be directly applied to RV and that a better understanding of RV function and RV failure pathology is crucial in order to develop efficient and specific therapeutics for this cardiac condition.

$\mathrm{PH}$ is a complex disease with several etiologies and its remodeling can result from the interaction of different factors such as genetic background, epigenetic modifications and pathobiological environmental factors. ${ }^{17}$ In the past decade, microRNAs emerged as small, non-coding RNA molecules with the ability to repress or induce degradation of mRNAs and thereby to regulate gene expression during various cellular processes, in many different tissues, including the myocardium. ${ }^{18}$ Numerous studies have elucidated the role of microRNAs 
throughout cardiovascular development and remodeling. ${ }^{19,20}$ Abnormal expression and dysregulation of numerous miRNAs have been associated to the onset and development of $\mathrm{PAH}$. Studies using animal models of chronic hypoxia- (mice and rats) or monocrotaline- (MCT, rats) induced PAH mainly focused on alterations in microRNA expression patterns of the pulmonary artery smooth muscle or endothelial cells. In concordance, microRNAs such as miR-17/92, ${ }^{21,22} \mathrm{miR}-27 \mathrm{a},{ }^{23} \mathrm{miR}-96,{ }^{24} \mathrm{miR}-126,{ }^{25} \mathrm{miR}-130,{ }^{26} \mathrm{miR}-143 / 145^{27}$ and miR-210, ${ }^{28,29}$ all known to be involved either in cell proliferation, vascular remodeling or apoptosis, were identified as playing important roles in the pathogenesis of $\mathrm{PAH}$. miR-126 is downregulated in skeletal muscle of PAH patients and its lower expression levels seem to decrease specifically the RV vascular endothelial growth factor (VEGF)-induced angiogenesis and exercise tolerance observed in these patients. ${ }^{30}$ Correcting miR-126 low levels resulted in improved RV function and increased microvascular density in experimental $\mathrm{PAH}^{30}$ By having mainly concentrated on the vascular alterations, presently little is known about the alterations in microRNA expression patterns in the RV upon remodeling, although evidence points to distinct gene expression profiles of both ventricles under stress conditions. ${ }^{31}$ Similarly, also miR-208 is downregulated via myocyte enhancer factor-2 (Mef2) during the compensatory phase of RV hypertrophy in MCT-induced $\mathrm{PH}^{32}$ MiR-208 downregulation potentiates the effects of tumor necrosis factor- $\alpha(\mathrm{TNF}-\alpha)$ leading to Mef2 inhibition and consequent suppression of its crucial metabolic angiogenic and contractile adaptation of the RV to pressure overload. ${ }^{32}$ This inhibition by such feedback loop leads to rapid RV decompensation and heart failure.

During LV remodeling, calcineurin activation results in pathological hypertrophy ${ }^{33}$ and modulation of calcineurin-nuclear factor of activated T-cells (NFAT) signaling activity results in reduced LV hypertrophy and improved function. ${ }^{34}$ Similarly, calcineurin activation also contributes to RV remodeling induced by pulmonary artery banding (PAB) in mice. ${ }^{35}$ We have previously identified miR$199 \mathrm{~b}$ as a pro-hypertrophic microRNA during LV remodeling, which, in response to pressure overload, induces calcineurin/NFAT-signaling activity leading to exaggerated LV remodeling and cardiac dysfunction. ${ }^{36}$

Since we have successfully targeted the calcineurin/NFAT pathway via modulation of miR-199b in experimental left-sided heart failure ${ }^{36}$ in this study we aimed at understanding the contribution of miR-199b to RV remodeling in response to pressure overload induced by $P A B$. 


\section{Materials and methods}

\section{Animal models and pulmonary artery banding surgery}

Animal models employed in this study consist of mice carrying murine miR-199b transgene $^{36}$ under control of alpha-myosin heavy chain promoter ( $\left.\alpha-\mathrm{MHC}\right)$ in C57BL/6 background and non-transgenic littermates (WT). Pulmonary artery banding (PAB) was performed, as described below, in mice older than 8 weeks from both genders. Animals were anesthetized with ketamine (75 mg/kg BW) and medetomine $(1.0 \mathrm{mg} / \mathrm{kg} \mathrm{BW})$ via intra-peritoneal injections and placed in a supine position on a heating pad $\left(37^{\circ} \mathrm{C}\right)$. Then animals were intubated with a $20 \mathrm{G}$ needle and ventilated with room air using a MiniVent mouse ventilator (Hugo Sachs Elektronik, Germany; stroke volume $250 \mu \mathrm{L}$, respiratory rate 210 breaths per minute). The chest was entered and the pericardium was opened in order to isolate the pulmonary artery. Then the pulmonary artery (PA) was subjected to constriction with 27-gauge needle. After PAB surgery, the chest was closed and the effect of medetomine was antagonized with atipamazole (1-2.5 mg/kg BW) via subcutaneous injections. Post-operative pain relief was provided with buprenorphine $(0.1 \mathrm{mg} / \mathrm{kg})$ twice daily for 2-3 consecutive days. Sham-operated animals underwent the same procedure without the constriction of PA. All protocols were reviewed and approved by the Animal Care and Use Committee of the University of Maastricht and were performed according to the rules formulated in the Dutch law on care and use of experimental animals.

\section{Transthoracic eEchocardiography}

High-resolution echocardiography (Vevo 2100, VisualSonics, Toronto, Canada), using a single-element mechanical transducer with a center frequency of $30 \mathrm{MHz}$, was performed on self-breathing mice under anesthesia ( $2 \%$ isoflurane and $98 \%$ oxygen) to acquire two dimensional images of pulmonary infundibulum using the parasternal short axis view at the level of aortic valve and pulsed-wave Doppler recording of the pulmonary flow. ${ }^{37}$ The following parameters were obtained after averaging 3 or more cardiac cycle per mouse: pulmonary acceleration time (PAT, defined as the time from the onset of flow to peak velocity), right ventricular ejection time (ET, the time from the onset to the termination of pulmonary flow) and the ratio of PAT to ET.

\section{Hemodynamic studies}

Mice were anaesthetized by inhalation of $8 \%$ sevoflurane. After endotrachealintubation, anesthesia was maintained with $2.5-3 \%$ sevoflurane. Mechanical ventilation with $100 \% \mathrm{O}_{2}$ was set at $150 . \mathrm{min}^{-1}$ with tidal volume adjusted for body 
weight, and positive end-expiratory pressure (PEEP) held at $2 \mathrm{cmH}_{2} \mathrm{O}$ (MouseVent $^{\mathrm{TM}}$ - Automatic Ventilator, Physiosuite, Kent Scientific). Mice were placed on a heating pad and temperature kept at $38^{\circ} \mathrm{C}$ (RightTemp ${ }^{\mathrm{TM}}$ Temperature Monitor \& Homeothermic Controller, Physiosuite, Kent Scientific). Electrocardiogram (Animal Bio Amp, FE136, ADInstruments), peripheral oximetry (MouseSTATTM - Pulse Oximeter \& Heart Rate Monitor, Physiosuite, Kent Scientific), capnography, minute ventilation (CapnoScan ${ }^{\mathrm{TM}}$ - End-Tidal $\mathrm{CO}_{2}$ Monitor, Physiosuite, Kent Scientific) and body temperature were recorded throughout. The right jugular vein was catheterized with a $24 \mathrm{G}$ intravenous catheter after surgical microdissection (Wilde M651, Leica microsystems, Cambridge, UK) for infusion of $16 \mathrm{ml} / \mathrm{Kg} / \mathrm{h}$ warmed saline solution (NE-1000, New Era Pump Systems). A left thoracotomy was performed in right lateral decubitus. A silk thread was passed around the inferior vena cava (IVC) to allow transient occlusion. Pressure-volume $(\mathrm{P}-\mathrm{V})$ 1F catheters were inserted through the apex and positioned along the long axes of the LV and RV (models PVR1045 and PVR-1035, Millar Instruments, respectively). After 15 minutes of stabilization, baseline and IVC occlusion recordings were obtained at endexpiration. Volume channel was changed between catheters allowing alternate recording the LV or RV signal. P-V signals were continuously acquired (MPVS 300 , Millar Instruments), digitally recorded at a sampling rate of $1000 \mathrm{~Hz}$ (ML880 PowerLab 16/30, Millar Instruments), and analyzed by software (PVAN 3.5, Millar Instruments). Analysis included stroke volume, ejection fraction, cardiac output, stroke work (SW), arterial elastance and load-independent indices derived with software (PVAN) from P-V relationships obtained with IVC occlusions, such as preload-recruitable SW, and end-systolic and end-diastolic $\mathrm{P}-\mathrm{V}$ relationships. Catheters parallel conductance was calculated after $10 \mu \mathrm{L}$ hypertonic saline $(30 \%)$ injection. Upon completion of experiments, animals were euthanized by exsanguination under anesthesia ( $8 \%$ sevoflurane) and heparinized blood was kept for volume calibration with standard cuvettes (PVAN).

\section{RNA isolation, cDNA conversion and real-time RT-PCR}

Total RNA was isolated from mouse heart tissue using TRIzol reagent (Invitrogen) according to manufacture's instructions. Then RNA (1 ug) was reverse-transcribed with either M-MLV reverse transcriptase (Promega, Madison, WI, USA) or for miRNA transcript detection with miScript Reverse Transcription Kit (Qiagen). Real-time PCR was performed on a BioRad iCycler (Biorad) using SYBR Green (VWR). Transcript quantities were compared using the relative $\mathrm{Ct}$ method, where the amount of target normalized to the amount of endogenous control (L7 for mRNAs and U6 (miScript Primer Assays) for 
miRNAs) and relative to the control sample is given by $2^{-\Delta \mathrm{Ct}}$. Primer sequences for both miRNA and mRNA detection are available on request.

\section{Histology, immunohistochemistry and immunofluorescence}

For histological analysis, hearts were arrested in diastole, perfusion-fixed with $4 \%$ paraformaldehyde, embedded in paraffin and cut into 4- $\mu \mathrm{m}$ sections. Paraffin sections were stained with: Sirius Red for detection of fibrillar collagen; and FITC-labelled wheat-germ-agglutinin (WGA, Sigma) to visualize and quantify the cell cross-sectional area. Collagen deposition, cell surface areas and capillary density were determined using ImageJ software. Slides were visualized by using a Leica DM2000 and a Leica DM3000 microscope for bright field and fluorescence imaging, respectively.

\section{Statistical analysis}

All data are presented as mean \pm standard error of mean (SEM). The variables were analyzed using Student's t-test and two-way analysis of variance (ANOVA) to assess statistical significance between groups. The significant effects evaluation was conducted using Tukey's multiple comparison tests, with an adjusted calculation of $p$-value. Probability values $p<0.05$ were considered statistically significant.

\section{Results}

\section{Cardiac expression of miR-199b in RV remodeling induced by PAB}

To assess whether miR-199b is involved in RV failure, we subjected wild-type (WT) mice and transgenic mice with cardiac-specific overexpression of miR199b (MHC-199b or TG) ${ }^{36}$ to sham or PAB surgery for 6 weeks. Real-time PCR to determine the expression levels of miR-199b in the four different animal groups revealed upregulation of miR-199b in WT mice after PAB (Figure 4.1a). As expected, MHC-199b animals express high levels of miR-199b but this is not further exacerbated after PAB, when compared to sham-operated animals (Figure 4.1a).

\section{Effect of heart-specific overexpression of miR-199b on RV remodeling after $P A B$}

Hypertrophy of the right heart, which occurs as a consequence of impaired hemodynamics in PAB, was confirmed by wheat-germ agglutinin staining showing increased cardiomyocyte size in the hearts of the animals that were 
subjected to PAB (Figure 4.1b, 4.1d). RV hypertrophy was also determined by the Fulton index, the ratio of right ventricular weight to left ventricular plus septum weight $(R V / L V+S)$. An increased Fulton index was observed 6 weeks after PAB in both WT and MHC-199b animals, however, the effect in the TG animals did not reach significance (Figure 4.1c). In agreement, the hearts of both WT and MHC-199b animals subjected to PAB displayed deposition of collagen and formation of fibrotic lesions (Figure 4.1b, 4.1e) even though this effect was less predominant in the TG animals (Figure 4.1e), 6 weeks post$\mathrm{PAB}$. We assessed expression levels of transforming growth factor beta (TGF- $\beta$ ) as a gene involved in fibrotic lung disease and as a potential target gene of the miR-199 family. No significant differences were observed between the different groups (Figure 4.1f). Similarly, we also determined expression levels for notch1, member of the NOTCH signaling pathway and a validated target of miR-199b but not clear differences between the different animal groups were observed (Figure 4.1g). Although not statistically significant, we observed a tendency for the NFATc regulatory gene Rcan1-4 to increase after PAB in WT animals (Figure 4.1h). miR-199b transgenic mice (TG) however, did not reveal differences as response to pressure overload (Figure 4.1h).

In line with the very moderate increase in RV hypertrophy in WT mice upon $P A B$, expression levels of typical markers of cardiac hypertrophy including natriuretic peptide $A$ (nppa) and beta myosin heavy chain $(\beta-M H C)$ were not changed among the different groups (Figure 4.1i, 4.1j). All in all, these data evidence that increased miR-199b expression does not add to the effect of the RV pressure overload to which the mice were exposed to during our study.

\section{Effect of miR-199b overexpression on cardiac performance in pressure overload-induced RV remodeling}

Although miR-199b TG mice do not display an obvious pathological baseline phenotype nor cardiac dysfunction, these animals are more sensitive to cardiac stress than WT mice. ${ }^{36}$ Here, we evaluated whether increased cardiac miR-199b expression levels also result in higher susceptibility to RV biomechanical stress. The effect of PAB on pathological RV remodeling was assessed by echocardiography and hemodynamic characterization of the RV through pressure-volume measurements. 
a

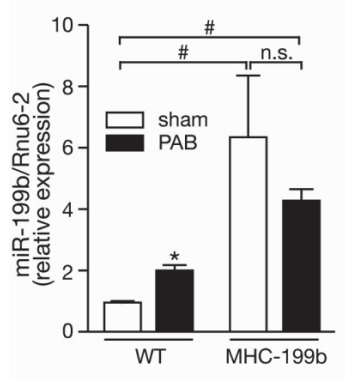

C

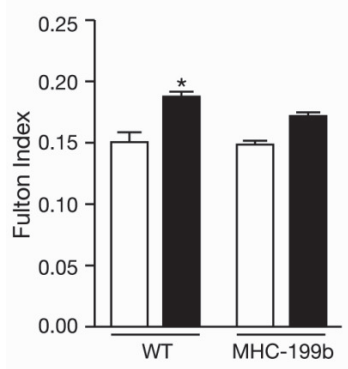

f

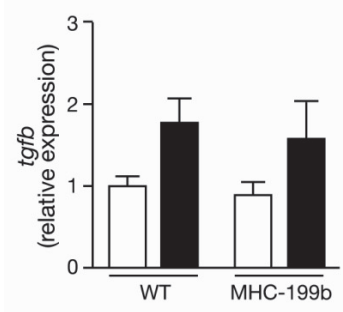

i

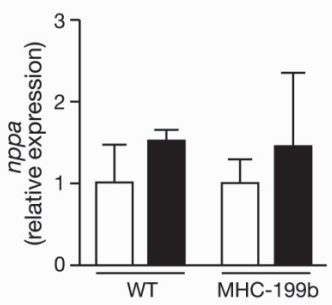

b

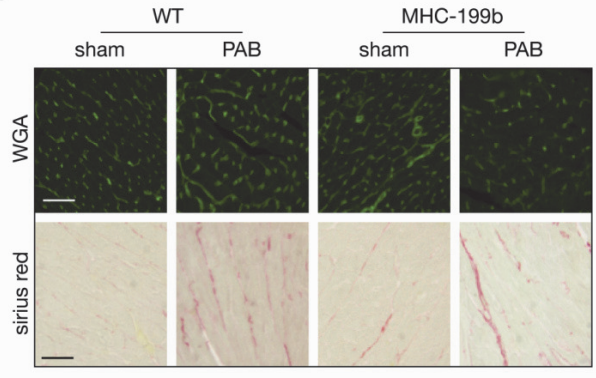

d

e
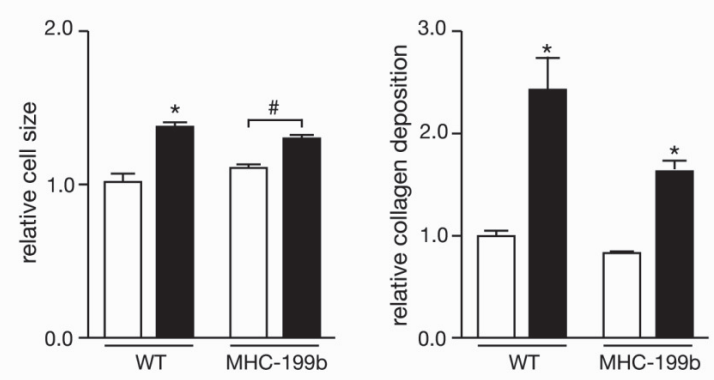

h
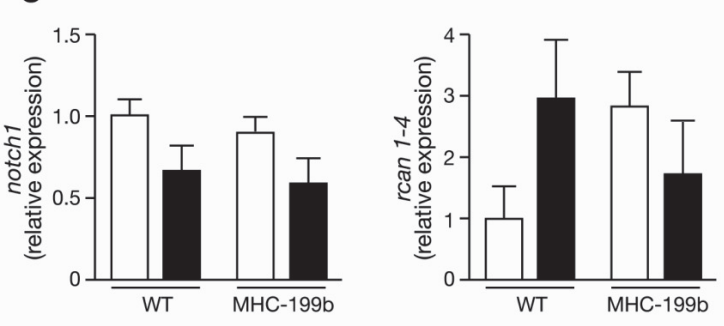

j

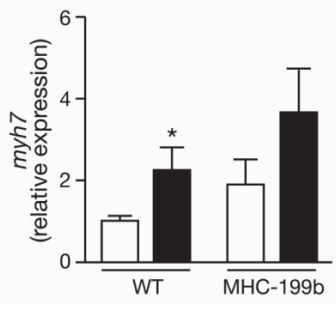

Figure 4.1 Increased expression levels of miR-199b does not further affect cardiac function under conditions of right ventricular pressure overload. a) Real-time PCR analysis of miR-199b abundance in hearts from WT or TG (MHC-199b) animals subjected to either sham or PAB surgery; Rnu6-2 was used as a reference gene for normalization. b) Representative images of wheat-germ agglutinin (WGA, upper panels) or Sirius Red- 
stained RV sections (upper panels) from WT or TG (MHC-199b) animals subjected to either sham or PAB surgery; c) Fulton index calculated as ratio of RV free wall weight over septum plus LV free wall weight; d) Quantification of cardiomyocyte surface area from conditions in B; e) Quantification of collagen deposition from conditions in B by using ImageJ software; f-j) Real-time PCR analysis of transcript abundance for transforming growth factor beta (tgfb), notch1, natriuretic peptide atrial natriuretic factor (nppa), $\beta$-myosin heavy chain (myh7) and regulator of calcineurin 1 isoform 4 (rcan1-4) respectively in hearts of WT or TG (MHC-199b) animals subjected to either sham or $\mathrm{PAB}$ surgery. ${ }^{*} P<0.05$, compared with the corresponding control group; $\# P<0.05$, compared with the experimental group (mean \pm s.e.m.). $\mathrm{N}=3-7$ in all groups.

Echocardiographic measurements revealed a decrease in cardiac output (CO) of the RV in hearts from both WT and TG animals subjected to $P A B(4.21 \pm 0.96$ vs. $3.29 \pm 0.74$, WT-sham vs. WT-PAB, $P<0.05 ; 3.78 \pm 0.86$ vs. $3.08 \pm 0.87, P=0.053$, Table 4.1). Pulsed-wave Doppler was used to measure pulmonary artery acceleration time (PAAT) and the ratio of pulmonary acceleration time (PAT) to ejection time (ET, time interval between the onset and end of the systolic flow velocity) and their ratio (PAT/ET), which have previously been described to be applied to estimate pulmonary artery systolic pressure in mice. ${ }^{37}$ We observed slightly shortened PAAT and ET as well as decreased PAT/ET in WT animals after PAB confirming elevated RV pressure in these animals. While TG animals showed a trend to decrease these parameters, the effects were not statistically significant (Figure 4.2a, 4.2b and Table 4.1).

a

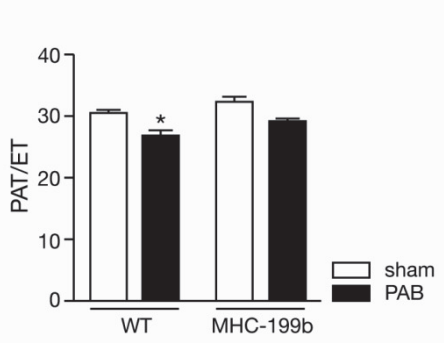

b

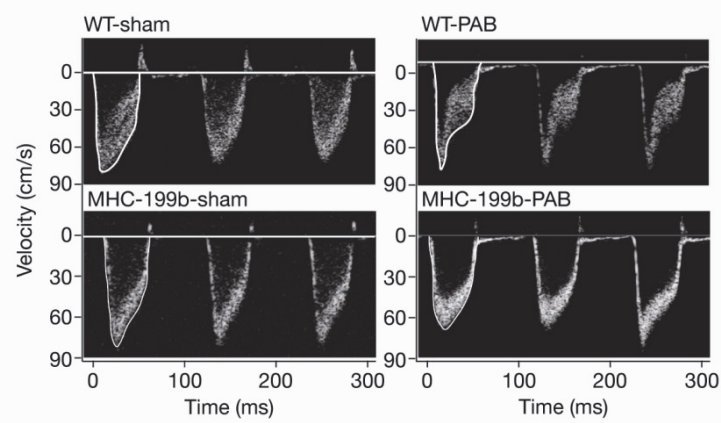

Figure 4.2 Echocardiographic assessment of the effect of miR-199b overexpression under right ventricular pressure overload conditions on cardiac function. a) Pulsed-wave Doppler was used to determine the ratio of pulmonary acceleration time (PAT) to ejection time (ET); b) Representative images of pulsed-wave Doppler tracings across the pulmonary valve in WT or TG (MHC-199b) mice subjected to either sham or PAB surgery. ${ }^{*} P<0.05$, compared with the corresponding control group. $\mathrm{N}=7-11$ in all groups. 


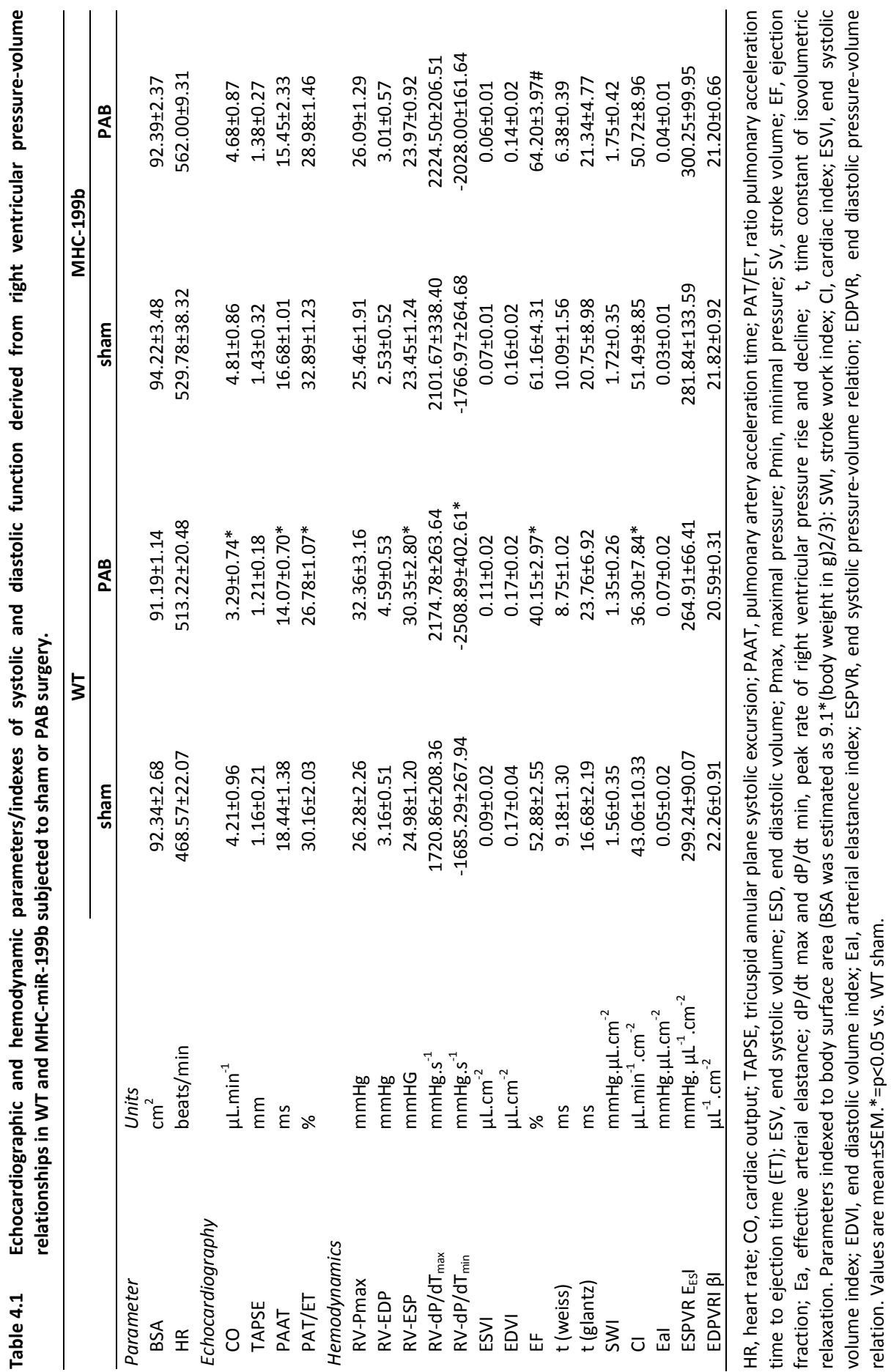


At week 6 after PAB, WT animals displayed a significant increase in RV overload assessed by augmented end systolic pressures (RVESP) but no differences were observed between sham- and PAB-operated miR-199b TG animals (Table 4.1). In agreement, the differences in $\mathrm{dP} / \mathrm{dt}_{\max }$ and $\mathrm{dP} / \mathrm{dt}_{\min }$ between WT animals subjected to sham or PAB seem larger than in TG animals. However, although these results indicate a clear trend, the effects observed were not statistically significant (Table 4.1).

PAB-induced right ventricular stress in WT animals resulted in a mild reduction of systolic function reflected by decreased ejection fraction (EF, Figure 4.3a), but no RV dilation, as reflected by no significant changes in ventricular volumes (ESVI and EDVI), or arterial elastance (Eal, Figure 4.3b) after PAB. Although cardiac index $(\mathrm{Cl})$ seems to decrease in WT animals after PAB (43.06 \pm 10.33 vs. $36.30 \pm 7.84$, WT-sham vs. WT PAB), only a trend was observed for the TG animals (51.49 \pm 8.85 vs. $43.76 \pm 8.96$, MHC-199b-sham vs. MHC-199b-PAB, Table 4.1). Regarding diastolic function, while relaxation was similar between all groups, the tendency of increased stiffness observed in WT animals after PAB was not observed in miR-199b TG mice as assessed by EDP and EDPVR (Table 4.1 and Figure 4.3a-c). In conclusion, these results suggest that overexpression of miR-199b in the myocardium has little or no effect to RV remodeling under the pressure conditions applied in our study..

\section{Discussion}

The pro-hypertrophic function of $\mathrm{miR}-199 \mathrm{~b}$ in the LV has been extensively described in a previous study from us. ${ }^{36}$ Relatedly, miR-199b, when overexpressed in the heart, has been shown to induce exaggerated cardiac dysfunction and pathological remodeling in the left side of the heart in response to pressure overload. ${ }^{36}$ In order to generate comprehensive understanding regarding to the role of miR-199b in the whole heart under stress conditions, in this study we aimed at demonstrating the contribution of miR-199b during RV remodeling induced by pressure overload. However, in our PAB model and experimental conditions, overexpression of miR-199b failed to induce additional effects to the RV remodeling process. This can partly be explained by the fact that our animal model has developed mild pressure increase in the pulmonary artery upon banding as explained below. 
a

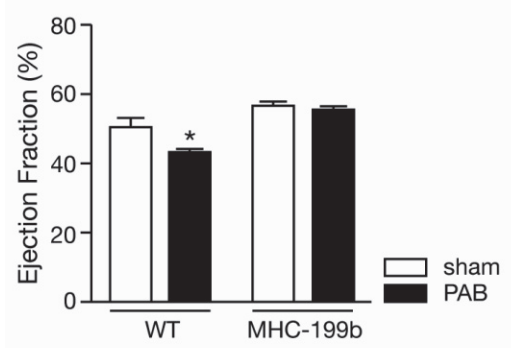

C

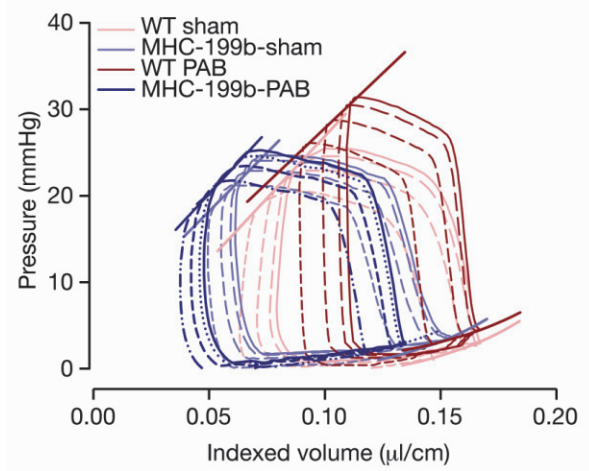

b

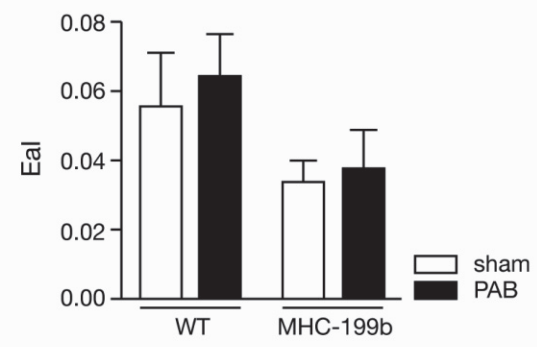

Figure 4.3 Hemodynamic assessment of the effect of miR-199b overexpression under right ventricular pressure overload conditions on cardiac function. Hemodynamic assessment of parameters such as a) RV ejection fraction (EF) and b) arterial elastance index (Eal); c) Representative pressure-volume loops of hearts of WT or TG (MHC$199 \mathrm{~b})$ mice subjected to either sham or PAB surgery. ${ }^{*} P<0.05$, compared with the corresponding control group. $\mathrm{N}=7-11$ in all groups.

Knowledge obtained from studies on LV adaptation cannot be directly inferred to the RV since both ventricles are morphologically and genetically different. ${ }^{38,39}$ Although the RV is functionally different by being coupled to the low-resistance pulmonary vasculature, ${ }^{40}$ it remains unknown whether it generates a distinctive responses to common stressors. ${ }^{41}$ In the LV, calcineurin/NFAT activation is a central inducer of pathological hypertrophy ${ }^{33}$ and targeting of this particular signaling pathway has been successfully achieved in both experimental and clinical LV failure. ${ }^{36}$ Noteworthy, functional adaptation of the RV to abnormal loading conditions seems to be associated with increased levels of modulatory calcineurin interacting protein 1 (MCIP1) expression, suggestive of calcineurin activation during pathological RV remodeling. ${ }^{35}$ We have previously shown that miR-199b is a direct calcineurin/NFAT target gene that increases in expression 
in mouse and human heart failure. Elevated cardiac miR-199b levels is associated with left ventricular hypertrophic growth and failure by targeting the nuclear NFAT kinase dual-specificity tyrosine-(Y)-phosphorylation regulated kinase 1a (Dyrk1a) in a feed-forward mechanism that affects calcineurinresponsive gene expression. Mice overexpressing miR-199b or deficient for Dyrk1a, are sensitized to pressure overload and display stress-induced cardiomegaly through reduced Dyrk1a expression. Despite its clear role during stress-induced LV remodeling, the role of miR-199b during the RV pathological response to sustained stress is not established.

Under normal physiological conditions, the RV is coupled to the pulmonary vascular bed, characterized by low resistance and high compliance. Upon stress conditions as a result of pulmonary hypertension or congenital heart diseases, the RV responds by increasing contractility and hypertrophic growth and if RV stress continues, these initial adaptive changes will progress into RV dysfunction and failure. In order to understand RV adaptation different models of RV deviant pressure loading conditions have been developed mainly in the rat. ${ }^{42,43}$ In this study, we used a model of RV pressure overload in mice, developed by subjecting the animals to pulmonary artery banding (PAB) surgery. ${ }^{35} \mathrm{We}$ demonstrated that WT mice with increased RV pressure load display increased levels of miR-199b expression in the RV suggesting involvement of this microRNA during pathological remodeling of the RV. Induction of miR-199b expression in WT animals upon PAB may be related to the hypertrophic response observed in these animals as pressure overload of the RV in WT animals resulted in elevated Fulton index and cardiomyocyte size, both indicative of cell hypertrophic growth. These results resemble the observations upon subjecting the LV to pressure overload ${ }^{36}$ by transverse aortic constriction (TAC) where increased miR-199b expression levels were accompanied by cardiomyocyte hypertrophic growth and elevated heart to body weight ratios.

Also at the level of fibrotic lesions, miR-199b TG animals display less collagen deposition after PAB than WT animals subjected to stress. Transforming growth factor beta (TGF- $\beta$ ) has been implicated in the pathophysiology of $\mathrm{PAH}^{44}$ and seems to be a target of the miRNA-199 family. ${ }^{45}$ Alterations in TGF- $\beta$ expression levels could very well explain the reduced levels of fibrosis observed in the MHC-199b animals after PAB, however, we were not able to detect differences in expression after PAB compared to sham in both WT and TG animals, suggesting that the observed effects on fibrosis are a secondary response to stress and independent from miR-199b expression levels. One of the limitations of our study is the lack of mechanistic insights by identifying target genes that could explain the differences in stress response of TG compared to WT hearts. In this regard, NOTCH signaling has been implicated in the development of $\mathrm{PH}$, with clear effects on the vasculature. ${ }^{46}$ Moreover, several members of the 
NOTCH signaling pathway have been validated as direct target genes for miR$199 b^{47}$ and several others are predicted to be targets. ${ }^{48}$ Although we have assessed the expression levels of several of $\mathrm{NOTCH}$ signaling genes we could not find significant changes between the different groups and therefore were not able to associate the observed phenotypes with NOTCH signaling.

The fact that many hemodynamic parameters did not significantly change between the different groups is another down aspect of our study. Although for most of the parameters assessed there were clear change trends between WTsham and WT-PAB groups, these effects did not reach statistical significance. Because both PAB hemodynamic assessment of cardiac function are technically very challenging, the size of our animal groups may be reflecting these challenges by showing high variation between animals within the different groups. Increasing the groups considerably may allow for statistical significance.

Because our surgical banding seems to only mildly increase RV end systolic pressure when compared to previous studies ${ }^{35}$ this supports a moderate banding of the pulmonary artery in our study. However, as this increase was sufficient to impair contractility and decrease cardiac output in WT animals, we believe to have generated an animal model mimicking a mild version of pulmonary artery banding (PAB). This could partly explain why the additional effect of miR-199b overexpression is overruled in our animal model. As previously indicated, the modulation of microRNA levels can reveal different effects on the heart depending on the severity of the disease induced in an animal model. ${ }^{49}$ Besides, miRNAs can have differential expression patterns during development of a disease suggesting that a microRNA can reveal a stage-specific regulatory function. ${ }^{50}$ Therefore, it remains necessary to investigate the role of miR-199b in a severe model of RV failure before drawing a firm conclusion on the function of this miRNA during RV remodeling.

\section{Acknowledgments}

P.D.C.M. was supported by a NWO-MEERVOUD grant (836.12.001) from the Netherlands Organization for Health Research and Development, and the Dutch Heart Foundation grant NHS2010B261. None of the authors has conflicts of interest to declare. 


\section{References}

1. Simon MA. Assessment and treatment of right ventricular failure. Nat Rev Cardiol 2013;10(4): 204-18.

2. Voelkel NF, Quaife RA, Leinwand LA, Barst RJ, McGoon MD, Meldrum DR, et al. Right ventricular function and failure: report of a National Heart, Lung, and Blood Institute working group on cellular and molecular mechanisms of right heart failure. Circulation 2006;114(17): 1883-91.

3. Bogaard HJ, Abe K, Vonk Noordegraaf A, Voelkel NF. The right ventricle under pressure: cellular and molecular mechanisms of right-heart failure in pulmonary hypertension. Chest 2009;135(3):794-804.

4. Norozi K, Wessel A, Alpers V, Arnhold JO, Geyer S, Zoege M, et al. Incidence and risk distribution of heart failure in adolescents and adults with congenital heart disease after cardiac surgery. Am J Cardiol 2006;97(8):1238-43.

5. D'Alonzo GE, Barst RJ, Ayres SM, Bergofsky EH, Brundage BH, Detre KM, et al. Survival in patients with primary pulmonary hypertension. Results from a national prospective registry. Ann Intern Med 1991;115(5):343-9.

6. McLaughlin VV, Sitbon O, Badesch DB, Barst RJ, Black C, Galie N, et al. Survival with first-line bosentan in patients with primary pulmonary hypertension. Eur Respir J 2005;25(2):244-9.

7. Sandoval J, Bauerle O, Palomar A, Gomez A, Martinez-Guerra ML, Beltran M, et al. Survival in primary pulmonary hypertension. Validation of a prognostic equation. Circulation 1994;89(4): 1733-44.

8. Borgdorff MA, Dickinson MG, Berger RM, Bartelds B. Right ventricular failure due to chronic pressure load: What have we learned in animal models since the $\mathrm{NIH}$ working group statement? Heart Fail Rev 2015;20(4):475-91.

9. Haddad F, Doyle R, Murphy DJ, Hunt SA. Right ventricular function in cardiovascular disease, part II: pathophysiology, clinical importance, and management of right ventricular failure. Circulation 2008;117(13):1717-31.

10. Sutendra G, Dromparis P, Paulin R, Zervopoulos S, Haromy A, Nagendran J, et al. A metabolic remodeling in right ventricular hypertrophy is associated with decreased angiogenesis and a transition from a compensated to a decompensated state in pulmonary hypertension. $\mathrm{J} \mathrm{Mol}$ Med (Berl) 2013;91(11):1315-27.

11. Bogaard HJ, Natarajan R, Henderson SC, Long CS, Kraskauskas D, Smithson L, et al. Chronic pulmonary artery pressure elevation is insufficient to explain right heart failure. Circulation 2009;120(20):1951-60.

12. Guglin M, Verma S. Right side of heart failure. Heart Fail Rev 2012;17(3):511-27.

13. Friedberg MK, Redington AN. Right versus left ventricular failure: differences, similarities, and interactions. Circulation 2014;129(9):1033-44.

14. MacNee W. Pathophysiology of cor pulmonale in chronic obstructive pulmonary disease. Part One. Am J Respir Crit Care Med 1994;150(3):833-52.

15. Katz WE, Gasior TA, Quinlan JJ, Lazar JM, Firestone L, Griffith BP, et al. Immediate effects of lung transplantation on right ventricular morphology and function in patients with variable degrees of pulmonary hypertension. J Am Coll Cardiol 1996;27(2):384-91.

16. Schulman LL, Leibowitz DW, Anandarangam T, DiTullio MR, McGregor CC, Smith CR, et al. Variability of right ventricular functional recovery after lung transplantation. Transplantation 1996;62(5):622-5.

17. Tude, RM, Archer SL, Dorfmuller P, Erzurum SC, Guignabert C, Michelakis E, et al. Relevant issues in the pathology and pathobiology of pulmonary hypertension. J Am Coll Cardiol 2013; 62(25 Suppl):D4-12.

18. Ha M, Kim VN. Regulation of microRNA biogenesis. Nat Rev Mol Cell Biol 2014;15(8):509-24.

19. Espinoza-Lewis RA, Wang DZ. MicroRNAs in heart development. Curr Top Dev Biol 2012; 100:279-317.

20. Divakaran V, Mann DL. The emerging role of microRNAs in cardiac remodeling and heart failure. Circ Res 2008;103(10):1072-83. 
21. Brock M, Trenkmann M, Gay RE, Michel BA, Gay S, Fischler M, et al. Interleukin-6 modulates the expression of the bone morphogenic protein receptor type II through a novel STAT3microRNA cluster 17/92 pathway. Circ Res 2009;104(10):1184-91.

22. Caruso P, MacLean MR, Khanin R, McClure J, Soon E, Southgate M, et al. Dynamic changes in lung microRNA profiles during the development of pulmonary hypertension due to chronic hypoxia and monocrotaline. Arterioscler Thromb Vasc Biol 2010;30(4):716-23.

23. Kang BY, Park KK, Green DE, Bijli KM, Searles CD, Sutliff RL, et al. Hypoxia mediates mutual repression between microRNA-27a and PPARgamma in the pulmonary vasculature. PLoS One 2013;8(11):e79503.

24. Wallace E, Morrell NW, Yang XD, Long L, Stevens H, Nilsen M, et al. A Sex-Specific MicroRNA-96/5-Hydroxytryptamine 1B Axis Influences Development of Pulmonary Hypertension. Am J Respir Crit Care Med 2015;191(12):1432-42.

25. Potus F, Malenfant S, Graydon C, Mainguy V, Tremblay E, Breuils-Bonnet S, et al. Impaired angiogenesis and peripheral muscle microcirculation loss contribute to exercise intolerance in pulmonary arterial hypertension. Am J Respir Crit Care Med 2014;190(3):318-28.

26. Bertero T, Lu Y, Annis S, Hale A, Bhat B, Saggar R, et al. Systems-level regulation of microRNA networks by miR-130/301 promotes pulmonary hypertension. J Clin Invest 2014; 124(8):3514-28.

27. Caruso P, Dempsie Y, Stevens HC, McDonald RA, Long L, Lu R, et al. A role for miR-145 in pulmonary arterial hypertension: evidence from mouse models and patient samples. Circ Res 2012;111(3):290-300.

28. Gou D, Ramchandran R, Peng X, Yao L, Kang K, Sarkar J, et al. miR-210 has an antiapoptotic effect in pulmonary artery smooth muscle cells during hypoxia. Am J Physiol Lung Cell Mol Physiol 2012;303(8):L682-91.

29. Jin Y, Pang T, Nelin LD, Wang W, Wang Y, Yan J, et al. MKP-1 is a target of miR-210 and mediate the negative regulation of miR-210 inhibitor on hypoxic hPASMC proliferation. Cell Biol Int 2015;39(1):113-20.

30. Potus F, Ruffenach G, Dahou A, Thebault C, Breuils-Bonnet S, Tremblay E, et al. Downregulation of MicroRNA-126 Contributes to the Failing Right Ventricle in Pulmonary Arterial Hypertension. Circulation 2015;132(10):932-43.

31. Modesti PA, Vanni S, Bertolozzi I, Cecioni I, Lumachi C, Perna AM, et al. Different growth factor activation in the right and left ventricles in experimental volume overload. Hypertension 2004;43(1):101-8.

32. Paulin R, Sutendra G, Gurtu V, Dromparis P, Haromy A, Provencher S, et al. A miR-208-Mef2 axis drives the decompensation of right ventricular function in pulmonary hypertension. Circ Res 2015;116(1):56-69.

33. Wilkins BJ, Dai YS, Bueno OF, Parsons SA, Xu J, Plank DM, et al. Calcineurin/NFAT coupling participates in pathological, but not physiological, cardiac hypertrophy. Circ Res 2004;94(1): 110-8.

34. van Rooij E, Doevendans PA, Crijns HJ, Heeneman S, Lips DJ, van Bilsen M, et al. MCIP1 overexpression suppresses left ventricular remodeling and sustains cardiac function after myocardial infarction. Circ Res 2004;94(3):e18-26.

35. Bartelds B, Borgdorff MA, Smit-van Oosten A, Takens J, Boersma B, Nederhoff MG, et al. Differential responses of the right ventricle to abnormal loading conditions in mice: pressure vs. volume load. Eur J Heart Fail 2011;13(12):1275-82.

36. da Costa Martins PA, Salic K, Gladka MM, Armand AS, Leptidis S, el Azzouzi H, et al. MicroRNA-199b targets the nuclear kinase Dyrk1a in an auto-amplification loop promoting calcineurin/NFAT signalling. Nat Cell Biol 2010;12(12):1220-7.

37. Thibault HB, Kurtz B, Raher MJ, Shaik RS, Waxman A, Derumeaux G, et al. Noninvasive assessment of murine pulmonary arterial pressure: validation and application to models of pulmonary hypertension. Circ Cardiovasc Imaging 2010;3(2):157-63.

38. Ho SY, Nihoyannopoulos P. Anatomy, echocardiography, and normal right ventricular dimensions. Heart 2006;92 Suppl 1:i2-13.

39. Srivastava D. Making or breaking the heart: from lineage determination to morphogenesis. Cell, 2006;126(6):1037-48. 
40. Haddad F, Hunt SA, Rosenthal DN, Murphy DJ. Right ventricular function in cardiovascular disease, part I: Anatomy, physiology, aging, and functional assessment of the right ventricle. Circulation 2008;117(11):1436-48.

41. Olson EN. Gene regulatory networks in the evolution and development of the heart. Science 2006;313(5795):1922-7.

42. Bar H, Kreuzer J, Cojoc A, Jahn L. Upregulation of embryonic transcription factors in right ventricular hypertrophy. Basic Res Cardiol 2003;98(5):285-94.

43. Faber MJ, Dalinghaus M, Lankhuizen IM, Steendijk P, Hop WC, Schoemaker RG, et al. Right and left ventricular function after chronic pulmonary artery banding in rats assessed with biventricular pressure-volume loops. Am J Physiol Heart Circ Physiol 2006;291(4):H1580-6.

44. Morrell NW, Adnot S, Archer SL, Dupuis J, Jones PL, MacLean MR, et al. Cellular and molecular basis of pulmonary arterial hypertension. J Am Coll Cardiol 2009;54(1 Suppl): S20-31.

45. Zhang Y, Fan KJ, Sun Q, Chen AZ, Shen WL, Zhao ZH, et al. Functional screening for miRNAs targeting Smad4 identified miR-199a as a negative regulator of TGF-beta signalling pathway. Nucleic Acids Res 2012;40(18):9286-97.

46. Li X, Zhang X, Leathers R, Makino A, Huang C, Parsa P, et al. Notch3 signaling promotes the development of pulmonary arterial hypertension. Nat Med 2009;15(11):1289-97.

47. Garzia L, Andolfo I, Cusanelli E, Marino N, Petrosino G, De Martino D, et al. MicroRNA-199b$5 p$ impairs cancer stem cells through negative regulation of HES1 in medulloblastoma. PLoS One 2009;4(3):e4998.

48. Dweep H, Gretz N. miRWalk2.0: a comprehensive atlas of microRNA-target interactions. Nat Methods 2015;12(8):697.

49. Bernardo BC, Gao XM, Tham YK, Kiriazis H, Winbanks CE, Ooi JY, et al. Silencing of miR-34a attenuates cardiac dysfunction in a setting of moderate, but not severe, hypertrophic cardiomyopathy. PLoS One 2014;9(2):e90337.

50. Sayed D, Hong C, Chen IY, Lypowy J, Abdellatif M. MicroRNAs play an essential role in the development of cardiac hypertrophy. Circ Res 2007;100(3):416-24. 


\section{Chapter 5}

miR-199b is a regulator of left ventricular remodeling following myocardial infarction

Burcu Duygu, Ella M. Poels, Rio Juni, Nicole Bitsch, Serve Olieslagers, Leon J. de Windt, Paula A. da Costa Martins

Adapted from

Non-coding RNA Res. In press 


\section{Abstract}

Myocardial infarction (MI), the globally leading cause of heart failure, morbidity and mortality, involves post-Ml ventricular remodeling, a complex process including acute injury healing, scar formation and global changes in the surviving myocardium. The molecular mechanisms involved in adverse post-infarct left ventricular remodeling still remain poorly defined. Recently, microRNAs have been implicated in the development and progression of various cardiac diseases as crucial regulators of gene expression. We previously demonstrated that in a murine model of pressure overload, a model of heart failure secondary to aortic stenosis or chronic high blood pressure, elevated myocardial expression of miR$199 b-5 p$ is sufficient to activate calcineurin/NFAT signaling, leading to exaggerated cardiac pathological remodeling and dysfunction. Given the differences in left ventricular remodeling secondary to post-infarct healing and pressure overload, we evaluated miR-199b function in post-MI remodeling. We confirmed that the expression of miR-199b is elevated in the post-infarcted heart. Transgenic animals with cardiomyocyte-restricted overexpression of miR199b-5p displayed exaggerated pathological remodeling after MI, reflected by severe systolic and diastolic dysfunction and fibrosis deposition. Conversely, therapeutic silencing of miR-199b-5p in Ml-induced cardiac remodeling by using an antagomir to specifically inhibit endogenous miR-199b-5p in vivo, resulted in efficient suppression of cardiac miR-199b-5p expression and attenuated cardiac dysfunction and dilation following MI. Mechanistically, miR-199b-5p influenced the expression of three predicted target genes in post-infarcted hearts, dual specificity tyrosine-phosphorylation-regulated kinase 1A (Dyrk1a), the notch1 receptor and its ligand jagged1. In conclusion, here we provide evidence supporting that stress-induced miR-199b-5p participates in post-infarct remodeling by simultaneous regulation of distinct target genes. 


\section{Introduction}

Acute myocardial infarction (MI) is one of the major causes of mortality and morbidity in humans. ${ }^{1} \mathrm{Ml}$ occurs when blood supply to the left ventricular (LV) wall of the heart is hindered due to an occlusion in the coronary arteries ${ }^{2}$ and consequently leading to massive cardiomyocyte death. A complex remodeling process is then initiated involving scar formation in the infarct zone, interstitial fibrosis in the border zone between the infarct and non-infarct area, cardiomyocyte hypertrophy and capillary rarefaction in the non-infarct remote zone. Eventually, these changes provoke impaired cardiac contractility and, ultimately, heart failure. ${ }^{3}$ Moreover, post-infarction remodeling is associated with a higher incidence of arrhythmia and sudden cardiac death. ${ }^{4}$ Hence, therapeutic strategies targeting pathological remodeling following $\mathrm{Ml}$ could provide a promising strategy for post-MI management and heart failure. In this regard, we and others have identified a variety of stress-induced microRNAs (miRNAs) as regulators of crucial mechanisms in the development of heart failure and acting as promising therapeutic targets. ${ }^{5-10}$ These short ( 22 nucleotide) single stranded RNA molecules modulate gene expression by binding to 'seed regions' on protein-coding transcripts and leading to translational inhibition or degradation of mRNAs. ${ }^{11}$ Importantly, a single miRNA likely simultaneously targets dozens of mRNAs, while individual mRNAs display several seed regions for different miRNAs, providing and enormous regulatory capacity for posttranscriptional gene regulation.

Previously, stress-induced miR-199b-5p was identified as a potent regulator of pathologic cardiac hypertrophy by functioning as an activator of calcineurin/nuclear factor of activated T-cell (CnA/NFAT) signaling. ${ }^{5}$ MiR-199b$5 p$ exerts its function by targeting Dual-specificity tyrosine-phosphorylation regulated kinase 1a (Dyrk1a), a nuclear kinase responsible for NFAT rephosphorylation and translocation from the nucleus to the cytoplasm, essentially acting as an inhibitor of CnA/NFAT signaling. Therapeutic inhibition of miR-199b-5p by using a cholesterol-conjugated antagomir provoked inhibition of cardiac CnA/NFAT activity, attenuated pathological remodeling and preserved cardiac contractility after pressure overload, identifying miR-199b-5p as a therapeutic target to treat hypertension-induced forms of heart failure. ${ }^{5}$ In the present study, we aimed at exploring the function of miR-199b-5p (referred to as miR-199b), if any, in post-infarct remodeling in the mouse using gain-of-function and therapeutic silencing approaches. We confirmed that the expression of miR$199 \mathrm{~b}$ is elevated in the post-infarcted heart. Transgenic animals with cardiomyocyte-restricted overexpression of miR-199b displayed exaggerated pathological remodeling after $\mathrm{MI}$, reflected by severe systolic and diastolic dysfunction and fibrosis deposition. Conversely, therapeutic silencing of miR- 
$199 \mathrm{~b}$ in Ml-induced cardiac remodeling by using an antagomir to specifically inhibit endogenous miRNA-199b in vivo, resulted in efficient suppression of cardiac miR-199b expression and attenuated cardiac dysfunction and dilation following MI. Mechanistically, miR-199b influenced the expression of three predicted target genes in post-infarcted hearts, dual specificity tyrosinephosphorylation-regulated kinase 1A (Dyrk1a), the notch1 receptor and its ligand jagged1. In conclusion, here we provide evidence supporting that stress-induced miR-199b participates in post-infarct remodeling by simultaneous regulation of distinct target genes.

\section{Materials and methods}

\section{Mouse models}

Mice used in this study were male and female B6129S2F1 wild-type mice (Charles River Laboratories) of 2-6 months of age. Other mice used in this study were transgenic mice overexpressing miR-199b-5p in the postnatal myocardium under control of the $5.5 \mathrm{~kb}$ murine alpha-myosin heavy chain ( $\mathrm{MHC}$ ) promoter (miR-199b TG). ${ }^{5}$ Sample size was determined by a power calculation based on an echocardiographic effect size. Randomization of subjects to experimental groups was based on a single sequence of random assignments. Animal caretakers and investigators were blinded to group allocation during the experiment and/or when assessing the outcome. All protocols were performed according to institutional guidelines and approved by local Animal Care and Use Committees. All mice were housed on a $12 \mathrm{hr}: 12 \mathrm{hr}$ light:dark cycle in a temperature-controlled environment with ad libitum access to water and chow at Innoser Netherlands BV, a commercial mouse breeding company with a quarterly animal health monitoring system that complies with FELASA guidelines and recommendations.

\section{Myocardial infarction and transthoracic echocardiography}

Myocardial infarction (MI) was performed in 2-3 month-old mice by permanent ligation of the left coronary artery as previously described. ${ }^{13}$ Sham-operated animals underwent the same procedure without the occlusion of the left coronary artery. For Doppler-echocardiography, mice were shaved, lightly anaesthetized with isoflurane (mean 1\% in oxygen) and allowed to breathe spontaneously through a nasal cone. Non-invasive, echocardiographic parameters were measured using a digital cardiac ultrasound platform (Vevo 770, VisualSonics, Toronto, Canada), and employing a single-element mechanical transducer with a center frequency of $30 \mathrm{MHz},(\mathrm{M}$ - and $\mathrm{B}$-mode), on self-breathing mice under 
anesthesia ( $2 \%$ isoflurane and $98 \%$ oxygen) to evaluate left ventricular dimensions and function. ${ }^{5}$ In M-mode, the following parameters were obtained: AWthd, anterior wall thickness in diastole; LVIDd, left ventricular internal diameter in diastole; PWthd, posterior wall thickness in diastole; AWths, anterior wall thickness in systole; LVIDs, left ventricular internal diameter in systole; PWths, posterior wall thickness in systole; PWths, posterior wall thickness in systole; LVmass, left ventricular mass and FS, fractional shortening.

\section{Antagomir administration}

Chemically modified antisense oligonucleotides designed to target mmu-miR199b-5p (5'-GAACAGGUAGUCUAAACACUGGG//3CholTEG-3';antagomir-

$199 \mathrm{~b})$ with a $3^{\prime}$ cholesterol conjugation and 2 phosphorothioate (PT) bonds at the very first $5^{\prime}$ end and 4 PT bonds between the last $3^{\prime}$ bases ${ }^{14}$ was synthesized at Integrated DNA Technologies (IDT, Leuven, Belgium).

As control we generated an antagomir against $C$. elegans miR-39-5p (5'-AAGGCAAGCUGACCCUGAAGUU-3'/3CholTEG-3'), which does not target mammalian sequences (antagomir-ctrl). Female and male B6129S2F1 mice were first subjected to sham or MI surgery and injected intraperitoneally with antagomir-199b (80 mg/kg body weight dissolved in sterile PBS) or antagomirctrl for 3 consecutive days.

\section{Real time RT- PCR}

Total RNA $(1 \mu \mathrm{g})$ was applied to either miR-based or mRNA-based reverse transcription (RT). Real-time PCR was performed on a BioRad iCycler (Biorad) using SYBR Green. Transcript quantities were compared using the relative $\mathrm{Ct}$ method, where the amount of target normalized to the amount of endogenous control (L7 or U6 for mRNAs or miRNAs, respectively) and relative to the control sample is given by $2^{-\Delta \Delta C t}$. Primers used for protein-coding transcripts are provided in Supplementary Table 5.1. For microRNA real-time PCR, miRNAs were isolated with TRIzol reagent (Invitrogen) and CDNA was generated with the miScript Reverse Transcription Kit (Qiagen). For real-time PCR detection of miRNAs, miScript Primer Assays and the miScript SYBR Green PCR Kit (Qiagen) were used. Primers for miRNA detection included miR-199b-5p, 5'-CCCAGTGTTTAGACTACCTGTTC and Universal reverse 5'-GAATCGAGCACCAGTTACGC.

\section{Western blotting}

SDS PAGE electrophoresis and blotting were performed as previously described. ${ }^{15}$ In short, whole tissue or cell lysates were produced in RIPA buffer supplemented with PhosSTOP (Roche) and Protease inhibitor cocktail (Roche). 
Subsequently samples were boiled in $4 \times$ Leammli buffer, including $2 \%$ $\beta$-mercaptoethanol, for $5 \mathrm{~min}$ at $95^{\circ} \mathrm{C}$. SDS-PAGE and Western blotting were performed using the Mini-PROTEAN 3 system (Bio-Rad). Blotted membranes were blocked in 5\% BSA/TBS-Tween. Primary antibody labeling was performed overnight at $4^{\circ} \mathrm{C}$. Secondary IgG-horseradish peroxidase (HRP)-conjugated antibodies were applied for $2 \mathrm{~h}$ at room temperature. Following incubation with an antibody, blots were washed for $3 \times 10 \mathrm{~min}$ in TBS-Tween. Images were generated using Supersignal West Dura Extended Duration ECL Substrate (Pierce) and the LAS-3000 documentation system (FujiFilm Life Science). Stripping was performed with Restore Western blot stripping buffer (Pierce). Outputs were normalized for loading and results are expressed as an n-fold increase over the values of the control group in densitometric arbitrary units. Primary antibodies that were used included rabbit polyclonal anti-Dyrk1A (Santa Cruz, 1:500), mouse monoclonal anti- $\alpha$-tubulin (Sigma, 1:1000). Secondary antibodies included polyclonal rabbit anti-mouse IgG-HRP (DAKO, 1:5000) and polyclonal swine anti-rabbit IgG-HRP (DAKO, 1:5000).

\section{Histological analysis and (immunofluorescence) microscopy}

For histological analysis, hearts were arrested in diastole, perfusion-fixed with $4 \%$ paraformaldehyde, embedded in paraffin and cut into 4- $\mu \mathrm{m}$ sections. Paraffin sections were stained with haematoxylin and eosin (H\&E) for routine histological analysis; Sirius Red for detection of fibrillar collagen and FITC-labeled wheatgerm-agglutinin (WGA) to visualize and quantify the cell cross-sectional area. Cell surface areas and infarct size were determined using ImageJ software. Sirius Red stained sections were used to determine the infarct size. Epicardial infarct ratio was obtained by dividing the epicardial infarct lengths by the epicardial circumferences from all sections. Endocardial infarct ratio was calculated similarly. Infarct size derived from this approach was calculated as [(epicardial infarct ratio + endocardial infarct ratio)/2] $\times 100 .^{16}$ Slides were visualized using a Leica DM 2000 for bright field and Leica DM3000 for fluorescence imaging.

\section{microRNA target prediction}

Putative microRNA-199b target genes were identified using the microRNA databases and target prediction tools miRBase (http://microrna.sanger.ac.uk/), PicTar (http://pictar.mdc-berlin.de/) and TargetScan (http://targetscan.org/ index.html). 


\section{Statistical analysis}

The results are presented as mean \pm standard error of the mean. Statistical analyses were performed using Prism software (GraphPad Software Inc.), and consisted of ANOVA followed by Tukey's test when group differences were detected at the $5 \%$ significance level, or Student's $t$-test when comparing two experimental groups. Differences were considered significant when $P<0.05$.

\section{Results}

\section{Cardiac overexpression of miR-199b exacerbates LV remodeling following MI}

We have previously established the therapeutic potential of targeting miR-199b in a murine model of pressure overload-induced heart failure. ${ }^{5}$ In the present follow-up study we aimed at determining the involvement of miR-199b, if any, during pathological cardiac remodeling induced by myocardial infarction (MI). To this end, wild-type (WT) and cardiac-specific miR-199b transgenic mice (miR-199b TG or TG), ${ }^{5}$ were subjected to either sham surgery or MI for 4 weeks. WT animals displayed increased cardiac miR-199b expression levels when subjected to Ml compared to the sham group (Figure 5.1a). As expected, higher miR-199b expression was observed in transgenic hearts compared to WT mice. All animals subjected to 4 weeks of Ml developed severe cardiac dysfunction as evidenced by decreased fractional shortening (FS), a parameter of systolic function, and increased left ventricular internal diameters (LVIDd), indicating a profound dilation post-infarction (Figure 5.1b and 5.1c; Table 5.1). TG mice developed severe systolic dysfunction compared to WT animals indicating that increased miR-199b expression levels sensitized the heart to Ml-induced dysfunction (Figure 5.1b). We also observed diastolic dysfunction in all experimental post-Ml groups as evidenced by an increased E/A ratio ('E' early; ' $A$ ' late ventricular filling velocity measured by mitral valve Doppler; Figure 5.1d; Table 5.1), but only post-infarcted TG animals displayed an E/A ratio above 2, indicating restrictive filling of the LV. The observed cardiac phenotypes correlated with increased transcript abundance of cardiac stress genes (Figure 5.1e) including atrial natriuretic factor (Nppa), a-skeletal actin (Acta1) and $\beta$-myosin heavy chain (Myh7). Taken together, these results indicate that cardiac miR-199b overexpression sensitizes the myocardium to geometric postinfarction remodeling, cardiac dysfunction and the induction of stress marker gene expression. 
a

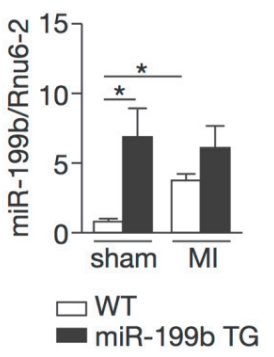

b

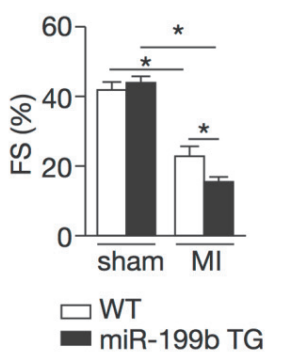

C

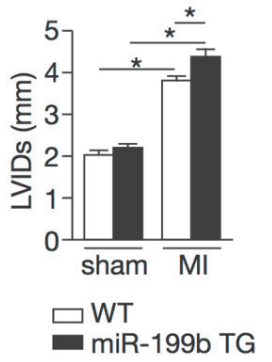

d

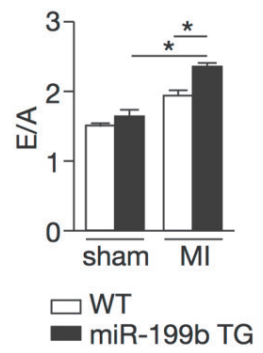

e

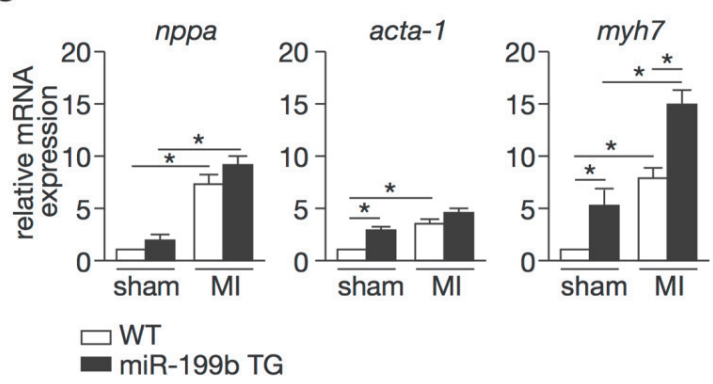

Figure 5.1 Cardiac specific overexpression of miR-199b sensitizes the heart to MI. a) Realtime PCR analysis of miR-199b transcript abundance in hearts from wild type (WT) or miR-199b transgenic mice (TG) subjected to either sham or MI. Rnu6-2 was used as a reference gene for normalization. (b-d) Assessment of cardiac functional parameters by cardiac echocardiography, in WT and miR-199b transgenic mice (TG) after 4 weeks of either sham or Ml surgery: b) fractional shortening (FS), c) LV internal diameter at systole (LVIDs) and d) early to late ventricular filling velocity (E/A). e) Real-time PCR analysis of transcript abundance for the fetal gene markers natriuretic peptide atrial natriuretic factor (nppa), a-skeletal actin (acta1) and $\beta$-myosin heavy chain (myh7) in the hearts from WT or miR-199b transgenic mice (TG), 4 weeks after either sham or MI operation. $n=6-9,{ }^{\star} P<0.05$ (mean \pm s.e.m.).

Next, we evaluated the extent of cardiac hypertrophic growth and fibrotic scar formation following Ml. ${ }^{3,17}$ Although post-infarcted hearts displayed increased heart weights, this effect was exacerbated in TG animals. Accordingly, crosssectional cardiomyocytes surface areas were increased after MI with the cells being slightly more hypertrophic in the TG animals (Figure 5.2a, 5.2c). This finding of mild increase in cardiac cell hypertrophy in the TG animals after MI, in combination with the observed exaggerated dilation response secondary to MI suggests that miR-199b overexpression promotes a switch from concentric to eccentric hypertrophy response in the viable myocardium after MI. Next, we investigated infarct scar size, a main determinant of outcome after MI. ${ }^{18}$ Although the scar size on the left anterior wall distal to the occluded LAD was comparable between WT and TG hearts (Figure 5.2d), the amount of fibrosis in 
the border zone of TG hearts was more extensive compared to WT hearts (Figure 5.2e and 5.2f). Conclusively, miR-199b overexpression promotes, on the one hand, a mild cardiac concentric hypertrophic phenotype in the viable remote myocardium, and on the other hand, LV dilatation. Furthermore, it does not influence infarct healing but stimulates exaggerated fibrotic deposition in the remote myocardium in post-infarcted hearts.

Table 5.1 Morphometric and echocardiographic characteristics of WT and miRNA-199b TG mice subjected to 4 weeks of sham or MI.

\begin{tabular}{lcccc}
\hline & \multicolumn{2}{c}{ Sham } & \multicolumn{2}{c}{ MI } \\
\cline { 2 - 5 } & WT & miR-199b TG & WT & miR-199b TG \\
\hline $\mathbf{n}$ & 11 & 8 & 7 & 13 \\
HW/BW & $4.61 \pm 0.09$ & $4.31 \pm 0.18$ & $6.30 \pm 0.59^{*}$ & $6.10 \pm 0.25^{*}$ \\
HW/TL & $6.82 \pm 0.21$ & $7.06 \pm 0.23$ & $7.99 \pm 0.19^{*}$ & $8.83 \pm 0.21^{*} \#$ \\
LV mass (mg) & $187.72 \pm 13.42$ & $208.11 \pm 19.52$ & $354.71 \pm 9.24^{*}$ & $343.03 \pm 19.48^{*}$ \\
LV mass/BW (mg/g) & $5.89 \pm 0.73$ & $5.50 \pm 0.67$ & $12.48 \pm 0.40^{*}$ & $9.50 \pm 0.56^{*} \#$ \\
LV mass/TL (mg/mm) & $8.5 \pm 0.54$ & $8.9 \pm 0.81$ & $14.78 \pm 1.16^{*}$ & $15.51 \pm 0.93^{*}$ \\
IVSd (mm) & $1.59 \pm 0.08$ & $1.64 \pm 0.10$ & $2.09 \pm 0.07^{*}$ & $2.06 \pm 0.09^{*}$ \\
IVSs (mm) & $1.22 \pm 0.12$ & $1.61 \pm 0.08^{*}$ & $1.87 \pm 0.09^{*}$ & $1.84 \pm 0.11^{*}$ \\
LVIDd (mm) & $3.57 \pm 0.18$ & $3.83 \pm 0.58$ & $4.58 \pm 0.18^{*}$ & $4.52 \pm 0.22^{*}$ \\
LVIDs (mm) & $2.08 \pm 0.15$ & $2.18 \pm 0.11$ & $3.85 \pm 0.13^{*}$ & $4.30 \pm 0.15^{*} \#$ \\
LVPWd (mm) & $1.31 \pm 0.02$ & $1.40 \pm 0.08$ & $1.64 \pm 0.06^{*}$ & $1.38 \pm 0.06^{*} \#$ \\
LVPWs (mm) & $2.29 \pm 0.05$ & $2.15 \pm 0.11$ & $1.48 \pm 0.08^{*}$ & $1.71 \pm 0.04^{*} \#$ \\
FS (\%) & $41.73 \pm 3.25$ & $43.08 \pm 2.57$ & $22.69 \pm 2.59^{*}$ & $16.01 \pm 1.32^{*} \#$ \\
E/A (mm/s) & $1.59 \pm 0.06$ & $1.68 \pm 0.06$ & $1.79 \pm 0.09$ & $2.24 \pm 0.06^{*} \#$ \\
\hline
\end{tabular}

Data are expressed as means \pm SEM. HW, heart weight; BW, body weight; TL, tibia length; LV, left ventricular; IVSd, interventricular septal thickness at end-diastole; IVSs, interventricular septal thickness at end-systole; LVIDd, left ventricular internal dimension at end-diastole; LVIDs, left ventricular internal dimension at end-systole; LVPWd, left ventricular posterior wall thickness at enddiastole; LVPWs, left ventricular posterior wall thickness at end-systole; FS, fractional shortening; E/A, Doppler E/A ratio. * indicates $P<0.05$ vs wt-sham group; \#, indicates $P<0.05$ vs experimental group.

\section{In vivo miR-199b silencing attenuates post-infarction remodeling}

Next, we evaluated post-infarction remodeling following an in vivo silencing approach for miR-199b. To this end, animals were randomized to either receive antagomir-control or antagomir-199b treatment for 3 consecutive days before being subjected to sham or Ml surgery. We observed that while miR-199b expression was augmented in the LV after MI in antagomir-control treated mice, miR-199b was effectively silenced in the myocardium after administration of antagomir-199b (Figure 5.3a). As expected, antagomir-control treated mice developed severe systolic dysfunction and LV dilation following MI (Figure 5.3b and 5.3c; Table 5.2). Interestingly, infarcted mice receiving antagomir-199b demonstrated a clear attenuation of cardiac dysfunction accompanied by a mild suppression of myocardial dilation (Figure 5.3b and 5.3c; Table 5.2). 
a

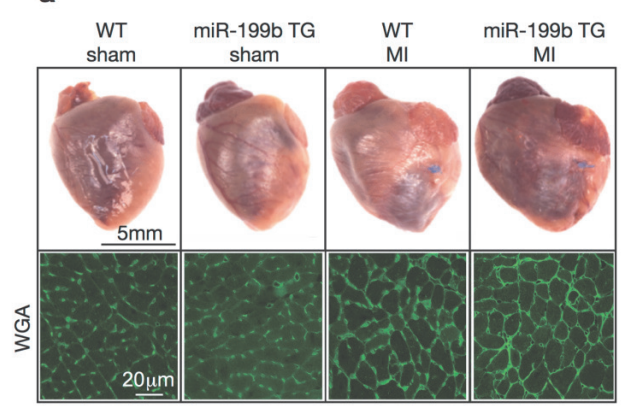

b

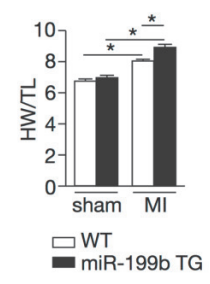

C

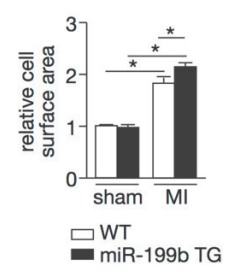

d

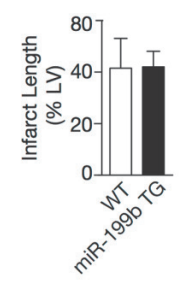

e

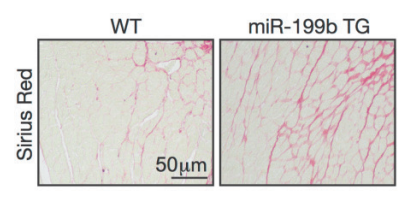

f

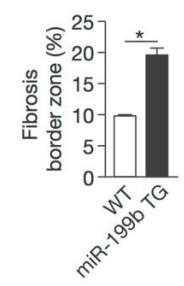

Figure 5.2 miR-199b overexpression results in exaggerated fibrosis in the border zone during post-myocardial infarct remodeling. a) Representative images of whole hearts (top panels) or wheat-germ agglutinin (WGA)-labeled (lower panels) histological sections, b) gravimetric analysis of corrected heart weights and c) quantification of cardiomyocyte surface area of WT or miR-199b transgenic (TG) mice hearts after either 4 weeks of sham or Ml surgery. d) Quantification of infarct sizes in WT and miR-199b transgenic (TG) animals, 4 weeks after MI. e) Representative images of Sirius redstained histological sections and f) quantification of collagen deposition in the border zone of WT or miR-199b transgenic (TG) hearts after MI. $n=6-10,{ }^{*} P<0.05$ (mean \pm s.e.m.).

Histological analysis demonstrated that cross-sectional surface areas of cardiomyocytes were increased to the same extent in antagomir-control or antagomir-199b-treated mice following MI (Figure 5.3d and 5.3e), which was also reflected at the whole organ level by measuring heart weight-to-tibia length ratios (Figure 5.3f). No major inhibition of stress marker gene induction was observed between infarcted mice receiving either antagomir-control or antagomir-199b (Figure 5.3g). As we did not detect major differences regarding scar size and collagen deposition at the histological level (data not shown), we also assessed the expression levels of several fibrosis-related genes such as collagen type I alpha 2 chain (col1a2), collagen type 3 alpha 1 chain (col3a1) and fibronectin-1 (fn1) (Figure 5.3h). 
a

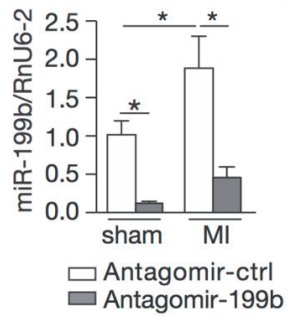

b

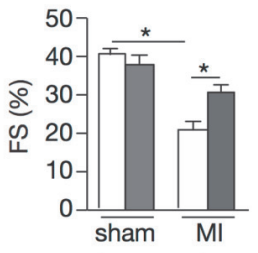

$\square$ Antagomir-ctrl $\square$ Antagomir-199b
C

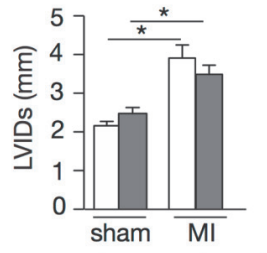

$\square$ Antagomir-ctrl

$\square$ Antagomir-199b d

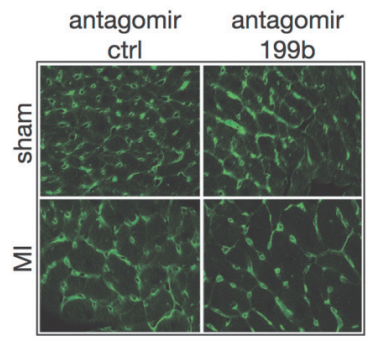

e

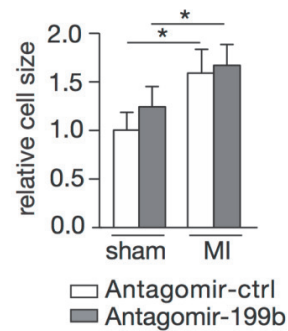

f

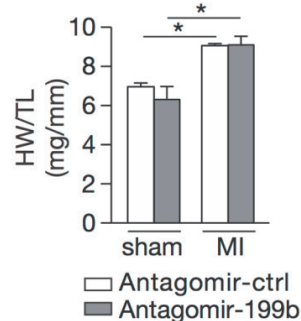

g
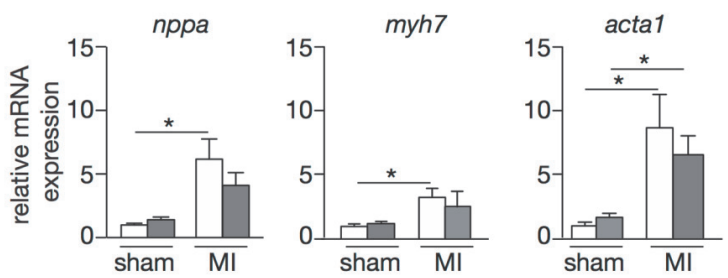

$\square$ Antagomir-ctrl

$\square$ Antagomir-199b

h
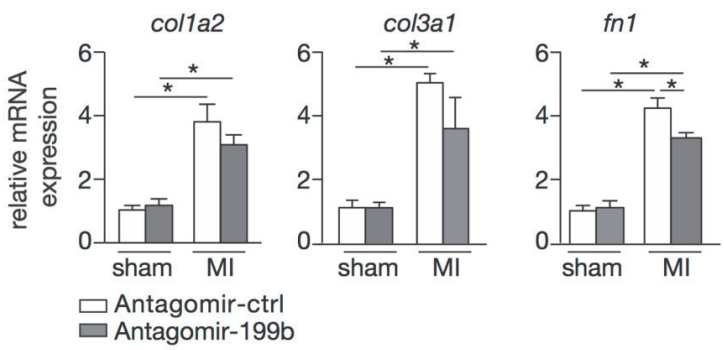

Figure 5.3 Pharmacological inhibition of miR-199b attenuates cardiac dysfunction following MI. a) Real-time PCR analysis of miR-199b expression levels in the LV of antagomircontrol or antagomir-199b-treated animals after subjection to either 4 weeks of sham or MI. Rnu6-2 was used as a reference gene for normalization. b,c) Quantification of (b) fractional shortening (FS) and (c) LV internal diameter at systole (LVIDs) by echocardiography in antagomir-control or antagomir-199b-treated mice after subjection to 4 weeks of either sham or MI. d) Representative images of WGA-labeled cardiac histological sections from mice subjected to sham or MI, and treated either with antagomir-control or antagomir-199b. e) Quantification of cardiomyocyte surface area in 
histological sections from mice subjected to sham or $\mathrm{MI}$, and treated either with antagomir-control or antagomir-199b. f) Gravimetric analysis of corrected hearts weights of animals that underwent sham or MI surgery and after treatment with antagomircontrol or antagomir-199b. g) Real-time PCR analysis of transcript abundance of the fetal gene markers: natriuretic peptide atrial natriuretic factor (nppa), $\beta$-myosin heavy chain (myh7) and the sarcomeric proteins $\alpha$-skeletal actin (acta1) in antagomir-control or antagomir-199b treated mice after subjection to 4 weeks of sham or MI. h) Real-time PCR analysis of transcript abundance of fibrosis related genes: collagen type I alpha 2 chain (col1a2), collagen type 3 alpha 1 chain (co/3a1) and fibronectin-1 (fn1) in antagomir-control or antagomir-199b treated mice after subjection to 4 weeks of sham or MI. $n=8-13{ }^{*} P<0.05$ (mean \pm s.e.m.).

Whereas for the collagens there was reduced mRNA expression in the mice treated with antagomir-199b but this effect did not reach statistical significance, we did observe significant reduction in fibronectin1 expression in the mice treated with antagomir-199b compared to the control group (Figure 5.3h). In conclusion, our in vivo silencing approach for miR-199b shows therapeutic effects on post-infarction remodeling in mice, with pronounced improvement of systolic contractility, reduction of LV dilation and reduced fibrosis-related gene expression, but no major differences in cardiomyocyte hypertrophy or "fetal" gene induction in the remote myocardium.

Table 5.2 Morphometric and echocardiographic characteristics of mice subjected to 4 weeks of sham or MI and treated either with antagomir-control or antagomir-199b.

\begin{tabular}{lcccc}
\hline & \multicolumn{2}{c}{ Sham } & \multicolumn{2}{c}{ MI } \\
\cline { 2 - 5 } & $\begin{array}{c}\text { Antagomir- } \\
\text { control }\end{array}$ & Antagomir-199b & $\begin{array}{c}\text { Antagomir- } \\
\text { control }\end{array}$ & Antagomir-199b \\
\hline $\mathbf{n}$ & 13 & 8 & 11 & 11 \\
HW/BW (mg/g) & $7.16 \pm 0.43$ & $5.65 \pm 0.81$ & $8.28 \pm 1.03$ & $8.64 \pm 0.53$ \\
HW/TL (mg/mm) & $7.07 \pm 0.28$ & $6.47 \pm 0.76$ & $9.01 \pm 0.43^{*}$ & $9.06 \pm 0.67^{*}$ \\
LV mass (mg) & $95.01 \pm 6.51$ & $113.32 \pm 6.01$ & $151.71 \pm 24.18^{*}$ & $182.29 \pm 14.30^{*}$ \\
LV mass/BW (mg/g) & $4.04 \pm 0.22$ & $4.42 \pm 0.17$ & $5.58 \pm 0.28^{*}$ & $6.93 \pm 0.46^{*} \#$ \\
LV mass/TL (mg/mm) & $4.32 \pm 0.43$ & $4.97 \pm 0.51$ & $6.94 \pm 0.23^{*}$ & $7.99 \pm 0.33^{*}$ \\
IVSd (mm) & $0.99 \pm 0.03$ & $1.02 \pm 0.05$ & $0.84 \pm 0.08$ & $0.87 \pm 0.08$ \\
IVSs (mm) & $1.46 \pm 0.05$ & $1.49 \pm 0.06$ & $1.21 \pm 0.10^{*}$ & $1.19 \pm 0.10^{*}$ \\
LVIDd (mm) & $3.70 \pm 0.10$ & $3.83 \pm 0.12$ & $4.97 \pm 0.28^{*}$ & $5.20 \pm 0.25^{*}$ \\
LVIDs (mm) & $2.19 \pm 0.12$ & $2.38 \pm 0.16$ & $3.91 \pm 0.33^{*}$ & $3.55 \pm 0.28^{*}$ \\
LVPWd (mm) & $0.79 \pm 0.06$ & $0.92 \pm 0.04$ & $0.92 \pm 0.07$ & $1.04 \pm 0.09^{*}$ \\
LVPWs (mm) & $1.20 \pm 0.05$ & $1.35 \pm 0.05$ & $1.23 \pm 0.08$ & $1.29 \pm 0.07$ \\
FS (\%) & $40.81 \pm 2.02$ & $37.85 \pm 2.36$ & $21.32 \pm 2.69^{*}$ & $31.73 \pm 1.74^{*} \#$ \\
E/A (mm/s) & $1.40 \pm 0.05$ & $1.24 \pm 0.04$ & $1.36 \pm 0.07$ & $1.33 \pm 0.05$ \\
\hline
\end{tabular}

\section{Downstream effectors of miR-199b in post-MI remodeling}

Next, we investigated the mechanisms by which miR-199b may induce an exaggerated cardiac dysfunction and LV remodeling following MI. Our group earlier established that miR-199b exerts its pro-hypertrophic function in the 
pressure-overloaded heart by regulating signaling strength of the calcineurin/nuclear factor of activated T-cell (CnA/NFAT) pathway. In line, we found Rcan 1-4 transcript expression, a sensitive marker of cardiac NFAT activity, upregulated in response to $\mathrm{MI}$, indicative of activation of this signaling pathway following MI. However, no additional activation was discernable in postinfarcted TG mice with miR-199b overexpression (Figure 5.4a). We also could not observe differences in transcript or abundance or protein expression of Dualspecificity tyrosine-phosphorylation regulated kinase 1a (Dyrk1a), a previously validated target gene of miR-199b in the myocardium (Figure 5.4b-d). Conversely, we also evaluated Rcan1-4 and Dyrk1a transcript abundance in the experimental infarction groups receiving antagomir control or antagomir-199b. Although the data show no significant differences for both transcripts (Figure 5.4e and 5.4f), western blot analysis revealed an increase in Dyrk1a expression levels in infarcted hearts after antagomir-199b treatment (Figure 5.4g and 5.4h). Altogether, these data suggest that miR-199b silencing in the post-infarcted heart may still involve CnA/NFAT signaling by direct regulation of Dyrk1a expression, but to a less extent than what we previously observed in pressure-overloaded hearts. ${ }^{5}$ Therefore, we conclude that miR-199b expression promotes adverse remodeling and cardiac dysfunction following $\mathrm{Ml}$ in a response that must require additional target genes to play a synergistic effect along with specific players of CnA/NFAT signaling.

a

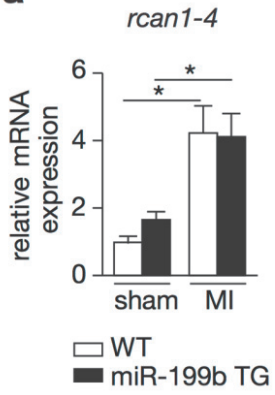

b

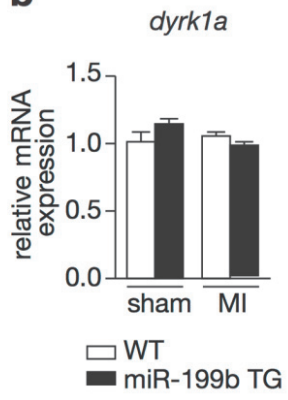

C

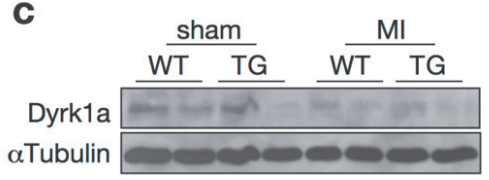

d

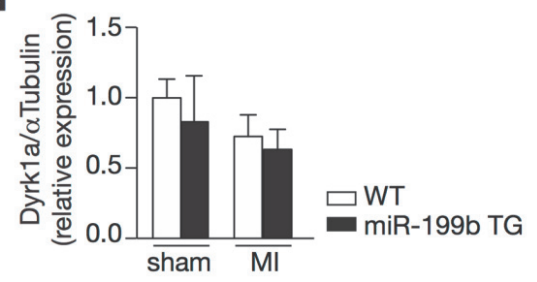


e

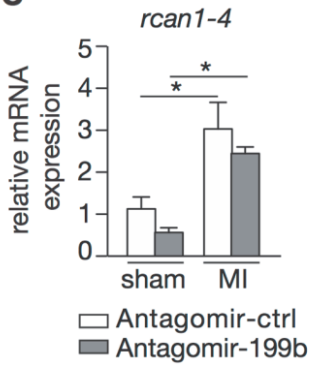

g

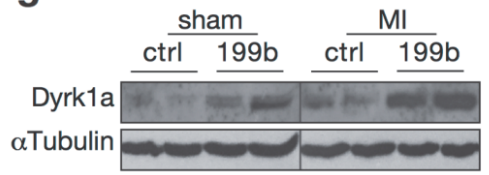

f

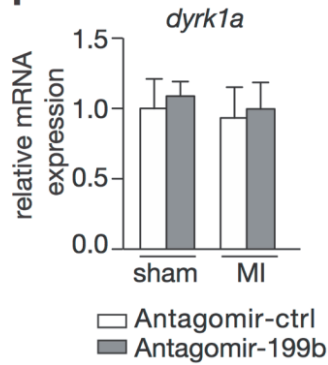

h

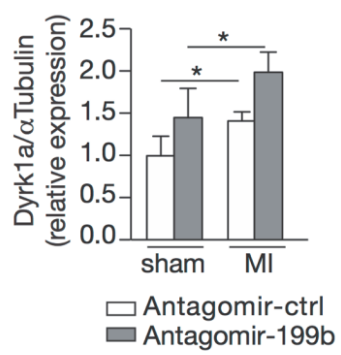

Figure 5.4 Improved cardiac function after pharmacological inhibition of miRNA-199b involves CnA/NFAT signaling. a,b) Real-time PCR analysis of transcript abundance of (a) rcan1-4 and (b) dyrk1a in WT or miR-199b transgenic (TG) murine hearts after subjection to 4 weeks of sham or Ml. c) Western blot analysis of endogenous Dyrk1a and aTubulin in WT or miR-199b transgenic (TG) murine hearts after subjection to 4 weeks of sham or Ml. d) Quantification of aTubulin-corrected Dyrk1A western blot signals from (c). e,f) Real-time PCR analysis of transcript abundance of (e) rcan1-4 and (f) dyrk1a in hearts from mice subjected to sham or MI, and treated either with antagomir-control or antagomir-199b. g) Western blot analysis of endogenous Dyrk1a and aTubulin in murine hearts subjected to sham or $\mathrm{Ml}$, and treated either with antagomir-control or antagomir-199b. h) Quantification of aTubulin-corrected Dyrk1A western blot signals from (g). $n=5-9{ }^{*} P<0.05$ (mean \pm s.e.m.).

Because miRNAs target multiple transcripts by virtue of the presence of a specific seed region, we evaluated the expression of additional miR-199b target genes in post-infarcted hearts. To this end, we analyzed target prediction databases for miR-199b and identified two members of the Notch signaling pathway as potential targets of miR-199b, Notch1 andJagged1. The Notch pathway is of particular interest here because increased activity of Notch1 in the adult heart after a cardiac insult has been associated with beneficial effects on cardiac function and remodeling, ${ }^{19-25}$ Moreover, Jagged1is a validated direct target of miR-199b and an inverse correlation between miR-199b andNotch1 expression in cancer cells was previously demonstrated. ${ }^{26-28}$ The sequence alignments between mature mmu-miR-199b-5p and sequences in the 3'UTR of Jagged1 and Notch1 displayed perfect sequence complementarity between 
the transcripts and miR-199b (Figure 5.5a). In line, we found that transcript abundance for both Jagged1 andNotch1 were enhanced in WT post-infarcted hearts, while in TG animals subjected to MI their expression was at control level (Figure 5.5b and 5.5c). Vice versa, the hearts of WT mice receiving antagomir199b displayed a clear derepression of both Jagged1 and Notch1 transcripts (Figure 5.5d and 5.5e). Conclusively, these results demonstrate that miR-199b acts as a negative regulator of the protective Notch signaling pathway during LV remodeling following $\mathrm{MI}$.

a

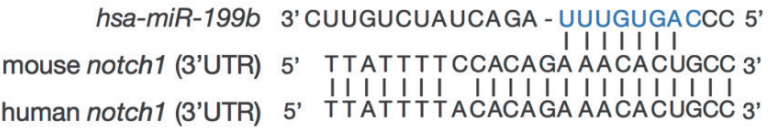

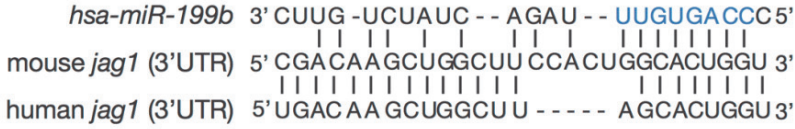

b
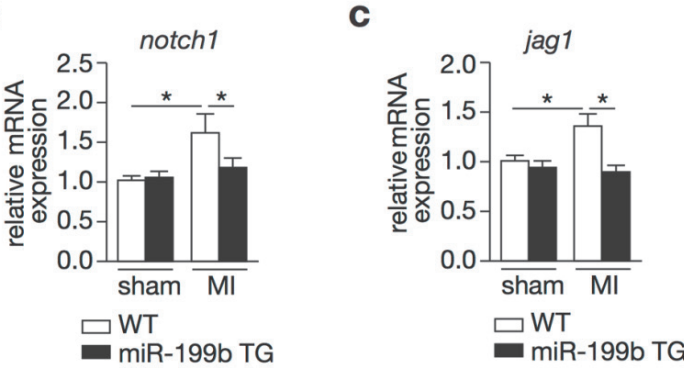

d
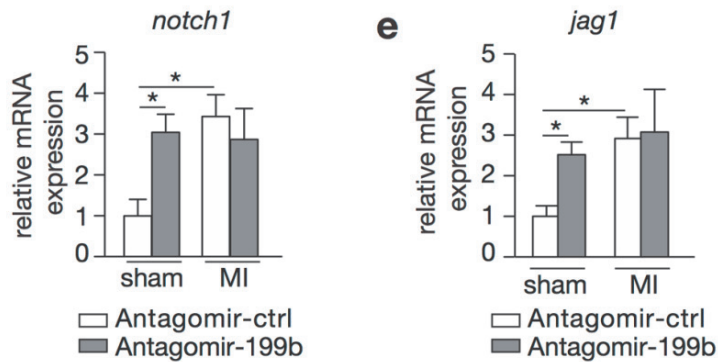

Figure 5.5 miR-199b regulation of post-MI cardiac remodeling involves the Notch signaling pathway. a) Sequence alignment of human miR-199b seed region and 3'UTRs of human and mouse notch1 and jagged1. b,c) Real-time PCR analysis of transcript abundance of (b) notch1 and (c) jagged1 in WT or miR-199b transgenic (TG) murine hearts after 4 weeks of sham or Ml. (d,e) Real-time PCR analysis of transcript abundance of (b) notch1 and (c) jagged1 in murine hearts subjected to sham or MI, and treated either with antagomir-control or antagomir-199b. $n=4-6{ }^{*} P<0.05$ (mean \pm s.e.m.). 


\section{Discussion}

Our study suggests that under volume overload conditions, miR-199b is still able to affect CnA/NFAT signaling by direct regulation of Dyrk1A expression but also interferes with the Notch pathway during pathological remodeling after myocardial infarction (MI), which is associated with elevated levels of fibrosis in the border zone. We detected activation of the CnA/NFAT signaling pathway in the LV of Ml-subjected hearts by measuring transcript levels of calcineurin 1 isoform 4 (Rcan1-4), a sensitive target gene activated by CnA/NFAT and often used to evaluate signaling strength of this cascade. ${ }^{29}$ We observed higher Rcan1-4expression levels in hearts from mice receiving myocardial infarction, suggesting that CnA/NFAT signaling is indeed activated in the postinfarcted heart as observed previously by us. ${ }^{13}$ In contrast, Dyrk1a transcript levels, a previously validated target of miR-199b, were not dysregulated in LV after MI, which in part may explain why we did not observe a further activation of pathological CnA/NFAT signaling in post-infarcted hearts from transgenic mice. ${ }^{5}$ In line, the cardiac hypertrophic response induced by MI was also similar in both miR-199b transgenic and WT animals providing another piece of evidence for a seemingly equal activation of CnA/NFAT signaling regardless of miR-199b overexpression. $^{30-32}$ While miR-199b knockdown does not affect Dyrk1a transcript levels, we observed an increase in protein expression levels in hearts that received miR-199b antagomir treatment after undergoing a myocardial infarct. Nevertheless, antagomir treatment seems to have a milder effect on Dyrk1A expression when compared to our previous observations in pressure overloaded hearts. ${ }^{5}$ All in all, our data implies that miR-199b in post-infarct remodeling may exert a slightly different function through regulation of different downstream targets compared to situations where pressure overload ensues maladaptive hypertrophy.

Target prediction databases and literature searches highlighted two additional targets of miR-199b, Notch1 and Jagged1, both previously associated with MIinduced cardiac remodeling. Previously, it was demonstrated that miR-199b is involved in chemotaxis resistance of ovarian cancer via targeting Jagged1 and thereby altering the Notch signaling pathway. ${ }^{26}$ In meduloblastoma cells, miR$199 \mathrm{~b}$ impairs the engrafting potential in the cerebellum of athymic/nude mice by influencing Hes1 expression, a transcription factor of the Notch pathway. ${ }^{27,28}$ Finally, miR-199b is also a key modulator of endothelial cell differentiation derived from induced pluripotent stem cells by targeting the Notch ligand jagged1. ${ }^{33}$ Evolutionarily conserved, the Notch pathway is an essential signaling cascade in the development of metazoans. ${ }^{34}$ In mammals, signal transduction is initiated once one of the four Notch receptors (Notch1-4) interacts with membrane tethered ligands such as jagged (jagged 1 and 2) and the delta-like 
(Delta-like 1, 3 and 4) family. ${ }^{34}$ Both receptors and ligands are transmembrane proteins involving the Notch pathway in the communication between two neighboring cells. ${ }^{35}$ Upon ligand binding, activation of Notch receptor is followed by proteolytic cleavage by TACE (TNF- $\alpha$ converting enzyme) and the multicomponent $\mathrm{y}$-secretase complex to release the intercellular domain of Notch (NICD) and allowing translocate to the nucleus. Once in the nucleus, a transcription activator complex is formed with the DNA binding protein family CSL [CBF1/RBPJ-kappa/Su $(\mathrm{H}) / \operatorname{Lag} 1]^{36,37}$ inducing the transcription of Notch downstream target genes such as bHLH (basic helix-loop-helix) repressors of the Hairy/enhancer of split (Hes) family. TheHes family includes Hes1 and Herp (Hairy-related transcription factors) also known as Hey. ${ }^{38-40}$

While mutations in the Notch signaling pathway have been associated with human congenital heart defects including Alagille syndrome, bicuspid aortic valve disease, calcification of the heart valves, and ventricular septal defects, ${ }^{41-44}$ and the essential role of Notch pathway during cardiac development has been experimentally established, ${ }^{45}$ the function of Notch in the adult heart is somewhat a matter of controversy. ${ }^{46}$ Several of the aforementioned studies revealed induced Notch signaling activity in the myocardium either by direct injection of a Notch1-activating antibody in the border zone or by cardiac-specific overexpression of Jagged1, with both approaches leading to improved cardiac function following MI. ${ }^{20,25}$ In our study, we also observed increased Notch1 and Jagged1 expression after antagomir-199b treatment in the sham-operated animals suggesting that these two genes act downstream of miR-199b. Analysis of protein levels and target gene validation experiments are still necessary to establish these two genes as direct target genes of miR-199b involved in pathological cardiac remodeling post-MI.

In summary, we demonstrated that myocardial overexpression of miR-199b results in exaggerated pathological remodeling in a mouse model of $\mathrm{MI}$, while in vivopharmacological silencing of miR-199b using an antagomir approach had therapeutic functional effects. The observed effects may result from a synergism between the CnA/NFAT and Notch signaling pathways. Given that stress-induced miRNAs target a variety of genes, here we provided evidence that miRNAs may regulate different targets and act on different signaling pathways depending on the context of the stress. Previously, miR$199 \mathrm{~b}$ was shown to exert its function via activation of the CnA/NFAT pathway in pressure overload-induced cardiac remodeling whereas upon volume overload we observe a milder effect on CnA/NFAT signaling but in addition, miR-199b also exerts its cardio-protective effects by influencing the protective Notch signaling pathway. 


\section{References}

1. Mozaffarian D, et al. Heart Disease and Stroke Statistics--2015 Update: A Report From the American Heart Association. Circulation 2015;131(4):e29-322

2. Maseri A, Chierchia S, Davies, G. Pathophysiology of coronary occlusion in acute infarction. Circulation 1986;73:233-9.

3. French BA, Kramer CM. Mechanisms of postinfarct left ventricular remodeling. Drug Discov Today Dis Mech 2007;4:185-96.

4. Gaudron P, et al. Time course of cardiac structural, functional and electrical changes in asymptomatic patients after myocardial infarction: Their inter-relation and prognostic impact. J Am Coll Cardiol 2001;38:33-40.

5. da Costa Martins PA, et al. MicroRNA-199b targets the nuclear kinase Dyrk1a in an autoamplification loop promoting calcineurin/NFAT signalling. Nat Cell Biol 2010;12:1220-7.

6. Ren XP, et al. MicroRNA-320 is involved in the regulation of cardiac ischemia/reperfusion injury by targeting heat-shock protein 20. Circulation 2009;119:2357-66..

7. Hinkel R, et al. Inhibition of microRNA-92a protects against ischemia/reperfusion injury in a large-animal model. Circulation 2013;128:1066-75.

8. Meloni M, et al. Local inhibition of microRNA-24 improves reparative angiogenesis and left ventricle remodeling and function in mice with myocardial infarction. Mol Ther 2013;21: 1390-402.

9. Fiedler J, et al. MicroRNA-24 regulates vascularity after myocardial infarction. Circulation 2011; 124:720-30 (2011).

10. Hu S, et al. MicroRNA-210 as a novel therapy for treatment of ischemic heart disease. Circulation 2010;122(11 Suppl):S124-31.

11. Ha M, Kim VN. Regulation of microRNA biogenesis. Nat Rev Mol Cell Biol 2014;15:509-24.

12. Molkentin JD, et al. A calcineurin-dependent transcriptional pathway for cardiac hypertrophy. Cell 1998;93:215-28.

13. van Rooij E, et al. MCIP1 overexpression suppresses left ventricular remodeling and sustains cardiac function after myocardial infarction. Circ Res 2004;94:e18-26.

14. Krützfeldt J, et al. Silencing of microRNAs in vivo with 'antagomirs'. Nature 2005;438:685-9.

15. Dirkx E, et al. Nfat and miR-25 cooperate to reactivate the transcription factor Hand2 in heart failure. Nat Cell Biol 2013;15:1282-93.

16. Takagawa J, et al. Myocardial infarct size measurement in the mouse chronic infarction model: comparison of area- and length-based approaches. J Appl Physiol 2007;102:2104-11.

17. Pfeffer MA, Braunwald E. Ventricular remodeling after myocardial infarction. Experimental observations and clinical implications. Circulation 1990;81:1161-72.

18. Ørn S, et al. Effect of left ventricular scar size, location, and transmurality on left ventricular remodeling with healed myocardial infarction. Am J Cardiol 2007;99:1109-14.

19. Croquelois $\mathrm{A}$, et al. Control of the adaptive response of the heart to stress via the Notch1 receptor pathway. J Exp Med 2008;205:3173-85.

20. Kratsios $\mathrm{P}$, et al. Distinct roles for cell-autonomous notch signaling in cardiomyocytes of the embryonic and adult heart. Circ Res 2010;106:559-72.

21. Øie, E. et al. Activation of Notch signaling in cardiomyocytes during post-infarction remodeling. Scand Cardiovasc J 2010;44:359-66.

22. Boopathy AV, et al. Intramyocardial Delivery of Notch Ligand-Containing Hydrogels Improves Cardiac Function and Angiogenesis Following Infarction. Tissue Eng Part A. 2015;21(1718):2315-22.

23. Li,Y, Hiroi Y, Liao JK. Notch Signaling as an Important Mediator of Cardiac Repair and Regeneration After Myocardial Infarction. Trends Cardiovasc Med 2010;20:228-31.

24. Gude NA, et al. Activation of Notch-mediated protective signaling in the myocardium. Circ Res 2008;102:1025-35.

25. Nemir M, et al. The Notch pathway controls fibrotic and regenerative repair in the adult heart. Eur Heart J 2014;35:2174-85. 
26. Liu MX, et al. Epigenetic silencing of microRNA-199b-5p is associated with acquired chemoresistance via activation of JAG1-Notch1 signaling in ovarian cancer. Oncotarget 2014;5:944-58.

27. Garzia L, et al. MicroRNA-199b-5p impairs cancer stem cells through negative regulation of HES1 in medulloblastoma. PLoS One 2009;4(3):e4998.

28. Andolfo I, et al. The micro-RNA 199b-5p regulatory circuit involves Hes1, CD15, and epigenetic modifications in medulloblastoma. Neuro Oncol 2012;14:596-612.

29. Yang J, et al. Independent signals control expression of the calcineurin inhibitory proteins MCIP1 and MCIP2 in striated muscles. Circ Res 2000;87:E61-8.

30. Wilkins BJ, et al. Calcineurin/NFAT Coupling Participates in Pathological, but not Physiological, Cardiac Hypertrophy. Circ Res 2004;94:110-8.

31. Heineke J, Molkentin JD. Regulation of cardiac hypertrophy by intracellular signalling pathways. Nat. Rev. Mol. Cell Biol 2006;7:589-600.

32. Molkentin JD. Parsing good versus bad signaling pathways in the heart role of calcineurinnuclear factor of activated t-cells. Circ Res 2013;113:16-9.

33. Chen T, et al. MicroRNA-199b modulates vascular cell fate during ips cell differentiation by targeting the notch ligand jagged1 and enhancing VEGF signaling. Stem Cells 2015;33: 1405-18.

34. Andersson ER, Sandberg R, Lendahl U. Notch signaling: simplicity in design, versatility in function. Development 2011;138:3593-612.

35. Lai EC. Notch signaling: control of cell communication and cell fate. Development 2004;131: 965-73.

36. Blaumueller CM, Qi H, Zagouras P, Artavanis-Tsakonas S. Intracellular cleavage of Notch leads to a heterodimeric receptor on the plasma membrane. Cell 1997;90:281-91.

37. Lieber T, Kidd S, Young MW. Kuzbanian-mediated cleavage of Drosophila Notch. Genes Dev. 2002;16:209-21.

38. Nishimura M, et al. Structure, chromosomal locus, and promoter of mouse Hes2 gene, a homologue of Drosophila hairy and Enhancer of split. Genomics 1998;49:69-75.

39. Maier MM, Gessler M. Comparative analysis of the human and mouse Hey1 promoter: Hey genes are new Notch target genes. Biochem Biophys Res Commun 2000;275:652-60.

40. Kovall R. More complicated than it looks: assembly of Notch pathway transcription complexes. Oncogene 2008;27:5099-109.

41. Oda T, et al. Mutations in the human Jagged1 gene are responsible for Alagille syndrome. Nat Genet 1997;16:235-42.

42. Kamath BM, et al. NOTCH2 mutations in Alagille syndrome. J Med Genet 2012;49:138-44.

43. Garg V, et al. Mutations in NOTCH1 cause aortic valve disease. Nature 2005;437:270-4.

44. Donovan J, Kordylewska A, Jan YN, Utset MF. Tetralogy of fallot and other congenital heart defects in Hey2 mutant mice. Curr Biol 2002;12:1605-10.

45. Niessen K, Karsan A. Notch signaling in cardiac development. Circulation Research 2008;102: 1169-81.

46. Felician G, et al. Epigenetic modification at Notch responsive promoters blunts efficacy of inducing Notch pathway reactivation after myocardial infarction. Circ Res 2014;115:636-49. 


\section{Supplementary Table}

Table S5.1 Primer sequences used for quantitative real time PCR.

\begin{tabular}{|c|c|c|}
\hline Gene name & Gene identification & sequence \\
\hline Nppa & (NM_008725) & $\begin{array}{l}\text { 5'-TCTTCCTCGTCTTGGCCTTT3' } \\
\text { 5'-CCAGGTGGTCTAGCAGGTTC-3' }\end{array}$ \\
\hline Acta1 & (NM_009606) & $\begin{array}{l}\text { 5'-CCGGGAGAAGATGACTCAAA-3' } \\
\text { 5'-GTAGTACGGCC GGAAGCATA-3' }\end{array}$ \\
\hline Myh7 & (NM_080728) & $\begin{array}{l}\text { 5'-CGGACCTTGGAAGACCAGAT-3' } \\
\text { 5'-GACAGC TCCCCATTCTCTGT-3' }\end{array}$ \\
\hline Rcan1.4 & (NM_019466) & $\begin{array}{l}\text { 5'-GCTTGACTGAGAGAGCGAGTC-3' } \\
\text { 5'-CCACACAAGCAATCAGGGAGC-3' }\end{array}$ \\
\hline$L 7$ & (NM_011291) & $\begin{array}{l}\text { 5'-GAAGCTCATCTATGAGAAGGC-3' } \\
\text { 5'-AAGACGAAGGAGCTGCAGAAC-3' }\end{array}$ \\
\hline NOTCH1 & (NM_008714) & $\begin{array}{l}\text { 5'-TCAGGGGTGTCTTCCAGATCC-3' } \\
\text { 5'-CAGCATCCACATTGTTCACC-3' }\end{array}$ \\
\hline JAGGED1 & (NM_0138602) & $\begin{array}{l}\text { 5'-CCCAACTGTGAAATTGCTGA-3' } \\
\text { 5'-CAGCCTGGAGAACACTCACA-3' }\end{array}$ \\
\hline COL1A2 & (NM_007743.3) & $\begin{array}{l}\text { 5'-CCAGCGAAGAACTCATACAGC-3' } \\
\text { 5'- GGACACCCCTTCTACGTTGT-3' }\end{array}$ \\
\hline COL3A1 & (NM_009930.2) & $\begin{array}{l}\text { 5'-GCCCACAGCCTTCTACAC-3' } \\
\text { 5'-CCAGGGTCACCATTTCTC-3' }\end{array}$ \\
\hline FN1 & (NM_001276408.1) & $\begin{array}{l}\text { 5'-CGAGGTGACAGAGACCACAA-3' } \\
\text { 5'-CTGGAGTCAAGCCAGACACA-3' }\end{array}$ \\
\hline
\end{tabular}




\section{Chapter}

Comparison of different chemically modified inhibitors of miR-199b in vivo

Burcu Duygu, Rio Juni, Nicole Bitsch, Kees Burgraaf, Jan B.M. Wit, Leon J. de Windt, Paula A. da Costa Martins

In preparation 


\section{Abstract}

MicroRNAs (miRNAs) have recently received great attention for their regulatory roles in diverse cellular processes and for their contribution to several pathologies. Modulation of miRNAs in vivo provides beneficial therapeutic strategies for the treatment of many diseases as evidenced by various preclinical studies. However, specific issues regarding the in vivo use of microRNA inhibitors (antimiRs) such as organ-specific delivery, optimal dosing and formulate the best chemistry to obtain efficient microRNA inhibition remain to be addressed. Here, we aimed at comparing the in vivo efficacy of different chemistry-based antimiR oligonucleotides to inhibit cardiac expression of miR-199b, a highly promising therapeutic target for the treatment of pressure overload-induced cardiac dysfunction. For that purpose, four different designs of oligonucleotides to inhibit miR-199b were initially developed and systemically administered to wild-type mice on three consecutive days followed by organ harvesting seven days after the first injection in order to quantify the dosedependent changes in miR-199b expression levels. As a result, when comparing the efficiency of each inhibitor at the highest applied dose in this study, antagomir was able to completely decrease the level of miR-199b while LNA revealed 50 percent inhibition in the heart. On the other hand, the Zen-AMO and F/MOE chemistries failed to repress miR-199b in the heart at any given dosages in vivo. Further optimization was achieved by subjecting the antagomir and LNA nucleotides to additional chemical modifications. Interestingly, antagomir modification by replacing the cholesterol moiety from 3' to the 5'end of the molecule significantly improved the inhibitory capacity as reflected by a 75 percent downregulation of miR-199b expression already at a concentration of $5 \mathrm{mg} / \mathrm{kg} /$ day. When a LNA-RNA molecule was tested instead of LNA-DNA, similar results could be obtained but upon administration of $80 \mathrm{mg} / \mathrm{kg} / \mathrm{day}$. These findings show that, from all the chemistries tested by us, an antagomir carrying the cholesterol group at the 5'end was the most efficient inhibitor of miR-199b in the heart, in vivo. Moreover, our data also emphasize the importance of chemistry optimization and best dose range finding to achieve the greatest efficacy. 


\section{Introduction}

MicroRNAs (miRNAs) are a class of small, non-coding endogenous RNA molecules that regulate gene expression at the post-transcriptional level. ${ }^{1}$ These regulatory small RNAs are first transcribed from the intron regions in the genome by RNA polymerase II as a long primary transcript (pri-miRNA). Further processing in the nucleus by a protein complex containing the RNAse III enzyme Drosha generates a stem loop-shaped precursor molecule (pre-miRNA) that will be exported to the cytoplasm and processed into a transient miRNA duplex (18-22 nucleotide in length) by DICER, another RNAse III enzyme. ${ }^{1}$ Based on the thermodynamic stability of each individual strand of the duplex, one strand is the biologically functional miRNA while the other one is considered to be inactive (miRNA star, miRNA* or passenger strand). ${ }^{2}$ In general, miRNA* is believed to be degraded, while the mature strand is incorporated into a protein complex the so-called RNA-inducing silencing complex (RISC). ${ }^{3}$ Subsequently, a single stranded miRNA will be used as a guide molecule to direct negative posttranscriptional regulation by binding imperfectly to 3 ' untranslated region (UTR) of cognate mRNAs. ${ }^{4}$ This negative regulation can be achieved by inhibition of translation at different stages such as initiation, elongation and deadenylation and often leads to degradation of the target mRNA. ${ }^{4}$ miRNAs are estimated to regulate up to $30 \%$ of the protein-coding gene content of the human genome, mostly due to their individual capacity to bind and consequently regulate as many as 100 different mRNAs. ${ }^{5}$ Likewise, one mRNA can carry numerous binding sites for different miRNAs, many of them acting in similar biological processes, resulting in a complex but potent regulatory network.

In the past decade, the critical role of miRNAs in various cellular processes was recognized and the expression of numerous protein-coding genes involved in fundamental mechanisms such as cellular proliferation and differentiation, apoptosis, metabolism and immune responses have been reported to be under regulation of miRNAs. ${ }^{6-10}$ It is currently established that abnormalities in miRNA biology can contribute to diverse pathologies including cancer, neurodegenerative disorders, cardiovascular diseases and impairment of the immune system. ${ }^{11-15}$ Hence, miRNAs have emerged as potential therapeutic targets in many diseases.

The general aim of miRNA-based therapeutics is to restore miRNA expression levels either by increasing the downregulated miRNAs or inhibiting the upregulated miRNAs in a specific disease stage/condition. In this regard, there has been a great focus in the generation of antisense oligonucleotides harbouring the full or partial complementary reverse sequence of a mature miRNA (antimiRs) to inhibit endogenous expression levels of a specific miRNA. 
Very often, 2'-O-Methyl RNA (2'OMe) bases are used in antimiRs to achieve high binding affinity for the target miRNA and protect the RNA molecule from nuclease cleavage. ${ }^{16,17}$ Furthermore, to increase oligonucleotide stability in plasma $^{18}$ phosphorothioate groups (PS), which exchanges a sulfur atom for a non-bridging oxygen in the phosphate backbone, were also incorporated into antimiRs to avoid oligonucleotide cleavage at the phosphate bonds. While PS modifications increase the stability against nucleases, they also reduce the binding affinity $(\mathrm{Tm})$ of antimiRs by $0.25^{\circ} \mathrm{C}$ per modified linkage. ${ }^{19}$ Another strategy is to use 2'OMe-modified nucleic acids linked with PS bonds at both ends of the molecule in order to protect against exonuclease activity together with a cholesterol group attached to the 3' end of the molecule to facilitate in vivo delivery. ${ }^{20}$ These specifically designed oligonucleotides were first described as 'antagomirs'. ${ }^{20}$ Intravenous administration of naked antagomirs has revealed sufficient uptake by target tissues at relatively high doses $(80 \mathrm{mg} / \mathrm{kg}$ per body weight). ${ }^{21}$ Synthetic 2' modifications such as 2'-O-Methoxyethyl (2'MOE) and 2' Fluoro (2'F) were shown to further enhance binding affinity and nuclease resistance of antimiRs. ${ }^{22,23}$ Another modification that confers the oligonucleotide high stability against nuclease attack while providing great target affinity (average Tm of $2.4 \mathrm{C}$ per modification) ${ }^{24}$ is to connect $2^{\prime} \mathrm{O}$ to the $4^{\prime} \mathrm{C}$ via a methylene bridge locking the molecule into a 3' endo sugar conformation and generate a locked nucleic acid (LNA) ${ }^{25}$ It has been reported that LNA-RNA mixmers, rather than LNA-DNA mixmers, show increased silencing potency in cell culture. ${ }^{26,27}$ LNA-DNA mixmers consists of a molecule where the middle 10 DNA nucleotides are flanked by 3 LNA modified nucleotides on each site, while the LNA-RNA combination harbors 11 2'OME capped RNA nucleotides with 5 LNA nucleotides distributed over the total sequence. Another type of modification was obtained by linking a novel non-nucleotide N,N-diethyl-4(4-nitronaphthalen-1-ylazo)-phenylamine group, so-called ZEN, at or near each end of a phosphodiester 2'OMe RNA oligonucleotide. ${ }^{28}$ This new design has been shown to have high potency to inhibit miRNA in vitro at low concentrations with high specificity and low toxicity in cell culture. ${ }^{28}$

As various pre-clinical studies are ongoing to assess their therapeutic potential of miRNA inhibition in cardiovascular disease models, a consideration of optimal chemistry for the cardiovascular system is still warranted. The first clinical trial (phase I/II) using LNA-modified DNA phosphorothioate antisense oligonucleotides against miR-122 to treat chronic hepatitis has yielded successful outcomes. ${ }^{29}$ miR-122, the most abundant miRNA in the liver, binds in the hepatitis $\mathrm{C}$ virus (HCV) genome to provide stability and viral reproduction. ${ }^{30}$ Patients who received miR-122 inhibitors revealed a dose-dependent reduction in HCV levels without any major adverse effects and without any mutation on the miR-122 binding side in the HCV genome. ${ }^{29}$ Despite all these promising 
achievements, issues such as tissue-specific delivery, inhibitory potency of different chemistries, stability, kidney clearance and cellular uptake remain challenging and need to be addressed.

Here, we aimed at comparing the in vivo efficacy of six different chemistry-based antimiRs oligonucleotides to inhibit miR-199b, a promising therapeutic target for the treatment of pressure overload-induced cardiac dysfunction. ${ }^{31}$

\section{Materials and methods}

\section{Animals}

Adult (older than 8 weeks), B6129SF1/J female mice were used. All protocols were reviewed and approved by the Animal Care and Use Committee of the University of Maastricht and performed according to the rules formulated by Dutch law on care and use of experimental animals.

\section{AntimiR administration}

We used the following chemically-modified oligonucleotides to specifically inhibit miRNA-199b: antagomir-199b with a cholesterol group either at the 3' or 5' end of the molecule (ant-199b-3' and ant-199b-5'), synthesized by Eurogentec, and LNA-DNA-199b, LNA-RNA-199b 2'F/MOE-199b and Zen-AMO-199b, synthesized by Integrated DNA technologies (IDT). Animals received either vehicle (PBS, $0.1 \mathrm{ml}$ ) or the different oligonucleotides (in $0.1 \mathrm{ml}$ PBS) by intraperitoneal injections on three consecutive days at a dose ranging from 0.05 , $0.5,1,5,10,20,40$ and $80 \mathrm{mg} \mathrm{kg}$ body weight day ${ }^{-1}$. Animals were sacrificed and tissue was harvested seven days after starting the treatment.

\section{RNA isolation and real-time PCR}

Total RNA was isolated using TRIzol reagent (Invitrogen) according to the manufacturer's instructions. $1 \mu \mathrm{g}$ of total RNA $(1 \mu \mathrm{g})$ was applied to either miRbased or mRNA-based reverse transcription. Real-time PCR was performed on a BioRad iCycler (Biorad) using SYBR Green. Transcript quantities were compared using the relative $\mathrm{Ct}$ method, where the amount of target normalized to the amount of endogenous control (L7) and relative to the control sample is given by $2^{-\Delta \Delta C t}$. Primer sequences for all mRNAs quantified are listed in Table 6.1. For microRNA real-time PCR, miRNAs were isolated with TRIzol reagent (Invitrogen) and cDNA was generated with the miScript Reverse Transcription Kit (Qiagen). For real-time PCR detection of microRNAs, an 
Exiqon microRNA primer (Exiqon) and the ExiLENT SYBR green master mix (Exiqon) were used.

Table 6.1 Primers sequences used to detect mRNAs.

\begin{tabular}{|l|l|l|}
\hline Gene $(\mathrm{mRNA})$ & Forward sequence & Reverse sequence \\
\hline notch1 & 5'-TCAGGGTGTCTTCCAGATCC & 5'-CAGCATCCACATTGTTCACC \\
\hline jag1 & 5'-CCCAACTGTGAAATTGCTGA & 5'-CAGCCTGGAGAACACTCACA \\
\hline dyrk1a & 5'-TGACAGAGTGGAGCAAGAATGGGT & 5'-TTTGTTCATGAGCTCAAGCAGCCG \\
\hline gsk3b & 5'-CAGTGGTGTGGATCAGTTGG & 5'-ACCTTTGTCCAAGGATGTGC \\
\hline gbcr5a & 5'-GAGTTTCGACAGCTCCCAAG & 5'-AGTGTGTCCCCCATCTCAAG \\
\hline myl6b & 5'-CTGCTGCCAAGTCTACACCA & 5'-AATTCCTCCAGCTGGTCCTT \\
\hline cited2 & 5'-CATCGGCTGTCCCTCTATGT & 5'-CATATGGTCTGCCATTTCCA \\
\hline
\end{tabular}

\section{Statistical analysis}

The results are displayed as mean \pm standard error of the mean (s.e.m). Statistical analyses were performed using Prism software (GraphPad Software), and consisted of Student's t-test when comparing two experimental groups. Differences were considered significant when $\mathrm{P}<0.05$.

\section{Results}

Design of four different chemically modified oligonucleotides to inhibit miR-199b expression

To compare the efficacy of different chemistry-based oligonucleotides to inhibit microRNAs (miRNAs), we initially designed four different antimiR oligonucleotides to inhibit miR-199b in vivo (Figure 6.1a and 6.1b). These antisense oligonucleotides comprehend different chemical modifications affecting different compound properties such as stability, cellular uptake, specificity and delivery. In this regard, antagomir harbors a 2'-O-methyl (2'-OMe) backbone linked by phosphodiester and phosphorothioates bonds and is conjugated to a cholesterol group in order to increase cellular uptake. ${ }^{20}$ The first antagomir contained the cholesterol group at the 3' end of the RNA molecule. 2'F-MOE is a mix of 2' fluoro (2' $\mathrm{F})$ and 2'-O-2-methoxyethyl- modified oligonucleotides bound via phosphodiester bonds. ${ }^{22,23}$ We also tested a ZEN ((N,Ndiethyl-4-(4-nitronaphthalen-1-ylazo)-phenylamine)-modified 2'-OMe conjugated to a cholesterol group at the 3' end of the RNA molecule and the ZEN modifier linked via phosphate linkages to the ribose backbone of the oligonucleotide. ${ }^{28}$ Lastly, a locked nucleic acid (LNA) combined with DNA and a full 
phosphorothioate backbone ${ }^{25}$ designed to target bases 2 to 17 of the 5 ' region of the mature miR-199b sequence was compared to a combination of LNA and OMe modified RNA nucleotides, ${ }^{26,27}$ designed to target the same region, regarding their potency in inhibiting miR-199b.

a

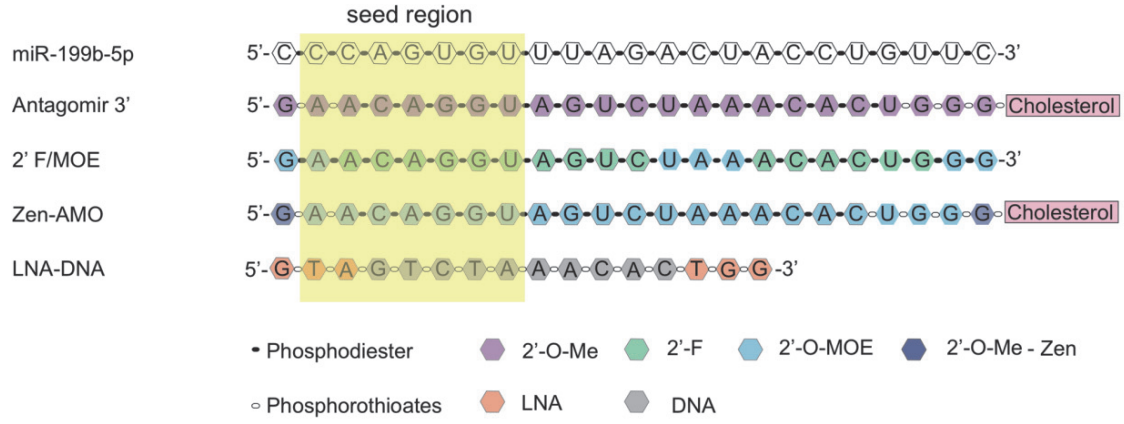

b
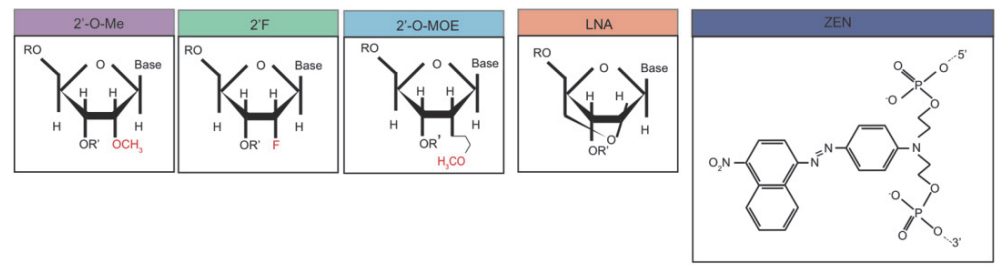

C

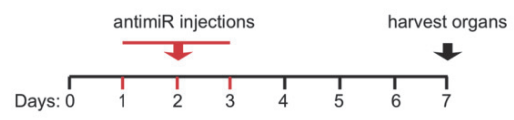

Figure 6.1 Schematic representation of chemically modified antimiR-199b oligonucleotides and experimental design. (a) The mature sequence of miR-199b indicated on the top panel and seed sequence highlighted. Each box with different color represents one oligonucleotide carrying a specific chemical modification. (b) Each color corresponds to a specific chemical modification. (c) Schematic experimental design. Animals were administered either vehicle (control) or different antimiRs at ranging doses for 3 consecutive days via intraperitoneal injections. 7 days after the first injection the organs were harvested for further molecular analysis.

\section{Efficiency of different chemically modified oligonucleotides in inhibiting miR-199b expression in vivo}

In order to compare the efficiency of the different oligonucleotides in inhibiting miR-199b expression in vivo, we treated animals with different doses of each antimiR, ranging from 0.05 to $80 \mathrm{mg} / \mathrm{kg}$ body weight (BW)/day, delivered on 
three consecutive days by intraperitoneal injections (Figure 6.1c). As control, we included a group of animals, which received vehicle (saline) in a similar delivery scheme. Seven days after the first injection, animals were sacrificed and several organs were harvested for further molecular analysis (Figure 6.1c). While a dose-dependent decrease in the levels of miR-199b expression in myocardial tissue was observed after treatment with antagomir-199b and LNA-199b, F/MOE-199b and Zen-AMO-199b did not inhibit miR-199b in the heart within the dose range applied, assessed one week after treatment (Figure 6.2a-d). Antagomir-199b showed effective inhibition already at a relatively low dose $\left(\mathrm{IC}_{50}=8.1 \mathrm{mg} / \mathrm{kg} /\right.$ day $)$ and completely reduced miR-199b expression at a dose of $80 \mathrm{mg} / \mathrm{kg} /$ day (Figure 6.2a) LNA-199b, on the other hand, displayed an IC 50 of $16.1 \mathrm{mg} / \mathrm{kg} /$ day and achieved maximum inhibition at the dose of $80 \mathrm{mg} / \mathrm{kg} / \mathrm{day}$, which is the highest treatment dose in our study (Figure 6.2b).

a
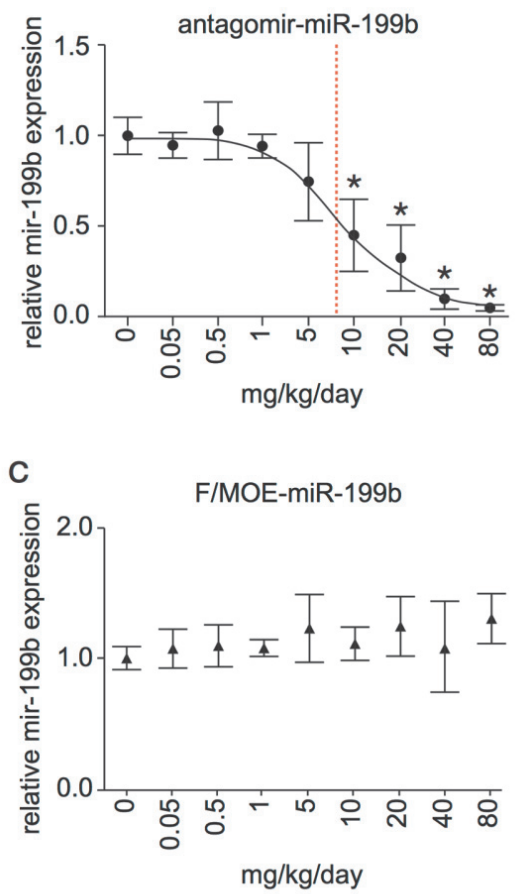

b
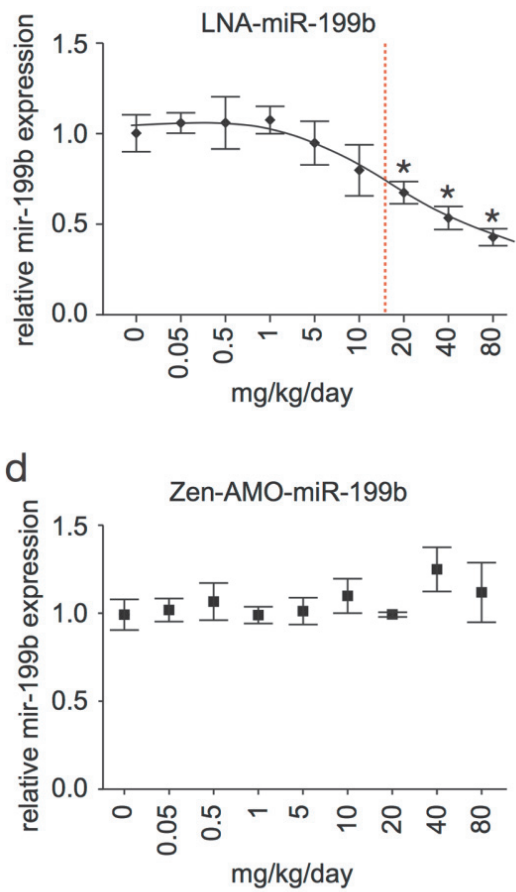

Figure 6.2 Dose-dependent inhibition of miR-199b in myocardial tissue after antagomir-199b or LNA-199b treatment. Dose response analysis of miR-199b repression in the heart 7 days after (a) antagomir-199b, (b) LNA-199b, (c) F/MOE-199b and (d) Zen-AMO$199 \mathrm{~b}$ administration. $I_{50}$ is represented by the dashed red line. $\mathrm{n}: 5,{ }^{*} P<0.05$ (mean \pm s.e.m.). 
Since Zen-AMO-199b and F/MOE-199b were unable to inhibit miR-199b levels in the heart, we questioned whether these antimiR chemistries had a general defect in entering the myocardium and analyzed whether they were able to silence miR-199b in other organs. To investigate this, we first determined the expression profile of miR-199b in organs such as liver, kidney and lung. Among these, the lung displayed the highest miR-199b expression levels, followed by the heart, kidney and liver (Figure 6.3a). Secondly, we compared the expression levels of miR-199b in myocardium, kidney, liver and lung after treatment of animals with each of the different antimiRs at the highest 3 doses $(20,40$, $80 \mathrm{mg} / \mathrm{kg} /$ day) (Figure 6.3b-e). Both antagomir-199b and LNA-199b efficiently downregulated miR-199b levels and their inhibitory effect in the lung, kidney and liver was achieved at a lower dose compared to the heart (Figure 6.3c-e). At a dose of $20 \mathrm{mg} / \mathrm{kg} /$ day, both antimiRs demonstrated approximately $98 \%$ inhibition of miR-199b (Figure 6.3c-e). In contrast, Zen-AMO-199b and F/MOE-199b failed to reduce miR-199b expression levels in all of the tested organs tested at the given doses (Figure 6.3b-e). These findings indicate that Zen-AMO and F/MOE oligonucleotides were unable to accumulate in the myocardium and achieve inhibition of their target miRNA, even at very high dosages tested. This renders the Zen-AMO and F/MOE chemistries unsuitable to achieve cardiac miRNA inhibition in vivo.
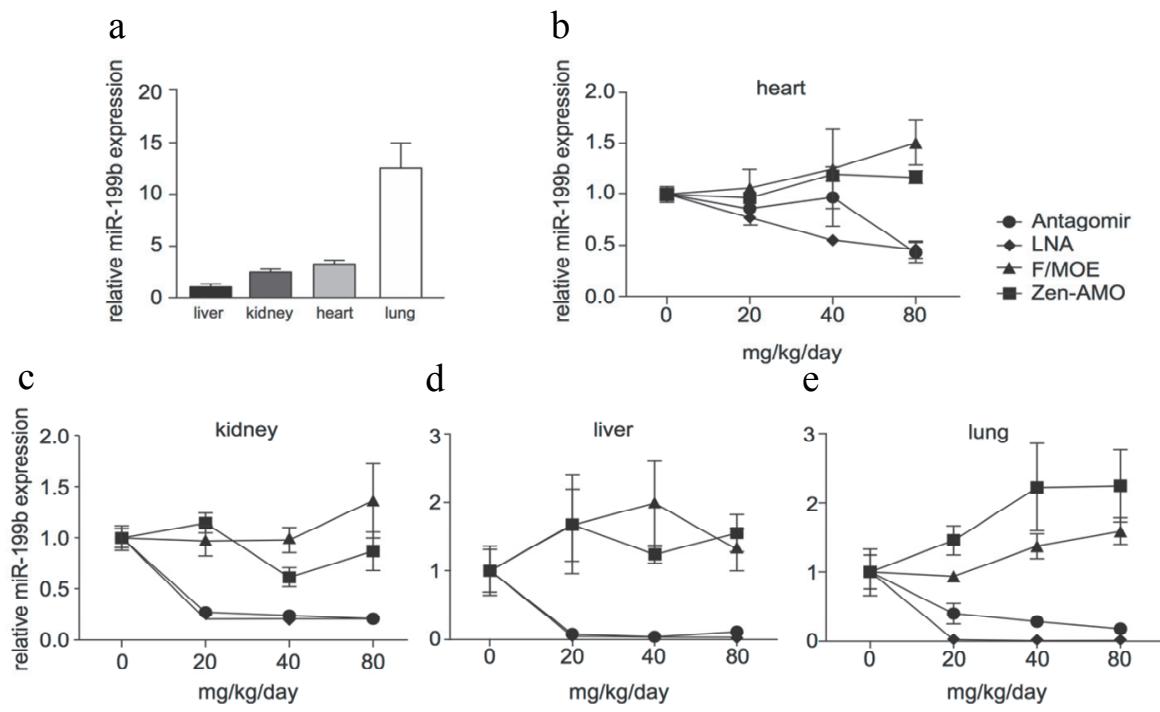

Figure 6.3 Antagomir-199b and LNA-199b treatment resulted in efficient silencing of miR-199b in the kidney, lung and liver compared to heart. (a) Real-time PCR analysis of miR-199b expression in liver, kidney, heart and lung. Rnu6-2 was used as a reference gene for normalization. Expression levels in other organs are calculated relative to liver. Dose response expression levels of miR-199b after treatment with antagomir-199b, LNA-199b, F/MOE-199b and Zen-AMO-199b in (b) the heart, (c) kidney, (d) liver and (e) lung. $n: 3-4,{ }^{*} P<0.05$ (mean \pm s.e.m.). 


\section{Chemistry optimization and maximal efficient doses finding}

As our results indicated antagomir and LNA as the most suitable chemical modifications to increase oligonucleotide efficiency in inhibiting miR-199b in vivo, we next assessed whether further chemical or sequence modifications would further increase the potency of antagomir and LNA. For this purpose, we modified the antagomir so that the cholesterol group was added to the 5' instead of the 3' end (Figure 6.4). Due to the fact that the current and well-established solid support phosphoramidite-based synthesis of the oligonucleotides is performed in a 3' to 5' fashion, attaching the cholesterol unit only at the end stage of the synthesis process facilitates purification of the resulting oligonucleotides and increases purity, as reflected by $95.6 \%$ purity of the 5 ' in contrast to $85.6 \%$ of the 3' compound. Regarding the LNA oligonucleotides, we changed the sequence to RNA instead of DNA since prior studies have shown that this can increase their inhibitory potency in cell culture ${ }^{26,27}$ (Figure 6.4).

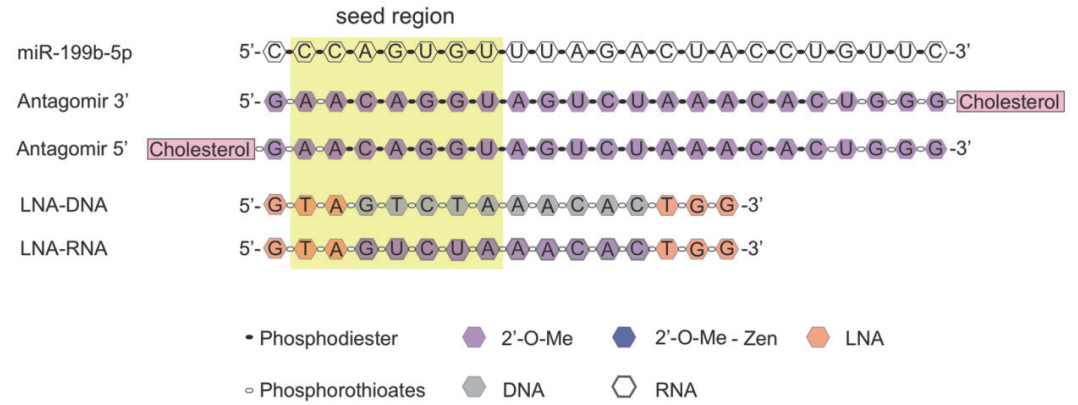

Figure 6.4 Schematic representation of chemically modified antimiR-199b oligonucleotides. The mature sequence of miR-199b indicated on the top panel and seed sequence highlighted. Each box with different color represents one oligonucleotide carrying a specific chemical modification. Each color corresponds to a specific chemical modification.

Furthermore, we also increased the doses range by including dosages of 160 and $240 \mathrm{mg} / \mathrm{kg} /$ day to investigate whether for any of the chemistries a maximal affect can be achieved at higher concentrations than $80 \mathrm{mg} / \mathrm{kg} / \mathrm{day}$ and to test whether rodents can tolerate these high concentrations of the oligonucleotides. The results revealed that adding the cholesterol group to the 5' end substantially increased the potency of the antagomir to inhibit miR-199b expression, as reflected by $\mathrm{IC}_{50}=1.1 \mathrm{mg} / \mathrm{kg} /$ day and a $75 \%$ inhibition at $5 \mathrm{mg} / \mathrm{kg} / \mathrm{day}$ (Figure 6.5a, b). In turn, LNA-RNA was more potent than LNA-DNA by showing a $60 \%$ inhibition of $\mathrm{miR}-199 \mathrm{~b}$ expression at $20 \mathrm{mg} / \mathrm{kg} /$ day, despite a similar $\mathrm{IC}_{50}$ of $15 \mathrm{mg} / \mathrm{kg} /$ day (Figure 6.5c). While for both antagomirs, $100 \%$ inhibition was 
reached at a concentration of $80 \mathrm{mg} / \mathrm{kg} / \mathrm{day}$, we did observe more than $75 \%$ inhibition with the LNA-RNA with the high concentrations used. As expected, with concentrations such as 160 and $240 \mathrm{mg} / \mathrm{Kg} / \mathrm{day}$ the animals had difficulties tolerating them. For all the chemistries tested at 160 and $240 \mathrm{mg} / \mathrm{kg} / \mathrm{day}$ concentrations, we observed that, in general, the animals showed severe signs of discomfort such as cachexia, increased respiratory rate and lack of physical activity, with increased mortality regardless of the chemistry. This data indicates that in general, antimiR concentrations above $80 \mathrm{mg} / \mathrm{Kg} /$ day induce severe in vivo toxicity.

a

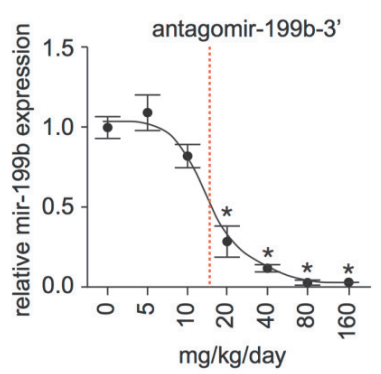

b

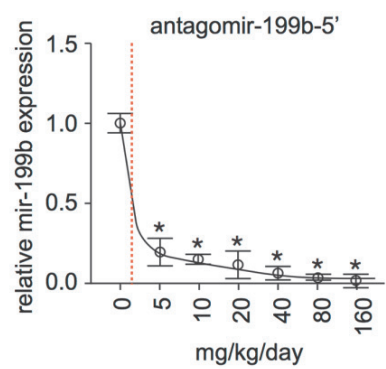

C

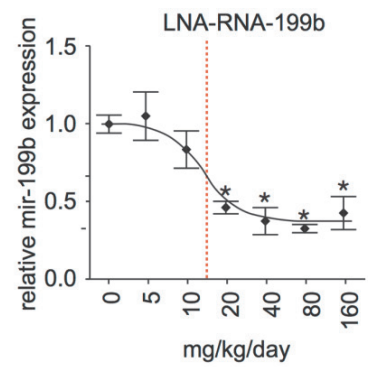

Figure 6.5 Dose-dependent inhibition of miR-199b in myocardial tissue after antagomir-199b or LNA-RNA-199b treatment. Dose response analysis of miR-199b repression in the heart 7 days after (a) antagomir-199b-3', (b) antagomir-199b-5' and (c) LNA-RNA-199b. $\mathrm{IC}_{50}$ is represented by the dashed red line. n:5, ${ }^{*} P<0.05$ (mean \pm s.e.m.).

\section{De-repression of various miR-199b targets}

Next, we analyzed how effective the most potent chemistries are with respect to de-repression of miR-199b target genes. Since the function of a miRNA is determined by its target mRNAs, the pharmacological effect of an antimiR directly relates to re-activation of target genes. To this end, we determined the transcript levels of 5 validated miR-199b target genes (Figure 6.6a, b). Since the highest tolerable dose was $80 \mathrm{mg} / \mathrm{kg} /$ day for both antagomir-199b (5') and LNA-RNA, we assessed the expression of target genes at 20,40 and 80 $\mathrm{mg} / \mathrm{kg} /$ day. Expectedly, transcriptional levels of validated target genes Jagged 1 (Jag1) and Dual-specificity tyrosine phosphorylation-regulated kinase 1a (Dyrk1a) were increased upon inhibition of miR-199b and this was observed for each of the chemistries. Predicted targets such as Notch1 and G-protein coupled receptor $5 a(G p c R 5 a)$ revealed a mild increase in mRNA expression while others such as Glycogen synthase kinase 3 beta (Gsk3b) and Myosin light chain $6 \mathrm{~b}(M y / 6 b)$ remained unchanged after treatment, regardless of the chemistry of the ASO (Figure 6a, b). These data indicate that miR-199b binding 
to the 3'UTR of Gsk3b and Myl6b may result in translational repression or deadenylation of the mRNA, only affecting protein levels, with no changes at the transcript level. Nonetheless, these data indicate that both antagomir-5' and LNA-RNA resulted in de-repression of validated miR-199b target genes, indicating that the antisense oligonucleotides indeed resulted in target engagement.
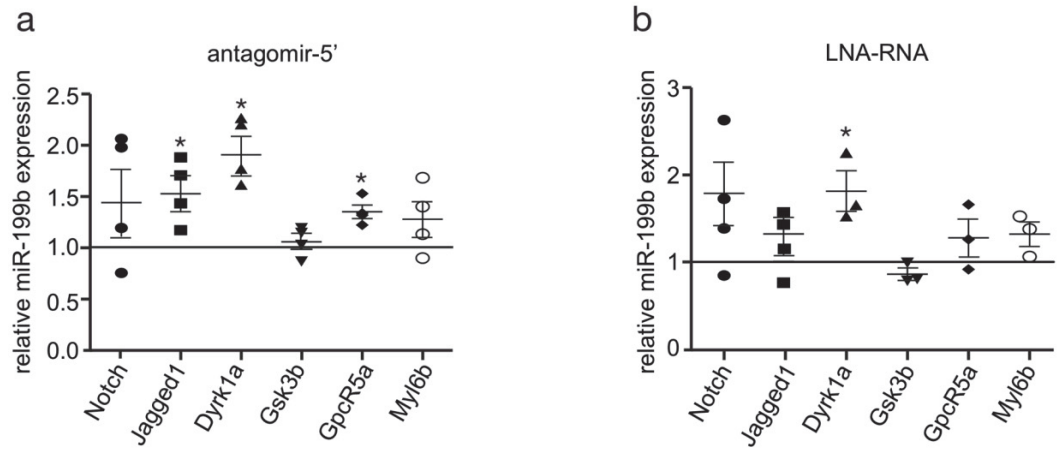

Figure 6.6 Altered expression levels of miR-199b predicted or validated target genes in the heart after antagomir-199b or LNA-199b treatment. Real-time PCR analysis of notch1, jagged1, Dyrk1a, Gsk3b, GpcR5a and Myl6b in the heart after (a) antagomir$199 \mathrm{~b}$ or (b) LNA-199b treatment. Expression levels are calculated relative to the levels after vehicle treatment $\mathrm{n}: 3-4,{ }^{\star} P<0.05$ (mean \pm s.e.m.).

\section{Discussion}

In this study, we directly compared the potency of four different antimiRs to inhibit miR-199b in vivo and demonstrated that different chemical modifications lead to variations in oligonucleotide inhibitory capacity. LNA and antagomir were the most potent inhibitors among the 4 different antimiRs tested in the different organs but the degree of inhibition in different organs was highly divergent. While almost complete knockdown of miR-199b was achieved in lung, liver and kidney, antimiR efficacy was much lower in the heart suggesting preferential accumulation of antimiRs in kidney and liver. ${ }^{32}$ These findings point to the importance of organ-specific delivery of antimiRs in order to avoid undesired side effects outside of the organ/cell of interest.

Unlike previous reports showing higher potency of LNA compared to antagomirs in inhibiting miR-122 in the liver, we have not observed pronounced differences between LNA-DNA and antagomir in their efficiency to antagonize miR-199b at 
the given dosages, in any of the examined organs. ${ }^{33}$ In addition, administration of lower LNA-DNA doses did not repress miR-199b expression levels in the heart in contrast to earlier findings for other miRNAs. ${ }^{34-36}$ These discrepancies suggest that the activity of antimiRs may be dependent on some characteristics of individual microRNAs such as mature sequence, availability and turnover rate.

A report by Thum et al., demonstrated the variation in potency of different antimiRs to inhibit miR-21 in the heart. ${ }^{37}$ By comparing the efficacy of three antimiRs; cholesterol-conjugated antimiR, F/MOE and LNA, either 2 or 19 days after systemic administration, they could conclude that cholesterol-conjugated antimiR and F/MOE have stronger long-term inhibitory effects compared to LNADNA. While the long-term inefficiency of LNA may be related to its small size (8 nucleotide in length whereas other antimiRs are 22 nucleotide-long), these findings are in agreement with ours in that a miRNA may display different inhibition patterns when targeted by different antimiR oligonucleotides.

Although LNA and antagomir are widely applied antimiRs in most preclinical studies, in the present study, two other relatively new antimiR modifications namely F/MOE and Zen-AMO were also evaluated for their potency in vivo. ZenAMO has been generated by insertion of a novel non-nucleotide compound named 'Zen' via phosphorothioate (PS) linkages to the 2'OMe RNA backbone. ${ }^{28}$ This modification was shown to increase binding affinity and prevent exonuclease degradation in vitro. ${ }^{28}$ On the other hand, PS modifications of ZenAMOs lowers binding affinity and subsequently potency unless short antisense oligonucleotides (such as 12-14mers) are used that can penetrate tissues and enter cells with higher efficiency than long antimiRs. ${ }^{38}$ This may be the explanation for the ineffectiveness, in this study, of Zen-AMO to inhibit miR$199 \mathrm{~b}$, as we employed the full-length (23 nucleotide) oligonucleotide administered without any delivery vehicle, which could have increased the potency. Although this problem was overcome for the antagomirs after conjugation with cholesterol, it seems that even after cholesterol conjugation, Zen-AMO delivery and efficiency in the heart is still impaired. Therefore, further studies are required to explain possible causes driving the impotency of the ZenAMO used in this study. Up to date, the efficacy of Zen-AMO was analyzed only in cell cultures ${ }^{39}$ and so the present study is the first to assess the potency of this antimiR in vivo.

In contrast to Zen-AMO, in vivo efficacy of F/MOE has been verified in several preclinical disease models. Swarbrick et al. reported achieving sufficient downregulation of miR-380-5p in tumors from an orthotopic mouse model of neuroblastoma after intraperitoneal injection of a specific F/MOE, twice weekly for three weeks, and the treatment resulting in reduced tumor size and weight. ${ }^{40}$ 
Later, Rayner et al. demonstrated that F/MOE-induced inhibition of miR-33a/b in a low-density lipoprotein (LDL) receptor-deficient mouse with established atherosclerotic plaques resulted in increased plasma high-density lipoprotein (HDL) levels and regression of atherosclerosis providing a promising treatment strategy. ${ }^{41}$ In fact, this group was the first to show the potency of F/MOE to specifically inhibit miR-33a/b in the liver of non-human primates. ${ }^{10}$ It is important to note that these therapeutic effects were obtained at low doses of F/MOE (5 to $25 \mathrm{mg} / \mathrm{kg} / \mathrm{day})$. However, and since the position of 2'F and 2'MOE modifications in the final oligonucleotide can affect potency, due to lack of detailed information regarding the chemical modifications used in the study by Rayner et al, we cannot really compare their study with ours. ${ }^{42}$ The fact that we did not observe an effect after administration of either F/MOE or Zen-AMO cannot be attributed to their mechanism of action. F/MOE sequesters target miRNA in a heteroduplex in a similar manner as LNA ${ }^{42,43}$ and Zen-AMO most likely leads to degradation of the target miRNA as it shares a similar chemical modification (except for the Zen modifier) as an antagomir. ${ }^{20,44}$ In this study, F/MOE and Zen-AMO did not efficiently inhibit miR-199b in vivo. Although there is one report showing the efficiency of F/MOE (10 and $80 \mathrm{mg} / \mathrm{kg} /$ day) to inhibit a miR-21 in the heart, ${ }^{37}$ further studies to explain the pharmacokinetic properties of F/MOE and the discrepancies observed with our study are still necessary.

Although our results indicate antagomir and LNA as the most potent oligonucleotide chemical modifications to inhibit miR-199b in vivo, we were able to further increase their inhibitory efficiency by changing the position of the cholesterol group on the antagomir, and by changing the DNA component of the LNA into RNA. The reason for the apparent 4 to 5-fold increase in silencing miR$199 \mathrm{~b}$ by merely changing the local of the cholesterol unit is surprising to us. As we did not expect that moving the cholesterol unit from the 3' to the 5' position would increase the potency, the increased performance should be sought for in the ability of the resulting oligonucleotide to reach the site of action. Since the pharmacokinetic properties are known to be strongly depended on the ability of the oligonucleotide to bind to and release from plasma protein, ${ }^{45}$ this might result in the pronounced effect.

The efficiency of antimiR treatment on miRNA inhibition can be determined by multiple approaches. In this study, the primary readout was the direct change in miRNA expression levels determined by real-time quantitative PCR (QPCR). When directly assessing miRNA expression levels, one must consider that in some instances technical burdens may lead to data misinterpretation as excessive amounts of antimiR can interfere with primer annealing or extension during real-time $\mathrm{PCR}$ or the antimiR may be released from subcellular compartments during RNA isolation, which in turn, may result in binding of 
antimiR to the target miRNA during sample preparation. ${ }^{46}$ Taking these aspects into consideration, we further confirmed the potency of antagomir and LNA to repress $\mathrm{miR}-199 \mathrm{~b}$, at a dose of $80 \mathrm{mg} / \mathrm{kg} /$ day, by assessing de-repression of target mRNAs by QPCR. High-throughput data supports increased miRNA levels result in decreased expression levels of many target mRNAs, with a positive correlation existing between mRNA and protein levels after miRNA repression. $^{47-51}$ In summary, there are several different antimiR designs. The choice of antimiR design is dependent on the experimental goal and in this report, we pointed out the importance of organ specific delivery as well as the characteristics of the miRNA of interest to achieve optimal knockdown after antimiR administration. Moreover, it is crucial to comprehensively assess antimiR efficacy by combining analysis of miRNA expression levels with detection of mRNA or protein levels of target genes and therapeutic effects in relevant animal models. Here, we did not characterize cardiac function since we do not expect any adverse effects related to miR-199b inhibition as previously shown by us. ${ }^{31}$ While issues such as target specificity, toxicity and pharmacokinetics should receive special attention when using antimiRs in vivo, we did not address them in the present study.

In conclusion, out of four antimiR tested here, LNA and antagomir are the most potent inhibitors of miR-199b in heart, liver, lung and kidney whereas administration of F/MOE and Zen-AMO did not repress miR-199b levels in those organs. The reason of F/MOE and Zen-AMO inefficiency remains to be explained in future studies. For the antagomir, placing the cholesterol on the 5'end resulted in a significant impact in inhibitory efficiency, suggesting increased potency or improved delivery, the latter being most likely. 


\section{References}

1. Ha M, Kim VN. Regulation of microRNA biogenesis. Nat Rev Mol Cell Biol 2014;15(8):509-24.

2. O'Toole AS, Miller S, Haines N, Zink MC, Serra MJ. Comprehensive thermodynamic analysis of 3 ' double-nucleotide overhangs neighboring Watson-Crick terminal base pairs. Nucleic Acids Res 2006;34(11):3338-44.

3. Winter J, Jung S, Keller S, Gregory RI, Diederichs S. Many roads to maturity: microRNA biogenesis pathways and their regulation. Nat Cell Biol 2009;11(3):228-34.

4. Filipowicz W, Bhattacharyya SN, Sonenberg N. Mechanisms of post-transcriptional regulation by microRNAs: are the answers in sight? Nat Rev Genet 2008;9(2):102-14.

5. Lewis BP, Burge CB, Bartel DP. Conserved seed pairing, often flanked by adenosines, indicates that thousands of human genes are microRNA targets. Cell 2005;120(1):15-20.

6. Lenkala D, LaCroix B, Gamazon ER, Geeleher P, Im HK, Huang RS. The impact of microRNA expression on cellular proliferation. Hum Genet 2014;133(7):931-8.

7. Zhao $\mathrm{H}$, Wen $\mathrm{G}$, Huang $\mathrm{Y}, \mathrm{Yu} \mathrm{X}$, Chen $\mathrm{Q}$, Afzal TA, et al. MicroRNA-22 regulates smooth muscle cell differentiation from stem cells by targeting methyl CpG-binding protein 2. Arterioscler Thromb Vasc Biol 2015;35(4):918-29.

8. Jovanovic M, Hengartner MO. miRNAs and apoptosis: RNAs to die for. Oncogene 2006; 25(46):6176-87.

9. Dumortier O, Hinault C, Van Obberghen E. MicroRNAs and metabolism crosstalk in energy homeostasis. Cell Metab 2013;18(3):312-24.

10. Schickel R, Boyerinas B, Park SM, Peter ME. MicroRNAs: key players in the immune system, differentiation, tumorigenesis and cell death. Oncogene 2008;27(45):5959-74.

11. Lu M, Zhang Q, Deng M, Miao J, Guo Y, Gao W, et al. An analysis of human microRNA and disease associations. PLoS One 2008;3(10):e3420.

12. Lin S, Gregory RI MicroRNA biogenesis pathways in cancer. Nat Rev Cancer 2015;15(6): 321-33.

13. Abe M, Bonini NM. MicroRNAs and neurodegeneration: role and impact. Trends Cell Biol 2013; 23(1):30-6.

14. Quiat $D$, Olson EN. MicroRNAs in cardiovascular disease: from pathogenesis to prevention and treatment. J Clin Invest 2013;123(1):11-8.

15. O'Connell RM, Rao DS, Chaudhuri AA, Baltimore D. Physiological and pathological roles for microRNAs in the immune system. Nat Rev Immunol 2010;10(2):111-22.

16. Meister $G$, Landthaler M, Dorsett $Y$, Tuschl T. Sequence-specific inhibition of microRNA- and siRNA-induced RNA silencing. RNA 2004;10(3):544-50.

17. Hutvagner G, Simard MJ, Mello CC, Zamore PD. Sequence-specific inhibition of small RNA function. PLoS Biol 2004;2(4):E98.

18. Eder PS, DeVine RJ, Dagle JM, Walder JA. Substrate specificity and kinetics of degradation of antisense oligonucleotides by a $3^{\prime}$ exonuclease in plasma. Antisense Res Dev 1991;1(2): 141-51.

19. Lennox KA, Sabel JL, Johnson MJ, Moreira BG, Fletcher CA, Rose SD, et al. Characterization of modified antisense oligonucleotides in Xenopus laevis embryos. Oligonucleotides 2006; 16(1):26-42.

20. Krutzfeldt J, Rajewsky N, Braich R, Rajeev KG, Tuschl T, Manoharan M, et al. Silencing of microRNAs in vivo with 'antagomirs'. Nature 2005;438(7068):685-9.

21. Krutzfeldt J, Kuwajima S, Braich R, Rajeev KG, Pena J, Tuschl T, et al. Specificity, duplex degradation and subcellular localization of antagomirs. Nucleic Acids Res 2007;35(9):2885-92.

22. Esau C, Davis S, Murray SF, Yu XX, Pandey SK, Pear M, et al. miR-122 regulation of lipid metabolism revealed by in vivo antisense targeting. Cell Metab 2006;3(2):87-98.

23. Freier SM, Altmann $\mathrm{KH}$. The ups and downs of nucleic acid duplex stability: structure-stability studies on chemically-modified DNA:RNA duplexes. Nucleic Acids Res 1997;25(22):4429-43.

24. Petersen M, Wengel J. LNA: a versatile tool for therapeutics and genomics. Trends Biotechnol 2003;21(2):74-81. 
25. Petersen M, Bondensgaard K, Wengel J, Jacobsen JP. Locked nucleic acid (LNA) recognition of RNA: NMR solution structures of LNA:RNA hybrids. J Am Chem Soc 2002;124(21):5974-82.

26. Lennox KA, Behlke MA. A direct comparison of anti-microRNA oligonucleotide potency. Pharm Res 2010;27(9):1788-99.

27. Lennox KA, Behlke MA. Chemical modification and design of anti-miRNA oligonucleotides. Gene Ther 2011;18(12):1111-20.

28. Lennox KA, Owczarzy R, Thomas DM, Walder JA, Behlke MA. Improved Performance of AntimiRNA Oligonucleotides Using a Novel Non-Nucleotide Modifier. Mol Ther Nucleic Acids 2013; 2:e117.

29. Janssen HL, Reesink HW, Lawitz EJ, Zeuzem S, Rodriguez-Torres M, Patel K, et al. Treatment of HCV infection by targeting microRNA. N Engl J Med 2013;368(18):1685-94.

30. Jopling CL, Yi M, Lancaster AM, Lemon SM, Sarnow P. Modulation of hepatitis C virus RNA abundance by a liver-specific MicroRNA. Science 2005;309(5740):1577-81.

31. da Costa Martins PA, Salic K, Gladka MM, Armand AS, Leptidis S, el Azzouzi $\mathrm{H}$, et al. MicroRNA-199b targets the nuclear kinase Dyrk1a in an auto-amplification loop promoting calcineurin/NFAT signalling. Nat Cell Biol 2010;12(12):1220-7.

32. Obad S, dos Santos CO, Petri A, Heidenblad M, Broom O, Ruse C, et al. Silencing of microRNA families by seed-targeting tiny LNAs. Nat Genet 2011;43(4):371-8.

33. Elmen J, Lindow M, Schutz S, Lawrence M, Petri A, Obad S, et al. LNA-mediated microRNA silencing in non-human primates. Nature 2008;452(7189):896-9.

34. Grueter CE, van Rooij E, Johnson BA, DeLeon SM, Sutherland LB, Qi X, et al. A cardiac microRNA governs systemic energy homeostasis by regulation of MED13. Cell 2012;149(3): 671-83.

35. Patrick DM, Montgomery RL, Qi X, Obad X, Kauppinen S, Hill JA, et al. Stress-dependent cardiac remodeling occurs in the absence of microRNA-21 in mice. J Clin Invest 2010;120(11): 3912-6.

36. Duygu B, de Windt LJ, da Costa Martins PA. Targeting microRNAs in heart failure. Trends Cardiovasc Med 2016;26(2):99-110

37. Thum T, Chau N, Bhat B, Gupta SK, Linsley PS, Bauersachs J, et al. Comparison of different miR-21 inhibitor chemistries in a cardiac disease model. J Clin Invest 2011;121(2):461-2; author reply 462-3.

38. Cazenave C, Stein CA, Loreau N, Thuong NT, Neckers LM, Subasinghe C, et al. Comparative inhibition of rabbit globin mRNA translation by modified antisense oligodeoxynucleotides. Nucleic Acids Res 1989;17(11):4255-73.

39. Melkman-Zehavi T, Oren R, Kredo-Russo S, Shapira T, Mandelbaum AD, Rivkin N, et al. miRNAs control insulin content in pancreatic beta-cells via downregulation of transcriptional repressors. EMBO J 2011;30(5):835-45.

40. Swarbrick A, Woods SL, Shaw A, Balakrishnan A, Phua Y, Nguyen A, et al. miR-380-5p represses p53 to control cellular survival and is associated with poor outcome in MYCNamplified neuroblastoma. Nat Med 2010;16(10):1134-40.

41. Rayner KJ, Sheedy FJ, Esau CC, Hussain FN, Temel RE, Parathath S, et al. Antagonism of miR-33 in mice promotes reverse cholesterol transport and regression of atherosclerosis. $\mathrm{J}$ Clin Invest 2011;121(7):2921-31.

42. Davis S, Propp S, Freier SM, Jones LE, Serra MJ, Kinberger G, et al. Potent inhibition of microRNA in vivo without degradation. Nucleic Acids Res 2009;37(1):70-7.

43. Elmen J, Lindow M, Silahtaroglu A, Bak M, Christensen M, Lind-Thomsen A, et al. Antagonism of microRNA-122 in mice by systemically administered LNA-antimiR leads to up-regulation of a large set of predicted target mRNAs in the liver. Nucleic Acids Res 2008;36(4):1153-62.

44. Torres AG, Fabani MM, Vigorito E, Gait MJ. MicroRNA fate upon targeting with anti-miRNA oligonucleotides as revealed by an improved Northern-blot-based method for miRNA detection. RNA 2011;17(5):933-43.

45. Geary RS, Norris D, Yu R, Bennett CF. Pharmacokinetics, biodistribution and cell uptake of antisense oligonucleotides. Adv Drug Deliv Rev 2015;87:46-51.

46. Stenvang J, Petri A, Lindow M, Obad S, Kauppinen S. Inhibition of microRNA function by antimiR oligonucleotides. Silence 2012;3(1):1. 
47. Baek D, Villen J, Shin C, Camargo FD, Gygi SP, Bartel DP. The impact of microRNAs on protein output. Nature 2008;455(7209):64-71.

48. Selbach M, Schwanhausser B, Thierfelder N, Fang Z, Khanin R, Rajewsky N. Widespread changes in protein synthesis induced by microRNAs. Nature 2008;455(7209):58-63.

49. Lim LP, Lau NC, Garrett-Engele P, Grimson A, Schelter JM, Castle J, et al. Microarray analysis shows that some microRNAs downregulate large numbers of target mRNAs. Nature 2005; 433(7027):769-73.

50. Volinia S, Visone R, Galasso M, Rossi E, Croce CM. Identification of microRNA activity by Targets' Reverse EXpression. Bioinformatics 2010;26(1):91-7.

51. Guo H, Ingolia NT, Weissman JS, Bartel DP. Mammalian microRNAs predominantly act to decrease target mRNA levels. Nature 2010;466(7308):835-40. 



\section{Summary}

Heart failure (HF) evolves as a result of various pathological conditions including myocardial infarction (MI), hypertension and atrial fibrillation. ${ }^{1}$ Depending on the pathological cause, the myocardium undergoes different remodeling processes leading to deteriorated heart function., ${ }^{2,3}$ Despite advances in treatment strategies, prevalence and incidence of HF remain to be substantial since more than 23 million people worldwide have been diagnosed with HF. ${ }^{4-6}$ Therefore, a better understanding of the underlying mechanisms of development and progression to HF is required to generate novel and more efficient therapeutic strategies (Chapter 2). In this regard, microRNAs (miRNAs) have drawn great attention for their involvement in the regulation of key signaling pathways and for being beneficial therapeutic targets in preclinical models. ${ }^{7,8}$ In this thesis, we aimed at demonstrating the involvement of microRNA-199b (miR-199b), a previously defined pro-hypertrophic miRNA, ${ }^{9}$ in right ventricular remodeling after pulmonary artery banding in mice (Chapter 4) and also in left ventricular remodeling post-myocardial infarction (MI) (Chapter 5 ). We revealed that cardiac miR-199b expression is upregulated under stress conditions in both right and left ventricular (Figure 7.1). In the left ventricular, overexpression of miR-199b results in exaggerated cardiac function after volume overload and moreover, inhibition of miR-199b levels leads to partial improvement of cardiac dysfunction induced by $\mathrm{Ml}$, indicating that miR-199b has an important function in the left ventricular under stress conditions and thus, inhibition of miR-199b provides a promising treatment strategy for left sided heart failure.

In our study (Chapter 5), we inhibited miR-199b by treating animals with an antagomir, a widely used microRNA inhibitor in preclinical research, also previously used by us. ${ }^{9}$ Since anti-sense oligonucleotide technology is rapidly advancing with several different chemistry-based antimiRs being developed with altered properties such as nuclease resistance, binding affinity and cellular uptake, we also evaluated different chemistry-based antimiR oligonucleotides regarding their efficiency to decrease miR-199b expression levels in the heart (Chapter 6). From all tested chemistries, antagomir and LNA were shown to be the most potent inhibitors of miR-199b in the heart. This potency was further improved by changing the cholesterol moiety from the 3 ' to the 5'end of the molecule leading to almost $100 \%$ inhibition of miR-199b cardiac expression levels. Although LNA-RNA molecules displayed an increased inhibitory capacity, in comparison to LNA-DNA, the efficiency of antagomir (harboring the cholesterol group at the 5'end) was still much higher. Moreover, both antagomir and LNA molecules were able to inhibit miR-199b expression levels in other organs such as lung, liver and kidney, indicating the need of developing organspecific delivery methods for anti-microRNA therapeutics to avoid unwanted side effects. 

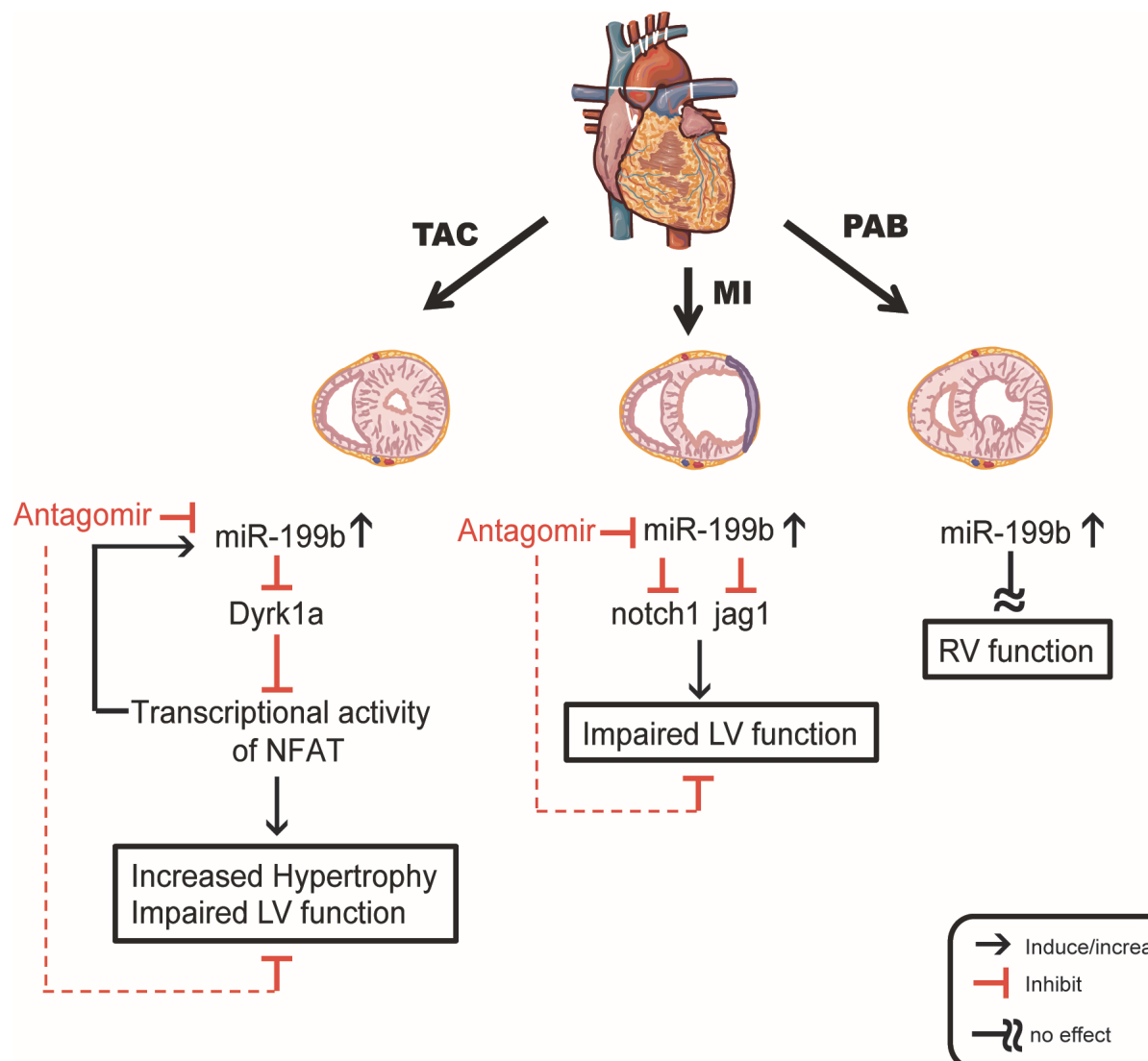

Figure $7.1 \mathrm{miR}-199 \mathrm{~b}$ involvement in heart failure. miR-199b expression is upregulated in three different preclinical models of heart failure. Upon pressure overload by trans aortic constriction (TAC), miR-199b regulates the activity of calcineurin/ nuclear factor of activated T-cell (NFAT) in an auto-amplification loop by targeting Dual specificity tyrosine-phosphorylation-regulated kinase $1 \mathrm{~A}$ (Dyrk1a) resulting in increased hypertrophic growth and impaired LV function. Moreover, inhibition of miR-199b by an antagomir, after TAC, results in efficient recovery of pathological remodeling and cardiac dysfunction due to decreased activity of the calcineurin/NFAT pathway. Also, overexpression of miR-199b in a murine model of myocardial infarction (MI) is associated with decreased levels of notch and jagged1, two members of the Notch signaling pathway, giving rise to impaired LV function. Furthermore, antagomir treatment after MI partially rescues pathological phenotype. On contrary to the adverse effect of miR-199b overexpression in the LV, miR-199b expression failed to effect cardiac function in the RV after pulmonary artery banding (PAB). All these studies highlight the distinct involvement of miR-199b in different etiologies of heart failure. 
Here, we demonstrated the therapeutic value of miR-199b in different preclinical models mimicking distinct etiologies of human heart failure. It holds great importance to comprehensively understand the underlying mechanisms of a complex disease such as heart failure in order to develop new and efficient treatment strategies. In addition, advancements in anti-sense technology enable efficient targeting of miRNAs in vivo and provide promising clinical applications for the treatment of heart failure in the near future.

\section{Regulatory roles of microRNAs in heart failure}

MiRNAs have been associated with a wide range of human pathologies by functioning as essential regulators of gene expression. ${ }^{10}$ As summarized in Chapter 3, the role of specific miRNAs have been described in the different processes of pathological cardiac remodeling such as cardiac hypertrophy (miR-25, miR-378, miR499, miR-208, miR-133, miR-1 and miR-199b), fibrosis (miR-29, miR-21 and miR-101a), angiogenesis (miR-17 92, miR-24, miR-126, miR-26a and miR-146a) and inflammation (miR-155) in preclinical models of $\mathrm{HF}^{8}$. As HF is the end stage of various cardiac pathologies, the key to develop novel miRNA-based therapeutic strategies lies under the specification of miRNA activity for each of those pathologies.

Previously, miR-199b has been identified as an important inducer of pathological hypertrophy of the LV under chronic pressure overload conditions. ${ }^{9}$ Considering the fact that substantial morphological, genetic and molecular differences exist between left and right ventricle, ${ }^{11,12}$ differentially expressed miRNAs have been identified in murine models when comparing hypertrophic remodeling and/or failure between LV and RV. Four miRNAs (miR-34a, -28, -148a and -93) were found to be upregulated in the RV after pressure overload while they remained unchanged or downregulated in the LV under pressure. ${ }^{13}$ In Chapter 4, we determined to investigate whether pro-hypertrophic function of miR-199b is also involved in the right ventricular remodeling after increased pulmonary artery pressure. Different animal models have been developed to study pulmonary artery hypertension ${ }^{14}$ and, as expected, each model having specific limitations and advantages. ${ }^{15}$ In our study, we employed a model of pulmonary artery banding $(\mathrm{PAB})$, induced by a permanent banding around the pulmonary artery to establish increased RV afterload. ${ }^{16}$ The main advantages of this model are the induction of pressure overload and, subsequently, RV hypertrophy without pulmonary vascular remodeling ${ }^{17}$ as well as stable constriction of blood flow which enables evaluation of RV remodeling under pressure. In addition, the mechanistic similarities with the TAC model, where LV afterload is induced by transaortic banding, ${ }^{16}$ enable to determine whether miR-199b executes comparable function in the LV and RV hypertrophy. In this regard, miR-199b is 
regulated by calcineurin (CnA)/ nuclear factor of activated T-cell (NFAT) activity, ${ }^{9}$ an established signaling cascade responsible for the hypertrophic response in the myocardium, ${ }^{18,19}$ and transgenic mice overexpressing an active form of $\mathrm{CnA}$ develop massive biventricular hypertrophy precipitating in severe cardiac dysfunction and HF as early as 18 days after birth. ${ }^{20,21}$ Interestingly, inhibition of $\mathrm{CnA}$ activity results in attenuation of hypertrophy and pathological remodeling in both animals models of left-side $\mathrm{HF}^{20,22-25}$ and hypoxia-induced pulmonary hypertension and RV hypertrophy. ${ }^{26}$ In agreement, we observed induced activity of CnA/NFAT in the RV of wildtype mice after PAB. ${ }^{27}$

In order to gain more insights on the function of miR-199b in different etiologies of $\mathrm{HF}$, we investigated the effect of cardiac overexpression of miR-199b in response to volume overload induced by MI. LV remodeling after MI reveals a unique pattern involving the infarcted region (fibrotic scar) and leading to hypertrophic growth of the non-infarcted myocardium and eventually to cardiac dilatation. ${ }^{28}$ Previous findings suggest the involvement of CnA/NFAT signaling during post-MI remodeling. ${ }^{19,29}$ Since miR-199b was identified as a prohypertrophic miRNA regulated by the CnA/NFAT pathway, we hypothesized that miR-199b is also involved in LV remodeling after MI. Indeed, cardiac overexpression of miR-199b sensitized the heart to volume overload as demonstrated by exaggerated cardiac dysfunction and abrupt collagen deposition in the border zone of the infarct (Chapter 5). However, in contrast to previous reports, ${ }^{9}$ miR-199b overexpression does not further activate the CnA/NFAT signaling pathway after MI. These somewhat opposite findings suggest that different cardiac stressors may alter specific molecular mechanisms in order to obtain distinct remodeling patterns. In agreement, a recent study showed that anti-miR-208a treatment resulted in activation of different genes in Ml-operated rats compared to Dahl salt sensitive rats on a high salt diet as a model for hypertension induced heart failure indicating the divergent regulatory capacity of miR-208a depending on the cause of disease. ${ }^{30}$ Moreover, comparison of differentially expressed genes between rat hearts subjected to either pressure or volume overload revealed that besides the commonly regulated genes, several other genes are stress-specific regulated. ${ }^{31,32}$

Next, we investigated whether other possible targets of miR-199b could be responsible for the observed Ml-induced phenotypes. In cancer, the regulatory function of miR-199b has been firmly established through the Notch pathway, ${ }^{33-36}$ with notch1 and jagged1 being predicted target genes. A few reports indicate upregulation of notch1 and its ligand jagged 1 in the adult myocardium upon cardiac stress and a subsequent protective role following cardiac injury whereas their pharmaceutical or genetic ablation results in detrimental effects. ${ }^{37-41}$ We also observed an increase in expression of notch1 
and jagged1 in the adult hearts subjected to MI. Moreover, after MI, miRNA-199b transgenic hearts revealed reduced expression of notch1 and jagged1 providing a possible explanation for the exaggerated pathological phenotype seen in these mice compared to wildtype. Induction of Notch signaling takes place in the border zone and is associated with anti-hypertrophic, anti-fibrotic and pro-angiogenic responses in the adult myocardium. ${ }^{38,40,42,43}$ Similarly, the elevated fibrosis observed in the border zone of MI-miRNA-199b transgenic hearts could be related to blunted Notch activity by inhibition of notch1 and jagged1 expression after cardiac restricted upregulation of miR-199b.

\section{Therapeutic potential of miRNAs in heart failure}

The capacity of miRNAs to regulate different molecular pathways involved in a specific disease process establishes them as suitable therapeutic targets in the treatment of various pathologies including HF. ${ }^{7}$ As a consequence, advances in miRNA-based technologies enable us to modulate miRNA expression in an organism and currently, several preclinical studies using these technologies have generated promising outcomes for HF, as summarized in Chapter 3. Formerly, the therapeutic efficacy of targeting miR-199b in a pressure overload murine model of HF using an anti-microRNA (antimiR) conjugated to a cholesterol moiety (antagomir), has been established. ${ }^{9,44}$ In this thesis, we provide evidence of a regulatory role of miR-199b during post-MI remodeling and of the therapeutic relevance of inhibiting miR-199b post MI as demonstrated by enhanced cardiac function after antagomir treatment.

Our main focus was to obtain efficient inhibition of miR-199b in the heart. However, further phenotyping in chapter 6 revealed that miR-199b is also expressed in other organs such as kidney, lung and liver. Furthermore, our most potent inhibitors antagomir and LNA reduced the expression of miR-199b in these organs. The physiological and functional significance of these findings is still unknown. It is actually conceivable that miR-199b may exert important renoprotective effects, especially in diabetic nephropathy, a condition in which miRNAs play a pivotal role ${ }^{45}$ and inhibition of the NFAT/calcineurin pathway has been shown to be beneficial. ${ }^{46}$

Therefore, future studies should address whether antagomirs directed against miR-199b have pleiotropic beneficial effects or may cause unforeseen side effects in other organs. Reassuringly, we did not observe any mortality in our animal studies, and no apparent changes in gross anatomy of kidney, liver and lungs, albeit we cannot fully exclude that miR-199b may have some, yet unknown, protective effects. To circumvent such issues, Hinkel et al, showed that local delivery of LNA directed against miR-92a to the heart with a catheter 
can greatly enhance the therapeutic value, while limiting side effects compared to systemic delivery. ${ }^{47}$ A similar set-up may be devised to achieve strong and tissue specific knockdown of miR-199b in the heart. This is not an unrealistic approach, since many patients are already undergoing catheterization in both the work-up and in the acute treatment of myocardial infarction, making this procedure already suitable for local drug delivery.

In this thesis, we draw attention mainly to inhibitors of miRNAs as therapeutic tools since our miRNA of interest (miR-199b) is increased in response to cardiac stress and hence its inhibition provides therapeutic impact. However, it is also possible to restore the expression of miRNAs in vivo when the downregulation of a miRNA occurs in a disease state. One way is to apply synthetic RNA duplexes that are developed to mimic endogenous miRNA functions. These mimics can carry chemical modifications ${ }^{48}$ or can be applied using cationic lipids to facilitate cellular uptake and stability. ${ }^{49}$ Alternatively, a novel delivery system using nonviable minicells generated from bacterial cells after inactivating their cell division has been developed. ${ }^{50}$ In addition, these carriers can be coated with anti- epithelial growth factor receptor (EGFR) antibody to achieve cancer cell specific targeted therapy. ${ }^{50}$ Currently, in Phase I clinical trial MesomiR 1 (ClinicalTrials.gov:NCT02369198) is testing the effect of miR-15/16 mimics packed in such nanocells $\left(\mathrm{EDV}^{\mathrm{TM}}\right)$ targeted with anti-EGFR antibody in malignant pleural mesothelioma (MPM) patients. ${ }^{51}$ On the other hand, Phase I clinical studies of MRX34, miR-34 mimic, in multiple cancers was terminated due to multiple immune-related severe adverse events highlighting the significance of targeted delivery of miRNA-based therapeutics to avoid off-target affects (ClinicalTrials.gov:NCT01829971). Another way to retrieve miRNA expression is by the use of viral vectors such as adeno associated viruses (AVV). ${ }^{52}$ The number of different serotype of AVV allow for tissue-specific targeting which can be further improved in combination with tissue specific promoters. ${ }^{53}$

MicroRNA expression levels have been shown to be differentially regulated in response to conventional heart failure treatments such as beta blockers in idiopathic dilated cardiomyopathy patients (iDCM) ${ }^{54}$ Moreover, increased levels of miR-320 and reduced levels of miR-26b and miR-21 in Dahl sensitive hypertensive rat model were reversed to normal levels after treatment with a selective beta blocker, nebivolol but not treatment with atenolol. ${ }^{55}$ Additional study revealed that both nebivolol and atenolol have an effect on miR-133 levels in high salt-treated rats. ${ }^{56}$ These studies point out the importance of potential effects of standard heart failure treatments on miRNA biology and likelihood to intervene with novel therapeutic strategies. Further investigation of the effects combining current with new therapies is highly valuable since clinical trials can be performed in addition to standard treatments. 


\section{Future perspectives and concluding remarks}

In this thesis, we emphasized the significance of better understanding miRNA activity in different pathologies of HF in order to develop reliable and more efficient therapeutic strategies than the current ones.

We identified new potential targets of miR-199b, jagged1 and notch1, players in the Notch pathway, supporting the possibility that miRNAs may involve in various molecular mechanisms depending on the induced cardiac stress. Upregulation of notch1 and its ligand jagged1 in the adult myocardium after stress was previously reported to provide protection from cardiac injury, whereas their pharmaceutical or genetic ablation causes exaggerated cardiac dysfunction. Consequently, a better understanding of the miRNA activity in underlying mechanisms of a disease is a prerequisite before establishing an individual miRNA as a therapeutic target in a certain disease. Hence, further identification of miR-199b targets is essential in order to profile the complex gene network wherein miR-199b is involved. Currently, various high throughput techniques enable the identification of miRNA targets in a large scale. In this regard, RNA sequencing can be applied to determine the change in transcript abundance after alterations in miRNA levels either by overexpression using mimics or downregulation by antimiRs. ${ }^{57}$ Moreover, proteomics tools enable the detection of alterations in global protein levels after modification of miRNA expression. ${ }^{58}$ The drawback of the mentioned approaches is the lack of information regarding indirect molecular interactions. However, strategies using co-immunoprecipitation of Argonaute -2 (AGO2), a component of RNA silencing complex (RISC), along with the mRNA:miRNA duplex and further identification by microarray or deep sequencing allow the determination of direct targets. ${ }^{59}$ The application of these approaches in the future would greatly increase our understanding of the biological role of miR-199b.

As highlighted in Chapter 5, limitations of antimiR technology such as organ specific delivery, cellular uptake and optimal dosages to obtain efficient inhibition of target miRNA remain to be overcome prior to clinical application of antimiR drugs. One promising approach to optimize the bioavailability of antimiR oligonucleotides is to develop polymer-based nanoparticles as vehicles for in vivo applications. For instance, polyethylenimine (PEI), a broadly used polymer, due to its high cationic charge density potential, aids in the cellular uptake of the therapeutics. ${ }^{60}$ Another option is to use poly(lactide-co-glycolide) (PLGA) particles with the advantage of high loading capacity and various surface modifications for beneficial pharmacodynamics. ${ }^{61,62}$ Furthermore, studies from siRNA technology revealed the possibility of antibody conjugation in order to obtain tissue/cell type specific delivery of this anti-sense therapeutics. ${ }^{63,64}$ In cancer biology, antibodies targeting highly expressed cancer cell surface 
proteins can be utilized in order to achieve tumor-specific delivery. For instance, linking human epidermal growth factor receptor 2 (HER2) antibody to a nanocarrier of siRNA resulted in $80 \%$ inhibition of targeted mRNA and protein level in a xenograft model of ovarian cancer. ${ }^{65} \mathrm{~A}$ relatively recent report has shown that conjugation of anti-CD71 (Tf receptor) Fab' fragment to a siRNA targeting hypoxanthine-guanine phosphoribosyltransferase (HPRT) efficiently and stably downregulated HPRT gene in calf and cardiac muscle but not in the liver or the spleen. ${ }^{66}$ Moreover, when intramuscular injection of a conjugate generated by linking siRNA against myostatin gene and anti-CD71 Fab' fragment was applied to a mouse model of peripheral artery disease, calf muscles were hypertrophied leading to increased running performance. ${ }^{66}$ Since $\mathrm{miR}-199 \mathrm{~b}$ is also expressed in other tissues besides the heart, application of the above-mentioned delivery methods would corroborate the therapeutic potency of miR-199b in the future.

To generate comprehensive knowledge on the biological function of miR-199b is essential before designing and initiating any clinical studies. For this purpose, generation of a genetic cardiac-specific knockout miR-199b mouse line is a future crucial step in gaining mechanistic insight on the role of miR-199b in cardiac pathologies. This goal can be achieved by using conditional targeted gene knockout technologies ${ }^{67}$ which enable elimination of single gene expression in a specific tissue or even in a cell type at a desired time. This approach, although not therapeutically feasible, could provide a better view over the specific effects of silencing one specific microRNA in one specific tissue since antimiRs, although therapeutically relevant, result in global inhibitory effects on different cell types and tissues which makes it difficult to determine the specific role of a miRNA in the desired cell type, tissue or organ. In addition, cardiac tissue from knockout animals can be used for RNA sequencing or proteomics to determine the changes in global gene expression after silencing miR-199b under physiological or pathological conditions. 


\section{References}

1. Kemp CD, Conte JV. The pathophysiology of heart failure. Cardiovasc Pathol 2012;21(5): 365-71.

2. Konstam MA, Kramer DG, Patel AR, Maron MS, Udelson JE. Left ventricular remodeling in heart failure: current concepts in clinical significance and assessment. JACC Cardiovasc Imaging 2011;4(1):98-108.

3. Haque ZK, Wang DZ. How cardiomyocytes sense pathophysiological stresses for cardiac remodeling. Cell Mol Life Sci 2017;74(6):983-1000.

4. Mozaffarian D, Benjamin EJ, Go AS, Arnett DK, Blaha MJ, Cushman M, et al. Heart disease and stroke statistics--2015 update: a report from the American Heart Association. Circulation 2015;131(4):e29-322.

5. Roger VL. Epidemiology of heart failure. Circ Res 2013;113(6):646-59.

6. Bleumink GS, Knetsch AM, Sturkenboom MC, Straus SM, Hofman A, Deckers JW, et al. Quantifying the heart failure epidemic: prevalence, incidence rate, lifetime risk and prognosis of heart failure The Rotterdam Study. Eur Heart J 2004;25(18):1614-9.

7. Melman YF, Shah R, Das S. MicroRNAs in heart failure: is the picture becoming less miRky? Circ Heart Fail 2014;7(1):203-14.

8. Duygu B, de Windt LJ, da Costa Martins PA. Targeting microRNAs in heart failure. Trends Cardiovasc Med 2016;26(2):99-110.

9. da Costa Martins PA, Salic K, Gladka MM, Armand AS, Leptidis S, el Azzouzi H, et al. MicroRNA-199b targets the nuclear kinase Dyrk1a in an auto-amplification loop promoting calcineurin/NFAT signalling. Nat Cell Biol 2010;12(12):1220-7.

10. Mendell JT, Olson EN. MicroRNAs in stress signaling and human disease. Cell 2012;148(6): 1172-87.

11. Ho SY, Nihoyannopoulos P. Anatomy, echocardiography, and normal right ventricular dimensions. Heart 2006;92 Suppl 1:i2-13.

12. Srivastava $D$. Making or breaking the heart: from lineage determination to morphogenesis. Cell 2006;126(6):1037-48.

13. Reddy S, Zhao M, Hu DQ, Fajardo G, Hu S, Ghosh Z, et al. Dynamic microRNA expression during the transition from right ventricular hypertrophy to failure. Physiol Genomics 2012;44(10):562-75.

14. Maarman G, Lecour S, Butrous G, Thienemann F, Sliwa K. A comprehensive review: the evolution of animal models in pulmonary hypertension research; are we there yet? Pulm Circ 2013;3(4):739-56.

15. Colvin KL, Yeager ME. Animal Models of Pulmonary Hypertension: Matching Disease Mechanisms to Etiology of the Human Disease. J Pulm Respir Med 2014;4(4):198.

16. Tarnavski O, McMullen JR, Schinke M, Nie Q, Kong S, Izumo S. Mouse cardiac surgery: comprehensive techniques for the generation of mouse models of human diseases and their application for genomic studies. Physiol Genomics 2004;16(3):349-60.

17. Dias CA, Assad RS, Caneo LF, Abduch MC, Aiello VD, Dias AR, et al. Reversible pulmonary trunk banding. II. An experimental model for rapid pulmonary ventricular hypertrophy. J Thorac Cardiovasc Surg 2002;124(5):999-1006.

18. Molkentin JD. Calcineurin-NFAT signaling regulates the cardiac hypertrophic response in coordination with the MAPKs. Cardiovasc Res 2004;63(3):467-75.

19. Wilkins BJ, Dai YS, Bueno OF, Parsons SA, Xu J, Plank DM, et al. Calcineurin/NFAT coupling participates in pathological, but not physiological, cardiac hypertrophy. Circ Res 2004;94(1): 110-8.

20. Sussman MA, Lim HW, Gude N, Taigen T, Olson EN, Robbins J, et al. Prevention of cardiac hypertrophy in mice by calcineurin inhibition. Science 1998;281(5383):1690-3.

21. Moreth K, Afonso LC, Fuchs H, Gailus-Durner V, Katus HA, Bekeredjian R, et al. Erratum to: High throughput phenotyping of left and right ventricular cardiomyopathy in calcineurin transgene mice. Int J Cardiovasc Imaging 2015;31(6):1137. 
22. Lim HW, De Windt LJ, Mante J, Kimball TR, Witt SA, Sussman MA, et al. Reversal of cardiac hypertrophy in transgenic disease models by calcineurin inhibition. J Mol Cell Cardiol 2000; 32(4):697-709.

23. De Windt LJ, Lim HW, Bueno OF, Liang Q, Delling U, Braz JC, et al. Targeted inhibition of calcineurin attenuates cardiac hypertrophy in vivo. Proc Natl Acad Sci USA 2001;98(6):3322-7.

24. Shimoyama M, Hayashi D, Zou Y, Takimoto E, Mizukami M, Monzen K, et al. Calcineurin inhibitor attenuates the development and induces the regression of cardiac hypertrophy in rats with salt-sensitive hypertension. Circulation 2000;102(16):1996-2004.

25. Kamiya H, Okumura $\mathrm{K}$, Ito $\mathrm{M}$, Saburi $\mathrm{Y}$, Tomida $\mathrm{T}$, Hayashi $\mathrm{K}$, et al. Calcineurin inhibitor attenuates cardiac hypertrophy due to energy metabolic disorder. Can J Cardiol 2001;17(12): 1292-8.

26. Koulmann N, Novel-Chate V, Peinnequin A, Chapot R, Serrurier B, Simler N, et al. Cyclosporin A inhibits hypoxia-induced pulmonary hypertension and right ventricle hypertrophy. Am J Respir Crit Care Med 2006;174(6):699-705.

27. Bartelds B, Borgdorff MA, Smit-van Oosten A, Takens J, Boersma B, Nederhoff MG, et al. Differential responses of the right ventricle to abnormal loading conditions in mice: pressure vs. volume load. Eur J Heart Fail 2011;13(12):1275-82.

28. French BA, Kramer CM. Mechanisms of Post-Infarct Left Ventricular Remodeling. Drug Discov Today Dis Mech 2007;4(3):185-96.

29. van Rooij E, Doevendans PA, Crijns HJ, Heeneman S, Lips DJ, van Bilsen M, et al. MCIP1 overexpression suppresses left ventricular remodeling and sustains cardiac function after myocardial infarction. Circ Res 2004;94(3):e18-26.

30. Eding JE, Demkes CJ, Lynch JM, Seto AG, Montgomery RL, Semus HM, et al. The Efficacy of Cardiac Anti-miR-208a Therapy Is Stress Dependent. Mol Ther 2017;25(3):694-704.

31. Miyazaki H, Oka N, Koga A, Ohmura H, Ueda T, Imaizumi T. Comparison of gene expression profiling in pressure and volume overload-induced myocardial hypertrophies in rats. Hypertens Res 2006;29(12):1029-45.

32. Mirotsou M, Watanabe CM, Schultz PG, Pratt RE, Dzau VJ. Elucidating the molecular mechanism of cardiac remodeling using a comparative genomic approach. Physiol Genomics 2003;15(2):115-26.

33. Liu MX, Siu MK, Liu SS, Yam JW, Ngan HY, Chan DW. Epigenetic silencing of microRNA$199 b-5 p$ is associated with acquired chemoresistance via activation of JAG1-Notch1 signaling in ovarian cancer. Oncotarget 2014;5(4):944-58.

34. Garzia L, Andolfo I, Cusanelli E, Marino N, Petrosino G, De Martino D, et al. MicroRNA-199b$5 p$ impairs cancer stem cells through negative regulation of HES1 in medulloblastoma. PLoS One 2009;4(3):e4998.

35. Andolfo I, Liguori L, De Antonellis $\mathrm{P}$, Cusanelli E, Marinaro F, Pistollato $\mathrm{F}$, et al. The micro-RNA 199b-5p regulatory circuit involves Hes1, CD15, and epigenetic modifications in medulloblastoma. Neuro Oncol 2012;14(5):596-612.

36. Chen T, Margariti A, Kelaini S, Cochrane A, Guha ST, Hu Y, et al. MicroRNA-199b Modulates Vascular Cell Fate During iPS Cell Differentiation by Targeting the Notch Ligand Jagged1 and Enhancing VEGF Signaling. Stem Cells 2015;33(5):1405-18.

37. Croquelois A, Domenighetti AA, Nemir M, Lepore M, Rosenblatt-Velin N, Radtke F, et al. Control of the adaptive response of the heart to stress via the Notch1 receptor pathway. J Exp Med 2008;205(13):3173-85.

38. Kratsios P, Catela C, Salimova E, Huth M, Berno V, Rosenthal N, et al. Distinct roles for cellautonomous Notch signaling in cardiomyocytes of the embryonic and adult heart. Circ Res 2010;106(3):559-72.

39. Oie E, Sandberg WJ, Ahmed MS, Yndestad A, Laerum OD, Attramadal H, et al. Activation of Notch signaling in cardiomyocytes during post-infarction remodeling. Scand Cardiovasc $\mathrm{J}$ 2010;44(6):359-66.

40. Boopathy AV, Martinez MD, Smith AW, Brown ME, Garcia AJ, Davis ME. Intramyocardial Delivery of Notch Ligand-Containing Hydrogels Improves Cardiac Function and Angiogenesis Following Infarction. Tissue Eng Part A 2015;21(17-18):2315-22. 
41. Li,Y, HiroiY, Liao JK. Notch signaling as an important mediator of cardiac repair and regeneration after myocardial infarction. Trends Cardiovasc Med 2010;20(7):228-31.

42. Gude NA, Emmanuel G, Wu W, Cottage CT, Fischer K, Quijada P, et al. Activation of Notchmediated protective signaling in the myocardium. Circ Res 2008;102(9):1025-35.

43. Nemir M, Metrich M, Plaisance I, Lepore M, Cruchet S, Berthonneche C, et al. The Notch pathway controls fibrotic and regenerative repair in the adult heart. Eur Heart $\mathrm{J} 2014 ; 35(32)$ : 2174-85.

44. Krutzfeldt J, Rajewsky N, Braich R, Rajeev KG, Tuschl T, Manoharan M, et al. Silencing of microRNAs in vivo with 'antagomirs'. Nature 2005;438(7068):685-9.

45. Simpson K, Wonnacott A, Fraser DJ, Bowen T. MicroRNAs in Diabetic Nephropathy: From Biomarkers to Therapy. Curr Diab Rep 2016;16(3):35.

46. Zhang L, Li R, Shi W, Liang X, Liu S, Ye Z, et al. NFAT2 inhibitor ameliorates diabetic nephropathy and podocyte injury in db/db mice. Br J Pharmacol 2013;170(2):426-39.

47. Hinkel R, Penzkofer D, Zuhlke S, Fischer A, Husada W, Xu QF, et al. Inhibition of microRNA92a protects against ischemia/reperfusion injury in a large-animal model. Circulation 2013; 128(10):1066-75.

48. Montgomery RL, Yu G, Latimer PA, Stack C, Robinson K, Dalby CM, et al. MicroRNA mimicry blocks pulmonary fibrosis. EMBO Mol Med 2014;6(10):1347-56.

49. Icli B, Wara AK, Moslehi J, Sun X, Plovie E, Cahill M, et al. MicroRNA-26a regulates pathological and physiological angiogenesis by targeting BMP/SMAD1 signaling. Circ Res 2013;113(11):1231-41.

50. MacDiarmid JA, Mugridge NB, Weiss JC, Phillips L, Burn AL, Paulin RP, et al. Bacterially derived $400 \mathrm{~nm}$ particles for encapsulation and cancer cell targeting of chemotherapeutics. Cancer Cell 2007;11(5):431-45.

51. Reid G, Kao SC, Pavlakis N, Brahmbhatt H, MacDiarmid J, Clarke S, et al. Clinical development of TargomiRs, a miRNA mimic-based treatment for patients with recurrent thoracic cancer. Epigenomics 2016;8(8):1079-85.

52. Dirkx E, Gladka MM, Philippen LE, Armand AS, Kinet V, Leptidis S, et al. Nfat and miR-25 cooperate to reactivate the transcription factor Hand2 in heart failure. Nat Cell Biol 2013; 15(11):1282-93.

53. Kotterman MA, Schaffer DV. Engineering adeno-associated viruses for clinical gene therapy. Nat Rev Genet 2014;15(7):445-51.

54. Sucharov CC, Kao DP, Port JD, Karimpour-Fard A, Quaife RA, Minobe W, et al. Myocardial microRNAs associated with reverse remodeling in human heart failure. JCI Insight 2017;2(2): e89169.

55. Ling S, Nanhwan M, Qian J, Kodakandla M, Castillo AC, Thomas B, et al. Modulation of microRNAs in hypertension-induced arterial remodeling through the beta1 and beta3adrenoreceptor pathways. J Mol Cell Cardiol 2013;65:127-36.

56. Ye H, Ling S, Castillo AC, Thomas B, Long B, Qian J, et al. Nebivolol induces distinct changes in profibrosis microRNA expression compared with atenolol, in salt-sensitive hypertensive rats. Hypertension 2013;61(5):1008-13.

57. Xu G, Fewell C, Taylor C, Deng N, Hedges D, Wang X, et al. Transcriptome and targetome analysis in MIR155 expressing cells using RNA-seq. RNA 2010;16(8):1610-22.

58. Jovanovic M, Reiter L, Picotti P, Lange V, Bogan E, Hurschler BA, et al. A quantitative targeted proteomics approach to validate predicted microRNA targets in C. elegans. Nat Methods 2010; 7(10):837-42.

59. Karginov FV, Conaco C, Xuan Z, Schmidt BH, Parker JS, Mandel G, et al. A biochemical approach to identifying microRNA targets. Proc Natl Acad Sci USA 2007;104(49):19291-6.

60. Boussif O, Lezoualc'h F, Zanta MA, Mergny MD, Scherman D, Demeneix B, et al. A versatile vector for gene and oligonucleotide transfer into cells in culture and in vivo: polyethylenimine. Proc Natl Acad Sci USA 1995;92(16):7297-301.

61. Uchegbu IF. Pharmaceutical nanotechnology: polymeric vesicles for drug and gene delivery. Expert Opin Drug Deliv 2006;3(5):629-40. 
62. Babar IA, Cheng CJ, Booth CJ, Liang X, Weidhaas JB, Saltzman WM, et al. Nanoparticlebased therapy in an in vivo microRNA-155 (miR-155)-dependent mouse model of lymphoma. Proc Natl Acad Sci USA 2012;109(26):E1695-704.

63. Song E, Zhu P, Lee SK, Chowdhury D, Kussman S, Dykxhoorn DM, et al. Antibody mediated in vivo delivery of small interfering RNAs via cell-surface receptors. Nat Biotechnol 2005;23(6): 709-17.

64. Kumar P, Ban HS, Kim SS, Wu H, Pearson T, Greiner DL, et al. T cell-specific siRNA delivery suppresses HIV-1 infection in humanized mice. Cell 2008;134(4):577-86.

65. Palanca-Wessels MC, Booth GC, Convertine AJ, Lundy BB, Berguig GY, Press MF, et al. Antibody targeting facilitates effective intratumoral siRNA nanoparticle delivery to HER2overexpressing cancer cells. Oncotarget 2016;7(8):9561-75.

66. Sugo T, Terada M, Oikawa T, Miyata K, Nishimura S, Kenjo E, et al. Development of antibodysiRNA conjugate targeted to cardiac and skeletal muscles. J Control Release 2016;237:1-13.

67. Doetschman T, Azhar M. Cardiac-Specific Inducible and Conditional Gene Targeting in Mice. Circ Res 2012;110(11):1498-512 



\section{Valorization}

\section{Relevance}

Heart failure remains one of the major public health problems with increasing morbidity and mortality worldwide. More than 20 million people currently suffer from heart failure and this prevalence steeply increases with age. ${ }^{1,2}$ According to the American Heart Association (AHA) 1 out of 5 adults at the age of 40 and above will likely to develop heart failure in their life time. ${ }^{3}$ Although current heart failure medication can ameliorate signs and symptoms, mortality rate 5 years after diagnosis has been reported to be as high as $45-60 \%$, and survival rate is lower than some of the most common forms of cancer. ${ }^{6,7}$ These reports are clearly pointing to the need for developing novel therapeutic strategies for the treatment of heart failure.

In the European Society of Cardiology (ESC) guidelines (2016), heart failure is defined as 'a clinical syndrome caused by structural and/or functional abnormality, resulting in a reduced cardiac output and/or elevated intracardiac pressures at rest or during stress. ${ }^{8}$ Being a complex syndrome, the etiology of heart failure is highly diversified and patients may develop various pathologies. As summarized in Chapter 2, both genetic factors and epigenetic mechanisms can significantly contribute to the development and progression of heart failure. ${ }^{9}$ Thus, a better understanding of these underlying mechanisms hold great significance in successfully developing effective therapies for heart failure patients.

\section{Target groups}

\section{Scientific community}

Among epigenetical mechanisms, microRNAs (miRNAs) have drawn great attention for their ability to regulate gene expression and thereby to be involved in various human diseases including heart failure. ${ }^{10,11}$ miRNAs exert their regulatory function by disturbing protein production after binding to target mRNAs and in that way, they are able to influence different cellular processes. ${ }^{12}$ To date, numerous miRNAs have been identified as regulators of pathological remodeling processes leading to heart failure including hypertrophy, fibrosis, apoptosis and angiogenesis. ${ }^{13,14}$ Previously, microRNA-199b (miR-199b), a miRNA associated with cardiac hypertrophy, has been established by our group as a promising therapeutic target using an animal model mimicking human aortic stenosis. ${ }^{15}$ However, differential expression patterns of miRNAs depending on the etiology of heart failure (ischemic, aortic stenosis and/or idiopathic) have been reported. ${ }^{16}$ In this regard, further analysis of miR-199b has been performed in this thesis using different animal models consisting of myocardial infarction 
(Chapter 5) and right ventricular failure (Chapter 4). In accordance with our previous data, targeting miR-199b in an animal model of myocardial infarction was also shown to be beneficial, even though our molecular studies suggested that miR-199b carried out its function in this animal model via a different molecular pathway. Thereby, the findings reported in this thesis are of great importance for the scientific community, indicating that comprehensive studies into the distinct subtypes of heart failure are required to determine therapeutic significance of a molecule before extrapolating preclinical data to clinical application.

\section{Biotechnology and pharmaceutical industry}

What makes miRNAs valuable therapeutic targets for the treatment of heart failure is the feasibility to modulate miRNA expression levels in living organisms such as animals and humans. While microRNA mimics, synthetic double stranded RNA molecules, confer the ability to supplement microRNA function, ${ }^{17}$ antimiRs which are chemically modified single stranded small oligonucleotides, can block the function of targeted miRNA by direct binding. ${ }^{18}$

Preclinical investigation has provided invaluable information not only on the therapeutic efficacy of these new generation drugs in diseased animals but also on their limitations. ${ }^{19}$ Several antimiRs have been generated by using diverse chemical modifications in order to improve specific properties such as cellular uptake, stability, inhibitory capacity and thereby, to enhance their efficacy for in vivo applications. In Chapter 6, we have compared features of four promising antimiRs (against miR-199b), carrying distinct chemical moieties. The efficacy of these inhibitors was determined by analyzing expression of miR-199b levels after treatment with antimiRs compared to control treated animals. As a result, two of these antimiRs namely antagomir and locked nucleic acid (LNA) revealed similar effects on the miR-199b expression levels in the heart while Zen-AMO and FMOE were unable to inhibit miR-199b in any organ examined suggesting the difficulty to optimally develop such compounds with robust activity. In addition, antagomir and LNA manifested inhibitory capacity in other organs such as liver, lung and kidney besides heart, demonstrating organ aspecificity. Since most of the miRNAs identified to play a role in heart failure are not tissue specific, organ specific delivery of antimiR drugs is an important issue to overcome before clinical use considering the possible occurrence of unwanted side effects in patients. In a large animal model of heart failure this issue has been resolved by application of an antimiR with a catheter, which enables regional delivery. ${ }^{20}$ Even more, the stronger therapeutic effect was achieved after local delivery when compared to systemic injection. ${ }^{20}$ This approach is highly feasible in the clinic since patients suffering from myocardial infarction are undergoing this procedure for acute treatment. 
Herewith, the comprehensive overview in Chapter 3 together with experimental findings in Chapter 6 provides substantial information to pharmaceutical and biotechnology companies developing and manufacturing antisense RNA therapeutics.

\section{Patients and society}

Increasing prevalence and incidence with poor prognosis of heart failure contribute to high cost to patients, society and health care system. Moreover, heart failure is a long-term condition that deteriorates slowly over time. Current treatment strategies involving multiple medications and changes in life style only aim to improve symptoms and quality of patients' daily life. Therefore, a more innovative and effective treatment approach for heart failure is necessary to reduce this burden from patients and society. For instance, as demonstrated by animal studies, antimiRs have stable inhibitory effect on miRNA function for months ${ }^{21}$ and that can greatly decrease the need to apply medication (in this case antimiRs) at high frequency for chronic diseases such as heart failure. Thus, heart failure patients can benefit greatly from this advantage since they receive lifelong treatment with multiple drugs at changing frequencies. Although our approach is not yet applied in the clinic, we provide relevant findings to be used for future drug developments.

\section{Innovation and implementation}

In the past years, miRNAs have drawn considerable attention as key molecular players in development of various diseases. Their involvement in key signaling pathways and feasibility of miRNA modulation in vivo makes them invaluable therapeutic targets. There has been a rapid progress of miRNA based drug development by virtue of their therapeutic potential. Currently, TargomiRs containing miR-16 based mimic (NCT02369198) are under investigation in phase I clinical trials for their safety and efficiency in patients with different forms of cancer. Furthermore, phase I and Ila clinical trials for miRNA-122 anti-miRNA oligonucleotide (miravirsen) in chronic hepatitis $C$ patients have been completed with successful outcome. ${ }^{22}$ Although there are no current clinical investigations with miRNA based drugs for the treatment of heart failure, the application of antimiR oligonucleotides or miRNA mimics in heart failure animal models have been carried out by numerous groups as extensively discussed in Chapter 3.

In this thesis, we further characterized 'miR-199b' and analyzed its function and therapeutic value in different etiologies of heart failure. Further investigation in large animal models of heart failure is obviously required to corroborate the clinical value of miR-199b before testing in patients. In addition, we have experimentally demonstrated the possibility to modulate amount of miRNAs in 
the heart of small animals but also challenges of developing antisense RNA therapeutics against miRNAs and we extensively discussed literature presenting future directions for their improvement in the context of human heart failure. All in all, scientific findings from this thesis can be valorized as being a basis for the development of an innovative therapy against heart failure. 


\section{References}

1. Roger VL. Epidemiology of heart failure. Circ Res 2013;113(6):646-59.

2. Mozaffarian D, Benjamin EJ, Go AS, Arnett DK, Blaha MJ, Cushman M, et al. Heart Disease and Stroke Statistics-2016 Update: A Report From the American Heart Association. Circulation 2016;133(4):e38-360.

3. Curtis LH, Whellan DJ, Hammill BG, Hernandez AF, Anstrom KJ, Shea AM, et al. Incidence and prevalence of heart failure in elderly persons, 1994-2003. Arch Intern Med 2008;168(4):418-24.

4. Ho KK, Anderson KM, Kannel WB, Grossman W, Levy D. Survival after the onset of congestive heart failure in Framingham Heart Study subjects. Circulation 1993;88(1):107-15.

5. Bui AL, Horwich TB, Fonarow GC. Epidemiology and risk profile of heart failure. Nat Rev Cardiol 2011;8(1):30-41.

6. Stewart S, Maclntyre K, Hole DJ, Capewell S, McMurray JJ. More 'malignant' than cancer? Five-year survival following a first admission for heart failure. Eur J Heart Fail 2001;3(3):315-22.

7. Stewart S, Ekman I, Ekman T, Oden A, Rosengren A. Population impact of heart failure and the most common forms of cancer: a study of 1162309 hospital cases in Sweden (1988 to 2004). Circ Cardiovasc Qual Outcomes 2010;3(6):573-80.

8. Ponikowski P, Voors AA, Anker SD, Bueno H, Cleland JG, Coats AJ, et al. 2016 ESC Guidelines for the diagnosis and treatment of acute and chronic heart failure: The Task Force for the diagnosis and treatment of acute and chronic heart failure of the European Society of Cardiology (ESC). Developed with the special contribution of the Heart Failure Association (HFA) of the ESC. Eur J Heart Fail 2016;18(8):891-975.

9. Duygu B, Poels EM, da Costa Martins PA. Genetics and epigenetics of arrhythmia and heart failure. Front Genet 2013;4:219.

10. Vegter EL, van der Meer P, de Windt LJ, Pinto YM, Voors AA. MicroRNAs in heart failure: from biomarker to target for therapy. Eur J Heart Fail 2016;18(5):457-68.

11. Wong LL, Wang J, Liew OW, Richards AM, Chen YT. MicroRNA and Heart Failure. Int J Mol Sci 2016;17(4):502.

12. Wahid F, Shehzad A, Khan T, Kim YY. MicroRNAs: synthesis, mechanism, function, and recent clinical trials. Biochim Biophys Acta 2010;1803(11):1231-43.

13. Wang J, Liew OW, Richards AM, Chen YT. Overview of MicroRNAs in Cardiac Hypertrophy, Fibrosis, and Apoptosis. Int J Mol Sci 2016;17(5).

14. Suarez Y, Sessa WC. MicroRNAs as novel regulators of angiogenesis. Circ Res 2009;104(4): 442-54.

15. da Costa Martins PA, Salic K, Gladka MM, Armand AS, Leptidis S, el Azzouzi H, et al. MicroRNA-199b targets the nuclear kinase Dyrk1a in an auto-amplification loop promoting calcineurin/NFAT signalling. Nat Cell Biol 2010;12(12):1220-7.

16. Ikeda S, Kong SW, Lu J, Bisping E, Zhang H, Allen PD, et al. Altered microRNA expression in human heart disease. Physiol Genomics 2007;31(3):367-73.

17. Wang Z. The guideline of the design and validation of MiRNA mimics. Methods Mol Biol 2011; 676:211-23.

18. Stenvang J, Petri A, Lindow M, Obad S, Kauppinen S. Inhibition of microRNA function by antimiR oligonucleotides. Silence 2012;3(1):1.

19. Duygu B, de Windt LJ, da Costa Martins PA. Targeting microRNAs in heart failure. Trends Cardiovasc Med 2016;26(2):99-110.

20. Hinkel R, Penzkofer D, Zuhlke S, Fischer A, Husada W, Xu QF, et al. Inhibition of microRNA92a protects against ischemia/reperfusion injury in a large-animal model. Circulation 2013; 128(10):1066-75.

21. Montgomery RL, Hullinger TG, Semus HM, Dickinson BA, Seto AG, Lynch JM, et al. Therapeutic inhibition of miR-208a improves cardiac function and survival during heart failure. Circulation 2011;124(14):1537-47.

22. Janssen HL, Reesink HW, Lawitz EJ, Zeuzem S, Rodriguez-Torres M, Patel K, et al. Treatment of HCV infection by targeting microRNA. N Engl J Med 2013;368(18):1685-94. 
Appendices

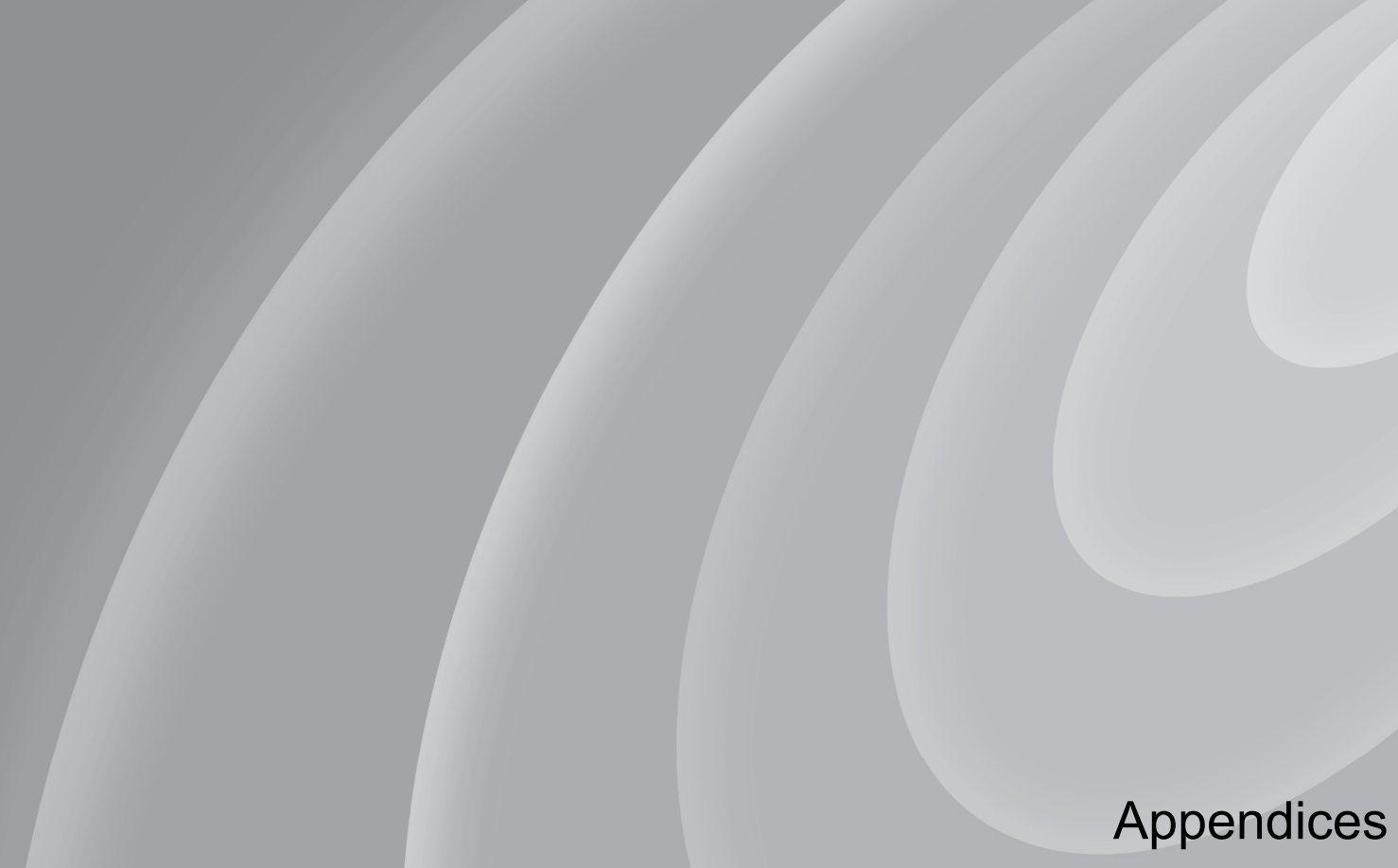





\section{Acknowledgement}

I am a person who cannot really express her feelings verbally but try to show with actions. Therefore, I would like to take the advantage of this part of my thesis to express my gratitude to everyone who has touched my life before, during or after my $\mathrm{PhD}$.

Paula da Costa Martins, you are a great example of an ambitious woman who is a successful scientist and a devoted mother. I am always amazed about your positive attitude and how you make the best of things. Also, it seems like we share a similar path of being a Mediterranean woman, having a Dutch partner and getting used to the Dutch culture :-). That is why I think we could have a connection and a good relation. I am highly appreciative for the opportunity of doing my PhD with you and all the chances I got to visit other labs abroad. Obrigada!

Prof. Leon de Windt, I admire that you are looking for truly new insights into the field that you are studying. What's even better is that you encourage your students to do the same. Another unique talent you have is your ability to put complex concepts into very elegant metaphors. I thank you for the many things you have thought me. I am really optimistic that one day your ideas will find their way into clinical practice.

I am grateful to the reading committee consisting of Prof. dr. Chris Reutelingsperger, Prof. dr. Monika Stoll, Prof. dr. Erik Biessen, Prof. dr. MarieJose Goumans, Prof. dr. Rudolph de Boer for their careful consideration of this manuscript.

Dear Ella, we were first officemates and then became close friends. Do you remember how much fun it was at Salzburg (Roche Continents) to dance out apoptosis? :) I kept my cool costume as a memorial of that day. Hahaha... I admire your dedication and hard work as a doctor. Thank you for being by my side at my defense and for all the support.

Dear Mora, Morita; you definitely brought the warm and joyful atmosphere of Spanish culture into the Lab. I am so lucky to be friends with you. I always admire your dedication as a scientist starting at 7 am and coming to the lab to check the cells in the middle of the night despite being terrified of dark corridors. I am sure all this hard work will pay off soon. How 'amazing' is that you are at the same time so affectionate and devoted to Sofia; your little angel. I wish you a happy life together with Pedro and Sofia. 
Dear old and new colleagues from the lab; First, I would like to thank you all again for such an amazing goodbye party!! It was truly so special and unforgettable. When Rio started playing his guitar and singing, I was little surprised but the real shock came when all of you started singing together:

'Keep smiling, keep shining

Knowing you can always count on me, for sure

That's what friends are for

For good times and bad times

I'll be on your side forever more

That's what friends are for'

I am happy that we became more than colleagues. None of you should forget that you can also always count on me. I am looking forward to our next Salsa party, heh Andrea? And next house warming from Ellen $:$... Internations with Martina... Morning coffees with Antonio and so many experiments with Nicole from Amsterdam to Porto () Chatting with Jullie and her valuable advices... Laughing with Serve and listening to stories about his crazy tours with the band... Boat and pool parties with Leoanne... songs from Rio.. Chats during lunch with Ricardo... I collected so many good memories with you guys. These moments are my gifts from you all. New members of the lab Lara and Indira; since you both are at the beginning of your PhD adventure, I wish you both lots of good luck and success.

Also, I would like to mention old colleagues, who were at the lab at the beginning of my PhD; Kanita, Natasha, Monika, Gustavo, Virginie, Hamid and Steve. Unfortunately, we did not have so much time together but we had couple of really nice borrels at the kitchen and party at Leon's inauguration. And Steve, I finally managed to convince you to come to one of the PhD theatre play, such a success for me $:$. I wish all of you a successful career and a happy life.

I further would like to thank the colleagues from the Heyman's and Volders' lab with whom we share the floor. We worked in harmony and never hesitated to share protocols or solutions. Thanks guys for all the help; Rick, Wouters V., Tim, Marieke, Wouters, Monika, Steffie, Kevin, Georg, Roel, Sandrine, Cristina M, Cristina A., Gabriele, Lilian

And Barbara; you were truly a great help, especially during the arrangement of the date of my promotion, boekje, letters and invitations. Thank you so much!!.

To all my international colleagues: Bedankt, Merci, Grazie, Gracias, Obrigado,

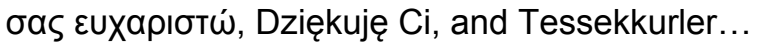


It was a great experience and learning process to guide students in the lab. I was lucky to have such smart and motivated students; Maxim, Tahir, João.

I would like to thank to Sara Leite, Diana S. Nascimento, André P. Lourenço, Adelino F. Leite-Moreira, Perpétua Pinto-do-Ó and Inês Falcão-Pires for our fruitful collaboration and your hospitality in your lab in the beautiful city of Porto.

Dr. Scheijen. Beste Jean, heel erg bedankt voor jouw hulp met 'The Cover' en heel lekker eten bij jou $(:)$.

Beste Tiny, ik ben dankbaar voor jouw hulp met de layout. Het is heel veel werk en je hebt heel goed werk gedaan. Bedankt!

Ik ben heel erg blij dat ik mijn carriere mag voortzetten op de afdeling transplantatie immunologie. Prof. Dr. Marcel Tilanus, ik ben u heel erg dankbaar dat $\mathrm{u}$ mij de kans heeft gegeven om in uw lab te komen werken en de fascinerende wereld van de immunology te leren kennen. Lotte Wieten en Christien Voorter, ik ben jullie heel dankbaar voor jullie begeleiding. Ik ben heel blij met mijn nieuwe collega's, jullie zijn heel behulpzaam en aardig.

I knew no one when I arrived in Maastricht. But thanks to PhD academy, I met so many enthusiastic, creative, intelligent, open and friendly people from all over the world. PhD Improv has certainly a special place in my heart since it enabled me to move out of my comfort zone and be silly in front of an audience. We had so much fun and so many unforgettable memories. My special gratitude goes to special people: Jessie, Merhdad, Sanne, Jan, Gabri, Nevena, Fred, Paul, Burcu K., Paula, Sofia, Jasper, Julie, Alejandro, Francesca, Jordi, Gintare, Irina.

The Turkish Mafia in Maastricht; our crime is to make fun of each other and just to laugh really hard $(-)$ besides of course talking about politics and asking 'what will happen to Turkey?' without an answer. I have such nice memories with each one of you that I am highly appreciative of. I hope not to lose contact with you wherever you go :) Sagliniza ve mutlulugunuza, Serefe: Ozge, Devrim, Elvin, Murat, Birol, Hande K, Emel, Cigdem, Memo, Seyda, Ayse, Kutay, Onur, Esra, Sevim, Cagri, Elcin.

I was not so familiar with 'fine dining' before I met you, my friends: Seher, Hande, Merve O., Merve S. I am happy that we did not miss 'Chateau Neercanne' with the concept of 'Last Supper in Maastricht' (-). Since one by one you are also leaving Maastricht $: \dot{B}$, I am already looking forward our reunion dinner somewhere in the world but of course ' fine dining' (-) Love you, ladies! 
Denizcan; our entrepreneur in Turkish Mafia, ambassador at Internations and a reliable true friend to me. The opportunity at Goldenrod came exactly at the right time and helped me to move on. It was challenging but enabled me to discover new abilities :) Highly appreciated Denizcan! Let's make an appointment for the next drink :)

Esincim; No one believed that you would leave Maastricht. And here you are in Sicily. I am happy for you because that was what you needed as a true free spirit (:) but I miss doing so many things with you; yoga in the park, going to the Friday market to buy fresh fish and baking bread :-) Nice times, my friend! Canimsin...

Groningen is the Noord end of The Netherlands and that's where I started my Dutch adventure. I would like to thank Prof. dr. Marianne Rots for giving me the opportunity to do my first year internship at her lab and to later support me with getting my $\mathrm{PhD}$ position. In addition, to all the lab members and especially my daily supervisor leneke, thank you so much for your kindness and help. In my second year, I joined the group of hematology. Thanks to Prof. dr. Jan J. Schuringa who let me join his group and to Carolien who spend hours with me at the fluorescence microscopy trying to see small green dots (;)

I would also like to express my appreciation to the professors and tutors from my Bachelor at Istanbul University. Thanks to Prof. dr. Ercan Arican, I came to The Netherlands as an Erasmus student, a milestone in my life. Also, his support to the Genetics Club gave us the opportunity to gain organizational and networking skills. Prof. dr. Avni Kuru always encouraged us to think outside of the box and in that way, still is a big inspiration. I am grateful to Dr. Cagatay Tarhan and Prof. dr. Aysegul Topal Sarikaya for their guidance during my Bachelor thesis. Finally, I would like to thank to Prof. dr. Nermin Gozukirmizi, Prof. dr. Nazli Arda, Prof. dr. Sule Ari, Dr. Neslihan Turgut Kara, Dr. Ozgur Cakir, Dr. Murat Pekmez, Dr. Evren Onay Ucar, Levent Dalyan and Dr. Bedia Palabiyik.

My friends from Istanbul University; Funda (Findik), Ozge (ozgus), Canan, Serhat (kanka), Yusuf, Simge, Melike, Gozde, Ilker, Selin; you guys made the University times very special with full of nice memories. I don't know where to start; our Trabzon adventure on the bus for 18 hours $(;)$, Canakkale without any sleep, Alanya holiday at Funda's summer house, many university festivals, Buyuk Ada for picnic and many more... Our Erasmus experience in Groningen with Ozgus, Funda and Burcin opened up new doors to all of us. ;) Although we are all at different places and a bit apart from each other, whenever we meet, we continue where we left $\odot$. Wish all of you happiness, success and full of joy in life. 
Burcin; Brcnmm; Coming to the Netherlands with you first as an Erasmus student and then to do our masters was such an eye opening adventure for me. I miss our long talks about everything in particular life and human relations. Luckily you are always with me; especially with the books that you gave me every year for my birthday. I still don't know your secret how you can find books that give me answers $:$.

Gulperi (Gulmosum);Peri arkadasim; We have such a strong bond that even the distances failed to put us apart.:- You have such a big and important place in my life that is difficult to express with words. But I know that you know. You are my 'perim' always giving me support, courage and motivation. Thank you so much for being always by my side!

Lieve Miep en John, ik ben gefascineerd door jullie toewijding voor jullie kinderen. Sinds onze eerste ontmoeting behandelen jullie mij als een van jullie dochters, ik heb mij altijd onderdeel van de familie gevoeld. Jullie hebben mij altijd in moeilijke tijden gesteund. Noraly en Irmelin, ik vind het heel leuk om tijd met jullie door te brengen. Mijn favorieten zijn paardrijden met Noraly en sporten als gekken met Irmelin $: ;$. Heel erg bedankt familie Hanssen voor alles!

Sevgili buyuk ailem; uzaklarda oldugumdan her zaman yaninizda olamasam da her Turkiye'ye donusumde beni sevgi ile karsiliyorsunuz ve bana verdiginiz degeri hissettiriyorsunuz. Ben de elimden geldigince teknolojik imkanlar ile yaninizda olmaya calisiyorum. () Cunku hepiniz benim hayatimin vazgecilmezisiniz. Semra teyzem ve Ismet enistem; insan buyuyunce bazi anlarin kiymetini daha iyi anliyor dogrusu. Simdi dusununce bana balayinizdan getirdiginiz gobegine basinca ses cikaran sari sacli bebek mesela; o guzel ve ozel aninizda bunu dusunmeniz o kadar kiymetli ki. Ve daha bunun gibi bir cok guzel sey icin tessekur ederim. Seher teyzem ve Kemal enistem; size haftasonlari kalmaya gelmemizi ve enistemin bana yumurta yedirtmesini hic unutmuyorum. Her biriniz cok guzel seyler kattiniz bana cok tessekur ederim. Selami amcam ve Nilgun abla; simdiki cocuklar gibi bir suru oyuncagim olmadi benim iyiki de olmadi cunku hepsi ayri ayri ozel oldu mesela amcamin Mardin'den getirdigi kirmizi uzaktan kumandali araba gibi. Amcacim hersey icin cok tesekkur ederim; ne zaman arasak yardim istesek hep orda oldun. Nilgun ablacim; beni her zaman guler yuzunle karsiladigin ve o lezzetli yemeklerin icin cok tesskur ederim. Cevat amacam; sisko amcam benim (;) seninle el kizartmaca oynamayi ne cok severdim benim rekabetci kisiligimi ortaya cikarirdi. Yaz aksamlarinda babaannemle senin isten gelisini bahcede beklerdik cunku ben hic evde oturmak istemezdim. Sisko gelince girerdik eve $:$ - Celal amcam ve Serpil yenge; amca bende olan emegin az degildir butun guzel gunler icin cok tessekur ederim. Ismail dayim ve Semahat yengem; dayicim Alacamda bize 
sabahlari getiridigin o firindan yeni cikmis sicacik pideleri hic unutmuyorum. Hatta bi gece sabaha karsi isil ile korku filmi seyrederken iceri sen girmistin de odumuz kopmustu :) Ama yengemin cigborekleri, sutlaclari ve baklavalari ayri ozeldir. Sizler hep uzakta olsanizda hicbir zaman o uzakligi hissetmedik. Sevgili kuzenlerim; Deniz ve Gorkem; Denizcim senin yolun cok acik bu azim ve caliskanlik ile cok guzel isler basaracagina inaniyorum. Serhat; az boy yarisi yapmazdik seninle ama sen tur bindirdin bana (:) Isilcim; seninle az gulup eglenmedik :) hatta bi gece teyzemlerin yazligin da merve, busra sen ve ben karnimiza agrilar girene kadar gulmustuk hatirlar misiniz? Volkan abi; bazi konular da fikir ayriligina dussek de hic tartismadan cok guzel muhhabbet ederdik seninle, iyi anlasirdik aslinda (:) Isil ve Volkan abi; esleriniz ve dunya tatlisi cocuklariniz ile omur boyu mutluluklar diliyorum. Benim cadilarim; Merve ve Busra; valla ablamla benim elimde buyudunuz resmen :) kuzenden ote kardes oldunuz bize. Simdi ikinizde kocaman oldunuz biriniz universiteden digeriniz liseden mezun oldu. Hayatin sizlere mutluluk, huzur ve saglik getirmesini dilerim. Anneannecim ve dedecim; cocuklugumun yaz tatilleri sizlerle Alacam'da gecti. Cok ilginctir denize dogru durust giremedigimiz icin hic gelmek istemesemde eve donus zamani geldiginde kocaman bir huzun kaplardi icimi, hic donmek istemezdim. Dilerim dedem huzur icindedir simdi ve anneanne sende daha uzun yillar bizi Alacam da agirlarsin $(-)$ Babaannem benim, elinde olsa pamuklara sarip oyle buyutecektin beni, o kadar emek ettin ki. Umarim emegini bosa cikarmamisimdir. Sen hep kendinden once cocuklarini torunlarini dusundun ben senin kadar fedekar bir insan tanimadim. Tek dilegim simdi huzur icinde olman. Hersey icin cok ama cok tessekkur ederim.

Hepinizi cok seviyorum ve herzaman buyuk bir aile olarak kalmak dilegi ile..

Annecim ve Babacim size tessekkur etmem gereken o kadar cok sey var ki nerden baslasam bilemiyorum. Oncelikle bana hayallerimin ve isteklerimin pesinden gitmem konusunda destek verdiginiz ve beni secimlerimde ozgur biraktiginiz icin size sonsuz minnettarim. Sevginizi ve desteginizi hep hissediyorum ve bu da bana guc veriyor. Sizin gibi acik ve ileri goruslu bir aileye sahip oldugum icin cok sansliyim. Sizi cok seviyorum.

Canim abliskom; sen olmasan ne yapardim hic bilmiyorum. Seni saatlerce sorunlarim ve korkularimla ali koysamda bir kere bile of demeden sabirla dinledin beni ve hep yardimci oldun. Hollanda'ya kadar gelsem de kurtulamadin benden (:) Benim icin cok degerli ve kiymetlisin! Seni cok seviyorum. Serkan abi senin de az basini sisirmedim (:) Sizinle yaptigimiz raki balik sohbetleri en cok ozlem duyduklarimin basinda. Ablamla birlikte cok cok mutlu olmanizi diliyorum. Hersey icin cok tesskkur ederim. 
Nordin; askusum; I never imagined that I could find my other half; especially in The Netherlands. Besides love, you brought so many colors to my life. Also, you deserve a huge credit for this bookje with your endless support. I love you so much bitanem. I am always there for you and I know you are for me! Herseyim. 



\section{Biography}

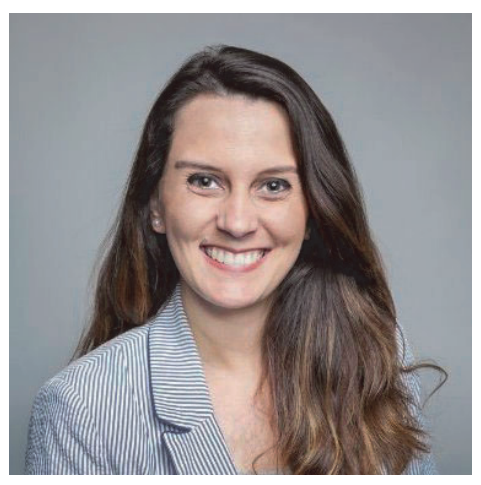

Burcu Duygu was born on 19 December 1984 in Istanbul, Turkey. During her Bachelor study, between 2006 and 2007, she received an Erasmus Grant from the European Commission to study for 6 months at the University of Groningen. In 2008, she obtained her Bachelor degree in Molecular Biology and Genetics from Istanbul University, Turkey. She then received a scholarship from the University of Groningen to study in a master program called Medical Pharmaceutical Sciences. During this time, she completed two internships at the groups of (Epi)genetic Editing and Experimental Hematology, respectively. In 2011, she started her PhD at the Department of Cardiology under supervision of Prof. dr. L. de Windt and Dr. P. da Costa Martins. She worked on the therapeutic value of microRNAs for the treatment of heart failure. During her PhD track, she joined several international conferences for oral and poster presentations and in 2015 she received a travel grant from Keystone Symposia to present her research in Colorado, USA. From 2016 onwards, she works at the Department of Transplantation Immunology and Tissue Typing at Maastricht University Medical Centre, The Netherlands. 


\section{List of publications}

- Burcu Duygu, Ben M. Matern, Mathijs Groeneweg, Christien EM. Voorter, Marcel GJ. Tilanus. Polymorphism at residue 156 of the new HLA-A*02:683 allele suggests immunological relevance. HLA (2017); 107-109.

- Burcu Duygu, Ella M. Poels, Rio Juni, Nicole Bitsch, Lara Ottaviani, Servé Olieslagers, Leon J. de Windt, Paula A. da Costa Martins. miR-199b-5p is a regulator of left ventricular remodeling following myocardial infarction. Noncoding RNA Res (2017); 1-9.

- Burcu Duygu, Leon J. de Windt, Paula A. da Costa Martins. Targeting microRNAs in heart failure. Trends Cardiovasc Med. (2016);26(2):99-110.

- Burcu Duygu, Paula A. da Costa Martins. miR-21: a star player in cardiac hypertrophy. Cardiovasc Res. (2015);105(3):235-7

- Burcu Duygu, Ella M. Poels, Paula A. da Costa Martins. Genetics and epigenetics of arrhythmia and heart failure. Front Genet. (2013);4:219

Oral presentation

- Keystone Symposia, Colorado, USA (2015)

- Heart Failure Congress, Lisbon, Portugal (2013

Poster presentation

- Vevo User Meeting (Echocardiography seminar), Hannover, Germany (2014)

- European Heart Failure Association Winter Research Meeting, Les Diablerets, Switzerland (2014)

- German-Dutch Joint Meeting, Heidelberg, Germany (2013)

- European Heart Failure Association Winter Research Meeting, Les Diablerets, Switzerland (2013)

- German-Dutch Joint Meeting, Heidelberg, Germany (2013)

- European Heart Failure Association Winter Research Meeting, Les Diablerets, Switzerland (2013)

- German-Dutch Joint Meeting (Poster Presentation), Kerkrade, The Netherlands (2012) 
